University of Rhode Island

DigitalCommons@URI

Open Access Dissertations

2017

\title{
Modeling Phase Behavior in Complex Systems Using the Gibbs- Helmholtz Constrained Equation of State
}

Heath Henley

University of Rhode Island, heath_henley@uri.edu

Follow this and additional works at: https://digitalcommons.uri.edu/oa_diss

\section{Recommended Citation}

Henley, Heath, "Modeling Phase Behavior in Complex Systems Using the Gibbs-Helmholtz Constrained Equation of State" (2017). Open Access Dissertations. Paper 647.

https://digitalcommons.uri.edu/oa_diss/647

This Dissertation is brought to you for free and open access by DigitalCommons@URI. It has been accepted for inclusion in Open Access Dissertations by an authorized administrator of DigitalCommons@URI. For more information, please contact digitalcommons-group@uri.edu. 


\section{MODELING PHASE BEHAVIOR IN COMPLEX \\ SYSTEMS USING THE GIBBS-HELMHOLTZ \\ CONSTRAINED EQUATION OF STATE}

BY

HEATH HENLEY

A DISSERTATION SUBMITTED IN PARTIAL FULFILLMENT OF THE

REQUIREMENTS FOR THE DEGREE OF

DOCTOR OF PHILOSOPHY

IN

CHEMICAL ENGINEERING

UNIVERSITY OF RHODE ISLAND

2017 


\section{DOCTOR OF PHILOSOPHY DISSERTATION}

$\mathrm{OF}$

\section{HEATH HENLEY}

\section{APPROVED:}

Dissertation Committee:

$\begin{array}{ll}\text { Major Professor } & \text { Angelo Lucia } \\ & \text { Michael Greenfield } \\ & \text { Orlando Merino } \\ \text { Nasser H. Zawia } & \text { DEAN OF THE GRADUATE SCHOOL }\end{array}$

UNIVERSITY OF RHODE ISLAND

2017 


\begin{abstract}
Modeling the phase and thermo-physical behavior of multi-component fluid systems using a cubic equation of state (EOS) is important for many industrially relevant applications. For example, simulations involving hydrocarbon recovery or carbon dioxide sequestration in geological formations rely on thermodynamic models to determine the phase behavior and density of the relevant reservoir fluid mixture. Accurate models for the density phase behavior of these fluids is required to make reliable predictions of the hydrocarbon production capability, or the carbon sequestration capacity of a given formation.

Cubic EOS models have remained the industry standard in thermodynamic modeling for fluid phase behavior for the last 50 years, probably due to the relative ease with which these models can be implemented and generally acceptable accuracy for many systems. However, the current models include empirical parameters that are regressed to pure component saturated liquid density and saturation pressure data, as well as binary (and higher order) mixture composition data. Conducting experiments to collect pure component data for the regression of EOS parameters can be expensive, especially at elevated temperatures and pressures. Further, collecting mixture data over the entire composition space at varying temperatures and pressure quickly becomes intractable (especially for mixture of three or more components). Clearly, a cubic EOS model which requires less data for the regression of parameters is desirable.

The multi-scale Gibbs-Helmholtz constrained (GHC) equation of state (EOS) is an innovative approach to EOS modeling which uses molecular scale information about the component(s) of interest to calculate bulk scale EOS parameters. More specifically,
\end{abstract}


the molecular attraction parameter ('a') in the two parameter Soave-Redlich-Kwong (SRK) EOS is calculated as a function of temperature using an expression derived from the Gibbs-Helmholtz equation (a classical thermodynamic relationship). Further, the GHC expression for the attraction parameter incorporates molecular level information using results of isobaric-isothermal Monte Carlo (NPT-MC) molecular simulations.

In this work, some aspects of the GHC EOS performance and thermodynamic consistency are investigated. Further, novel modeling frameworks are developed for the application of the GHC EOS to systems capable of forming simple structure I (sI) gas hydrates and molecular salts. Finally, the GHC EOS is incorporated into a fully compositional and thermal reservoir simulator. The GHC EOS is then used as the thermodynamic model for the underlying reservoir fluid in novel reservoir simulations relevant to enhanced oil recovery, carbon sequestration, and groundwater contamination modeling. 


\section{ACKNOWLEDGMENTS}

First and foremost, I would like to thank my $\mathrm{PhD}$ advisor, Professor Angelo Lucia, for all his support and guidance during the preparation of this work and during my time in his lab as an undergraduate. Without his unsolicited offer of an undergraduate research position in his lab, it is not likely I would have developed a desire to pursue graduate school. Without drawing on his years of expertise in the areas of thermodynamic modeling and mathematics for ideas and guidance, this work would not have been possible. I am also thankful to the funding agencies and industry sponsors that provided Professor Lucia with grants, which in turn provided me with teaching and research assistantship opportunities throughout my graduate career.

I would also like to acknowledge Professor Denis Voskov for his help and for giving us the opportunity to use the AD-GPRS reservoir simulator for this research.

In addition, I would like to express my gratitude to Professor Michael Greenfield and Professor Orlando Merino for their helpful comments, suggestions and questions during committee meetings and oral exams. I must acknowledge Ed Thomas for all of the insightful discussions we've shared throughout our time working together as undergraduate and graduate students.

Outside of the university, I must thank my family and friends for their continuing and unconditional support. Finally, I greatly appreciate Madeleine McDonough for her constant encouragement and positive demeanor, especially during some of the most difficult times. 


\section{PREFACE}

This dissertation is in manuscript format. Chapters 1-6 have been published in peer reviewed journals as indicated in the title page of each chapter. At the time of this writing, chapter 7 is in preparation for submission to Environmental Modelling and Software. 


\section{TABLE OF CONTENTS}

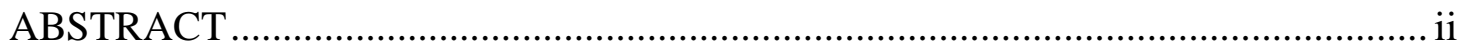

ACKNOWLEDGMENTS ......................................................................... iv

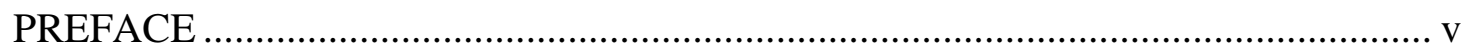

TABLE OF CONTENTS ............................................................................. vi

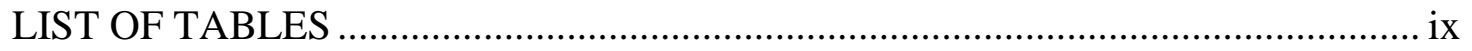

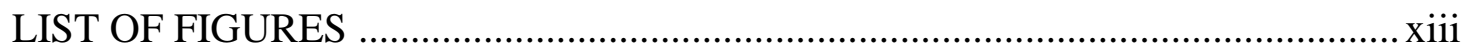

CHAPTER 1 - Thermodynamic consistency of the multi-scale Gibbs-Helmholtz constrained equation of state ................................................................... 1

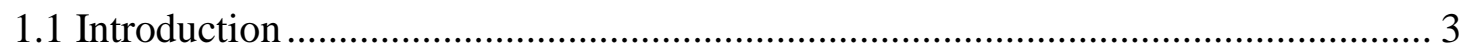

1.2 Thermodynamic Consistency: Theory and Verification .................................... 5

1.3 Density \& Phase Equilibrium Results............................................................ 22

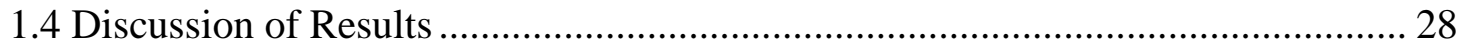

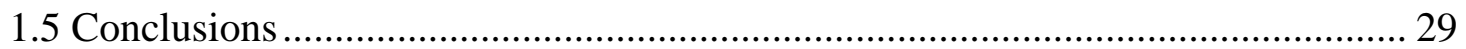

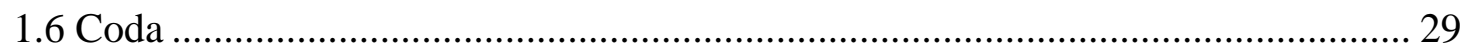

CHAPTER 2 - Density and phase equilibrium for ice and structure I hydrates using the Gibbs-Helmholtz constrained equation of state ............................................ 35

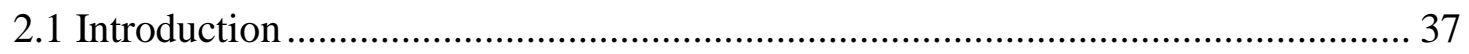

2.2 A Brief Review of Relevant Literature ......................................................... 39

2.3 The Multi-Scale Gibbs-Helmholtz Constrained (GHC) Equation ....................... 42

2.4 Modeling Hexagonal Ice Using the GHC Equation....................................... 44

2.5 Modeling Gas Hydrates Using the GHC Equation ......................................... 46

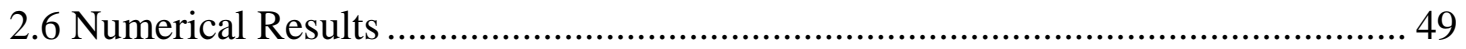


2.7 Conclusions

CHAPTER 3 - Multiphase equilibrium flash with salt precipitation in systems with

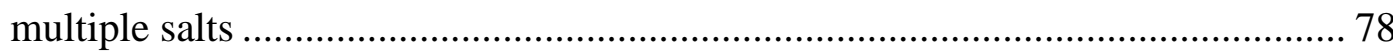

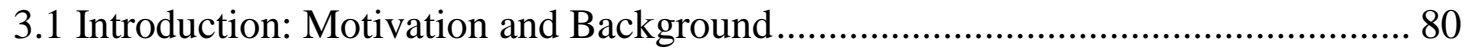

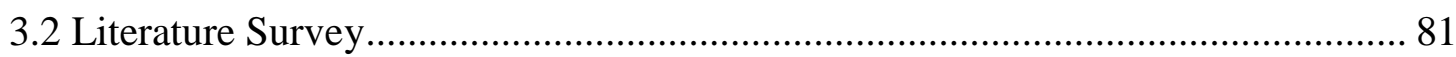

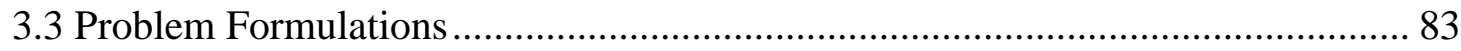

3.4 A Tearing Strategy for Finding Equilibrium Solubility Limits for Multiple Salts 90

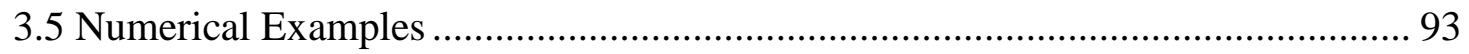

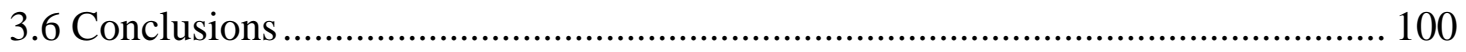

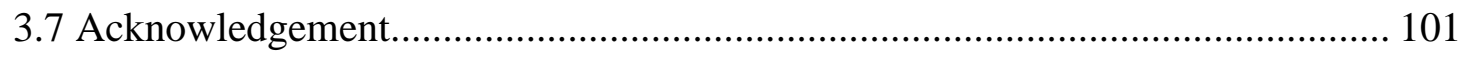

CHAPTER 4 - Constant pressure Gibbs ensemble Monte Carlo simulations for the prediction of structure I gas hydrate occupancy ........................................ 117

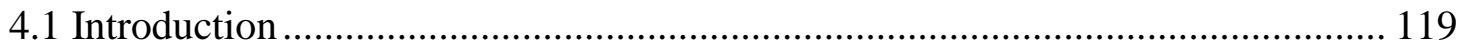

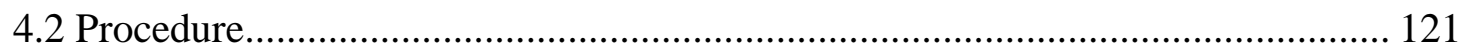

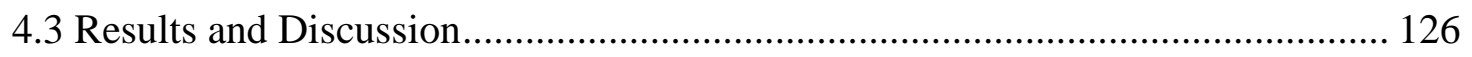

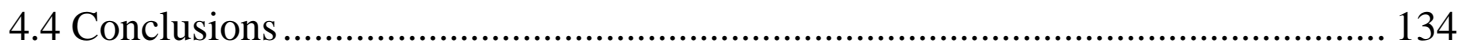

CHAPTER 5 - Fully compositional and thermal reservoir simulation ..................... 142

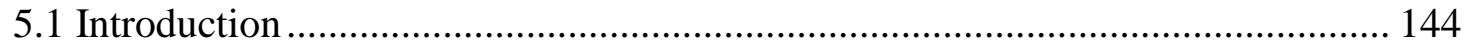

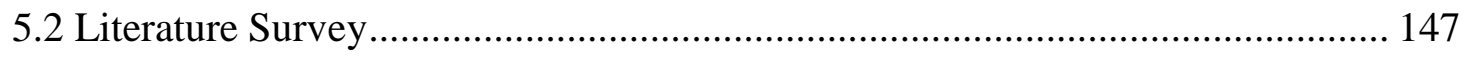

5.3 Reservoir Model Equations .............................................................. 150

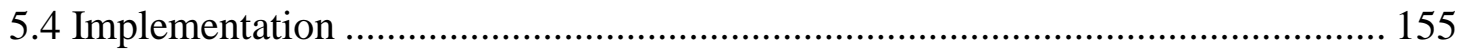

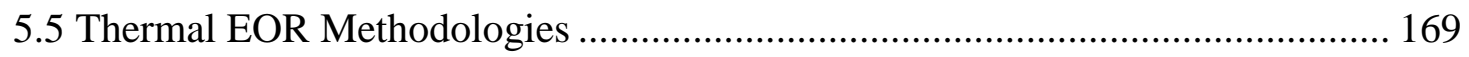

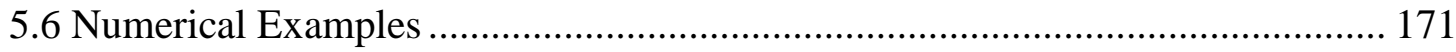


CHAPTER 6 - Fully compositional multi-scale reservoir simulation of various $\mathrm{CO}_{2}$

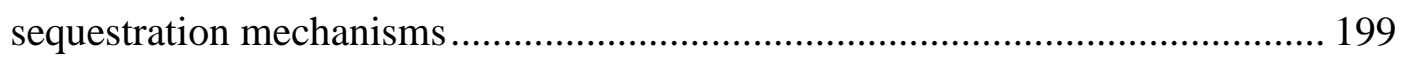

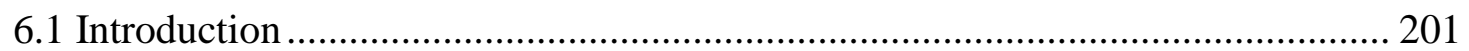

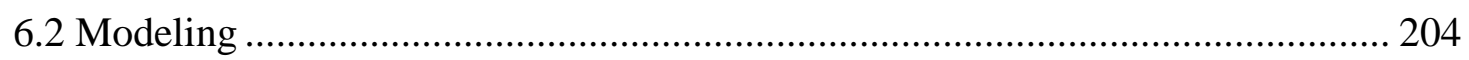

6.3 Natural formulation for reactive systems with precipitation and dissolution ...... 210

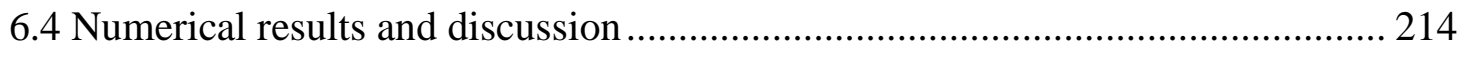

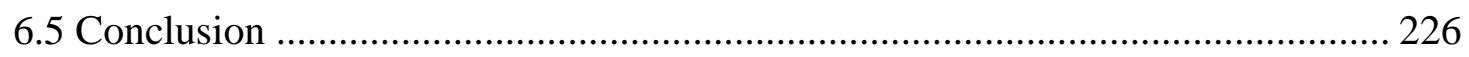

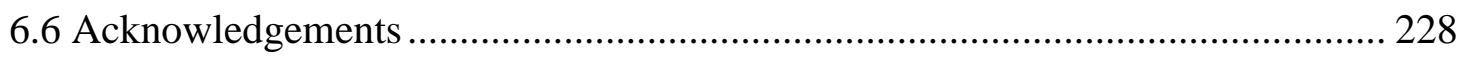

CHAPTER 7 - Fully compositional ground water simulation using AD-GPRS and

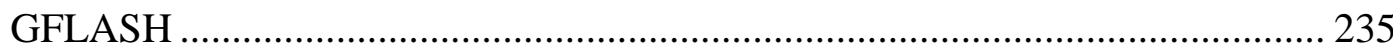

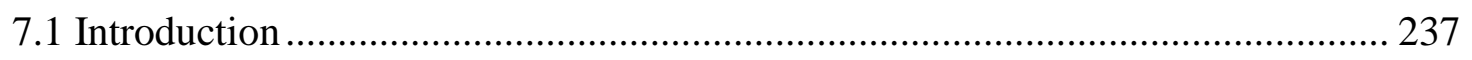

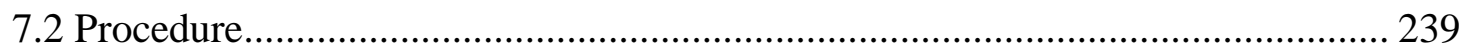

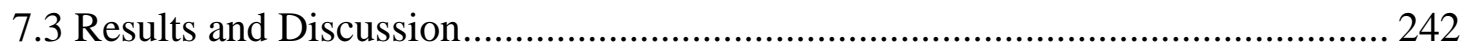

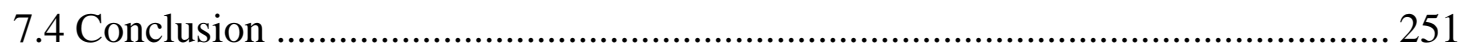

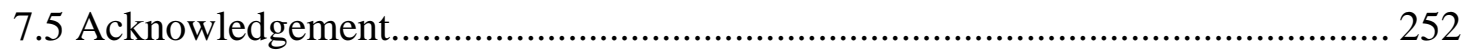




\section{LIST OF TABLES}

TABLE

PAGE

Table 1.1: Illustrative Statistics for a Reservoir Simulation Example ............................ 4

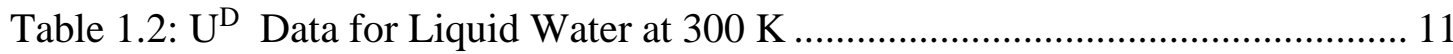

Table 1.3: Illustration of Thermodynamic Consistency for the GHC Equation for

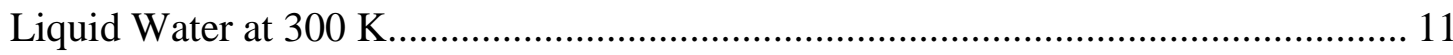

Table 1.4: Linear Interpolation of UD Data in Temperature ....................................... 12

Table 1.5: Thermodynamic Consistency Results for the GHC Equation for Liquid

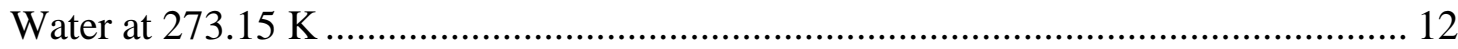

Table 1.6: Thermodynamic Consistency for the GHC Equation for Liquid Water at

273.15 K \& 220 bar.......................................................................................... 13

Table 1.7: Thermodynamic Consistency of the GHC Equation for Liquid Phase in

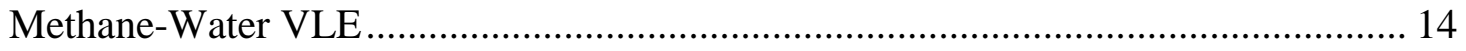

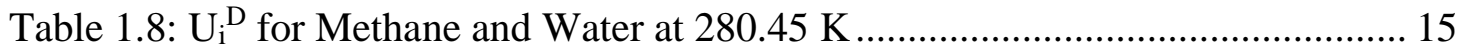

Table 1.9: Thermodynamic Consistency of GHC Equation for $\mathrm{CH}_{4}$-Water................ 15

Table 1.10: Feed and Equilibrium Phase Compositions for VLLE Solution................ 15

Table 1.11: Thermodynamic Consistency of GHC Equation for VLLE Problem at

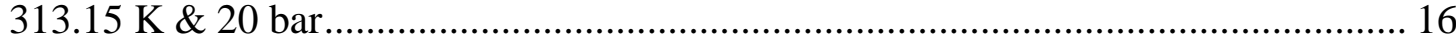

Table 1.12 - Internal Energies of Departure for $\mathrm{CO}_{2}$, Water and $3 \mathrm{~mol} \% \mathrm{CO}_{2}-97$

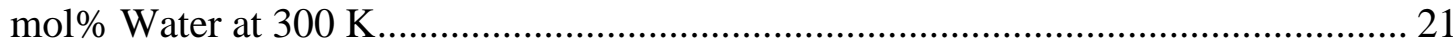

Table 1.13: Bulk Phase $\left(\partial \mathrm{U}^{\mathrm{D}} / \partial \mathrm{p}\right)_{\mathrm{T}}$ for the GHC EOS for Water at $273.15 \mathrm{~K} \ldots \ldots \ldots \ldots . . .21$

Table 1.14: Summary of Some Liquid Density Predictions for the SRK+, VTPR and

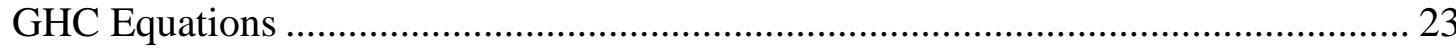


Table 1.15: Comparison of Molar Volumes for Water at 273.15 K Calculated Using

Pressure Dependent Energy Parameters in the GHC Equation................................ 24

Table 1.16: Experimental and Calculated Densities of $\mathrm{CO}_{2}-\mathrm{H}_{2} \mathrm{O}$ at $283 \mathrm{~K} \ldots \ldots \ldots \ldots . . . . .25$

Table 1.17: Some Mixture Density Results for SRK+, VTPR, ePSRK, and GHC

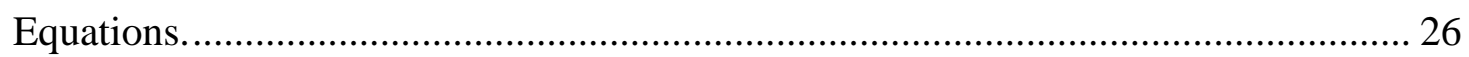

Table 1.18: Methane Solubility in Water for the SRK+, VTPR, and GHC Equations 27

Table 2.1: Methane Solubility in Water Predicted by the GHC Equation .................. 49

Table 2.2: Density of Sub-Cooled Hexagonal Ice ............................................... 50

Table 2.3: Melting Temperatures of 1h Ice Predicted by the Extended IAPWS-95 \&

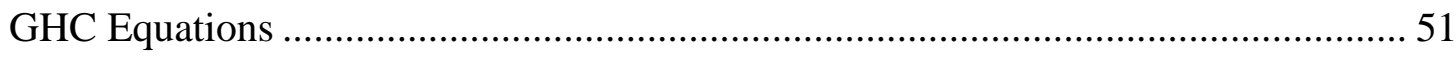

Table 2.4: Phase Equilibrium for $10 \mathrm{~mol} \%$ Methane-90 mol\% Water at $-1.15 \mathrm{C}$ and

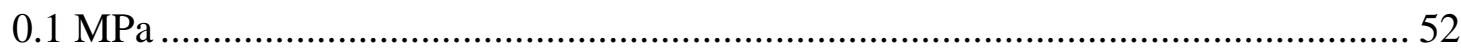

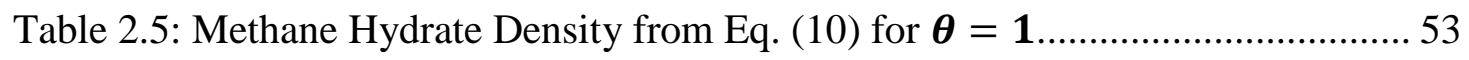

Table 2.6: Phase Equilibrium at Approximate Quadruple Point (272.751 K, 25.624

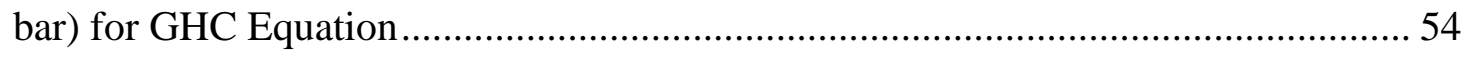

Table 2.7: Phase Equilibrium for 13 mol\% Methane- 87 mol\% Water at $-1.15 \mathrm{C}$ and

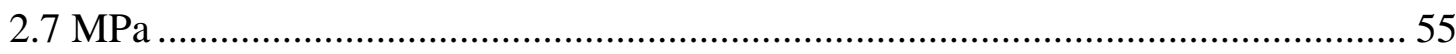

Table 2.8: Ice-Empty Hydrate Equilibrium at $-1.15 \mathrm{C}$ and $2.7 \mathrm{MPa}$........................ 57

Table 2.9: Phase Equilibrium for $13 \mathrm{~mol} \% \mathrm{CO}_{2}-87 \mathrm{~mol} \%$ Water at $-8.15 \mathrm{C}$ and 0.1

$\mathrm{MPa}$

Table 2.10: Carbon Dioxide Hydrate Density from Eq. (10) for $\boldsymbol{\theta}=\mathbf{1} \ldots \ldots \ldots \ldots \ldots \ldots . . . . . . . . .59$

Table 2.11: Phase Equilibrium for $13 \mathrm{~mol} \% \mathrm{CO}_{2}-87 \mathrm{~mol} \%$ Water at $-4 \mathrm{C}$ and $13 \mathrm{MPa}$ 
Table 3.1: Example Problems Studied in This Work

Table 3.2: First Flash Solution for Example 1 .................................................... 94

Table 3.3: Iterative Values of All Ions Using the Proposed Tearing Algorithm ......... 95

Table 3.4: Equilibrium and Ion Solubility Products and Solubility Limits for Example

1. 95

Table 3.5: Second and Global Flash Solution for Example 1 ................................. 96

Table 3.6: Feed Conditions for Example 2 at $255^{\circ} \mathrm{C}$ and 18 bar ............................... 97

Table 3.7: Numerical Results for First Flash Solution for Example 2 ....................... 98

Table 3.8: Equilibrium and Ion Solubility Products and Solubility Limits for Example

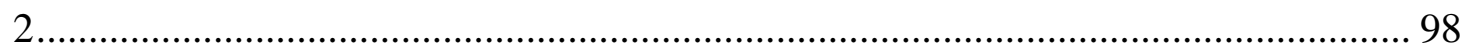

Table 3.9: Numerical Results for Second Flash Solution for Example 2 .................. 99

Table 3.10: Global Flash Solution for Example 2............................................. 100

Table 4.1: Relevant Simulation Potential Parameters.......................................... 124

Table 4.2: Experimental Methane Hydrate Occupancy vs. GEMC Occupancy ........ 129

Table 4.3: Methane Gas Hydrate Hydration Number Calculated by Anderson (2004)

versus Hydration Number Calculated from GEMC Results .................................. 130

Table 5.1: Numerical Results for Chemical Equilibrium of STRIP Combustion...... 173

Table 5.2: Composition of Production Water and Combined Feed for STRIP ......... 175

Table 5.3: Meta-stable Flash Solution to Combined Chemical and Phase Equilibrium

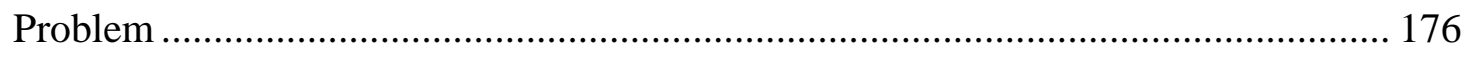

Table 5.4: Equilibrium and Ion Solubility Products for Example 3 ....................... 177

Table 5.5: Global Minimum Solution to Combined Chemical and Phase Equilibrium

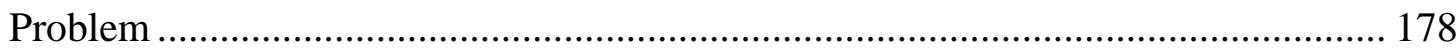


Table 5. 6: Statistics for Rigorous Flash Solutions for $\mathrm{CO}_{2}$-Decane-Water at 30 bars

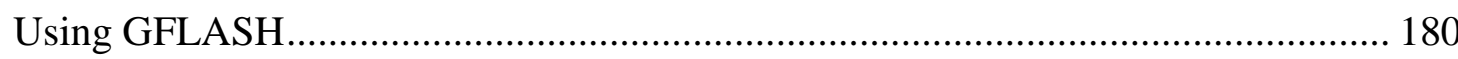

Table 5.7: Input Data for Example 5 .......................................................... 181

Table 5.8: Summary of Steam Injection and STRIP Performance for Example 5 ... 184

Table 5.9: Input Data for STRIP Simulation of Example 6 ................................ 185

Table 5.10: Statistics for STRIP Reservoir Simulation of Example 6.................... 187

Table 6.1: Presence of Components in Phases................................................... 213

Table 6.2: Status Table and Equations for Brine- $\mathrm{CO}_{2}$ System ............................... 214

Table 6.3: Initial Conditions for 50 x 50 x 1 Example....................................... 215

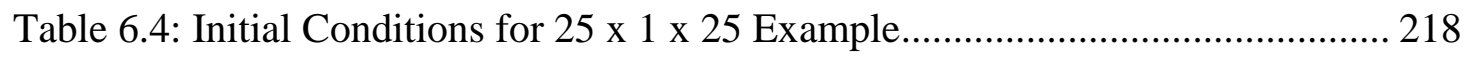

Table 6.5: Initial Composition in Lower Region for Example 3 ............................ 221

Table 7.1: Fluid Mixture Mole Fraction ........................................................ 243 


\section{LIST OF FIGURES}

FIGURE

PAGE

Figure 1.1: Isothermal Staircase Function for $\mathrm{U}^{\mathrm{D}}$ for Water versus Pressure. 18

Figure 1.2: Isothermal Staircase Functions for $\mathrm{U}^{\mathrm{D}}$ water and $\mathrm{U}^{\mathrm{D}}$ CO2-water versus Pressure

Figure 2.1: Melting Curve for Ice Predicted by the IAPWS-95 and GHC Equations . 52 Figure 4.1: Occupancy Isobars for Pure Methane Hydrate from GEMC Simulations with: Top: Flexible Hydrate Lattice and Bottom: Rigid Hydrate Lattice 128

Figure 4.2: Total Methane Hydrate Occupancy From vdW-P Compared to GEMC Simulations. Red triangles: results from GEMC with a rigid hydrate lattice. Blue circles: results from GEMC with a flexible hydrate lattice.

Figure 4.3: Pressure-Temperature Diagram for Simple Structure 1 Methane Hydrate results from the rigid lattice model are indicated using a blue dotted line, while results from the flexible model are indicated with a solid green line, all other symbols represent experimental data 132

Figure 4.4: $\operatorname{Ln}(\mathrm{p})$ versus (1/T) and a Linear Fit used with Equation (4.7) to Determine the Heat of Dissociation 133

Figure 5.1: STRIP Combustion Product Composition vs. Temperature for a Fuel-Rich Burner 173

Figure 5.2: $\mathrm{CO}_{2}$-Decane-Water Phase Behavior at $100{ }^{\circ} \mathrm{C}$ and $200{ }^{\circ} \mathrm{C}$ and 30 bars .179 Figure 5.3: Oil Saturation for Steam Injection (upper) and STRIP (lower) for Example 5 . 182

Figure 5.4: Sweep Ratio for Steam Injection and STRIP for Example 5 183 
Figure 5.5: Oil Recovery for Steam Injection and STRIP for Example 5

Figure 5.6: Oil and Gas Saturation Distributions for EOS and CSAT Simulations after 7000 Days 186

Figure 6.1: Information Flowchart for AD-GPRS/GFLASH Framework 210

Figure 6.3: Distribution of Equilibrium Phase State 217

Figure 6.4: Saturation distribution of $\mathrm{CO}_{2}$-rich phase 220

Figure 6.5: Distribution of $\mathrm{CO}_{2}$ mole fraction in the brine phase 220

Figure 6.6: Distribution of Precipitated $\mathrm{CaCO}_{3}\left(\mathrm{kmol} / \mathrm{m}^{3}\right)$. 220

Figure 6.7: Distribution of $\mathrm{CO}_{2}$ in Brine at Different Times and Macroscopic

Dissolution Rate of $\mathrm{CO}_{2}$ as a Function of Time for Simulation at $\mathrm{T}=345 \mathrm{~K}$ 223

Figure 6.8: Small-Scale Simulation Results with $\mathrm{CaCO}_{3}$ Precipitation: (upper row) overall $\mathrm{CO}_{2}$ composition; (middle row) porosity changes; (lower row) difference in $\mathrm{CO}_{2}$ composition for cases with and without porosity and permeability update 224 Figure 6.9: Small-Scale Simulation Results with $\mathrm{CaCO}_{3}$ Precipitation at Magnified Molar Volume: (upper row) overall $\mathrm{CO}_{2}$ composition; (middle row) porosity changes; (lower row) difference in $\mathrm{CO}_{2}$ composition for the previous case and the case with magnified molar volume.

Figure 6.10: Small-Scale Simulation Results with $\mathrm{CaCO}_{3}$ Precipitation and $\mathrm{NaCl}$ Dissolution: (upper row) overall $\mathrm{CO}_{2}$ composition; (lower row) porosity changes. . 226 Figure 7.1: Equilibrated Head (no pumping) 244 Figure 7.2: Layer 1 head distribution change after 5 days of pumping at an average of 190 gpm. 245 
Figure 7.3: Layer 2 head distribution change after 5 days of pumping at average rate of $190 \mathrm{gpm}$ 246

Figure 7.4: Change in head after pumping for 5 days at 800 gpm: layer 1 (left); layer 2 (right). 246

Figure 7.5: Change in head after pumping for 5 days at 1000 gpm: layer 1 (left); layer

2 (right). 247

Figure 7.6: Contaminant Distribution After 5000 Days (all sources) ...................... 248

Figure 7.7: Contaminant Distribution After 5000 Days (single source) ................... 248

Figure 7.8: Contaminant Concentration as a Function of Distance from Source ...... 250

Figure 7.9: n-Octane Phase Saturation after 5000 Days ...................................... 251 
CHAPTER 1 - Thermodynamic consistency of the multi-scale Gibbs-Helmholtz constrained equation of state

Published in Chemical Engineering Research and Design, September 2013

Heath Henley and Angelo Lucia

Chemical Engineering

University of Rhode Island

Kingston, RI 


\begin{abstract}
The multi-scale Gibbs-Helmholtz Constrained (GHC) equation is a new predictive cubic equation of state that constrains the energy parameter in the SRK equation to satisfy the Gibbs-Helmholtz equation. It makes use of internal energies of departure calculated from NPT Monte Carlo simulations at the molecular length scale and a novel up-scaling expression to determine the energy parameter at the bulk phase length scale.

In this article, it is shown that mathematical representation of isothermal molecular internal energies of departure as a staircase function in pressure leads directly to thermodynamic consistency of the multi-scale GHC equation. Experimentally validated numerical results for density for pure components and mixtures, two- and three-phase equilibrium, comparisons with other cubic EOS, and geometric illustrations are presented to illustrate key ideas and to show that the GHC equation provides both accurate and thermodynamically consistent numerical results.
\end{abstract}




\subsection{Introduction}

The multi-scale Gibbs-Helmholtz Constrained (GHC) equation of state is a new approach to equation of state (EOS) modeling and is currently part of a multi-phase equilibrium flash suite (GFLASH) used in two separate advanced reservoir simulators [Finite Element Heat \& Mass Transfer (FEHM) developed and supported by Los Alamos National Laboratory and Automatic Differentiation-General Purpose Research Simulator (AD-GPRS) developed and supported by Stanford University]. These simulators are used to model enhanced oil recovery (EOR), permafrost basins, and other reservoirs.

Reservoir simulation models are comprised of coupled unsteady-state mass and energy balance equations (nonlinear PDEs) plus constitutive relationships. For its part, GFLASH with the GHC equation is used to repeatedly solve equilibrium flash problems for each finite element or finite volume (i.e., grid block) in a reservoir at each time step in order to determine the number of equilibrium phases, their corresponding compositions and densities, and other thermodynamic properties (e.g., fugacity coefficients, chemical potentials, enthalpies, etc.). Reservoir simulation problems are generally computationally intensive. To illustrate, Table 1.1 gives some statistics associated with the simulation of a single 2D horizontal layer in a 'small' 3D reservoir, where each horizontal layer consists of approximately 5000 grid blocks. 
Table 1.1: Illustrative Statistics for a Reservoir Simulation Example

\begin{tabular}{|c|c|}
\hline Quantity & Value \\
\hline \# of components & $3-\mathrm{CO}_{2}, \mathrm{C}_{20} \mathrm{H}_{42}$, water \\
\hline \# flash problems = \# of grid block & 4867 \\
\hline grid block dimensions & $50 \mathrm{~m}^{2}$ \\
\hline \# of flash iterations/time step & 398,049 \\
\hline \# of EOS solves/time step & 790,712 \\
\hline flash time/time step & $2.95 \mathrm{CPU} \mathrm{sec}$ \\
\hline time per flash/time step & $0.00061 \mathrm{CPU} \mathrm{sec}$ \\
\hline time step & 2 days \\
\hline time horizon & $400 \mathrm{days}$ \\
\hline total simulation time & $24.58 \mathrm{CPU} \mathrm{min}$ \\
\hline
\end{tabular}

Table 1.1 illustrates the scope of this class of problems. Over the course of a simulation millions of flash solutions and density roots to the equation of state are required. Compare this to a distillation problem in which maybe hundreds or thousands of flash/roots to equation of state solutions are required. Clearly the size of reservoir simulation problems is orders of magnitude larger than distillation problems. Moreover, since reservoir models generally include multi-phase flow through porous media, it is extremely important to calculate both accurate and consistent densities and phase equilibrium. Incorrect densities and phase equilibrium impact the flow of each phase through the reservoir due to the coupling of the PDEs and poor estimates of either can, over time, corrupt a simulation.

The focus of this paper is the calculation of densities and fugacities using the multi-scale GHC equation of state. The objective of this article is to show that the GHC equation provides thermodynamically consistent densities and fugacities. Accordingly, this paper is organized in the following way. Section 1.2 provides the necessary theory and numerical verification of the thermodynamic consistency of the multi-scale GHC equation. Section 1.3 shows that the multi-scale GHC equation provides accurate density and phase equilibrium results in addition to being thermodynamically 
consistent. This is important because if the calculated results were not accurate, the GHC equation would not be useful in practice. Conclusions of this work are presented in section 1.4 .

\subsection{Thermodynamic Consistency: Theory and Verification}

In this section, the basic theory behind the multi-scale GHC equation and verification of thermodynamic consistency are presented.

\subsubsection{Theory}

Starting with the pVT relationship or equation of state (EOS)

$p=\frac{R T}{V-b}-\frac{a}{V(V+b)}$

and the Soave-Redlich-Kwong (SRK) expression for the natural log of the fugacity coefficient

$\ln (\varphi)=z-1-\ln \left[\frac{z(V-b)}{V}\right]-\left(\frac{a}{b R T}\right) \ln \left[\frac{V+b}{V}\right]$

Lucia (2010) used the temperature derivative of eq. 1.2, $\left(\frac{\partial \ln \varphi}{\partial T}\right)_{p}$, the Gibbs-Helmholtz equation

$\left(\frac{\partial \ln \varphi}{\partial T}\right)_{p}=-\frac{H}{R T^{2}}$

and the high-pressure limit, $\lim _{p \rightarrow \infty} V=b$, to derive the following expression for the attraction (or energy) parameter, $a$, in eq. 1.1 for pure liquids

$a(T, p)=\left[\frac{a\left(T_{c}, p_{c}\right)}{T_{c}}+\frac{b U^{D}}{T_{c} \ln 2}+\frac{2 b R \ln T_{c}}{\ln 2}\right] T-\frac{b U^{D}}{\ln 2}-\left[\frac{2 b R}{\ln 2}\right] T \ln T$

where $T_{c}$ is the critical temperature, $p_{c}$ is the critical pressure, $a\left(T_{c}, p_{c}\right)=$ $0.42748 R^{2} T_{c}^{2} / p_{c}, b$ is the molecular co-volume, $R$ is the gas constant, and $U^{D}$ is a molecular length scale internal energy of departure for the liquid phase given by $U^{D}=$ $U^{D}(T, p)=U(T, p)-U^{i g}(T)$, where $U^{i g}(T)$ is the ideal gas internal energy. Note 
that $U^{D}$ serves as a natural bridge between the molecular and bulk phase length scales. When eq. 1.4 is used to determine the energy parameter in Eq. 1.1, the EOS is called the multi-scale Gibbs-Helmholtz Constrained (GHC) equation of state.

The derivation for mixtures, follows essentially the same steps as that for pure components. Starting with the fundamental expressions

$\frac{G_{M}^{D}}{R T}=\ln \varphi_{M}-\sum \ln \varphi_{i}$

where $M$ denotes a mixture property and $\varphi_{i}$ is the pure component fugacity coefficient for component $i$ and

$\left(\frac{\partial \ln \varphi_{M}}{\partial T}\right)_{p, x}=-\frac{H_{M}^{D}}{R T^{2}}$

the general form of the EOS for the mixture

$p=\frac{R T}{V_{M}-b_{M}}-\frac{a_{M}}{V_{M}\left(V_{M}+b_{M}\right)}$

and the high-pressure limit, $\lim _{p \rightarrow \infty} V_{M}=b_{M}$, Lucia (2010) derived the expression for the energy parameter, $a_{M}$, given by

$a_{M}=\left\{\frac{0.42748 R^{2} T_{c M}}{p_{c M}}+\frac{b_{M} U_{M}^{D}}{T_{c M} \ln 2}+\frac{2 b_{M} R \ln T_{c M}}{\ln 2}\right\} T-\frac{b_{M} U_{M}^{D}}{\ln 2}-\left(\frac{2 b_{M} R}{\ln 2}\right) T \ln T$

where Kay's rules, $T_{c M}=\sum x_{i} T_{c i}$ and $p_{c M}=\sum x_{i} p_{c i}$, are used to determine mixture critical temperature and pressure, $b_{M}=\sum x_{i} b_{i}$, and $U_{M}^{D}=\sum x_{i} U_{i}^{D}$ and where the quantities $T_{c i}, p_{c i}, b_{i}$, and $U_{i}^{D}$ are pure component critical temperatures, critical pressures, molecular co-volumes, and internal energies of departure, and $x_{i}$ denotes the mole fraction of component i. Note that eq. 1.8 is analogous to the one fluid theory approximation of $a_{M}$. It is also important for the reader to understand that there is no explicit mixing rule for $a_{M}$ using pure component energy parameters, $a_{i}^{\prime} s$, and mixing and combining rules. 
The general form of the expression for the partial fugacity coefficient of component $i$ is

$$
\begin{aligned}
\ln \widehat{\varphi}_{l}=-\ln \left(\frac{V-b_{M}}{V}\right)+ & \frac{R T}{V-b_{M}}-\left(\frac{1}{n b_{M}}\right) \ln \left(\frac{V+b_{M}}{V}\right)\left(\frac{\partial n^{2} a_{M}}{\partial n_{i}}\right) \\
& +\left[\frac{a_{M}}{b_{M}^{2}} \ln \left(\frac{V+b_{M}}{V}\right)-\frac{a_{M}}{b_{M}\left(V+n b_{M}\right)}\right]\left(\frac{\partial n b_{M}}{\partial n_{i}}\right)-\ln Z_{M}
\end{aligned}
$$

which, using $\left(\frac{\partial n b_{M}}{\partial n_{i}}\right)=b_{i}$, simplifies to the

$\ln \widehat{\varphi}_{l}=\left(\frac{b_{i}}{b_{m}}\right)\left(z_{M}-1\right)-\ln \left(z_{M}-b_{M}\right)+\left(\frac{A_{M}}{B_{M}}\right)\left[\frac{b_{i}}{b_{M}}-\frac{\left(\frac{\partial n^{2} a_{M}}{\partial n_{i}}\right)}{a_{M}}\right] \ln \left(1+\frac{B_{M}}{z_{M}}\right)$

where $A_{M}=p a_{M} / R T^{2}$ and $B_{M}=\frac{p b_{M}}{R T}$. To complete the expression for $\ln \hat{\varphi}_{i}$ the derivative $\left(\frac{\partial n^{2} a_{M}}{\partial n_{i}}\right)$ must be determined. The expression for $\left(\frac{\partial n^{2} a_{M}}{\partial n_{i}}\right)$ is worked out in Lucia et al. (2012, on page 96), and for brevity is not repeated here. As noted in Lucia and Bonk (2012) the term $\left(\frac{\partial n^{2} a_{M}}{\partial n_{i}}\right) / a_{M}$ plays the role of the term $(2 / a \alpha)\left[\sum x_{i}\left(a \alpha_{i j}\right)\right]$ in the SRK equation with Lorentz-Berthelot mixing rules, where $a \alpha=\sum \sum x_{i} x_{j}(a \alpha)_{i j}$.

In summary, the multi-scale GHC equation of state starts with the exact same expression for $\ln (\varphi)$ or $\ln \widehat{\varphi}_{\iota}$, as the SRK EOS, calculates the temperature derivative of $\ln \varphi$ or $\ln \varphi_{M}$, and then uses the Gibbs-Helmholtz equation to constrain $a$ or $a_{M}$ to derive the novel expressions for the energy parameter given by eq. 1.4 and 1.8. The question central to this article is whether or not the a posteriori development of the multi-scale GHC expressions for $a$ and $a_{M}$ preserve thermodynamic consistency. As shown in section 1.2.3, and illustrated throughout this article, that depends on the methodology for estimating $U^{D}$ and $U_{M}^{D}$.

\subsubsection{Internal Energies of Departure from NPT Monte Carlo Simulations}


Before turning to the issue of thermodynamic consistency, the procedure for constructing look-up tables of pure component internal energies of departure using NPT Monte Carlo simulations is briefly described. Pure component look-up tables contain discrete sets of $U_{i}^{D}$ as a function of $T$ and $p$, at varying intervals of temperatures from $250-600 \mathrm{~K}$ (or $750 \mathrm{~K}$ in the case of water) and pressures from 1 to $600 \mathrm{bar}$. In generating one $U_{i}^{D}$ data point for a given $T$ and $p$, we typically use a small number of particles (e.g., $\mathrm{N}=32$ particles) and run 4 sets of 50,000 equilibration cycles $+400,000$ sampling cycles. Results for all 4 sets are then averaged and entered as a single data point in a look-up table. This procedure is described in considerable detail in Lucia et al. (2012) and has been cross validated against MCCCS Towhee [see http://towhee.sourceforge.net], an open source Monte Carlo simulation code.

The key points in generating and using molecular length scale information are (1) look-up tables contain discrete sets of $U_{i}^{D}$ data with uncertainty, (2) defining $U_{i}^{D}$ for points between values of $T$ and $p$ in look-up tables is open and can be done in any number of ways (e.g., by averaging, linear interpolation, etc.), and (3) each way of defining $U_{i}^{D}$ impacts thermodynamic consistency differently.

\subsubsection{Verification}

To verify the thermodynamic consistency of the GHC equation, the following expressions are needed

$V=R T\left(\frac{\partial \ln f}{\partial p}\right)_{T}=\frac{R T}{p}+R T\left(\frac{\partial \ln \varphi}{\partial p}\right)_{T}$

for pure components, and

$V_{M}=\sum x_{i} \bar{V}_{i}$ 
$\bar{V}_{i}=R T\left(\frac{\partial \ln \hat{f}_{i}}{\partial p}\right)_{T, x}=\frac{R T}{p}+R T\left(\frac{\partial \ln \widehat{\varphi}_{i}}{\partial p}\right)_{T, x}$

for mixtures. It is important for the reader to understand that eqs. 1.11 and 1.12-13 only hold locally (at a given state of the system) and therefore can only be verified at a given thermodynamic state. This means that while the derivation of $\ln \varphi$ requires that $a=$ $a(T)$ only, the condition of thermodynamic consistency only holds locally. This means that $a=a(T)$ only can be relaxed locally and we are free to define the functionality of a differently as long as we do not violate thermodynamic consistency.

The procedure for numerically verifying thermodynamic consistency is as follows:

1) Fix $T$ for pure components or $T$ and $x$ for mixtures. Set $\epsilon$ to some small number (e.g., $\left.10^{-4}\right)$.

2) Choose $p$.

3) Establish a methodology for determining $U_{i}^{D}$ at the given $T$ and $p$ (e.g., nearest point in look-up table, interpolation, etc.)

4) Compute $f=\varphi p$ or $\hat{f}_{i}=x_{i} \hat{\varphi}_{i} p$ as a function of $\mathrm{p}$ using eqs. 1.2 and 1.10, where $a$ and $a_{M}$ are calculated using eqs. 1.1 and 1.8 respectively.

5) Set $\Delta p$ (e.g., $10^{-3}$ ), calculate $p=p+\Delta p$, and use finite differences to approximate the pressure derivatives $\left(\frac{\Delta \ln f}{\Delta p}\right)_{T}$ or $\left(\frac{\Delta \ln \hat{f}_{i}}{\Delta p}\right)_{T, x}$.

6) Do the following:

a) For pure components, calculate $V$ from eq. 1.11 and $V^{E O S}$ by solving the GHC cubic EOS.

b) For mixtures, calculate $V_{M}$ from Eqs. 1.12 and 1.13 and $V_{M}^{E O S}$ by solving the GHC cubic EOS. 
7) Check the following difference
a) If $\left|V-V^{E O S}\right|<\epsilon$
b) if $\left|V_{M}-V_{M}^{E O S}\right|<\epsilon$

8) If the condition in $7 a$ ) or $7 b$ ) is satisfied, then the GHC equation is thermodynamically consistent.

The critical step with regard to thermodynamic consistency is the methodology used to determine $U_{i}^{D}(T, p)$, which can be conveniently separated into two parts - a temperature part and a pressure part. Some of the ways in which $U_{i}^{D}$ can be determined are as follows:

1) For any temperature, $T$, linear interpolation between the appropriate isothermal $U_{i}^{D}$ data in a look-up table can be used to determine $U_{i}^{D}(T, p)$.

2) There are various ways to include the pressure effect once the temperature effect has been calculated.

a) Average $U_{i}^{D}$ over the pressure range of interest, say $\overline{U_{i}^{D}}(T)$. In this case, $U_{i}^{D}(T, p)=\overline{U_{i}^{D}}(T)$ for all pressures at the given temperature, $T$. There will generally be a different average value at each temperature.

b) For the given pressure $p$, set $U_{i}^{D}(T, p)=$ nearest $U_{i}^{D}(T, p)$.

c) For the given pressure $p$, use linear interpolation in pressure.

We recommend using linear interpolation in temperature, as in step 1, followed by setting $U_{i}^{D}(T, p)=$ nearest $U_{i}^{D}(T, p)$, which is the equivalent of constructing isothermal staircase functions for $U_{i}^{D}(p)$.

Clearly 2a) yields thermodynamic consistency since the use of average $\overline{U_{i}^{D}}(T)$ at all pressure for any given $T$ implies $a$ and $a_{M}$ depend only on temperature. Also, 2b) 
yields thermodynamic consistency because the condition for thermodynamic consistency, $V=R T\left(\frac{\partial \operatorname{lnf} f}{\partial p}\right)_{T}$, involves only point functions, and thus holds locally. However, using linear interpolation in pressure is not recommended.

\subsubsection{Pure Components}

In this sub-section three separate cases for determining $U^{D}$ for pure components are described.

Case 1: Direct Use of $U^{D}$ in Look-Up Table. Table 1.2 gives $U^{D}(p)$ data for water at $300 \mathrm{~K}$. Table 1.3, on the other hand, shows the details of a specific computation at 100 bar that verifies the condition of thermodynamic consistency for the GHC equation using a finite difference pressure derivative for a pressure perturbation $\Delta p=10^{-3} \mathrm{bar}$. Table 1.3 clearly shows that the GHC equation satisfies the condition of thermodynamic consistency since $\left|V-V^{E O S}\right|=1.119 \times 10^{-7} \mathrm{~cm}^{3} / \mathrm{mol}$.

Table 1.2: $U^{D}$ Data for Liquid Water at $300 \mathrm{~K}$

\begin{tabular}{|c|c|c|}
\hline $\mathbf{P}(\mathbf{b a r})$ & $\boldsymbol{U}^{\boldsymbol{D}}\left(\mathbf{1 0}^{\mathbf{5}} \frac{\mathbf{c m}^{\mathbf{3}} \mathbf{b a r}}{\mathbf{m o l}}\right)$ & $\mathbf{2} \boldsymbol{\sigma}\left(\frac{\mathbf{c m}^{\mathbf{3}} \mathbf{b a r}}{\mathbf{m o l}}\right)$ \\
\hline 1 & -4.642509 & 555.76 \\
\hline 50 & -4.648747 & 523.10 \\
\hline 100 & -4.645808 & 516.56 \\
\hline 200 & -4.650324 & 491.37 \\
\hline 300 & -4.646392 & 629.42 \\
\hline 400 & -4.650447 & 215.09 \\
\hline
\end{tabular}

Table 1.3: Illustration of Thermodynamic Consistency for the GHC Equation for Liquid Water at $300 \mathrm{~K}$

\begin{tabular}{|l|c|c|}
\hline \multicolumn{1}{|c|}{ Quantity } & \multicolumn{2}{c|}{ Value } \\
\hline $\boldsymbol{T}(\boldsymbol{K})$ & base case & perturbed case \\
\hline $\boldsymbol{p}($ bar $)$ & 300 & 300 \\
\hline $\boldsymbol{U}^{\boldsymbol{D}}\left(\mathbf{c m}^{\mathbf{3}} \mathbf{b a r} / \mathbf{m o l}\right)$ & 100 & 100.001 \\
\hline $\boldsymbol{a}\left(\mathbf{c m}^{\mathbf{6}} \mathbf{b a r} / \mathbf{m o l}^{\mathbf{2}}\right)$ & -4.645808 & -4.645808 \\
\hline $\boldsymbol{Z}$ & $9,385,174,5726$ & $9,385,174,5726$ \\
\hline
\end{tabular}




\begin{tabular}{|l|c|c|}
\hline $\boldsymbol{\rho}\left(\mathbf{m o l} / \mathbf{c m}^{\mathbf{3}}\right)$ & 0.0555694781809 & 0.0555694785634 \\
\hline $\boldsymbol{V}\left(\mathbf{c m}^{\mathbf{3}} / \mathbf{m o l}\right)$ from EOS & 17.99549019955 & 17.99549008 \\
\hline $\boldsymbol{l n} \boldsymbol{f}$ & -6.165093091207913 & -6.165092369740478 \\
\hline$(\Delta \boldsymbol{l n} \boldsymbol{f} / \Delta \boldsymbol{p})_{\boldsymbol{T}}$ & 0.000721467435127 & \\
\hline $\boldsymbol{V}\left(\boldsymbol{c m}^{\mathbf{3}} / \mathbf{m o l}\right)$ from Eq. $\mathbf{1 2}$ & 17.99549008764 & \\
\hline$\left|\boldsymbol{V}-\boldsymbol{V}^{\text {EOS }}\right|$ & $1.119 \times 10^{-7}$ & \\
\hline
\end{tabular}

Case 2: Linear Temperature Interpolation of $U^{D}$. The results in Table 1.3 correspond to a case where $T$ and $p$ correspond to a data point in the $U^{D}$ look-up table for water.

Table 1.4: Linear Interpolation of UD Data in Temperature

\begin{tabular}{|c|c|c|c|}
\hline \multirow{2}{*}{$\mathbf{P}(\mathbf{b a r})$} & \multicolumn{3}{|c|}{$\boldsymbol{U}^{\mathbf{D}}\left(\mathbf{1 0}^{\mathbf{5}} \frac{\mathbf{c m}^{\mathbf{3}} \mathbf{b a r}}{\mathbf{m o l}}\right)$} \\
\hline & $\mathbf{2 7 0} \boldsymbol{K}$ & $\mathbf{2 7 3 . 1 5} \boldsymbol{K}$ & $\mathbf{3 0 0} \boldsymbol{K}$ \\
\hline 1 & -4.841921 & -4.820983 & -4.642509 \\
\hline 50 & -4.833546 & -4.814142 & -4.648747 \\
\hline 100 & -4.829923 & -4.810591 & -4.645808 \\
\hline 200 & -4.834568 & -4.815222 & -4.650324 \\
\hline 300 & -4.830789 & -4.811427 & -4.646392 \\
\hline 400 & -4.836228 & -4.816721 & -4.650447 \\
\hline
\end{tabular}

Suppose instead, the specified temperature did not correspond to a temperature in the look-up table for water. Then linear interpolation should be used. That is, suppose the $U^{D}$ look-up table for water contained data at 270 and $300 \mathrm{~K}$ but the given temperature was $273.15 \mathrm{~K}$. Table 4 shows the results of linear temperature interpolation of $U^{D}$. Table 1.5 shows results for the computational verification of thermodynamic consistency for a $T=273.15 K$ and $p=300$ bar and clearly shows that the GHC equation satisfies thermodynamic consistency since $\left|V-V^{E O S}\right|=1.695 \times 10^{-7} \mathrm{~cm}^{3} / \mathrm{mol}$.

Table 1.5: Thermodynamic Consistency Results for the GHC Equation for Liquid Water at 273.15 K

\begin{tabular}{|l|c|c|}
\hline \multicolumn{1}{|c|}{ Quantity } & \multicolumn{2}{|c|}{ Value } \\
\hline $\boldsymbol{T}(\mathrm{K})$ & base case & perturbed case \\
\hline $\boldsymbol{p}(\mathrm{bar})$ & $273.15 \mathrm{~K}$ & $273.15 \mathrm{~K}$ \\
\hline $\boldsymbol{U}^{\boldsymbol{D}}\left(\mathrm{cm}^{\mathbf{3}} \mathrm{bar} / \mathrm{mol}\right)$ & 300 & 300.001 \\
\hline
\end{tabular}




\begin{tabular}{|c|c|c|}
\hline$a\left(\mathrm{~cm}^{6} \mathrm{bar} / \mathrm{mol}^{2}\right)$ & $9,853,314.4525$ & $9,853,314.4525$ \\
\hline$Z$ & 0.2342242459732 & 0.2342250254902 \\
\hline$\rho\left(\mathrm{mol} / \mathrm{cm}^{3}\right)$ & 0.0563978449856 & 0.0563978452819 \\
\hline$V\left(\mathrm{~cm}^{3} / \mathrm{mol}\right)$ from $\mathrm{EOS}$ & 17.731173952732 & 17.73117386 \\
\hline $\ln f$ & -8.3842699423298 & -8.382691615823 \\
\hline$(\Delta \ln f / \Delta p)_{T}$ & 0.0007807474791 & \\
\hline$V\left(\mathrm{~cm}^{3} / \mathrm{mol}\right)$ from $\mathrm{Eq} .12$ & 17.731173783187 & \\
\hline$\left|V-V^{E O S}\right|$ & $1.695 \times 10^{-7}$ & \\
\hline
\end{tabular}

Case 3: Temperature and Pressure Effects on $U^{D}$. Table 1.6 repeats the same verification of thermodynamic consistency for the case where the temperature and pressure of interest do not correspond to a data point in the look-up table. Here the methodology for choosing $U^{D}$ consists of linear interpolation in temperature followed by $U^{D}(T, p)=$ nearest $U^{D}(T, p)$. Let $T=273.15 \mathrm{~K}$ and $p=220 \mathrm{bar}$. From Table $1.4, U^{D}(T, p)=$ nearest $U^{D}(T, p)=-4.815222 \times 10^{5} \mathrm{~cm}^{3} \mathrm{bar} / \mathrm{mol}$. Once again, the GHC equation satisfies the condition of thermodynamic consistency in this case since $\left|V-V^{E O S}\right|=$ $1.458 \times 10^{-7} \mathrm{~cm}^{3} / \mathrm{mol}$.

Table 1.6: Thermodynamic Consistency for the GHC Equation for Liquid Water at 273.15 K \& 220 bar

\begin{tabular}{|c|c|c|}
\hline \multirow[t]{2}{*}{ Quantity } & \multicolumn{2}{|c|}{ Value } \\
\hline & base case & perturbed case \\
\hline$T(K)$ & $273.15 \mathrm{~K}$ & $273.15 \mathrm{~K}$ \\
\hline$p($ bar $)$ & 220 & 220.001 \\
\hline$U^{D}\left(\mathrm{~cm}^{3} \mathrm{bar} / \mathrm{mol}\right)$ & -4.815222 & -4.815222 \\
\hline$a\left(\mathrm{~cm}^{6} \mathrm{bar} / \mathrm{mol}^{2}\right)$ & $9,858,492.5616$ & $9,858,492.5616$ \\
\hline$z$ & 0.17182926573979 & 0.1718300458695 \\
\hline$\rho\left(\mathrm{mol} / \mathrm{cm}^{3}\right)$ & 0.05637657017797 & 0.0563765704773 \\
\hline$V\left(\mathrm{~cm}^{3} / \mathrm{mol}\right)$ from $\mathrm{EOS}$ & 17.7378651599977 & 17.73786507 \\
\hline $\ln f$ & -8.4558504419592 & -8.4558496609170 \\
\hline$(\Delta \ln f / \Delta p)_{T}$ & 0.00078104212342 & \\
\hline$V\left(\mathrm{~cm}^{3} / \mathrm{mol}\right)$ from $\mathrm{Eq} .12$ & 17.737865305845 & \\
\hline$\left|V-V^{E O S}\right|$ & $1.458 \times 10^{-7}$ & \\
\hline
\end{tabular}


These exercises verifying the thermodynamic consistency of the GHC equation have been repeated for a large number of pure components and different conditions of temperature and pressure and in all cases the condition defining thermodynamic consistency (i.e., condition 7a) in section 1.2.3 was satisfied.

\subsubsection{Mixtures}

In this sub-section, verification of the thermodynamic consistency of the multiscale GHC equation for mixtures is presented.

\section{Methane-Water}

Mixtures of light gas and water are usually challenging so we have selected the methane-water system as a first example to illustrate the thermodynamic consistency of the multi-scale GHC equation for mixtures. Table 1.7 shows calculated results comparing the mixture volume calculated from the GHC EOS, $V_{M}^{E O S}$, and the mixture volume calculated using Eqs. 1.12 and 1.13, $V_{M}$, for methane-water VLE at conditions

of temperature and pressure given in Servio and Englezos (2002), where all $\left(\frac{\Delta \ln \hat{f}_{i}}{\Delta p}\right)_{T, x}$ were computed by forward finite differences using $\Delta p=10^{-3}$ bar.

Table 1.7: Thermodynamic Consistency of the GHC Equation for Liquid Phase in MethaneWater VLE

\begin{tabular}{|c|c|c|c|c|c|}
\hline $\boldsymbol{T}(\boldsymbol{K})$ & $\boldsymbol{p}(\boldsymbol{b a r})$ & $\boldsymbol{x}_{\boldsymbol{C H 4}}^{G H C}$ & $\boldsymbol{V}_{\boldsymbol{M}}^{\mathbf{E O S}}\left(\frac{\mathbf{c m}^{\mathbf{3}}}{\mathbf{m o l}}\right)$ & $\boldsymbol{V}_{\boldsymbol{M}}\left(\frac{\mathbf{c m}^{\mathbf{3}}}{\mathbf{m o l}}\right)$ & $\left|\boldsymbol{V}_{\boldsymbol{M}}-\boldsymbol{V}_{\boldsymbol{M}}^{\mathbf{E O S}}\right|$ \\
\hline 278.65 & 35 & 0.001104 & 17.82230032533609 & 17.82230041370546 & $8.836936871 \times 10^{-8}$ \\
\hline 280.45 & 35 & 0.001098 & 17.83846947890100 & 17.83846955976809 & $8.086709258 \times 10^{-8}$ \\
\hline 281.55 & 50 & 0.001379 & 17.85079049395588 & 17.85079044671112 & $4.724476454 \times 10^{-8}$ \\
\hline 282.65 & 50 & 0.001374 & 17.86063990857652 & 17.86063968280504 & $2.257714797 \times 10^{-7}$ \\
\hline 283.25 & 65 & 0.001660 & 17.86940920717577 & 17.86940924972613 & $4.255035435 \times 10^{-8}$ \\
\hline 284.35 & 65 & 0.001653 & 17.87928987627068 & 17.87928977668451 & $9.958616331 \times 10^{-8}$ \\
\hline
\end{tabular}

$V_{M}$ calculated from Eqs. 12 and 13, where $\left(\frac{\partial \ln \hat{f}_{i}}{\partial p}\right)_{T, x}$ is calculated using finite difference. 
Note that in each case, $\left|V_{M}-V_{M}^{E O S}\right|<10^{-6} \mathrm{~cm}^{3} / \mathrm{mol}$; and thus the condition of thermodynamic consistency is satisfied. Values of internal energies of departure for methane and water determined by the methodology described in section 1.2.3 can be found in Table 1.8 .

Table 1.8: $\mathrm{U}_{\mathrm{i}}^{\mathrm{D}}$ for Methane and Water at $280.45 \mathrm{~K}$

\begin{tabular}{|c|c|c|c|}
\hline \multicolumn{2}{|c|}{ Methane } & \multicolumn{2}{c|}{ Water } \\
\hline $\boldsymbol{p}(\boldsymbol{b a r})$ & $\boldsymbol{U}^{\boldsymbol{D}}\left(\mathbf{1 0}^{\mathbf{5}} \frac{\mathbf{c m}^{\mathbf{3}} \boldsymbol{b a r}}{\mathbf{m o l}}\right)$ & $\boldsymbol{p}(\boldsymbol{b a r})$ & $\boldsymbol{U}^{\boldsymbol{D}}\left(\mathbf{1 0}^{\mathbf{5}} \frac{\mathbf{c m}^{\mathbf{3}} \boldsymbol{b a r}}{\mathbf{m o l}}\right)$ \\
\hline 1 & -0.86132 & 1 & -4.77545 \\
\hline 35 & -0.86333 & 35 & -4.76963 \\
\hline 50 & -0.86421 & 50 & -4.77194 \\
\hline 65 & -0.86502 & 65 & -4.77085 \\
\hline 100 & -0.86690 & 100 & -4.76855 \\
\hline
\end{tabular}

The details of specific computation, including finite difference values for $\left(\frac{\Delta \ln \hat{f}_{i}}{\Delta p}\right)_{T, x}$ and computed partial molar volumes, verifying thermodynamic consistency of the GHC equation can be found in Table 1.9.

Table 1.9: Thermodynamic Consistency of GHC Equation for $\mathrm{CH}_{4}-$ Water

\begin{tabular}{|l|l|l|l|}
\hline & Methane & Water & Mixture \\
\hline $\boldsymbol{x}$ & 0.001098199 & 0.998901801 & \\
\hline$\Delta \boldsymbol{l n} \hat{\boldsymbol{f}}_{\boldsymbol{i}} / \Delta \boldsymbol{p}$ & 0.001465361138 & 0.000764257667 & \\
\hline$\overline{\boldsymbol{V}}_{\boldsymbol{i}}\left(\mathbf{c m}^{\mathbf{3}} / \mathbf{m o l}\right)$ & 34.16849145680 & 17.82052004429 & \\
\hline $\boldsymbol{V}_{\boldsymbol{M}}\left(\mathbf{c m}^{\mathbf{3}} / \mathbf{m o l}\right)$ & & & 17.83847337 \\
\hline $\boldsymbol{V}_{\boldsymbol{M}}^{\mathbf{E O S}}\left(\mathbf{c m}^{\mathbf{3}} / \mathbf{m o l}\right)$ & & & 17.83847324 \\
\hline
\end{tabular}

\section{$\underline{\mathrm{CO}_{2} \text {-Octane-Water }}$}

In this second example for mixtures, a vapor-liquid-liquid equilibrium (VLLE) flash solution is used to verify the thermodynamic consistency of the GHC equation.

Table 1.10: Feed and Equilibrium Phase Compositions for VLLE Solution

\begin{tabular}{|c|c|c|c|c|}
\hline & Feed & Liquid 1 & Vapor & Liquid 2 \\
\hline CO $_{2}$ & 0.3 & 0.000927 & 0.998475 & 0.101631 \\
\hline n-octane & 0.2 & $1.499 \times 10^{-10}$ & 0.001239 & 0.898365 \\
\hline
\end{tabular}




\begin{tabular}{|c|c|c|c|c|}
\hline water & 0.5 & 0.999073 & 0.000285 & $3.588 \times 10^{-6}$ \\
\hline phase fraction & 1 & 0.500384 & 0.277372 & 0.222244 \\
\hline density $\left(\mathbf{m o l} /\right.$ cm $\left.^{3}\right)$ & 0.017749 & 0.055088 & 0.000850 & 0.006435 \\
\hline
\end{tabular}

Table 1.10 gives the feed and equilibrium phase compositions for a flash of a $30 \mathrm{~mol} \%$ $\mathrm{CO}_{2}, 20 \mathrm{~mol} \%$ n-octane and $50 \mathrm{~mol} \%$ water at $313.15 \mathrm{~K}$ and 20 bar computed using the GHC equation. Table 1.11 on the other hand, provides details of the verification that the feed and both liquids in the VLLE satisfy conditions of thermodynamic consistency. Note that in all cases the condition of thermodynamic consistency is satisfied to a tolerance of at least $\epsilon=10^{-4}$.

Table 1.11: Thermodynamic Consistency of GHC Equation for VLLE Problem at 313.15 K \& 20 bar

\begin{tabular}{|c|c|c|c|c|}
\hline & Methane & Octane & Water & Mixture \\
\hline$U_{i}^{D}\left(\mathrm{~cm}^{3} / \mathrm{mol}\right)$ & -6250.34 & $-352,145.87$ & $-456,546.82$ & \\
\hline \multicolumn{5}{|l|}{ Feed } \\
\hline$x$ & 0.3 & 0.2 & 0.5 & \\
\hline$\Delta \ln \hat{f}_{i} / \Delta p$ & 0.00192701 & 0.00692305 & 0.00040258 & \\
\hline $\bar{V}_{i}\left(\mathrm{~cm}^{3} / \mathrm{mol}\right)$ & 50.1719576 & 180.250292 & 10.4816483 & \\
\hline$V_{M}\left(\mathrm{~cm}^{3} / \mathrm{mol}\right)$ & & & & 56.34246990 \\
\hline$V_{M}^{E O S}\left(\mathrm{~cm}^{3} / \mathrm{mol}\right)$ & & & & 56.32473184 \\
\hline$\left|V_{M}-V_{M}^{E O S}\right|$ & & & & $3.2869 \times 10^{-6}$ \\
\hline \multirow{2}{*}{\multicolumn{5}{|c|}{ Liquid 1}} \\
\hline & & & & \\
\hline$x$ & 0.000927 & $1.499 \times 10^{-10}$ & 0.999073 & \\
\hline$\Delta \boldsymbol{l n} \widehat{\boldsymbol{f}}_{i} / \Delta \boldsymbol{p}$ & 0.00129113 & 0.00627762 & 0.000696657 & \\
\hline $\bar{V}_{i}\left(\mathrm{~cm}^{3} / \mathrm{mol}\right)$ & 33.6157158 & 163.445547 & 18.13832042 & \\
\hline$V_{M}\left(\mathrm{~cm}^{3} / \mathrm{mol}\right)$ & & & & 18.15266904 \\
\hline$V_{M}^{E O S}\left(\mathrm{~cm}^{3} / \mathrm{mol}\right)$ & & & & 18.15266879 \\
\hline$\left|V_{M}-V_{M}^{E O S}\right|$ & & & & $2.4536 \times 10^{-7}$ \\
\hline \multirow{2}{*}{\multicolumn{5}{|c|}{ Liquid 2}} \\
\hline & & & & \\
\hline$x$ & 0.101631 & 0.898365 & $3.588 \times 10^{-6}$ & \\
\hline$\Delta \ln \widehat{f}_{i} / \Delta p$ & 0.00286247 & 0.00631953 & 0.00249126 & \\
\hline $\bar{V}_{i}\left(\mathrm{~cm}^{3} / \mathrm{mol}\right)$ & 74.5280348 & 164.536732 & 64.8625668 & \\
\hline$V_{M}\left(\mathrm{~cm}^{3} / \mathrm{mol}\right)$ & & & & 155.3885599 \\
\hline$V_{M}^{E O S}\left(\mathrm{~cm}^{3} / \mathrm{mol}\right)$ & & & & 155.3887433 \\
\hline$\left|V_{M}-V_{M}^{E O S}\right|$ & & & & $1.4362 \times 10^{-5}$ \\
\hline
\end{tabular}

\subsubsection{The Staircase Function}


This next section of the paper provides a brief summary of the underlying mathematical framework for the pressure dependence of $U_{i}^{D}$. Use of the methodology $U_{i}^{D}(T, p)=$ nearest $U_{i}^{D}(T, p)$ is equivalent to defining $U_{i}^{D}$ as a staircase function in pressure, where the staircase function is simply a mathematical construct that permits any quantity, in this case internal energy of departure, to vary with respect to any independent variable (e.g., pressure) and has the following mathematical properties:

1) It is not continuous everywhere. In fact, the smaller the step width (run) and step height (rise) of the staircase, the finer the granularity and number of points of discontinuity for a given range.

2) It has either a derivative or one-sided derivative of zero everywhere, except for at any discontinuity.

Figure 1.1 gives an illustration of a staircase function for $U_{i}^{D}$ for liquid water at 273.15 $\mathrm{K}$ for pressures between 10 and 100 bar for a run (or staircase width) of 10 bar. Thirtytwo (32) water molecules and an average of 4 runs of 50,000 equilibration steps and 400,000 production cycles were used to generate each $U_{i}^{D}$ data point (denoted by X) shown in Fig. 1.1. 


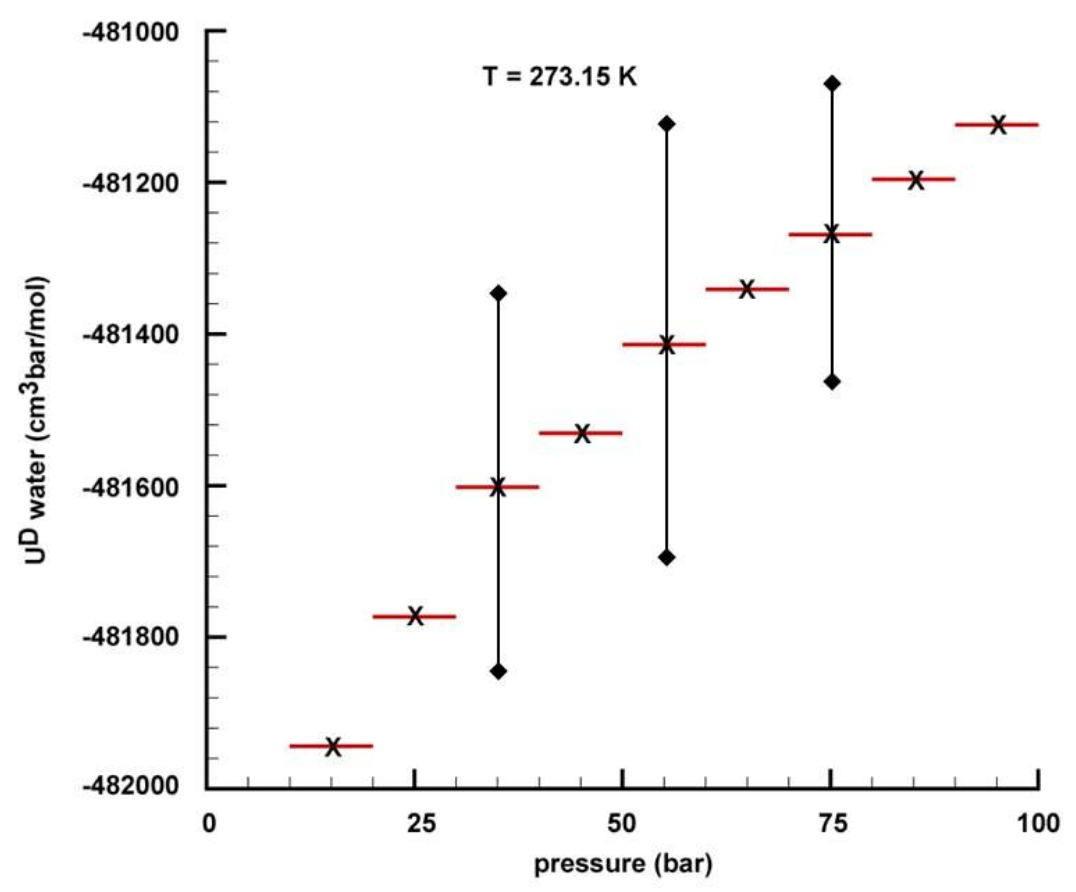

Figure 1.1: Isothermal Staircase Function for $\mathrm{U}^{\mathrm{D}}$ for Water versus Pressure

Figure 1.1 also shows the uncertainty in $U_{i}^{D}$ for the $95 \%$ confidence limit (or 2 standard deviations) for some of the discrete values of $U_{i}^{D}$, where uncertainties are shown as black diamonds with error bars.

Note that by adopting an isothermal staircase representation of the pressure dependence of the internal energy of departure the following statements are true:

1) $U_{i}^{D}$ clearly depends on pressure but the derivative (or one-sided derivative) of $U_{i}^{D}(T, p)$ with respect to $p$ at constant temperature, $\left(\partial U_{i}^{D} / \partial p\right)_{T}=0$.

2) The staircase can have any desired level of granularity.

3) Finer granularity can be adding more NPT Monte Carlo simulations data to the look-up table. Each step of the staircase would then have a smaller height (rise) and smaller run (width). 
4) The staircase function in Fig. 1.1 can also be interpreted as quasi-linearization of $U_{i}^{D}$ with respect to $p$, as described by Bellman (1973). Quasi-linearization in this context is simply a Taylor series of isothermal $U_{i}^{D}(T, p)$ expanded about a discrete data point with all pressure derivatives set to zero.

5) Since $\left(\partial U_{i}^{D} / \partial p\right)_{T}=0$ is everywhere zero, clearly implies that $(\partial a / \partial p)_{T}=0$ and therefore the multi-scale GHC equation is thermodynamically consistent.

The proposed staircase procedure for isothermal values of molecular $U_{i}^{D}$ with respect to pressure can be contrasted to other possible approaches where

1) A least-squares, chi-squared, or maximum likelihood function is used to fit internal energies of departure so that bulk phase $U_{i}^{D}$ can be treated as a smooth function of pressure.

2) Multiple NPT Monte Carlo simulations are run at different pressures, averaged, and then numerical differentiation is used to approximate bulk phase $\left(\partial U_{i}^{D} / \partial p\right)_{T}$

In contrast and regardless of granularity, using a staircase representation of $U_{i}^{D}$ versus $p$, gives molecular values of $\left(\partial U_{i}^{D} / \partial p\right)_{T}$ that are always zero for practical uses (eg. when evaluated at the pressure and temperature of interest).

Recall that molecular internal energies of departure for mixtures, $U_{M}^{D}$, are calculated using the simple linear mixing rule

$U_{M}^{D}=\sum x_{i} U_{i}^{D}$

where $x_{i}$ and $U_{i}^{D}$ are the mole fraction and internal energy of departure for the $\mathrm{i}^{\text {th }}$ component in the mixture. 


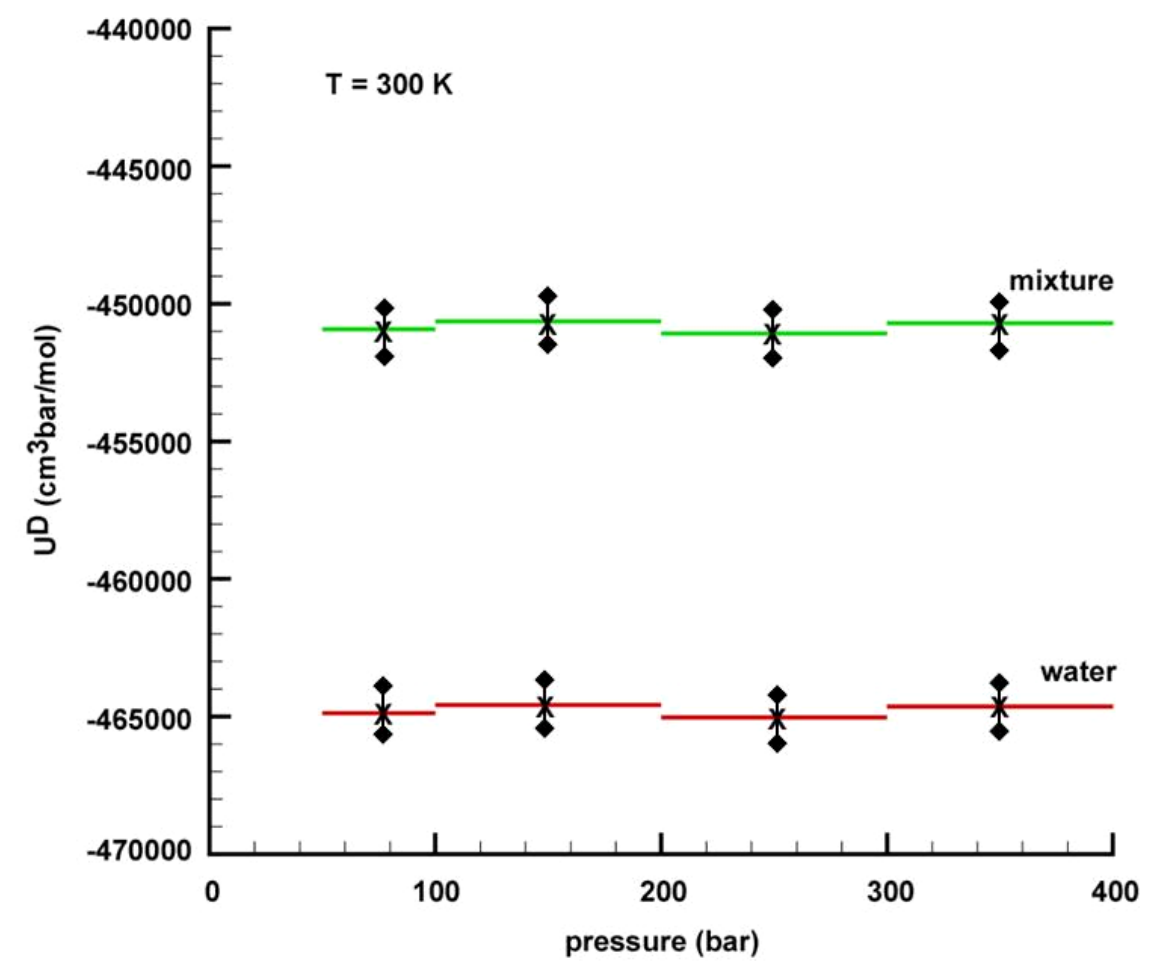

Figure 1.2: Isothermal Staircase Functions for $\mathrm{U}^{\mathrm{D}}$ water and $\mathrm{U}^{\mathrm{D}}$ CO2-water versus Pressure If each $U_{i}^{D}$ in eq. 1.14 is given by an isothermal staircase function in pressure, then $U_{M}^{D}$ is also an isothermal staircase function. Moreover, there is no restriction that the $U^{D}$ data points for each component need to coincide or that the height (rise) or width (run) of each staircase function for $U_{i}^{D}$ be the same. These facts are easily proved. However, in our opinion, it is more informative and instructive to give a clear geometric interpretation of these facts. Thus Fig. 1.2 shows the component staircase function for water, $U_{\text {water }}^{D}$, as well as the staircase function for $U_{M}^{D}$ for an aqueous-rich mixture of 3 mol\% carbon dioxide and 97 mol\% water with uncertainty bars. Due to the large differences in scale between $U_{\mathrm{CO} 2}^{D}$ and $U_{\text {water }}^{D}$, the staircase function for $U_{\mathrm{CO} 2}^{D}$ is not shown in Fig. 1.2. However, $U^{D}$ data for both components and the mixture are given in Table 1.12 to illustrate that the $U^{D}$ data points for $\mathrm{CO}_{2}$ and water do not need to coincide. 
Table 1.12 - Internal Energies of Departure for $\mathrm{CO}_{2}$, Water and $3 \mathrm{~mol} \% \mathrm{CO}_{2}-97 \mathrm{~mol} \%$ Water at $300 \mathrm{~K}$

\begin{tabular}{|c|c|c|c|c|c|}
\hline \multicolumn{2}{|r|}{ water } & \multicolumn{2}{|c|}{ carbon dioxide } & \multicolumn{2}{|r|}{ mixture } \\
\hline$p$ (bar) & $U^{D}\left(10^{5} \frac{\mathrm{cm}^{3} \mathrm{bar}}{\mathrm{mol}}\right)$ & $p$ (bar) & $U^{D}\left(10^{5} \frac{\mathrm{cm}^{3} \mathrm{bar}}{\mathrm{mol}}\right)$ & $p($ bar $)$ & $U^{D}\left(10^{5} \frac{\mathrm{cm}^{3} \mathrm{bar}}{\mathrm{mol}}\right)$ \\
\hline $50-100$ & -4.64874 & $50-75$ & -0.17592 & $50-100$ & -4.50927 \\
\hline $100-200$ & -4.64580 & $75-150$ & -0.77962 & $100-200$ & -4.50642 \\
\hline $200-300$ & -4.65032 & $150-225$ & -0.98094 & $200-300$ & -4.51081 \\
\hline $300-400$ & -4.64639 & $225-300$ & -1.03888 & $300-400$ & -4.50699 \\
\hline & & $300-400$ & -1.07664 & & \\
\hline
\end{tabular}

The conditions of temperature, pressure and composition in Fig. 1.2 were selected because they correspond to approximate conditions in Teng et al. (1997).

\subsubsection{Molecular vs. Bulk Phase $\left(\partial U^{D} / \partial p\right)_{T}$}

While the pressure functionality of $U^{D}$ at the molecular scale is given by the staircase function and its pressure derivative is everywhere zero, bulk phase values of $U^{D}$ can still be calculated from

$U^{D}=\left(\frac{1}{b}\right)\left[a-T\left(\frac{\partial a}{\partial T}\right)\right] \ln \left(1+\frac{b}{V}\right)$

and bulk phase pressure derivatives of the internal energy of departure readily computed from

$\left(\partial U^{D} / \partial p\right)_{T}=-\left[T(\partial V / \partial T)_{p}+p(\partial V / \partial p)_{T}\right]$

where the partial derivatives $(\partial V / \partial T)_{p}$ and $(\partial V / \partial p)_{T}$ are easily calculated from the equation of state. See p. 511 - 512 in Walas (1985) for a derivation of eq. 1.15. Moreover, for any phase one would expect the bulk phase value of $U^{D}$ to become more negative (i.e., move farther away from the ideal gas state of $U^{D}=0$ ) as pressure increases so $\left(\partial U^{D} / \partial p\right)_{T}$ should be negative.

Table 1.13: Bulk Phase $\left(\partial \mathrm{U}^{\mathrm{D}} / \partial \mathrm{p}\right)_{\mathrm{T}}$ for the GHC EOS for Water at $273.15 \mathrm{~K}$

\begin{tabular}{|c|c|c|c|}
\hline$p($ bar $)$ & $\begin{array}{c}\left(\partial U^{D} / \partial p\right)_{T} \\
\left(\mathrm{~cm}^{3} / \mathrm{mol}\right)\end{array}$ & $p(\mathrm{bar})$ & $\begin{array}{c}\left(\partial U^{D} / \partial p\right)_{T} \\
\left(\mathrm{~cm}^{3} / \mathrm{mol}\right)\end{array}$ \\
\hline
\end{tabular}




\begin{tabular}{|c|c|c|c|}
\hline 5.30 & -1.9977 & 210.28 & -1.9397 \\
\hline 12.60 & -1.9958 & 268.57 & -1.9239 \\
\hline 20.00 & -1.9939 & 326.95 & -1.9077 \\
\hline 27.40 & -1.9921 & 385.22 & -1.8911 \\
\hline 42.11 & -1.9884 & 443.49 & -1.8755 \\
\hline 56.81 & -1.9841 & 501.85 & -1.8601 \\
\hline 71.51 & -1.9801 & 560.11 & -1.8444 \\
\hline 86.31 & -1.9760 & 618.47 & -1.8289 \\
\hline 101.01 & -1.9720 & 676.71 & -1.8137 \\
\hline 115.71 & -1.9768 & 735.06 & -1.7986 \\
\hline 130.52 & -1.9631 & 793.29 & -1.7838 \\
\hline 151.89 & -1.9568 & & \\
\hline
\end{tabular}

Table 1.13 gives the bulk phase pressure derivative of internal energies of departure in the multi-scale GHC framework for liquid water at $273.15 \mathrm{~K}$ and shows that there are no inconsistencies created by the staircase approximation of $U^{D}$ at the molecular scale with regard to bulk phase internal energies and their associated pressure derivative.

\subsection{Density \& Phase Equilibrium Results}

A given equation of state must also provide accurate densities and phase equilibrium to be useful in practice.

\subsubsection{Pure Components}

Table 1.14 gives a comparison of liquid density predictions for the SRK equation (Soave, 1972) with Peneloux volume translation (SRK+) (Peneloux et al., 1982), the volume translated Peng-Robinson (VTPR) equation (Ahlers \& Gmehling, 2001), and the GHC equation with experimental data for a number of different compounds.

The symbol $N_{d}$ in Table 1.14 refers to the number of experimental data points and $A A D \%$ error is calculated as

$A A D \%=\frac{1}{N_{d}} \sum_{i=1}^{N_{d}} 100\left|\left(\rho_{i}^{\text {exp }}-\rho_{i}^{\text {calc }}\right)\right| / \rho_{i}^{\text {exp }}$

or

$A A D \%=\frac{1}{N_{d}} \sum_{i=1}^{N_{d}} 100\left|\left(V_{i}^{\text {exp }}-V_{i}^{\text {calc }}\right)\right| / V_{i}^{\text {exp }}$ 
depending on the way the experimental data was reported. The summation in the definition of $\mathrm{AAD} \%$ error is over all data points. Note that Table 1.14 shows that overall (under the conditions investigated here) the VTPR and GHC equations are superior to the SRK+ equation and that the multi-scale GHC equation provides more accurate density predictions than the VTPR equation.

Table 1.14: Summary of Some Liquid Density Predictions for the SRK+, VTPR and GHC Equations

\begin{tabular}{|c|c|c|c|c|c|c|c|}
\hline Compound & $T(K)$ & $p($ bar $)$ & $N_{d}$ & $\begin{array}{l}A A D \% \\
S R K+\end{array}$ & $\begin{array}{c}A A D \% \\
\operatorname{VTPR}\end{array}$ & $\begin{array}{c}A A D \% \\
G H C\end{array}$ & Data Reference \\
\hline methanol & $\begin{array}{c}283.15- \\
333.15\end{array}$ & $1-350$ & 77 & 4.74 & 0.60 & 0.66 & Goldon et al. (2007) \\
\hline $\mathrm{CO}_{2}$ & $\begin{array}{l}233.383- \\
297.644\end{array}$ & $84-316$ & 28 & 8.56 & 9.90 & 0.79 & Magee \& Ely (1986) \\
\hline benzene & $280-600$ & $1-500$ & 56 & 9.12 & 5.83 & 1.64 & $\begin{array}{c}\text { Kessel'man et al. } \\
(1970)\end{array}$ \\
\hline toluene & $270-400$ & $5.2-340$ & 181 & 10.62 & 1.12 & 1.22 & $\begin{array}{c}\text { Magee \& Bruno } \\
(1996)\end{array}$ \\
\hline m-xylene & $\begin{array}{l}293.15- \\
548.15\end{array}$ & $1-400$ & 63 & 13.72 & 4.12 & 2.38 & Vargaftik (1983) \\
\hline n-octane & $298-521$ & $1-2836$ & 188 & 13.14 & 2.65 & 1.51 & $\begin{array}{c}\text { Mora'vkova' et al. } \\
\text { (2006) } \\
\text { Caudwell et al. } \\
\text { (2009) } \\
\text { Liu et al. (2010) }\end{array}$ \\
\hline hexadecane & $\begin{array}{l}298.15- \\
348\end{array}$ & 1 & 8 & 25.79 & 4.22 & 1.30 & $\begin{array}{l}\text { Camin et al. (1954) } \\
\text { Dysthe et al. (2000) } \\
\text { Queimada et al. } \\
\text { (2003) }\end{array}$ \\
\hline tetracosane & $\begin{array}{l}324.25- \\
372.05\end{array}$ & $1-120.6$ & 58 & 33.13 & 3.25 & 1.60 & $\begin{array}{c}\text { van Hook \& Silver } \\
(1942) \\
\text { Templin (1956) } \\
\text { Peters et al. (1987) }\end{array}$ \\
\hline water & $\begin{array}{l}273.15- \\
303.15 \\
\end{array}$ & $5.3-793$ & 115 & 2.26 & 3.14 & 0.83 & $\begin{array}{c}\text { Kell \& Whalley } \\
(1965)\end{array}$ \\
\hline total/average & & & 774 & 11.32 & 2.83 & 1.31 & \\
\hline
\end{tabular}

Table 1.15 compares detailed calculations of molar density for liquid water at $273.15 \mathrm{~K}$ with the experimental data of Kell and Whalley (1965). Note again that the average $\mathrm{AAD} \%$ error in molar volume is quite small - less than $1 \%$. 
Extrapolating the results for average $U^{D}$ in Table 1.15 may seem reasonable.

However, notice that for water at $273.15 \mathrm{~K}$, the values of $U^{D}$ do not change very much as a function of pressure, and this is the primary reason why an average value of $U^{D}$ gives acceptable density predictions. Consider, on the other hand, n-octane at 298.15

$\mathrm{K}$. This situation is much different because the values of $U^{D}$ vary from $-3.97 \times 10^{5}$ to $5.58 \times 10^{5} \mathrm{~cm}^{3} \mathrm{bar} / \mathrm{mol}$ over the pressure range 100 to $700 \mathrm{bar}$. In this case, an average value of $U^{D}$ gives an $\mathrm{AAD} \%$ error in octane mass density of 0.85 when compared to experimental data from NIST, which is almost twice that for an isothermal staircase representation of $U^{D}$, which gives an $\mathrm{AAD} \%$ error of 0.46 .

Table 1.15: Comparison of Molar Volumes for Water at 273.15 K Calculated Using Pressure Dependent Energy Parameters in the GHC Equation

\begin{tabular}{|c|c|c|c|c|c|c|}
\hline$p$ (bar) & $V^{e x p} \mathrm{~cm}^{3} / g$ & $\begin{array}{l}V^{G H C} \\
\mathrm{~cm}^{3} / \mathrm{g}\end{array}$ & $U^{D}\left(10^{5} \frac{\mathrm{cm}^{3} \mathrm{bar}}{\mathrm{mol}}\right.$ & \% Error & $\begin{array}{l}V^{G H C} \\
\mathrm{~cm}^{3} / \mathrm{g}\end{array}$ & \% Error \\
\hline 5.30 & 0.999882 & 0.985710 & -4.8202486 & 1.417323 & 0.985746 & 1.413756 \\
\hline 12.60 & 0.999512 & 0.985675 & -4.8190009 & 1.384332 & 0.985707 & 1.381150 \\
\hline 20.00 & 0.999138 & 0.985640 & -4.8177360 & 1.350921 & 0.985667 & 1.348221 \\
\hline 27.40 & 0.998762 & 0.985623 & -4.8164712 & 1.315536 & 0.985628 & 1.315070 \\
\hline 42.11 & 0.998025 & 0.985570 & -4.8139570 & 1.247922 & 0.985548 & 1.250177 \\
\hline 56.81 & 0.997282 & 0.985500 & -4.8136492 & 1.181367 & 0.985469 & 1.184494 \\
\hline 71.51 & 0.996550 & 0.985430 & -4.8125840 & 1.115804 & 0.985391 & 1.119803 \\
\hline 86.31 & 0.995813 & 0.985360 & -4.8115116 & 1.049646 & 0.985311 & 1.054617 \\
\hline 101.01 & 0.995088 & 0.985308 & -4.8106384 & 0.982826 & 0.985231 & 0.990527 \\
\hline 115.71 & 0.994362 & 0.985221 & -4.8113211 & 0.919325 & 0.985154 & 0.926048 \\
\hline 130.52 & 0.993637 & 0.985133 & -4.8120090 & 0.855830 & 0.985076 & 0.861572 \\
\hline 151.89 & 0.992594 & 0.985011 & -4.8130015 & 0.763979 & 0.984964 & 0.768739 \\
\hline 210.28 & 0.989782 & 0.984679 & -4.8148340 & 0.515589 & 0.984656 & 0.517881 \\
\hline 268.57 & 0.987033 & 0.984399 & -4.8126312 & 0.266820 & 0.984353 & 0.271548 \\
\hline 326.95 & 0.984329 & 0.984103 & -4.8128934 & 0.022989 & 0.984051 & 0.028292 \\
\hline 385.22 & 0.981681 & 0.983754 & -4.8160630 & 0.211159 & 0.983752 & 0.211000 \\
\hline 443.49 & 0.979074 & 0.983458 & -4.8161323 & 0.447730 & 0.983457 & 0.447695 \\
\hline 501.85 & 0.976526 & 0.983179 & -4.8155411 & 0.681283 & 0.983163 & 0.679688 \\
\hline 560.11 & 0.974014 & 0.982866 & -4.8178194 & 0.908771 & 0.982872 & 0.90948 \\
\hline 618.47 & 0.971560 & 0.982552 & -4.8201016 & 1.131417 & 0.982584 & 1.13464 \\
\hline 676.71 & 0.969142 & 0.982239 & -4.8223790 & 1.351448 & 0.982299 & 1.35759 \\
\hline 735.06 & 0.966770 & 0.981927 & -4.8246608 & 1.567766 & 0.982015 & 1.576939 \\
\hline 793.29 & 0.964442 & 0.982380 & -4.8269379 & 1.859936 & 0.981735 & 1.793039 \\
\hline$A A D \%$ & & & & 0.980422 & & 0.980085 \\
\hline
\end{tabular}

* Experimental data from Kell \& Whalley (1965). 


\subsubsection{Mixtures}

In this sub-section, density and phase equilibrium results for a number of mixtures are presented and, where possible, calculated results are compared with experimental data.

\subsubsection{Density}

In this section, density predictions for $\mathrm{CO}_{2}$-water and $\mathrm{NaCl}$-water are presented to illustrate that the GHC equation provides accurate mixture densities in addition to being thermodynamically consistent. Density results for the GHC equations are also compared with predictions using the SRK+, PSRK, VTPR, and, where applicable, the ePSRK equations of state, and with experimental density data.

$\underline{\mathrm{CO}_{2}}$-Water

Table 1.16 further illustrates the efficacy of using a composite isothermal staircase function for $U_{M}^{D}$ and the multi-scale GHC approach by providing details of the density predictions of the SRK+, VTPR and GHC equations with the experimental data in Teng et al. (1997).

Table 1.16: Experimental and Calculated Densities of $\mathrm{CO}_{2}-\mathrm{H}_{2} \mathrm{O}$ at $283 \mathrm{~K}$

\begin{tabular}{|c|c|c|c|c|c|c|c|c|}
\hline $\boldsymbol{p}$ (bar) & $\boldsymbol{x}_{\boldsymbol{C O} 2}$ & $\begin{array}{c}\boldsymbol{\rho}^{\boldsymbol{e x p}} \\
\boldsymbol{k g} / \mathbf{m}^{3}\end{array}$ & $\boldsymbol{S R K +}$ & $\begin{array}{c}\text { \% } \\
\text { Error }\end{array}$ & VTPR & $\begin{array}{c}\text { \% } \\
\text { Error }\end{array}$ & GHC & \% Error \\
\hline 64.4 & 0.0279 & 1016.97 & 1042.31 & 2.49 & 1014.32 & 0.26 & 1025.61 & 0.85 \\
\hline 98.7 & 0.0294 & 1018.60 & 1043.30 & 2.42 & 1012.41 & 0.61 & 1026.47 & 0.77 \\
\hline 147.7 & 0.0305 & 1019.40 & 1044.77 & 2.49 & 1009.12 & 1.01 & 1027.45 & 0.79 \\
\hline 196.8 & 0.0316 & 1020.75 & 1046.07 & 2.48 & 1005.89 & 1.46 & 1028.43 & 0.75 \\
\hline 245.8 & 0.0326 & 1021.70 & 1047.33 & 2.51 & 1002.67 & 1.86 & 1029.34 & 0.75 \\
\hline 294.9 & 0.0334 & 1023.98 & 1048.51 & 2.40 & 999.4 & 2.40 & 1030.16 & 0.60 \\
\hline & & & & & & & & \\
\hline $\boldsymbol{A A D \%}$ & & & & 2.47 & & 1.27 & & 0.75 \\
\hline
\end{tabular}

Results for the GHC equation shown in Table 1.16 were calculated using an isothermal staircase function for $U_{M}^{D}$ with a width of 1 bar. Staircase functions for $\mathrm{CO}_{2}$ and water 
with runs of 1 bar were determined from the NPT Monte Carlo simulation data. Note that the VTPR equation shows the unusual trend of decreasing mass density with increasing pressure, which is counter to the pressure trend of the experimental density data in Teng et al. (1997). Critical properties and the $b$ parameter for water and $\mathrm{CO}_{2}$ can be found in the Appendix. Table 1.16 also shows that the multi-scale GHC equation outperforms the SRK+ and VTPR equations in predicting mass densities of aqueous phase $\mathrm{CO}_{2}$-water mixtures over the conditions investigated.

\section{$\underline{\mathrm{CO}}_{2}$-Water and $\mathrm{NaCl}-\mathrm{Water}$}

Table 1.17 summarizes some comparisons of experimental densities for mixtures with densities calculated by the SRK+, VTPR, Predictive SRK (PSRK) or electrolyte PSRK (ePSRK) of Kiepe et al. (2004), and GHC equations. Unfortunately, experimental liquid density data for mixtures is not as readily available as that for pure components.

Table 1.17: Some Mixture Density Results for SRK+, VTPR, ePSRK, and GHC Equations.

\begin{tabular}{|c|c|c|c|c|c|c|c|}
\hline Mixture & $N_{d}$ & \multicolumn{5}{|c|}{$A A D \%$ Error } & Reference \\
\hline & & SRK+ & VTPR & PSRK & ePSRK & GHC & \\
\hline $\mathrm{CO}_{2}-\mathrm{H}_{2} \mathrm{O}$ & 24 & 2.30 & 1.38 & 4.03 & NA & 0.67 & Teng et al. (1997) \\
\hline $\mathrm{NaCl}-\mathrm{H}_{2} \mathrm{O}$ & 68 & NA & NA & NA & 2.65 & 0.91 & Chen et al. (1977) \\
\hline
\end{tabular}

Nonetheless, Table 1.17 shows that the multi-scale GHC equation predicts the experimental density of the mixtures investigated here with $<1 \%$ AAD.

\subsubsection{Phase Equilibrium}

The phase equilibrium calculations of mixtures exhibiting vapor-liquid and vapor-liquid-liquid behavior are described in the next section.

Methane-Water VLE 
Here we compare vapor-liquid phase equilibrium (VLE) results for the SRK+, VTPR, and GHC equations in the form of solubility of methane in liquid water with experimental data taken from Servio and Englezos (2002) for conditions that admit a VLE solution. Methane composition in the equilibrium water-rich liquid phase is given in Table 1.18.

Table 1.18: Methane Solubility in Water for the SRK+, VTPR, and GHC Equations

\begin{tabular}{|c|c|c|c|c|c|c|}
\hline $\boldsymbol{T}(\boldsymbol{K})$ & $\boldsymbol{p}(\boldsymbol{b a r})$ & $\boldsymbol{x}_{\boldsymbol{C H}^{\boldsymbol{e x p}^{*}}}$ & SRK+ & VTPR & GHC & \% Error \\
\hline 278.65 & 35 & 0.001190 & $2.178 \times 10^{-6}$ & $1.924 \times 10^{-6}$ & 0.001104 & 7.20 \\
\hline 280.45 & 35 & 0.001102 & $2.354 \times 10^{-6}$ & $1.986 \times 10^{-6}$ & 0.001098 & 0.36 \\
\hline 281.55 & 50 & 0.001524 & $3.363 \times 10^{-6}$ & $2.748 \times 10^{-6}$ & 0.001379 & 9.51 \\
\hline 282.65 & 50 & 0.001357 & $3.524 \times 10^{-6}$ & $2.797 \times 10^{-6}$ & 0.001374 & 1.25 \\
\hline 283.25 & 65 & 0.001720 & $4.491 \times 10^{-6}$ & $3.500 \times 10^{-6}$ & 0.001660 & 3.49 \\
\hline 284.35 & 65 & 0.001681 & $4.705 \times 10^{-6}$ & $3.559 \times 10^{-6}$ & 0.001653 & 1.67 \\
\hline $\boldsymbol{A A D \%}$ & & & & & & 3.91 \\
\hline
\end{tabular}

* Experimental data taken from Table 1 in Servio \& Englezos. (2002).

J. Chem. Eng. Data 47, 89.

While there is some scatter in the GHC predictions of methane solubility in water shown in Table 1.18, overall these results are quite reasonable and capture all of the correct physics associated with gas solubility. In particular, the multi-scale GHC equation predicts decreasing methane solubility (degassing) with increasing temperature and higher methane solubility with increasing pressure. Remember, unlike many other EOS, the multi-scale GHC equation does not use binary interaction parameters $\left(\mathrm{k}_{\mathrm{ij}} \mathrm{s}\right)$ and is purely predictive. In contrast, calculated methane solubility in water using the SRK+ equation with no binary interaction parameter (i.e., $\mathrm{k}_{\mathrm{ij}}=0$ ) and the VTPR equation at the conditions given in Table 1.18 are quite poor - 3 orders of magnitude too low.

\section{$\mathrm{CO}_{2}$-Octane-Water VLLE}

The purpose of this example is to show that the multi-scale GHC equation is capable of reliably predicting 3-phase equilibrium. Therefore, consider again a mixture 
of $30 \mathrm{~mol} \% \mathrm{CO}_{2}, 20 \mathrm{~mol} \% \mathrm{n}$-octane and $50 \mathrm{~mol} \%$ water at $313.15 \mathrm{~K}$ and 20 bar. Table 1.10 gives the feed and VLLE solution. Pure component critical properties and $b$ parameters for the GHC equation can be found in the Appendix.

In this example, the VLLE solution is found by traversing a sequence of flash sub-problems - in this case from single liquid to liquid-liquid, to vapor-liquid, and finally to vapor-liquid-liquid equilibrium. The dimensionless Gibbs free energy for the feed is $\mathrm{G} / \mathrm{RT}=-0.897019$ while that for the vapor-liquid-liquid solution is clearly much lower, $\mathrm{G} / \mathrm{RT}=-2.519114$. False liquid-liquid and vapor-liquid equilibrium solutions exist with dimensionless Gibbs free energies of -1.750546 and -1.615669 respectively so the solution is, in fact, VLLE.

\subsection{Discussion of Results}

Theoretical analysis and numerical verification using finite difference values of $\left(\frac{\Delta \operatorname{lnf}}{\Delta p}\right)_{T}$ and $\left(\frac{\Delta \ln \hat{f}_{i}}{\Delta p}\right)_{T, x}$ were used to clearly show that the multi-scale GHC equation is thermodynamically consistent for pure components and mixtures. The novel idea of using an isothermal staircase function representation of molecular scale internal energies of departure, $U^{D}$, as a function of pressure was proposed and illustrated both geometrically and by reporting tabulated values of NPT Monte Carlo simulation data. We have shown that the GHC approach relaxes the assumption that the energy parameter is pressure independent (after the fact), and with an appropriate methodology for $U^{D}$ adjusts the energy parameter in a way that preserves thermodynamic consistency and is supported by the fact that the condition of thermodynamic consistency, $V=$ $R T\left(\frac{\partial \operatorname{lnf} f}{\partial p}\right)_{T}$, involves only point functions, and holds locally. 
A variety of density, fugacity, phase equilibrium, and thermodynamic consistency computations for a wide range of pure components and mixtures of light gases ( $\mathrm{CO}_{2}$ and methane), oil, and water were presented. Calculated densities and phase equilibrium results for the GHC equation were also extensively compared to results for the SRK equation with the Peneloux volume translation and the volume translated PengRobinson equation and validated using experimental data from the open literature. Our numerical results clearly illustrate that the multi-scale GHC equation is thermodynamically consistent and that it provides more accurate predictions of density and phase equilibrium when compared to other cubic EOS in the van der Waals family.

\subsection{Conclusions}

Both theory and computations were used to show that mathematical representation of internal energies of departure as isothermal staircase functions in

pressure ensures that the multi-scale GHC equation of state is thermodynamically consistent and, at the same time, provides more accurate density predictions for the systems considered in this work.

\subsection{Coda}

Computer outputs showing all of the details of all computations as well as pure component $U^{D}$ data are available by contacting A. Lucia. 


\section{References}

Ahlers, J., Gmehling, J., 2001. Development of a universal group contribution equation of state. 1. Prediction of liquid densities for pure compounds with a volume translated Peng-Robinson equation of state. Fluid Phase Equilibria 191, 177-188.

Bellman, R.E. 1973. Methods of nonlinear analysis. Academic Press, Inc. New York, NY.

Camin, D.L., Forziati, A.F., Rossini, F.D., 1954. Physical properties of n-hexadecane, n-decyclopentane, n-decyclohexane, 1-hexadecene, and n-decyclobenzene. J. Phys. Chem. 58, 440-442.

Caudwell, D.R., Trusler, J.P., Vesvic, V., Wakeham, W.A., 2009. Viscosity and density of five hydrocarbon liquids at pressures up to $200 \mathrm{MPa}$ and temperatures up to 473 K. J. Chem. Eng. Data 54, 359-366.

Chen, D.-T., Emmet, R.T., Millero, F.J., 1977. The apparent molar volumes of aqueous solutions of $\mathrm{NaCl}, \mathrm{KCl}, \mathrm{MgCl}_{2}, \mathrm{Na}_{2} \mathrm{SO}_{4}$, and $\mathrm{MgSO}_{4}$ from 0 to 1000 bar at 0,25 and $50{ }^{\circ}$ C. J. Chem. Eng. Data 22, 201-207.

Dysthe, D.K., Fuchs, A.H., Rousseau, B., 2000. Fluid transport properties by equilibrium molecular dynamics. III. Evaluation of united atom interaction potential models of pure alkanes. J. Chem. Phys. 112, 7581-7590.

Goldon, A., Dabrowska, K., Hofman, T., 2007. Densities and excess volumes of the 1,3dimethylimidazolium methylsulfate + methanol system from (313.15 to 33.15$) \mathrm{K}$ and pressures from (0.1 to 25) MPa. J. Chem. Eng. Data 52, 1830-1837.

Kell, G.S., Whalley, E., 1965. The PVT properties of water. I. Liquid water in the temperature range 0 to 150 degrees $\mathrm{C}$ and at pressures up to $1 \mathrm{~kb}$. Philosophical Transactions of the Royal Society of London. Series A. Mathematical and Physical Sciences 258 (1094), 565-614.

Kessel'man, P.M, et al. 1970. Transactions of the 3rd all-union conference on thermophysics, Thermophysical properties of gases. Nauka Press, Moscow.

Kiepe, J., Horstmann, S. Fischer, K., Gmehling, J., 2004. Application of the PSRK model for systems containing strong electrolytes. Industrial Engineering Chemistry Research 43, 6607-6615.

Liu, K., Wu, Y., McHugh, M.A., Baled, H., Enick, R.M., Morreale, B.D., 2010. Equation of state modeling of high-pressure, high-temperature hydrocarbon density data. J. Supercritical Fluids 55, 701-711. 
Lucia, A. 2010. A multi-scale Gibbs-Helmholtz constrained cubic equation of state. Journal of Thermodynamics 2010, article id: 238365.

Lucia, A., Bonk, B.M., Waterman, R.R., Roy, A., 2012a. A multi-scale framework for multi-phase equilibrium flash. Comput. Chem. Engng. 36, 79-98.

Lucia, A., Bonk, B.M., 2012b. Molecular geometry effects and the Gibbs-Helmholtz Constrained equation of state. Comput. Chem. Engng. 37, 1-14.

Magee, J.W., Bruno, T.J., 1996. Isochoric (p, $\rho, \mathrm{T})$ measurements for liquid toluene from $180 \mathrm{~K}$ to $400 \mathrm{~K}$ at pressures to $35 \mathrm{MPa}$. J. Chem. Eng. Data 41, 900-905.

Magee, J.W., Ely, J.F., 1986. Specific heats of saturated and compressed liquid and vapor carbon dioxide. Int. J. Thermophysics 7, 1163-1182.

Mora'vkova', L., Wagner, Z., Aim, K. Linek, J., 2006. (P, $\left.\mathrm{V}_{\mathrm{m}}, \mathrm{T}\right)$ measurements of (octane + 1-chlorohexane) at temperatures from $298.15 \mathrm{~K}$ to $328.15 \mathrm{~K}$ and at pressures up to $40 \mathrm{MPa}$. J. Chem. Thermodynamics 38, 861-870.

Peneloux, A., Rauzy, E., Freze, R., 1982. A consistent correction for Redlich-KwongSoave volumes. Fluid Phase Equilibria 8, 7-23.

Peters, C.J., van der Kooi, H.J., De Swaan Arons, J., 1987. Measurements and calculations of phase equilibria for (ethane + tetracosane) and $\left(\mathrm{p}, \mathrm{V}_{\mathrm{m}}, \mathrm{T}\right)$ of liquid tetracosane. J. Chem. Thermodynamics 19, 395-405.

Queimada, A.J., Quinones-Cisneros, S.E., Marrucho, I.M., Coutinho, J.A.P., Stenby, E.H., 2003. Viscosity and liquid density of asymmetric hydrocarbon mixtures. Int'l J. Thermophysics 24, 1221-1239.

Servio, P., Englezos, P., 2002. Measurement of dissolved methane in water in equilibrium with its hydrate. J. Chem. Eng. Data 47, 87-90.

Soave, G., 1972. Equilibrium constants from a modified Redlich-Kwong equation of state. Chemical Engineering Science 27, 1197-1203.

Templin, P.R., 1956. Coefficient of volume expansion for petroleum waxes and pure nparaffins. Industrial Engineering Chemistry 48, 154-161.

Teng, H., Yamasaki, A., Chun, M-K, Lee, H., 1997. Solubility of liquid $\mathrm{CO}_{2}$ in water at temperatures from $278 \mathrm{~K}$ to $293 \mathrm{~K}$ from $6.44 \mathrm{MPa}$ to $29.49 \mathrm{MPa}$ and densities of the corresponding aqueous phase. J. Chem. Thermodynamics 29, 1301-1310.

van Hook, A., Silver, L., 1942. Pre-melting anomalies of some long-chain normal paraffin hydrocarbons. J. Chem. Phys. 10, 686-690. 
Vargaftik, N.B., 1983. Handbook of physical properties of liquids and gases: Pure substances and mixtures, Hemisphere, 2nd ed., Bristol, UK.

Walas, S.M., 1985.Phase equilibria in chemical engineering. Butterworth Publishers, Stoneham, MA. 


\section{Nomenclature}

$a, a_{M} \quad$ pure component energy parameter, energy parameter for liquid mixture $b, b_{i}, b_{M} \quad$ molecular co-volume, pure component molecular co-volume, mixture molecular co-volume

$f, \hat{f}_{i} \quad$ fugacity, partial fugacity for component $\mathrm{i}$

$p, p_{c} \quad$ pressure, critical pressure

$R \quad$ universal gas constant

$T, T_{C} \quad$ absolute temperature, critical temperature

$U^{D}, U_{i}^{D}, U_{M}^{D}$ internal energy of departure for liquid, internal energy of departure for component $i$, mixture internal energy of departure

$V, \bar{V}_{i}, V_{M} \quad$ molar volume, $\mathrm{i}^{\text {th }}$ component partial molar volume, mixture molar volume

$x_{i} \quad \mathrm{i}^{\text {th }}$ component liquid mole fraction

$z \quad$ compressibility factor

\section{Greek symbols}

$\varphi, \hat{\varphi}_{i} \quad$ fugacity coefficient, $\mathrm{i}^{\text {th }}$ component partial fugacity coefficient

$\rho \quad$ molar density

$\omega \quad$ acentric factor

\section{Superscripts}

calc

calculated

$D \quad$ departure function

EOS equation of state

$\exp \quad$ experimental

ig ideal gas

Subscripts

C

$i$

$M$

critical property

component index

mixture 
Appendix 1: Critical Properties and Parameters

\begin{tabular}{|c|c|c|c|c|}
\hline compound & $\boldsymbol{T}_{\boldsymbol{c}}(\boldsymbol{K})$ & $\boldsymbol{p}_{\boldsymbol{c}}(\boldsymbol{b a r})$ & $\boldsymbol{\omega}$ & $\boldsymbol{b}^{\mathbf{G H C}}\left(\mathbf{c m}^{\mathbf{3}} / \mathbf{m o l}\right)$ \\
\hline water & 647.37 & 221.20 & 0.345 & 16.363 \\
\hline carbon dioxide & 304.20 & 73.80 & 0.224 & 28.169 \\
\hline methane & 190.56 & 45.92 & 0.008 & 29.614 \\
\hline n-octane & 568.83 & 24.86 & 0.396 & 143.145 \\
\hline
\end{tabular}


CHAPTER 2 - Density and phase equilibrium for ice and structure I hydrates using the Gibbs-Helmholtz constrained equation of state

Published in Chemical Engineering Research and Design, December 2014

Heath Henley, Edward Thomas, and Angelo Lucia

Chemical Engineering

University of Rhode Island

Kingston, RI 


\begin{abstract}
A new, rigorous framework centered around the multi-scale GHC equation of state is presented for predicting bulk density and phase equilibrium for light gas-water mixtures at condition where hexagonal ice and structure I hydrate phases can exist. The novel aspects of this new framework include (1) the use of internal energies of departure for ice and empty hydrate to determine densities, (2) contributions to the standard state fugacity of water in ice and empty hydrate from lattice structure, (3) computation of these structural contributions to standard state fugacity from compressibility factors and EOS parameters alone, and (4) the direct calculation of gas occupancy from phase equilibrium. Numerical results for densities and equilibrium for systems involving ice and/or gas hydrates predicted by this GHC-based framework are compared to predictions of other equations of state, density correlations, and experimental data where available. Results show that this new GHC-based EOS framework accurately predicts the densities of hexagonal water ice and structure I gas hydrates as well as phase equilibrium for methane-water and $\mathrm{CO}_{2}$-water mixtures.
\end{abstract}




\subsection{Introduction}

The general warming of land and oceans around the world has spawned interest in understanding long term environmental impacts associated with the melting of ice sheets and thawing of permafrost regions. Permafrost, which accounts for approximately $25 \%$ of the land mass in the Northern Hemisphere, is the general term used to describe land that remains below $0 \mathrm{C}$ for two or more years at depths that can range from less than a meter to around 1000 meters. While temperatures and pressures in permafrost regions vary, typical ranges are $-20 \mathrm{C}$ to $5 \mathrm{C}$ and 0.1 to $\sim 10 \mathrm{MPa}$ respectively.

Phase behavior in permafrost regions is quite complicated and can involve light gases (e.g., methane and carbon dioxide), liquid water, brines, hexagonal ice, and gas hydrates - depending on conditions. Understanding physical propertys and phase behavior in permafrost regions is important for several competing reasons:

1) The large amount of methane sequestered in permafrost is a potential source of low carbon fuel if it can be captured. According to Kvenvolden (1998) there is an estimated $2.1 \times 10^{16}$ standard cubic meters (SCM) of methane contained in hydrates on the ocean bottom, which is twice the energy sum of all other fossil fuels on Earth. There is also an estimated $7.4 \times 10^{14} \mathrm{SCM}$ in permafrost regions (see, MacDonald, 1990).

2) Thawing of permafrost increases microbial activity, which in turn has the potential to release large amounts of greenhouse gases $\left(\mathrm{CO}_{2}\right.$ and methane $)$.

3) Deeper locations in permafrost have been suggested as potential sites for carbon storage. 
The focus of this work is the modeling of physical properties, specifically density, and phase behavior of mixtures of light gas and water at conditions typically found in permafrost regions (i.e., temperatures ranging from 250 to $280 \mathrm{~K}$ and pressures from 0.1 to $\sim 10 \mathrm{MPa}$ ) using an equation of state. It is demonstrated that the multi-scale GibbsHelmholtz Constrained (GHC) equation (Lucia, 2010; Lucia et al, 2012; Lucia and Bonk, 2012), can be used to predict thermo-physical properties and phase equilibrium in systems involving gas, liquid, hexagonal (1h) ice and gas hydrate. Accordingly, this paper is organized in the following way. Section 2.2 gives a brief survey of relevant literature while section 2.3 provides some general background information for the multiscale Gibbs-Helmholtz Constrained (GHC) equation of state. In section 2.4, lattice structure considerations in defining the standard state fugacity of water in an ice phase, NPT Monte Carlo simulations of liquid water, and the Clausius-Clapeyron equation are used to extend the multi-scale GHC equation to calculate densities and phase equilibrium for hexagonal (1h) ice. A similar extension of the GHC equation that exploits structure in defining the standard state of water in a gas hydrate phase is described in Section 2.5. In section 2.6, several numerical examples that illustrate the accuracy of multi-scale GHC equation predictions of physical properties and phase behavior of $1 \mathrm{~h}$ ice and gas hydrates. Finally, conclusions of this work are described in section 2.7 .

\subsubsection{Ice and Gas Hydrates}

Most people have some intuitive feel for or understanding of ice, and hexagonal ice is the only ice that occurs naturally on Earth. As its name implies $1 \mathrm{~h}$ ice has a hexagonal lattice structure. Gas hydrates, on the other hand, are less well known and 
understood, despite the fact that they were discovered in 1810 (see, Ghiasi, 2012) and later identified as the cause of flow assurance problems in gas lines by Hammerschmidt (1934). Gas clathrate hydrates are non-stoichiometric compounds that occur at ambient temperature and moderate pressure. They are heterogeneous structures that consist of hydrogen bonded water molecules that form a hydrate lattice stabilized by small gas molecules called guests (e.g., methane, carbon dioxide, nitrogen, hydrogen, ethane, etc.). The empty hydrate lattice is not stable on its own. There are three naturally occurring hydrate structures found on Earth - type I (S1), type II (S2) and type H (SH), where the structure is determined by conditions of temperature and pressure and the guest molecule(s). Structure 1 hydrates are composed of two $5^{12}$ cages, six $5^{12} 6^{2}$ cages from 46 water molecules. Structure 2 hydrates are composed of sixteen $5^{12}$ cages, eight $5^{12} 6^{4}$ cages, and 136 water molecules. Finally, structure $H$ hydrates consist of three $5^{12}$ cages, two $4^{3} 5^{6} 6^{3}$ cages, and one $5^{12} 6^{8}$ cage and have 34 water molecules. Here the general notation $\mathrm{e}^{\mathrm{n}}$ describes a polygon such that has e edges and $\mathrm{n}$ faces.

\subsection{A Brief Review of Relevant Literature}

Many traditional equations of state (EOS) have been used to model various thermo-physical properties and phase equilibrium involving mixtures of light gases and water including the Soave-Redlich-Kwong (SRK) equation (Soave, 1972), the Peneloux volume translation (Peneloux et al., 1982) of the SRK equation (SRK+), the PengRobinson (PR) equation (Peng \& Robinson, 1976), the volume translated PR or VTPR equation (Ahlers \& Gmehling, 2001), and various forms of the Statistical Associating Fluid Theory (SAFT) equation (Huang \& Radosz, 1991). Other equations of state such as the cubic plus association (CPA) equation (Kontogeorgis, et al., 1996; Voutsas et al., 
2000) and the Elliott-Suresh-Donahue (ESD) equation (Elliott et al., 1990) have also been used. There are also specialized equations of state for water such as the International Association for the Properties of Water and Steam (or IAPWS-95) equation of Pruss and Wagner (2002), which is formulated in terms of the Gibbs free energy function. Within the family of cubic equations, only the volume translated equations, SRK+ and VTPR, are capable of predicting reasonably accurate densities (i.e., $\mathrm{AAD} \%$ error $\approx 4 \%$ ). The $\mathrm{CPA}, \mathrm{ESD}$, and SAFT models are much better at approximating properties and phase equilibrium of water and mixtures such as methanewater, $\mathrm{CO}_{2}$-water, etc. because they explicitly incorporate association (i.e., hydrogen bonding) in the residual Helmholtz free energy. Finally, the IAPWS-95 equation is the most accurate $(\sim \mathrm{AAD} \%$ error $<0.1 \%)$ for water because it involves a large number of parameters that have been regressed to a wide range of experimental data; however, it cannot be used for mixtures.

Equations of state for ice are also available. Within the van der Waals family of cubic equations, there is the translated Trebble-Bishnoi-Salim (TBS) equation of state (Salim \& Trebble, 1994), which is a six-constant EOS for solids that suffers from the same difficulties that many traditional cubic equations suffer from: (1) excessive use of empirical relationships to correct deficiencies in the basic theory, (2) poor density predictions without the use of volume translation, and (3) the need to regress parameters to experimental data. The four primary parameters (a, b, c and d) in the TBS equation must be matched to experimental solid density, saturation pressure, and solid and vapor fugacities at the triple point. The other two parameters, $m$ and $p$, are part of the $\alpha$ function for predicting vapor pressure. In addition, temperature and pressure-dependent 
binary interaction parameters are needed for reliable phase equilibrium computation. The IAPWS-95 model for water has been extended to $1 \mathrm{~h}$ ice by Feistel \& Wagner (2006) and is also a Gibbs potential equation of state. Like the model for liquid water (Wagner \& Pruss, 2002), the extended IAPWS-95 equation for $1 \mathrm{~h}$ ice has been fit to a large amount of experimental data (i.e., 14 independent parameters fit to 522 data points from 32 separate categories of experimental data). This experimental data includes specific Gibbs free energy data, specific entropy data, $(\partial \mathrm{p} / \partial \mathrm{T})$ data along the ice melting curve, heat capacity data, volumetric and volume-temperature derivative data, isentropic compressibility data, and isentropic compressibility-temperature derivative data. See Table 5 on page 1027 in Feistel and Wagner (2006). As a result, the extended IAPWS95 equation provides excellent agreement with experimental values of thermo-physical properties of hexagonal ice. Other approaches for modeling ice (e.g., Yoon et al., 2002) use a more traditional solid-liquid equilibrium formulation in which the fugacity of ice is expressed in terms of the fugacity of sub-cooled water and an exponential correction based on enthalpy and volumetric differences due to fusion.

The most commonly used models for predicting the properties of gas hydrates are based on the cell theory model developed by van der Waals and Platteeuw (1959) and given the acronym vdWP. A detailed derivation of the model from statistical mechanics as well as a very good survey of the relevant hydrate literature can be found in textbook by Sloan and Koh (2007). Here a brief overview of the modifications of the vdWP model is given starting with the work of Parrish and Prausnitz (1972) who extended the model to allow for the practical calculation of hydrate dissociation pressures for mixtures of guest molecules. Klauda and Sandler (2000) presented a 
fugacity-based model that removed the need for reference energy parameters for the empty hydrate lattice and relaxed the incorrect vdWP assumption that the volume of the crystal lattice is independent of guest molecule type. A similar model was developed by Ballard and Sloan (2002) and Jager and coworkers (2003). More recently, Bandyopadhyay and Klauda (2011) presented an updated fugacity model that uses the PSRK equation to represent the fluid phases in equilibrium with the hydrate. Other modifications include models that account for multiple cage occupancy (see, Klauda and Sandler, 2003; Martin, 2010), those that correct for the effects of guest-guest interactions on the Helmholtz energy (Zhdanov et al., 2012), and others (e.g., Jäger et al., 2013) that adapt the model originally developed by Ballard and Sloan (2002) so highly accurate reference EOS can be used. This last approach has also been tested against a large data set for $\mathrm{CO}_{2}$ hydrate.

The vdWP model with all of its recent adaptations has enjoyed great success and is used heavily in industry because of its accuracy and relative simplicity. However, it is a semi- empirical model that requires adjustable parameters to be regressed to experimental data. For this reason, it is difficult to make predictions about the phase behavior and properties of potentially hydrate-forming systems outside the ranges of experimental data.

\subsection{The Multi-Scale Gibbs-Helmholtz Constrained (GHC) Equation}

The multi-scale Gibbs-Helmholtz Constrained (GHC) equation, which is a modification of the Soave form of the Redlich-Kwong (RK) equation (Soave, 1972), is given by

$p=\frac{R T}{V-b}-\frac{a(T, p)}{V(V+b)}$ 
where $p$ is pressure, $T$ is temperature in Kelvins, $V$ is the molar volume, $R$ is the universal gas constant and $a$ and $b$ are the energy and molecular co-volume parameters respectively.

\subsubsection{Pure Components}

The multi-scale GHC equation is a radically different approach to EOS modeling that is based on three simple ideas:

1) The molecular co-volume for the liquid, $b^{L}$, is set equal to the molar volume of the pure solid or high density (glassy) liquid.

2) The liquid phase energy parameter, $a^{L}(T, p)$, is constrained to satisfy the GibbsHelmholtz equation, which results in the following expression for pure liquid components

$a^{L}(T, p)=\left[\frac{a\left(T_{c}, p_{c}\right)}{T_{c}}+\frac{b^{L} U^{D L}}{T_{c} \ln 2}+\frac{2 b^{L} R \ln T_{c}}{\ln 2}\right] T-\frac{b^{L} U^{D L}}{\ln 2}-\left[\frac{2 b^{L} R}{\ln 2}\right] T \ln T$

where $T_{c}$ is the critical temperature, $p_{c}$ is the critical pressure, $a\left(T_{c}, p_{c}\right)=$ $0.424478 R^{2} T_{c}^{2} / p_{c}$, and $U^{D L}$ is the internal energy of departure for the liquid phase given by $U^{D L}=U^{D L}(T, p)=U^{L}(T, p)-U^{i g}(T, p)$, where $U^{i g}(T, p)$ is the ideal gas internal energy. Note that $U^{D}$ serves as a natural bridge between the molecular and bulk fluid length scales.

3) The internal energy of departure, $U^{D L}$, is evaluated using NPT Monte Carlo simulations, where it is important to note that MC simulations are performed a priori and that the results are stored in pure component look-up tables for use in density and fugacity coefficient calculations. Molecular scale information in equation (2.2) is what makes the GHC equation a multi-scale equation of state. 


\subsubsection{Non-Electrolyte Mixtures}

For non-electrolyte liquid mixtures, the multi-scale GHC equation is

$a_{M}^{L}(T, p, x)=\left[\frac{a\left(T_{c M}, p_{c M}, x\right)}{T_{c M}}+\frac{b_{M}^{L} U_{M}^{D L}}{T_{c M} \ln 2}+\frac{2 b_{M}^{L} R \ln T_{c M}}{\ln 2}\right] T-\frac{b_{M}^{L} U_{M}^{D L}}{\ln 2}-\left[\frac{2 b_{M}^{L}}{\ln 2}\right] T \ln T$

where $b_{M}^{L}=\sum x_{i} b_{i}^{L}$ and $U_{M}^{D L}=\sum x_{i} U_{i}^{D L}, x_{i}$ is the liquid mole fraction of component $i$, and $b_{i}^{L}$ and $U_{i}^{D L}$ are the molecular co-volume and internal energy of departure for the $i^{\text {th }}$ pure liquid component. A detailed derivation can be found in the literature (Lucia, 2010; Lucia et al., 2012a). Mixture critical properties are calculated using Kay’s rules

$M_{c m}=\Sigma x_{i} M_{i} \quad$ for $i=1 \ldots C$

where $M$ is either critical temperature or critical pressure.

More detailed information associated with the GHC equation, its derivation, expressions for pure component and partial fugacity coefficients, and density and phase equilibrium predictions for a number of systems including pure liquid water, water-light gas mixtures, $\mathrm{n}$-alkanes of varying chain length, and electrolyte solutions can be found in references (Lucia, 2010, Lucia et al, 2012a; Lucia et al., 2012b). More recently, Lucia and Henley (2013) have shown that the GHC equation is thermodynamically consistent by demonstrating that it satisfies the relationship given by $R T\left(\frac{\partial \ln f}{\partial p}\right)_{T}=V$.

\subsection{Modeling Hexagonal Ice Using the GHC Equation}

To model hexagonal ice in the GHC framework, values for $b^{i c e}$ and $U^{D, i c e}$ are needed along with a means of calculating the pure component fugacity of ice.

\subsubsection{The Molecular Co-Volume and Internal Energy of Departure for Ice}


Two straightforward but important physical interpretations are required to apply the multi-scale GHC equation (i.e., eqs. (2.1) and (2.2) with appropriate values of $b$ and $\left.U^{D}\right)$ to $1 \mathrm{~h}$ ice:

1) In our opinion, the correct value for the molecular co-volume for $1 \mathrm{~h}$ ice is the molar volume of liquid water (i.e., $b^{i c e}=18.015 \mathrm{~cm}^{3} / \mathrm{mol}$ ) because ice melts under pressure.

2) The internal energy of departure for $1 \mathrm{~h}$ ice can be calculated in two different ways:

a) Using the expression

$$
U_{w}^{D, i c e}=U_{w}^{D}+U_{w}^{D, f u s}
$$

where $U_{w}^{D}$ is the internal energy of departure for liquid water (already available from NPT Monte Carlo simulation) and $U_{w}^{D, f u s}$ is the internal energy of departure associated with the fusion of water.

b) By direct NPT Monte Carlo simulations of $1 \mathrm{~h}$ ice using an appropriate potential model [e.g., TIP4P-Ew, TIP4P/Ice, etc.].

These two methods for determining $U_{w}^{D, i c e}$ are described and compared in considerable detail in Appendix A.

\subsubsection{A Reference State for Ice}

The fugacity coefficient of $1 \mathrm{~h}$ ice must be different from that of liquid water at phase equilibrium. Appendix B shows that the natural log of the fugacity coefficient for hexagonal ice can be rigorously expressed in the form

$\ln \varphi_{w}^{i c e}=\ln \varphi_{w}^{L}-\Delta^{i c e}$

where $\varphi_{w}^{i c e}$ and $\varphi_{w}^{L}$ are the fugacity coefficients of $1 \mathrm{~h}$ ice and liquid water respectively and $\Delta^{i c e}$ can be interpreted as a measure of the impact of long-range structure on the 
fugacity coefficient of ice and is assumed to be constant. This leads to the following expression for the standard state fugacity of ice

$f_{w}^{0, i c e}=S^{i c e} p$

where $S^{i c e}=\exp \left(\Delta^{i c e}\right)$. Herein, $S^{\text {ice }}$ is also referred to as a lattice structure contribution.

This approach is adopted because liquid water and $1 \mathrm{~h}$ ice both have tetrahedral kernels but ice has long-range hexagonal structure. Furthermore, since ice is a condensed phase, it is not unreasonable to assume that the impact of long-range structure to be constant. See Fig. A1. Taking the temperature derivative of Eq. 2.6 at constant pressure gives

$\left(\frac{\partial \ln \varphi_{W}^{i c e}}{\partial T}\right)_{p}=\left(\frac{\partial \ln \varphi_{W}^{L}}{\partial T}\right)_{p}$

Thus eq. (2.2) is directly applicable for determining the energy parameter for $1 \mathrm{~h}$ ice. See Appendix B for a discussion of the fundamental basis for Eqs. (2.6) and (2.8).

\subsection{Modeling Gas Hydrates Using the GHC Equation}

Although the approach for modeling gas hydrates using the GHC equation is similar to that of ice, it involves considerably more detail. This is because

1) Gas hydrates are unusual heterogeneous structures so it is not at all clear that the usual mixing rules apply.

2) Empty hydrate cages are not stable.

3) Standard states only apply to pure components.

The approach presented here starts with the idea of estimating the bulk density of an empty hydrate. Why? The reason is that some physically sensible way of estimating the fugacity (or Gibbs free energy) of pure or empty hydrate is needed in order for this 
framework for addressing phase equilibrium to be consistent with classical theory. In order to predict empty hydrate density using the GHC equation values of the internal energy of departure for an empty hydrate, $U_{w}^{D, M T}$, and molecular co-volume, $b_{w}^{\text {hyd }}$, are required.

\subsubsection{The Molecular Co-Volume and Internal Energy of Departure for Hydrate}

The value of the empty hydrate molecular co-volume is taken to be the same as that of a completely filled hydrate and given by

$b_{w}^{\text {hyd }}=0.148148 b_{C H 4}+0.851852 / \rho^{i c e}$

where $b_{C H 4}=29.614 \mathrm{~cm}^{3} / \mathrm{mol}$ and where the subscript $w$ denotes water and the superscript hyd represents hydrate. While it may appear that eq. (2.9) is the same as the usual linear mixing rule for $b_{M}$, it is not. Eq. (2.9) is interpreted as the high pressure limit of separable gas and solid phases in a hydrate. Additionally, within the GHC approach to hydrates, eq. (2.9) is used for both empty and filled gas hydrates regardless of the gas occupancy in the cages. Thus, there is no mole fraction weighted average of molecular co-volume for hydrate phases; is held fixed at the value given in eq. (2.9).

Because empty hydrates are not stable, considerable care must be taken to get estimates

of internal energies of departure $U_{w}^{D, M T}$. To do this, the following procedure was followed:

1) Placed guest molecules in the hydrate cages.

2) Equilibrated the simulations with the guest molecules present.

3) Removed the guest molecules.

4) Ran production cycles with restricted volume moves so that the empty cages would not collapse. 
NPT Monte Carlo simulations were performed for empty hydrate using the aforementioned procedure over relevant ranges of temperatures $(250$ to $280 \mathrm{~K})$ and pressures (1 to 100 bar). Values of $U_{w}^{D, M T}$ ranged from $-4.65 \times 10^{5}$ to $-4.58 \times 10^{5} \mathrm{~cm}^{3} \mathrm{bar} / \mathrm{mol}$.

\subsubsection{Gas Hydrate Density}

Next, a theory for predicting density for physically meaningful gas hydrates, which have gas molecules occupying the cavities or cages was developed. Because gas hydrates are heterogeneous structures, the density of an S1 gas hydrate is calculated using the expression

$\rho^{h y d}=(5.75+\theta) \rho^{M T} / 5.75$

where $\theta$ is the fractional occupancy of gas in the hydrate cages and ranges from 0 to 1 and where $\rho^{M T}$ is the empty hydrate density computed from the GHC equation [i.e., eq. (2.2)]. Note that eq. (2.10) is still an application of the multi-scale GHC equation to gas hydrates and, in our opinion, provides a straightforward, yet physically meaningful, way of computing hydrate density. Moreover, eq. (2.10) covers the full range of gas occupancy; thus, the more gas there is in the cages, the denser the hydrate. At the same time, it avoids many of the complications associated with composition dependence in determining hydrate properties like fugacity coefficients.

\subsection{A Reference State for Pure Water in Gas Hydrate}

To calculate a standard state for pure water in a hydrate phase we let $x_{w}^{\text {hyd }}=1$ and use a procedure identical to that in Appendix B for ice. This leads to the expression $f_{w}^{0, h y d}=S^{i c e} S^{M T} p$ 
where $S^{i c e}=\exp \left(\Delta^{i c e}\right)$ and $S^{M T}=\exp \left(\Delta^{M T}\right)$. The quantity $\Delta^{M T}=\ln \varphi_{w}^{i c e}-\ln \varphi_{w}^{M T}$ represents the difference in long range structure between $1 \mathrm{~h}$ ice and empty hydrate and can be interpreted as a second structural contribution. Appendix $\mathrm{C}$ gives all of the details of the derivation of eq. (2.11).

\subsection{Numerical Results}

In this section, numerical results are presented for density and phase equilibrium for light gas-water mixtures in regions where ice and gas hydrate can form. All numerical results presented in this section use the GHC equation of state (except for comparisons). Critical property and other relevant data are summarized in Appendix D.

\subsubsection{Methane-Water Mixtures}

Methane and water can exhibit a number of different phase equilibrium - gasliquid, gas-ice, gas-ice-hydrate, and gas-liquid-hydrate at conditions typical of permafrost.

\subsubsection{Methane-Water in Gas-Liquid Equilibrium}

Numerical results for methane-water have been reported by Lucia and Henley (2013), compared to experimental data of Servio \& Englezos (2002), and are reproduced here for the reader's convenience.

Table 2.1: Methane Solubility in Water Predicted by the GHC Equation

\begin{tabular}{|c|c|c|c|c|}
\hline $\boldsymbol{T}(\boldsymbol{K})$ & $\boldsymbol{p}$ (bar) & $\boldsymbol{x}_{\boldsymbol{C H}{ }^{{ }^{e x p}}}{ }^{*}$ & $\boldsymbol{x}_{\boldsymbol{C H} 4}{ }^{\boldsymbol{G H C}}$ & \% Error \\
\hline 278.65 & 35 & 0.001190 & 0.001104 & 7.20 \\
\hline 280.45 & 35 & 0.001102 & 0.001098 & 0.36 \\
\hline 281.55 & 50 & 0.001524 & 0.001379 & 9.51 \\
\hline 282.65 & 50 & 0.001357 & 0.001374 & 1.25 \\
\hline 283.25 & 65 & 0.001720 & 0.001660 & 3.49 \\
\hline 284.35 & 65 & 0.001681 & 0.001653 & 1.67 \\
\hline $\boldsymbol{A A D \%}$ & & & & 3.91 \\
\hline
\end{tabular}

* Experimental data taken from Table 1 in Servio \& Englezos. (2002). J. Chem. Eng. Data 47, 89. 
Table 2.1 shows that the GHC equation provides reasonable predictions of the solubility of methane in water at the conditions studied by Servio and Englezos (2002).

\subsubsection{Hexagonal Ice Density and the Ice-Water Melting Curve}

Before studying gas-ice equilibrium and to validate the theory developed in sections 2.4.1 and 2.4.2 and Appendix B, results for the density and ice-water melting curve as predicted by the GHC framework are presented.

Table 2.2 compares the densities predicted by the multi-scale GHC equation with those given in Feistel \& Wagner (p. 1040, Table 11, Feistel \& Wagner, 2006) for the extended IAPWS-95 equation over the range of interest in permafrost phase behavior. In the comparisons in Table 2.2 , the $\%$ error is given by $\%$ error $=$ $100\left|\rho^{I A P W S-95}-\rho^{G H C}\right| / \rho^{I A P W S-95}$.

Table 2.2: Density of Sub-Cooled Hexagonal Ice

\begin{tabular}{|c|c|c|c|c|}
\hline Temperature (K) & Pressure (MPa) & IAPWS-95* & GHC $^{* *}$ & \% error \\
\hline 260 & 0.1013 & 918.61 & 931.31 & 1.38 \\
\hline & 5 & 923.84 & 931.77 & 0.85 \\
\hline & 10 & 928.96 & 931.93 & 0.32 \\
\hline 270 & 0.1013 & 917.18 & 927.48 & 1.12 \\
\hline 273 & 0.1013 & 916.74 & 926.25 & 1.04 \\
\hline
\end{tabular}

* Reproduced from Table 11 in Feistel \& Wagner (2006).

** GHC equation with $U_{w}^{D, i c e}$ calculated using Eqs. (5) \& (A1).

Table 2.2 shows that the GHC equation captures the increase in $1 \mathrm{~h}$ ice density with decreasing temperature and that there is reasonably good agreement between the two EOS models. However, the GHC equation does not show the same sensitivity of ice density to temperature and pressure as the extended IAPWS-95 equation.

Table 2.3 shows melting temperatures of ice predicted by the extended IAPWS-95 and GHC equations as a function of pressure and clearly shows that the two EOS are in good quantitative agreement. 
Table 2.3: Melting Temperatures of 1h Ice Predicted by the Extended IAPWS-95 \& GHC Equations

\begin{tabular}{|c|c|c|c|c|}
\hline \multirow[t]{2}{*}{ Pressure (MPa)* } & \multicolumn{2}{|c|}{ Melting Temperature, $\mathbf{T}_{\mathrm{m}}(\mathrm{K})$} & \multirow[t]{2}{*}{$\Delta \mathbf{T}_{\mathbf{m}}(\mathbf{K})$} & \multirow[t]{2}{*}{$\%$ error } \\
\hline & IAPWS-95* & GHC & & \\
\hline 0.1013 & 273.159 & 273.151 & 0.048 & 0.0154 \\
\hline 2.1453 & 273 & 273.042 & 0.042 & 0.0154 \\
\hline 15.1355 & 272 & 272.041 & 0.041 & 0.0151 \\
\hline 27.4942 & 271 & 271.093 & 0.093 & 0.0343 \\
\hline 39.3133 & 270 & 270.189 & 0.189 & 0.0700 \\
\hline 50.6633 & 269 & 269.320 & 0.320 & 0.1190 \\
\hline 61.5996 & 268 & 268.493 & 0.493 & 0.1840 \\
\hline
\end{tabular}

* Reproduced from Table 19 in Feistel \& Wagner, p. 1045, 2006.

Figure 2.1 shows the ice-water melting curve over a much wider range of temperature and pressure for both EOS and, again, shows that there is good quantitative agreement up to 500 bar. Although there are some differences above 500 bar, those differences are small. Additionally, the IAPWS-95 EOS uses 14 parameters and is actually regressed to melting curve data, so it should give more accurate results. On the other hand, the GHC equation only uses two parameters and, in our opinion, does remarkably well at predicting the $1 \mathrm{~h}$ ice melting curve. 


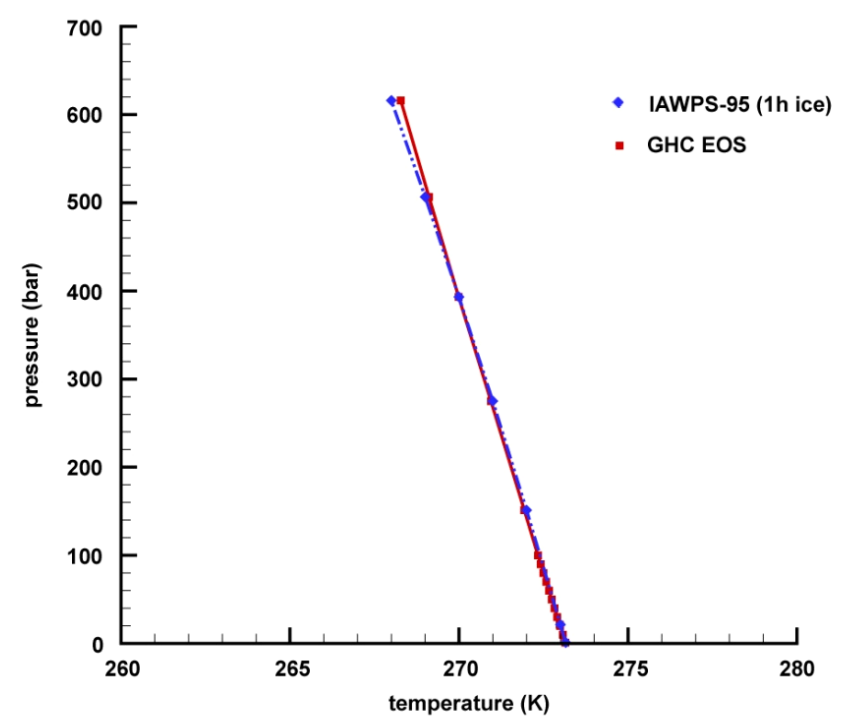

Figure 2.1: Melting Curve for Ice Predicted by the IAPWS-95 and GHC Equations

The results in Table 2.2 and 2.3 and Figure 2.1 show that the expression for the standard state fugacity for water in a hexagonal ice phase derived in Appendix B leads accurate predictions of ice/water phase equilibrium and density over the region investigated.

\subsubsection{Methane Gas-Ice Equilibrium}

At low enough temperature and pressure, methane and water will exhibit gassolid equilibrium with essentially pure phases. However, it is important to understand that other 'false' equilibrium (e.g., gas-liquid equilibrium) can be found at the same conditions. Table 2.4 presents results for the phase equilibrium of a mixture of $10 \mathrm{~mol} \%$ methane and $90 \mathrm{~mol} \%$ water at $272 \mathrm{~K}$ and 1 bar.

Table 2.4: Phase Equilibrium for 10 mol\% Methane-90 mol\% Water at $\mathbf{- 1 . 1 5} \mathrm{C}$ and $0.1 \mathrm{MPa}$

\begin{tabular}{|c|c|c|}
\hline & \multicolumn{2}{|c|}{ phase equilibrium } \\
\hline type of equilibrium & GSE & false GLE \\
\hline G/RT & -7.885069 & -7.880715 \\
\hline phase 1 & $1 \mathrm{~h} \mathrm{Ice}$ & Liquid \\
\hline phase 1 fraction & 0.899987 & 0.900014 \\
\hline phase 1 composition & $(0,1)$ & $\left(3.28 \times 10^{-5}, 0.999967\right)$ \\
\hline phase 1 density $\left(\mathbf{k g} / \mathbf{m}^{\mathbf{3}}\right)$ & 926.67 & 1015.041 \\
\hline & & \\
\hline
\end{tabular}




\begin{tabular}{|c|c|c|}
\hline phase 2 & Gas & Gas \\
\hline phase 2 fraction & 0.100013 & 0.099986 \\
\hline phase 2 composition & $\left(0.999841,1.59 \times 10^{-4}\right)$ & $\left(0.999840,1.60 \times 10^{-4}\right)$ \\
\hline phase 2 density $\left(\mathbf{k g} / \mathbf{m}^{3}\right)$ & 1.95 & 1.95 \\
\hline
\end{tabular}

At the given temperature, the pressure is too low for methane hydrate to form so this example represents a reasonable test of the capability of the multi-scale GHC EOS to find gas-solid equilibrium. Also, note that the correct global minimum Gibbs free energy solution is methane gas with a very small amount of water vapor in equilibrium with $1 \mathrm{~h}$ ice (GSE). However, there is a false gas-liquid equilibrium (GLE) solution with a value of G/RT that is only slightly higher than the gas-ice equilibrium solution. It is also possible to find a false gas-liquid-ice (GLSE) equilibrium at these conditions with a value of G/RT between that of the GS and GL equilibria and a very small amount of solid ( 3.5 mol\%/mol feed).

\subsubsection{Methane Hydrate Density}

The next example gives numerical results for GHC-predicted density of empty and filled hydrate and, in doing so, tests the validity of the theoretical material presented in sections 2.5.2 and 2.5.3 and Appendix C. Empty and filled methane hydrate densities are shown in Table 2.5. Table 2.5 also shows a comparison of the GHC-predicted filled methane hydrate density with the analytical expression given in Sloan and Koh (2007) and the Sloan and Koh expression with the temperature and pressure dependence of empty cell volume given by Klauda and Sandler (2000) included. Note that there is reasonably good agreement among all three methods.

Table 2.5: Methane Hydrate Density from Eq. (10) for $\theta=1$

\begin{tabular}{|c|c|c|c|c|c|}
\hline $\mathbf{T}(\mathbf{K})$ & $\mathbf{p}(\mathbf{b a r})$ & $\rho^{M T}\left(\mathbf{k g} / \mathbf{m}^{\mathbf{3}}\right)$ & $\rho^{\text {hyd }}\left(\mathbf{k g} / \mathbf{m}^{\mathbf{3}}\right)$ & $\rho^{\text {hyd } *}\left(\mathbf{k g} / \mathbf{m}^{\mathbf{3}}\right)$ & $\rho^{\text {hyd } * *}\left(\mathbf{k g} / \mathbf{m}^{\mathbf{3}}\right)$ \\
\hline 260 & 50 & 795.43 & 918.61 & 913.79 & 926.46 \\
\hline & 100 & 795.74 & 918.98 & 913.79 & 926.60 \\
\hline 270 & 50 & 788.48 & 910.59 & 913.79 & 924.05 \\
\hline
\end{tabular}




\begin{tabular}{|c|c|c|c|c|c|}
\hline & 100 & 788.96 & 911.14 & 913.79 & 924.19 \\
\hline 280 & 50 & 781.51 & 902.54 & 913.79 & 921.55 \\
\hline & 100 & 781.99 & 903.09 & 913.79 & 921.69 \\
\hline
\end{tabular}

* analytical expression from Sloan \& Koh (2007).

** Sloan \& Koh expression with Klauda \& Sandler (2000) temperature \& pressure dependent empty cell volume.

\subsubsection{The Quadruple Point for Methane-Water Equilibrium}

Below the melting point of ice, the phase equilibrium that exists is either methane gas-ice or methane hydrate-gas/ice equilibrium. That is, at low pressure, below pressures for which hydrate can form, methane gas is in equilibrium with $1 \mathrm{~h}$ ice. See Table 2.4 for an example of low pressure GSE. As one raises the pressure at fixed temperature, methane hydrate will form and gas hydrate will be in equilibrium with gas and/or ice - depending on the overall amounts of methane and water in the system. Above the melting point of ice the equilibrium changes from gas-liquid to methane hydrate-gas/liquid as a function of increasing pressure. One of the more challenging tasks in the neighborhood of the ice melting point is predicting the quadruple point - the temperature and pressure at which four phases (ice, methane hydrate, liquid water, and gas) co-exist. Anderson (2004) reports a quadruple point of $272.9 \mathrm{~K}$ and $25.63 \mathrm{bar}$. Table 2.6 gives calculated results for the GHC equation prediction of the quadruple point, which is approximately $272.751 \mathrm{~K}$ and 25.624 bar.

Table 2.6: Phase Equilibrium at Approximate Quadruple Point (272.751 K, 25.624 bar) for GHC Equation

\begin{tabular}{|c|c|c|c|}
\hline & \multicolumn{3}{|c|}{ phase equilibrium } \\
\hline type of equilibrium & GLE & GSE & HSE \\
\hline G/RT & -6.98926 & -6.98933 & -6.99003 \\
\hline phase 1 & Liquid & Ice & Ice \\
\hline phase 1 fraction & 0.860690 & 0.860058 & 0.008067 \\
\hline phase 1 composition & $(0.000804,0.999196)$ & $(0,1)$ & $(0,1)$ \\
\hline phase 1 density $\left(\mathbf{k g} / \mathbf{m}^{\mathbf{3}}\right)$ & 1014.05 & 926.39 & \\
\hline & & & Hydrate \\
\hline phase 2 & Gas & Gas & 0.991933 \\
\hline phase 2 fraction & 0.139310 & 0.139942 & \\
\hline
\end{tabular}




\begin{tabular}{|c|c|c|c|}
\hline phase 2 composition & $\left(0.999989,1.09 \times 10^{-}\right.$ & $\left(0.999989,1.09 \times 10^{-}\right.$ & $(0.140978,0.859022)$ \\
\hline phase 2 density $\left(\mathbf{k g} / \mathbf{m}^{\mathbf{3}}\right)$ & 19.19 & 19.19 & 901.31 \\
\hline occupancy & & & 0.9437 \\
\hline
\end{tabular}

Because the quadruple point is a singular point, it is very difficult to compute accurately. However, note that the GHC prediction of the quadruple point gives all three two-phase equilibrium that have dimensionless Gibbs free energies that are quite close (i.e., differing by $<10^{-3}$ ). Note also the predicted fractional occupancy of the gas in the hydrate phase is 0.9437 , which is quite close to the value of occupancy of 0.9461 predicted by the correlation in Parrish and Prausnitz (1972) but less close to the value of occupancy of $0.90 \pm 0.01$ predicted by Gibbs ensemble Monte Carlo simulation (GEMC).

\subsubsection{Sub-Cooled Methane Hydrate-Ice Equilibrium}

This last methane-water example in this article is used to illustrate that phase equilibrium and gas occupancy for conditions away from phase boundaries can be determined using the theoretical framework described in sections $2.3-2.5$ and Appendices A, B, and C. Consider permafrost conditions for a mixture of $13 \mathrm{~mol} \%$ methane and $87 \mathrm{~mol} \%$ water at $272 \mathrm{~K}$ and 27 bar. For the given problem (1) there is an excess amount of water, (2) methane hydrate should be in equilibrium with pure ice, and (3) the resulting phase equilibrium solution is away from the phase boundary. Numerical results for this example are shown in Table 2.7.

Table 2.7: Phase Equilibrium for 13 mol\% Methane-87 mol\% Water at -1.15 C and 2.7 MPa

\begin{tabular}{|c|c|c|c|}
\hline & \multicolumn{3}{|c|}{ phase equilibrium } \\
\hline type of equilibrium & false GLE & false GSE & HSE \\
\hline G/RT & -7.165528 & -7.168280 & -7.172040 \\
\hline phase 1 & Liquid & Ice & Ice \\
\hline phase 1 fraction & 0.870739 & 0.870062 & 0.019111 \\
\hline phase 1 composition & $(0.000850,0.999150)$ & $(0,1)$ & $(0,1)$ \\
\hline
\end{tabular}




\begin{tabular}{|c|c|c|c|}
\hline phase 1 density $\left(\mathrm{kg} / \mathrm{m}^{3}\right)$ & 1014.37 & 926.70 & 926.70 \\
\hline phase 2 & Gas & Gas & Hydrate \\
\hline phase 2 fraction & 0.129261 & 0.0999865 & 0.980889 \\
\hline phase 2 composition & $\begin{array}{c}0.999990,9.87 \times 10^{-} \\
6)\end{array}$ & $\begin{array}{c}0.999990,9.81 \times 10^{-} \\
6)\end{array}$ & $(0.132198,0.867802)$ \\
\hline phase 2 density $\left(\mathrm{kg} / \mathrm{m}^{3}\right)$ & 20.35 & 20.35 & 893.66 \\
\hline occupancy & & & 0.8759 \\
\hline
\end{tabular}

It is important to describe the phase equilibrium computations for this ice-gas hydrate equilibrium flash solution in a bit more detail. The water-to-methane ratio in the feed is equal to 6.6923 , well in excess of the value of 5.75 for a completely filled methane hydrate. Therefore, if methane hydrate is one of the equilibrium phases, there should also be excess water and this implies that either liquid water or ice will also exist. In addition, from Table 2.7 it is clear that ice should be the phase in equilibrium with methane hydrate at the given conditions. This is true because the false GSE solution has a lower value of G/RT than that for the false VLE solution. Moreover, in any icemethane hydrate equilibrium, methane is confined to the hydrate phase. Thus, defining equilibrium becomes a bit more challenging since, in theory, there is only a single chemical potential to use to define conditions of phase equilibrium. This is where the use of structural contributions to the ice and empty hydrate standard state fugacities for water become important. To define equilibrium the following condition is used

$\mu_{w}^{i c e}-\mu_{w}^{M T}=0$

It is also important to understand that eq. (2.12) is singular unless trace amounts of methane are permitted in the ice and empty hydrate phases. However, even if trace amounts of methane are present in these phases to avoid singularity, the problem is still so nearly singular that quadratic acceleration (see, Eq. (A2), p. 2562 in Lucia and Feng, 2003) is required to get convergence to a reasonable tolerance. 
To give the reader some appreciation for this last point, we have shown the calculated equilibrium solution to eq. (2.12) in the presence of trace amounts of methane at $272 \mathrm{~K}$ and 27 bar in Table 2.8 .

Table 2.8: Ice-Empty Hydrate Equilibrium at -1.15 C and 2.7 MPa

\begin{tabular}{|c|c|}
\hline type of equilibrium & Ice-Empty Hydrate \\
\hline G/RT & -7.172040 \\
\hline phase 1 & Ice \\
\hline phase 1 fraction & 0.019111 \\
\hline phase 1 composition & $\left(6.99 \times 10^{-5}, 0.999930\right)$ \\
\hline & \\
\hline phase 2 & Hydrate \\
\hline phase 2 fraction & 0.980889 \\
\hline phase 2 composition & $\left(7.23 \times 10^{-5}, 0.999928\right)$ \\
\hline
\end{tabular}

Using quadratic acceleration, the computations converge to the solution shown in Table 2.8 in 20 iterations. However, note how very close in composition both phases in Table 2.8 are; both contain less than 0.01 mol\% methane. The two critical pieces of information that come from solving eq. (2.12) in this manner are the ice and hydrate phase fractions. From these phase fractions, it is straightforward to determine the methane occupancy, gas hydrate density [i.e., using Eq. (2.10)], and corresponding value of G/RT for the hydrate phase - as well as G/RT for the ice-methane hydrate equilibrium solution.

For this particular example, the fractional occupancy of methane in the hydrate phase using Gibbs-ensemble Monte Carlo simulations was also calculated for the purpose of comparison. The value obtained from GEMC was $0.89 \pm 0.01$. Table 2.7, on the other hand, shows that the calculated fractional occupancy using the GHC-based framework developed in the work is 0.8759 , whereas the occupancy determined using the correlation in Parrrish and Prausnitz (1972) is 0.9497. Thus, it is clear that the 
proposed GHC-based framework for gas hydrates gives reasonable values of gas occupancy directly from phase equilibrium.

\subsubsection{Carbon Dioxide-Water Mixture}

Like methane-water mixtures, carbon dioxide-water mixtures can exhibit a number of different types of phase equilibrium - gas-liquid, liquid-liquid, gas-ice, hydrate-ice, and so on.

\subsubsection{Gas-Liquid Equilibrium}

In previous work, Lucia and co-workers (2012a) have compared phase equilibrium results for $\mathrm{CO}_{2}$-water predicted by the $\mathrm{GHC}$ EOS with those of the Predictive Soave-Redlich-Kwong (PSRK) equation and the experimental data from Coan \& King (1971). See example 6.6 and Fig. 14 in Lucia et al. (2012a). In general, both equations of state are in good agreement with experimental data with the GHC equation performing better overall.

\subsubsection{Carbon Dioxide Gas-Ice Equilibrium}

$\mathrm{CO}_{2}$-ice equilibrium is straightforward to compute using the GHC-based framework developed in this work. However, depending on conditions, there can be many other false equilibrium with values of G/RT that are close to the global minimum value of G/RT, as illustrated in Table 2.9. The presence of many equilibrium makes the prediction of the correct solution quite challenging.

Table 2.9: Phase Equilibrium for $13 \mathrm{~mol} \% \mathrm{CO}_{2}-87 \mathrm{~mol} \%$ Water at $-8.15 \mathrm{C}$ and $0.1 \mathrm{MPa}$

\begin{tabular}{|c|c|c|c|c|}
\hline & \multicolumn{4}{|c|}{ phase equilibrium } \\
\hline type of equilibrium & GSE & false LLE & false GLE & false HSE \\
\hline G/RT & -7.963541 & -7.791826 & -7.934062 & -7.963296 \\
\hline phase 1 & $1 \mathrm{~h}$ Ice & Liquid & Liquid & $1 \mathrm{~h}$ Ice \\
\hline phase 1 fraction & 0.870256 & 0.871749 & 0.870573 & 0.017992 \\
\hline phase 1 & $(0,1)$ & $(0.002010$, & $\left(6.60 \times 10^{-4}\right.$, & $(0,1)$ \\
composition & & $0.997990)$ & $0.999340)$ & \\
\hline
\end{tabular}




\begin{tabular}{|c|c|c|c|c|}
\hline $\begin{array}{c}\text { phase 1 density } \\
\left(\mathbf{k g} / \mathbf{m}^{\mathbf{3}}\right)\end{array}$ & 929.33 & 1016.81 & 1017.92 & 929.33 \\
\hline phase 2 & Gas & Liquid & Gas & Hydrate \\
\hline phase 2 fraction & 0.129744 & 0.128251 & 0.129427 & 0.982008 \\
\hline $\begin{array}{c}\text { phase 2 } \\
\text { composition }\end{array}$ & $(0.999992$, & $(0.999980$, & $(0.999992$, & $(0.132067$, \\
\hline $\begin{array}{c}\text { phase 2 density } \\
\left.\mathbf{( k g / m}^{\mathbf{3}}\right)\end{array}$ & $\left.8.18 \times 10^{-6}\right)$ & $\left.1.96 \times 10^{-5}\right)$ & $\left.8.46 \times 10^{-6}\right)$ & $0.867933)$ \\
\hline occupancy & 21.37 & 716.35 & 21.37 & 1097.18 \\
\hline
\end{tabular}

\subsubsection{Carbon Dioxide Hydrate Density}

The density of $\mathrm{CO}_{2}$ hydrate is considerably higher than that of methane hydrate due to the fact that $\mathrm{CO}_{2}$ is much heavier than methane. However, because $\mathrm{CO}_{2}$ hydrate is also a structure 1 hydrate, eq. (2.10) can be used to calculate hydrate density. Table 2.10 compares $\mathrm{GHC}$-predicted $\mathrm{CO}_{2}$ hydrate densities with densities calculated using the analytical expression given in Sloan and Koh (2007) with and without the Klauda and Sandler (2000) correction for empty hydrate cell volume.

Table 2.10: Carbon Dioxide Hydrate Density from Eq. (10) for $\theta=1$

\begin{tabular}{|c|c|c|c|c|c|}
\hline $\mathbf{T}(\mathbf{K})$ & $\mathbf{p}(\mathbf{b a r})$ & $\boldsymbol{\rho}^{\boldsymbol{M T}}\left(\mathbf{k g} / \mathbf{m}^{\mathbf{3}}\right)$ & $\boldsymbol{\rho}^{\boldsymbol{h y d}}\left(\mathbf{k g} / \mathbf{m}^{\mathbf{3}}\right)$ & $\boldsymbol{\rho}^{\boldsymbol{h y d} \boldsymbol{*}}\left(\mathbf{k g} / \mathbf{m}^{\mathbf{3}}\right)$ & $\boldsymbol{\rho}^{\boldsymbol{h y d}{ }^{* *}}\left(\mathbf{k g} / \mathbf{m}^{\mathbf{3}}\right)$ \\
\hline 260 & 20 & 803.28 & 1144.57 & 1114.89 & 1182.83 \\
\hline & 30 & 803.46 & 1144.82 & 1114.89 & 1182.54 \\
\hline 270 & 20 & 796.57 & 1135.00 & 1114.89 & 1182.86 \\
\hline & 50 & 797.90 & 1135.31 & 1114.89 & 1181.72 \\
\hline 280 & 50 & 789.73 & 1125.25 & 1114.89 & 1181.75 \\
\hline & 70 & 789.92 & 1125.52 & 1114.89 & 1180.53 \\
\hline
\end{tabular}

* analytical expression from Sloan \& Koh (2007).

** Sloan \& Koh expression with Klauda \& Sandler (2000) temperature \& pressure dependent empty cell volume.

Brewer et al. (1999) report a value of $1100 \mathrm{~kg} / \mathrm{m}^{3}$ for the bulk density of $\mathrm{CO}_{2}$ hydrate at $-4{ }^{0} \mathrm{C}$ and depths from 1100 to $1300 \mathrm{~m}$ (pressures ranging from $\sim 110$ to $130 \mathrm{bar}$ ). From Note 17 in Brewer et al. one can deduce that the fractional gas occupancy is 0.9583 . For the same conditions of temperature and pressure, the empty hydrate density predicted by the GHC equation is $0.0442967 \mathrm{~mol} / \mathrm{cm}^{3}$. Using the gas occupancy from Brewer et 
al. (1999), the molecular weight of $\mathrm{CO}_{2}$ hydrate is $21.59 \mathrm{~g} / \mathrm{gmol}$. From Eq. (2.10), the actual hydrate density for a fractional $\mathrm{CO}_{2}$ occupancy of 0.9583 is $0.051679 \mathrm{~mol} / \mathrm{cm} 3$, which when multiplied by the molecular weight of the $\mathrm{CO}_{2}$ hydrate gives a mass density of $1115.57 \mathrm{~kg} / \mathrm{m}^{3}$. This GHC-predicted value of $\mathrm{CO}_{2}$ hydrate density represents an error of $1.43 \%$. For the exact same conditions, the analytical expression in Sloan and Koh (2007) gives a density of $1101.02 \mathrm{~kg} / \mathrm{m}^{3}$ while the expression in Sloan and Koh with the Klauda and Sandler (2000) correction for empty hydrate cell volume results in a mass density of $1162.25 \mathrm{~kg} / \mathrm{m}^{3}$.

\subsubsection{Phase Equilibrium in Regions Where $\mathrm{CO}_{2}$ Hydrates Can Exist}

One of the interesting differences between methane hydrates and $\mathrm{CO}_{2}$ hydrates is the presence of liquid $\mathrm{CO}_{2}$ at high pressure so we consider an example that would potentially result in storage of $\mathrm{CO}_{2}$ in a hydrate phase. Let the temperature and pressure be $269.15 \mathrm{~K}$ and 130 bar respectively. At this pressure, $\mathrm{CO}_{2}$ is a liquid and the temperature and pressure are such that hydrate can form. Moreover, Brewer et al. (1999) provide clear experimental evidence that a hydrate phase can form from liquid $\mathrm{CO}_{2}$ at high pressures. See Fig. 2.3 and the associated discussions in Brewer et al. (1999). Finally, for hydrate in equilibrium with fluid phases (and not $1 \mathrm{~h}$ ice), the conditions defining equilibrium are the equality of chemical potentials for $\mathrm{CO}_{2}$ and water in all phases. Numerical results are shown in Table 2.11.

Table 2.11: Phase Equilibrium for $13 \mathrm{~mol} \% \mathrm{CO}_{2}-87 \mathrm{~mol} \%$ Water at $-4 \mathrm{C}$ and $13 \mathrm{MPa}$

\begin{tabular}{|c|c|c|c|}
\hline & \multicolumn{3}{|c|}{ phase equilibrium } \\
\hline type of equilibrium & false LLE & false SLE & HLLE \\
\hline G/RT & -7.341224 & -7.337202 & -7.365097 \\
\hline phase 1 & Liquid & Solid & Liquid \\
\hline phase 1 fraction & 0.886538 & 0.870542 & 0.873997 \\
\hline phase 1 composition & $(0.018762$, & $(0,1)$ & $(0.018782$, \\
& $0.981238)$ & & $0.981218)$ \\
\hline
\end{tabular}




\begin{tabular}{|c|c|c|c|}
\hline phase 1 density $\left(\mathrm{kg} / \mathrm{m}^{3}\right)$ & 1029.03 & 927.92 & \\
\hline phase 2 & Liquid & Liquid & Liquid \\
\hline phase 2 fraction & 0.113462 & 0.129458 & 0.111677 \\
\hline phase 2 composition & $\begin{array}{c}\left(0.999161,8.39 \times 10^{-}\right. \\
4)\end{array}$ & $\left(0.999157,8.43 \times 10^{-4}\right)$ & $\begin{array}{c}\left(0.999156,8.44 \times 10^{-}\right. \\
4)\end{array}$ \\
\hline phase 2 density $\left(\mathrm{kg} / \mathrm{m}^{3}\right)$ & 995.77 & 995.77 & 995.77 \\
\hline phase 3 & & & Hydrate \\
\hline phase 3 fraction & & & 0.014326 \\
\hline phase 3 composition & & & $(0.139740,0.860260)$ \\
\hline phase 3 density $\left(\mathrm{kg} / \mathrm{m}^{3}\right)$ & & & 1116.32 \\
\hline occupancy & & & 0.9432 \\
\hline
\end{tabular}

Note that the results in Table 2.11 are consistent with the experimental observations of Brewer et al. (1999), where the authors report the presence of a mass of flocculant $\mathrm{CO}_{2}$ hydrate along with liquid $\mathrm{CO}_{2}$ and, in their case, seawater. The GHC-estimated freezing point depression of water with $\mathrm{CO}_{2}$ solute mole fractions of 0.018762 or 0.018782 at an elevated pressure is approximately $-3.82{ }^{0} \mathrm{C}$. Thus, the estimated freezing point of the water phase at 130 bar pressure is $269.32 \mathrm{~K}$, which is very close to $269.15 \mathrm{~K}$. This, in our opinion, explains why the values of G/RT for the LLE and SLE flash solutions in Table 2.11 are so close. In addition, Brewer et al. state that after some time (17 days), they observed no hydrate present in their experiment - either because the hydrate phase dissolved or because it sank into the surrounding seawater. The GHC-predicted hydrate density shown in Table 2.11 is consistent with the hydrate phase sinking in water. Finally, the GHC-predicted density and fractional occupancy agree quite well with the density of $1100 \mathrm{~kg} / \mathrm{m}^{3}$ and occupancy of 0.9583 reported in Brewer et al. (1999).

The numerical aspects associated with computing the HLLE flash solution in Table 2.11 are somewhat complicated. Because there are two components and three phases, the solution is near singular and quadratic acceleration is required for reliable 
convergence. In this example, the HLLE flash computations converge to an accuracy of $10^{-6}$ in the 2-norm of the equality of chemical potentials in 9 iterations.

\subsection{Conclusions}

The multi-scale Gibbs-Helmholtz Constrained (GHC) equation of state-based framework has been extended for determining densities and phase equilibrium in light gas-water mixtures at conditions where ice and/or hydrates can exist. This extended framework is built around the use of the multi-scale GHC EOS, and the novel ideas that (1) make use of the GHC equation to determine densities of ice and empty hydrate, (2) derive and employ structural contributions to the standard state fugacities of ice and empty hydrate in phase equilibrium, (3) use of only densities and EOS parameters to determine these structural contributions, and (4) determine gas occupancy directly from phase equilibrium. A novel theoretical framework was developed and a number of examples for mixtures of methane-water and carbon dioxide-water at conditions relevant to hydrate formation were presented to show the efficacy of the proposed new approach. Numerical results clearly show that this extended multi-scale, GHC-based framework provides accurate predictions of densities, phase equilibrium, and gas occupancy for light gas-water mixtures for conditions where ice and/or gas hydrates exist. 


\section{Appendix A: Internal Energies of Departure for Ice}

Internal energies of departure for hexagonal ice can be determined either from $U^{D}$ for liquid water plus energies of fusion or by direct Monte Carlo Simulation.

\section{Internal Energies of Departure for Hexagonal Ice from Energies of Fusion}

Along the melting curve, internal energies of departure associated with fusion, $U_{w}^{D, f u s}$, needed in Eq. (2.5) can be calculated as follows:

i. A reference value of the internal energy of departure associated with fusion, $U_{w}^{D 0, f u s}$, can be estimated from data for the heat of fusion for water, which is abundantly available (at $273.15 \mathrm{~K}$ and $0.1013 \mathrm{MPa} ; \quad U_{w}^{D 0, f u s}=$ $\left.-0.600890325 \times 10^{5} \mathrm{~cm}^{3} \mathrm{bar} / \mathrm{mol}\right)$.

ii. The effect of temperature and pressure on $U_{w}^{D, f u s}$ along the melting curve can be included by using the Clausius-Clapeyron equation (see Smith et al., 2004) in the form

$U_{w}^{D, f u s}=U_{w}^{D 0, f u s}+\Delta V\left[\left(\frac{\partial p}{\partial T}\right) \Delta T+p\right]$

where $\Delta V=V_{w}^{i c e}-V_{w}^{L},\left(\frac{\partial p}{\partial T}\right)$ is the derivative of pressure with respect to temperature along the melting curve, and $\Delta T=T-273.15$.

iii. It is straightforward to calculate a very good estimate of the volume difference between $1 \mathrm{~h}$ ice and liquid water, $\Delta V$, needed in Eq. (A1) using the multi-scale GHC equation. To do this,

a) First calculate the density of liquid water at $273.15 \mathrm{~K}$ and $0.1013 \mathrm{MPa}$ using the GHC equation with values of $b_{w}^{L}=16.363 \mathrm{~cm}^{3} / \mathrm{mol}$ and $U_{w}^{D L}=$ $-4.820981356 \times 10^{5} \mathrm{~cm}^{3} \mathrm{bar} / \mathrm{mol}$, which is the value of $U^{D}$ for liquid 
water from NPT Monte Carlo simulations. The calculated molar density of liquid water is $\rho_{w}^{L}=0.0563139 \mathrm{~mol} / \mathrm{cm}^{3}$, which corresponds to a mass density of $1014.49 \mathrm{~kg} / \mathrm{m}^{3}$.

b) Next set $U_{w}^{D, f u s}=U_{w}^{D 0, f u s}$ and calculate $U_{w}^{D, i c e}=U_{w}^{D L}+U_{w}^{D, f u s}$ at $273.15 \mathrm{~K}$ and $0.1013 \mathrm{MPa}$. This gives a value of $U_{w}^{D, i c e}=$ $-5.4218889 \times 10^{5} \mathrm{~cm}^{3} \mathrm{bar} / \mathrm{mol}$.

c) Calculate the density of $1 \mathrm{~h}$ ice at $273.15 \mathrm{~K}$ and $0.1013 \mathrm{MPa}$ using the GHC equation [i.e., eqs. (2.1) and (2.2)] with $b_{w}^{i c e}=18.015 \mathrm{~cm}^{3} / \mathrm{mol}$ and $U_{w}^{D, i c e}=-5.4218889 \times 10^{5} \mathrm{~cm}^{3} \mathrm{bar} / \mathrm{mol}$, which gives a molar density of $\rho_{w}^{i c e}=0.05414412 \mathrm{~mol} / \mathrm{cm}^{3}$ or a mass density of $926.19 \mathrm{~kg} / \mathrm{m}^{3}$.

d) Finally, use the results from a) and c) to calculate a value of $\Delta V=V_{w}^{\text {ice }}-$ $V_{w}^{L}=\frac{1}{\rho_{w}^{i c e}}-\frac{1}{\rho_{w}^{L}}=1.69311 \mathrm{~cm}^{3} / \mathrm{mol}$

iv. Given the reference internal energy of fusion, $U_{w}^{D 0, f u s}$, and the change in volume, $\Delta V$, it is straightforward to use the Clausius-Calpeyron equation to estimate the derivative, $\left(\frac{\partial p}{\partial T}\right)$, along the melting curve at the reference temperature and pressure. By direct application of the Clausius-Clapeyron equation we have $\left(\frac{\partial p}{\partial T}\right)=\frac{H_{w}^{D 0, f u s}}{T \Delta V}=\frac{U_{w}^{D 0, f u s}}{T \Delta V}$

which holds since the term $p \Delta V$ is negligible compared to $U_{w}^{D 0, f u s}$. From Eq. (A2), we find that $\left(\frac{\partial p}{\partial T}\right)=\frac{-0.600890325 \times 10^{5} \mathrm{~cm}^{3} \mathrm{bar} / \mathrm{mol}}{(273.15 \mathrm{~K})\left(1.69311 \frac{\mathrm{cm}^{3}}{\mathrm{~mol}}\right)}=-129.902 \mathrm{bar} / \mathrm{K}$, which is close to the published experimental value of $-134.58 \mathrm{bar} / \mathrm{K}$ found in the open 
literature. See, for example, Table IV in Abascal et al. (2005) or p. 1034 in Feistel \& Wagner (2006).

v. To calculate $U_{w}^{D, f u s}$ at other T and p along the melting curve, use Eq. (A1) with the assumption that $\Delta V$ and $\left(\frac{\partial p}{\partial T}\right)$ remain constant at values of $\Delta V=1.69311 \mathrm{~cm}^{3} /$ $m o l$ and $\left(\frac{\partial p}{\partial T}\right)=-129.902 \mathrm{bar} / K$ respectively.

\section{Internal Energies of Departure for Hexagonal Ice from Direct Monte Carlo Simulation}

We have also calculated internal energies of departure for $1 \mathrm{~h}$ ice using the TIP4P-Ew force field model initialized from a hexagonal structure. The optimized force field parameters for liquid water used in the MC simulations of ice were taken from Horn et al. (2004) and are given in Appendix D. Figure A1 gives a snapshot of the crystal structure predicted by Monte Carlo simulation for $\mathrm{N}=96$ water molecules, $T=$ $272 \mathrm{~K}$ and $p=10 \mathrm{MPa}$ during the sampling (or production) phase. For these simulations, 50,000 equilibration cycles and 200,000 production cycles were used. The minimum energy structure for hexagonal ice at $0 K$ is also shown in Fig. A1 for comparison. 


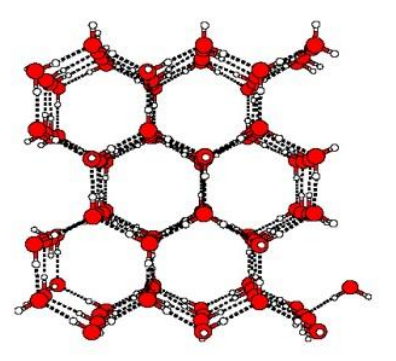

minimum energy structure

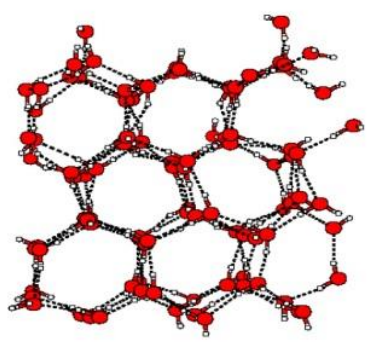

lattice at $272 \mathrm{~K}$

Figure A1: Comparison of Minimized and Simulated Structures of Hexagonal Ice

Note that the minimum energy structure (at $0 K$ ) is perfectly hexagonal while NPT Monte Carlo simulation using TIP4P-Ew gives a structure that shows some lattice distortion at the elevated temperature of $272 \mathrm{~K}$. Similar results were obtained using the TIP4P/Ice force field model (Abascal et al., 2004). The important point here is that NPT Monte Carlo simulations account for the effects of lattice distortion and this lattice distortion is correctly reflected in values of $U_{w}^{D, i c e}$.

It is also important to note that the estimation of $U^{D}$ for hexagonal ice from direct NPT Monte Carlo simulation is not restricted to the melting curve but can be used for any temperature and pressure. However, it is unclear if this distinction matters in practice since Table A1, which gives a comparison of $U_{w}^{D, i c e}$ calculated using energies of fusion and the Clausius-Clapeyron equation [i.e., Eqs. (A1) \& (A2)] with values of $U_{w}^{D, i c e}$ calculated from direct NPT Monte Carlo simulations, shows only relatively small differences in $U_{w}^{D, i c e}$ between the two methods over reasonable ranges of temperature and pressure. 
The results in Table A2 show that there is strong agreement between the two methods for determining internal energies of departure for hexagonal ice. Specifically, the $\%$ error, which is defined as \% error $=100 \mid U_{w}^{D, \text { ice }}(M C)-\left(U_{w}^{D L}+U_{w}^{D, f u s}\right) /$ $U_{w}^{D, \text { ice }}(M C) \mid$, is less than $3 \%$ and the standard deviation, $\sigma_{N}$, is small - despite the fact that estimations of $U_{w}^{D, i c e}$ using the Clausius-Clapeyron equation are really not strictly applicable at conditions that are not on the melting curve. Note that Table A1 also shows that the pressure effect on $U_{w}^{D, i c e}$ is small.

Table A2: Internal Energies of Departure for Hexagonal Ice

\begin{tabular}{|c|c|c|c|c|c|}
\hline \multirow[t]{2}{*}{$T(K)$} & \multirow[t]{2}{*}{$p(M P a)$} & \multicolumn{3}{|c|}{$U_{w}^{D, i c e}\left(\frac{10^{5} \mathrm{~cm}^{3} \mathrm{bar}}{\mathrm{mol}}\right)$} & \multirow[t]{2}{*}{ \% Error } \\
\hline & & $U_{w}^{D L}+U_{w}^{D, f u s}$ & NTP MC * & $2 \sigma_{N}$ & \\
\hline \multirow[t]{3}{*}{260} & 0.1 & -5.45437 & -5.60955 & 203.7649 & 2.77 \\
\hline & 5 & -5.48108 & -5.61205 & 536.3299 & 2.33 \\
\hline & 10 & -5.47443 & -5.61080 & 224.7205 & 2.43 \\
\hline \multirow[t]{3}{*}{270} & 0.1 & -5.43590 & -5.57666 & 207.6345 & 2.52 \\
\hline & 5 & -5.42835 & -5.57490 & 359.8061 & 2.63 \\
\hline & 10 & -5.42557 & -5.59308 & 335.1859 & 2.99 \\
\hline \multirow[t]{3}{*}{280} & 0.1 & -5.39142 & -5.53664 & 430.5228 & 2.62 \\
\hline & 5 & -5.38874 & -5.54026 & 362.6037 & 2.73 \\
\hline & 10 & -5.38620 & -5.54201 & 150.2200 & 2.81 \\
\hline
\end{tabular}

* Force field model $=$ TIP4P-Ew. 


\section{Appendix B: A Reference State for Water in a Hexagonal Ice Phase}

The expression for $\ln \varphi$ in the multi-scale GHC framework for a pure component is

$\ln \varphi=z-1-\ln (z-B)-(A / B) \ln (1+B / z)$

where $A=a p / R T^{2}$ and $B=b p / R T$. Application of Eq. (B1) to $1 \mathrm{~h}$ ice and liquid water gives

$$
\begin{aligned}
& \ln \varphi_{w}^{i c e}=z_{w}^{i c e}-1-\ln \left(z_{w}^{i c e}-B_{w}^{i c e}\right)-\left(\frac{A_{w}^{i c e}}{B_{w}^{i c e}}\right) \ln \left(1+\frac{B_{w}^{i c e}}{z_{w}^{i c e}}\right) \\
& \ln \varphi_{w}^{L}=z_{w}^{L}-1-\ln \left(z_{w}^{L}-B_{w}^{L}\right)-\left(\frac{A_{w}^{L}}{B_{w}^{L}}\right) \ln \left(1+\frac{B_{w}^{L}}{z_{w}^{L}}\right)
\end{aligned}
$$

Subtracting Eq. (B2) from Eq. (B3) and some algebra gives

$$
\begin{aligned}
\Delta^{i c e}= & \ln \varphi_{w}^{L}-\ln \varphi_{w}^{i c e}=z_{w}^{L}-z_{w}^{i c e}-\ln \left(z_{w}^{L}-B_{w}^{L}\right)+\ln \left(z_{w}^{i c e}-B_{w}^{i c e}\right) \\
& -\left(\frac{A_{w}^{L}}{B_{w}^{L}}\right) \ln \left(1+\frac{B_{w}^{L}}{z_{w}^{L}}\right)+\left(\frac{A_{w}^{i c e}}{B_{w}^{i c e}}\right) \ln \left(1+\frac{B_{w}^{i c e}}{z_{w}^{i c e}}\right)
\end{aligned}
$$

where $\Delta^{i c e}$ denotes the difference between the natural log of the fugacity coefficients for water and $1 \mathrm{~h}$ ice due to long-range structural differences between water and ice. Note that Eq. (B4) is a rigorous relationship between $\ln \varphi_{w}^{i c e}$ and $\ln \varphi_{w}^{L}$ and permits the calculation of the difference between the two fugacity coefficients from information that is readily available from density calculations for $1 \mathrm{~h}$ ice and water.

At conditions of ice-water phase equilibrium,

$G_{w}^{i c e}=G_{w}^{L}$

where $G$ denotes the Gibbs free energy, the subscript $w$ denotes water and the superscripts ice and $L$ represent hexagonal ice and liquid respectively. Equation (B5) can be expanded in the form 


$$
\begin{aligned}
G_{w}^{i c e} & =G_{w}^{0, i c e}+R T \ln x_{w}^{i c e}+R T \ln \varphi_{w}^{i c e}-R T \ln p \\
& =G_{w}^{0, L}+R T \ln x_{w}^{L}+R T \ln \varphi_{w}^{L}-\quad R T \ln p=G_{w}^{L}
\end{aligned}
$$

where $R$ is the universal gas constant. Because $x_{w}^{i c e}=x_{w}^{L}=1$, Eq. (B6) reduces to

$G_{w}^{0, i c e}+R T \ln \varphi_{w}^{i c e}=G_{w}^{0, L}+R T \ln \varphi_{w}^{L}$

However, Eq. (B7) implies

$G_{w}^{0, i c e}=G_{w}^{0, L}+R T\left(\ln \varphi_{w}^{i c e}-\ln \varphi_{w}^{L}\right)$

Use of Eq. (B4) in Eq. (B8) gives

$$
\begin{aligned}
G_{w}^{0, i c e} & =G_{w}^{0, L}+R T\left[z_{w}^{L}-z_{w}^{i c e}-\ln \left(z_{w}^{L}-B_{w}^{L}\right)+\ln \left(z_{w}^{i c e}-B_{w}^{i c e}\right)\right. \\
& \left.-\left(\frac{A_{w}^{L}}{B_{w}^{L}}\right) \ln \left(1+\frac{B_{w}^{L}}{z_{w}^{L}}\right)+\left(\frac{A_{w}^{i c e}}{B_{w}^{i c e}}\right) \ln \left(1+\frac{B_{w}^{i c e}}{z_{w}^{i c e}}\right)\right]
\end{aligned}
$$

As is usual in equation of state calculations, we choose the standard state fugacity of liquid water to be equal to the pressure. Using this fact and the definition of $\Delta^{i c e}$ from Eq. (B4) in Eq. (B9) gives

$G_{w}^{0, i c e}=G_{w}^{0, L}+R T \ln p+R T \Delta^{i c e}$

Defining $S^{i c e}=\exp \left(\Delta^{i c e}\right)$ implies $\Delta^{i c e}=\ln S^{i c e}$ and Eq. (B10) becomes

$G_{w}^{0, i c e}=G_{w}^{0, L}+R T \ln p+R T S^{i c e}$

All that remains is to evaluate $S^{i c e}$ at some reference state, say $T_{0}=273.15 \mathrm{~K}$ and $p_{0}=$ $0.1013 \mathrm{MPa}$, which is easily accomplished using information from density calculations at reference state conditions. Table B1 shows the values of the quantities needed in Eq. (B4) evaluated at $T_{0}$ and $p_{0}$. 
Table B1: Quantities for Calculating $S^{\text {ice }}$

\begin{tabular}{|l|c|c|}
\hline \multicolumn{1}{|c|}{ Quantity } & Liquid Water & Hexagonal Ice \\
\hline$z$ & 0.00078191 & 0.00085646 \\
\hline$A$ & 0.01912947 & 0.02234875 \\
\hline$B$ & 0.00072050 & 0.00079325 \\
\hline $\ln (z-B)$ & -9.6979892 & -9.6689374 \\
\hline$(A / B) \ln (1+B / z)$ & 17.3395588 & 18.4691635 \\
\hline
\end{tabular}

Using Eq. (B4) and the data in Table B1 in Eq. (B10) gives $\Delta^{i c e}=1.15855$ and $S^{i c e}=$ 3.18531 .

Thus, in general the standard state for $1 \mathrm{~h}$ ice at any temperature can be calculated from Eq. (B11) with $S^{i c e}=3.18531$. Also note that $G_{w}^{0, i c e}$ defined by Eq. (B11) is a function of temperature and pressure as it should be.

$\underline{\text { Remark }}$

It turns out that the value, $S^{i c e}=3.18531$, is very close to the second peak distance in the $\mathrm{O}-\mathrm{H}$ partial radial distribution function for $1 \mathrm{~h}$ ice (see Fig.1, p. 514 in Chau and Hardwick, 1998). However, it is unclear if there is a rigorous relationship between $\Delta^{i c e}$ and the $\mathrm{O}-\mathrm{H}$ partial radial distribution function or if this is just a coincidence. 


\section{Appendix C: A Reference State for Pure Water in a Gas Hydrate Phase}

At conditions of ice-hydrate phase equilibrium,

$G_{w}^{i c e} / R T=G_{w}^{h y d} / R T$

where the superscript hyd represents hydrate and all other quantities are defined as in Appendix B. Moreover,

$\frac{G_{w}^{i c e}}{R T}=\frac{G_{w}^{0, i c e}}{R T}+\ln x_{w}^{i c e}+\ln \varphi_{w}^{i c e}$

and

$\frac{G_{w}^{h y d}}{R T}=\frac{G_{w}^{0, h y d}}{R T}+\ln x_{w}^{h y d}+\ln \varphi_{w}^{h y d}$

From Eqs. (C2) and (C3) and the fact that $x_{w}^{i c e}=1$, since hexagonal ice is a pure phase, it follows that

$\frac{G_{w}^{0, h y d}}{R T}+\ln x_{w}^{h y d}+\ln \varphi_{w}^{h y d}=\frac{G_{w}^{0, i c e}}{R T}+\ln \varphi_{w}^{i c e}$

Rearranging Eq. (C4) gives

$\begin{aligned} \frac{G_{w}^{0, h y d}}{R T} & =\frac{G_{w}^{0, i c e}}{R T}+\ln \varphi_{w}^{i c e}-\ln x_{w}^{h y d}-\ln \varphi_{w}^{h y d} \\ & =\ln p+\Delta^{i c e}+\ln \varphi_{w}^{i c e}-\ln x_{w}^{h y d}-\ln \varphi_{w}^{h y d}\end{aligned}$

where $\Delta^{i c e}=\ln \varphi_{w}^{l i q}-\ln \varphi_{w}^{i c e}$ is the structural component of $G_{w}^{0, i c e}$ that represents the long range hexagonal order of solid hexagonal ice as defined in Appendix B.

To calculate a standard state of pure water in the hydrate phase we let $x_{w}^{\text {hyd }}=1$ in Eq. (C5), which means the hydrate cage is empty. This gives

$\frac{G_{w}^{0, h y d}}{R T}=\ln p+\Delta^{i c e}+\ln \varphi_{w}^{i c e}-\ln \varphi_{w}^{M T}=\ln p+\Delta^{i c e}+\Delta^{M T}$

where the quantity $\Delta^{M T}=\ln \varphi_{w}^{i c e}-\ln \varphi_{w}^{M T}$ represents a second structural component that captures the differences in long range structure between $1 \mathrm{~h}$ ice and empty hydrate. 
To calculate this second structural component contribution to the standard state for pure water in the hydrate phase we use the same strategy that we used for determining the structural component for $1 \mathrm{~h}$ ice. That is, we apply Eq. (B1) to determine the natural log of the fugacity coefficients for ice and empty hydrate and simply subtract the latter from the former to get $\Delta^{M T}$ in terms of compressibility and equation of state parameters, $A$ and $B$. The resulting expression for $\Delta^{M T}$ is

$$
\begin{aligned}
\Delta^{M T} & =z^{i c e}-z^{M T}-\ln \left(z^{i c e}-B^{i c e}\right)+\ln \left(z^{M T}-B^{M T}\right)-\left(\frac{A^{i c e}}{B^{i c e}}\right) \ln \left(1+\frac{B^{i c e}}{z^{i c e}}\right) \\
& +\left(\frac{A^{M T}}{B^{M T}}\right) \ln \left(1+\frac{B^{M T}}{z^{M T}}\right)
\end{aligned}
$$

which clearly shows that only EOS information is needed to determine $\Delta^{M T}$. Straightforward computations using the GHC equation of state shows that $\Delta^{M T}$ varies very little with temperature and pressure (i.e., values of between -2.51 and -2.21 over the temperature and pressure ranges shown in Table 1). Table $\mathrm{C} 1$ gives a sample calculation of $\Delta^{M T}$ at $270 \mathrm{~K}$ and $50 \mathrm{bar}$.

Table C1: Quantities for Calculating $S^{\text {hyd }}$

\begin{tabular}{|l|c|c|}
\hline \multicolumn{1}{|c|}{ Quantity } & Hexagonal Ice & Empty Hydrate \\
\hline$Z$ & 0.043254 & 0.0437682 \\
\hline$A$ & 1.148913 & 1.1568899 \\
\hline$B$ & 0.040150 & 0.0466179 \\
\hline $\ln (z-B)$ & -5.766967 & -5.455963 \\
\hline$(A / B) \ln (1+B / z)$ & 18.792192 & 16.137596 \\
\hline$\Delta^{M T}$ & & -2.3512243 \\
\hline$S^{M T}$ & & 0.0953 \\
\hline
\end{tabular}

$G_{w}^{0, h y d}=R T\left(\ln p+\ln S^{i c e}+\ln S^{M T}\right)$

where $S^{i c e}=\exp \left(\Delta^{i c e}\right)=3.18531$ and where $S^{M T}=\exp \left(\Delta^{M T}\right)$ is allowed to vary with $\Delta^{M T}$ computed by Eq. (C7). However, it is important to note that the value of $S^{M T}$ is a very weak function of pressure in the range 250 to $280 \mathrm{~K}$. 
We also repeated the same derivation of the structural component for empty hydrate by using water as the reference condition. Specifically, we re-wrote Eq. (C5) as

$$
\begin{aligned}
\frac{G_{w}^{0, h y d}}{R T} & =\frac{G_{w}^{0}}{R T}+\ln \varphi_{w}^{l i q}-\ln x_{w}^{h y d}-\ln \varphi_{w}^{h y d} \\
& =\ln p+\ln \varphi_{w}^{l i q}-\ln \varphi_{w}^{M T}=\ln p+\Delta^{M T}
\end{aligned}
$$

where $\Delta^{M T}=\ln \varphi_{w}^{l i q}-\ln \varphi_{w}^{M T}$ now measures the structural contribution to the hydrate standard state with respect to pure liquid water. This, in turn, led to an expression very similar to Eq. (C7). That is,

$$
\begin{aligned}
\Delta^{M T} & =z^{l i q}-z^{M T}-\ln \left(z^{l i q}-B^{l i q}\right)+\ln \left(z^{M T}-B^{h y d}\right)-\left(\frac{A^{l i q}}{B^{l i q}}\right) \ln \left(1+\frac{B^{l i q}}{z^{l i q}}\right) \\
& +\left(\frac{A^{M T}}{B^{M T}}\right) \ln \left(1+\frac{B^{M T}}{z^{M T}}\right)
\end{aligned}
$$

However, this choice for the expression for $\Delta^{M T}$ did not yield good results. 
Appendix D: Critical and Other Relevant Physical Property Data

Table D1: Critical and Other Physical Property Data

\begin{tabular}{|c|c|c|c|c|}
\hline Species & $\mathbf{T}_{\mathbf{c}}(\mathbf{K})$ & $\mathbf{p}_{\mathbf{c}}(\mathbf{M P a})$ & $\boldsymbol{\alpha}$ & $\mathbf{b}\left(\mathbf{c m}^{\mathbf{3}} / \mathbf{m o l}\right)$ \\
\hline Methane & 190.58 & 4.592 & 0.008 & 29.614 \\
\hline Water & 647.37 & 22.120 & 0.345 & 16.363 \\
\hline Carbon Dioxide & 304.20 & 73.80 & 0.224 & 28.169 \\
\hline
\end{tabular}

Table D2: NPT Monte Carlo Simulation Parameters

\begin{tabular}{|c|c|c|c|}
\hline $\begin{array}{c}\text { TIP4P-ew } \\
\text { (Horn et al., 2004) }\end{array}$ & $\frac{\boldsymbol{\epsilon}}{\boldsymbol{k}_{\boldsymbol{B}}}(\boldsymbol{K})$ & $\boldsymbol{\sigma}(\AA)$ & $\mathbf{q}(\mathbf{e})$ \\
\hline $\mathbf{O}$ & 81.8989 & 3.16435 & -1.0484 \\
\hline $\mathbf{H}$ & 0.0 & 0.0 & 0.5242 \\
\hline $\begin{array}{c}\text { TraPPE-UA } \\
\text { (Martin \& Siepmann, 1998) }\end{array}$ & & & \\
\hline $\boldsymbol{C H}_{\mathbf{4}}$ & 148.0 & 3.73 & 0.0 \\
\hline $\begin{array}{c}\text { EPM } \\
\text { (Harris \& Yung, 1995) }\end{array}$ & & & \\
\hline C & 28.999 & 2.785 & 0.6645 \\
\hline O & 82.997 & 3.064 & -0.33225 \\
\hline
\end{tabular}




\section{References}

Abascal, J.L.F., Sanz, E., Garcia Fernandez, R., Vega, C. 2005. A potential model for the study of ices and amorphous water: TIP4P/Ice. J. Chem. Phys. 122, 234511, 1-9.

Ahlers, J., Gmehling, J., 2001. Development of a universal group contribution equation of state. 1. Prediction of liquid densities for pure compounds with a volume translated Peng-Robinson equation of state. Fluid Phase Equil. 191, 177-188.

Anderson, G.K., 2004. Enthalpy of dissociation and hydration number of methane hydrate from the Clapeyron equation. J. Chem. Thermodynamics 36, 1119-1127.

Ballard, A.L., Sloan, E.D.S., 2002. The next generation of hydrate prediction I . Hydrate standard states and incorporation of spectroscopy. Fluid Phase Equil. 197, 371-383.

Bandyopadhyay, A.A., Klauda, J.B., 2011. Gas hydrate structure and pressure predictions based on an updated fugacity-based model with the PSRK equation of state. Ind. Eng. Chem. Res. 50(1), 148-157.

Brewer, P.G., Friederich, G., Peltzer, E.T., Orr, F.M. 1999. Direct experiments on the ocean disposal of fossil fuel $\mathrm{CO}_{2}$. Science 284, 943-945.

Chau, P.-L., Hardwick, A.J., 1998. A new order parameter for tetrahedral configurations. Molecular Physics 93(3), 511-519.

Coan, C.R., King, A.D., 1971. Solubility of water in compressed carbon dioxide, nitrous oxide, and ethane. Evidence of hydration of carbon dioxide and nitrous oxide in the gas phase. Journal of the American Chemical Society 93, 1857-1862.

Elliott, J.R., Suresh, S.J., Donohue, M.A., 1990. A simple equation of state for nonspherical and associating molecules. Ind. Eng. Chem. Res. 29, 1476-1485.

Feistel, R., Wagner, W. A., 2006. A new equation of state for $\mathrm{H}_{2} \mathrm{O}$ Ice 1h. J. Phys. Chem. Ref. Data 35, 1021-1047.

Ghiasi, M.M., 2012. Initial estimation of hydrate formation temperature of sweet natural gases based on new empirical correlation. J. Natural Gas Chem. 21(5), 508-512.

Hammerschmidt, E.G., 1934. Formation of gas hydrates in natural gas transmission lines. Ind. Eng. Chem. Fund. 26, 851-855.

Harris, J.,G., Yung, K.H. 1995. Carbon Dioxide's Liquid-Vapor Coexistence Curve and Critical Properties As Predicted by a Simple Molecular Model, J. Phys. Chem. 99 12021-12024. 
Horn, H.W., Swope, W.C., Pitera, J.W., Madura, J.D., Dick, T.J., Hura, G.L., HeadGordon, T., 2004. Development of an improved four-site water model for biomolecular simulations: TIP4P-Ew. J. Chem. Phys. 120, 9665-9678.

Huang, S.H., Radosz, M., 1991. Equation of state for small, large, polydisperse, and associating molecules: Extension to fluid mixtures. Ind. Eng. Chem. Res. 30, 19942005.

Jager, M. D., Ballard, A. L., Sloan, E. D., 2003. The next generation of hydrate prediction. Fluid Phase Equil. 211(1), 85-107.

Jäger, A., Vinš, V., Gernert, J., Span, R., Hrubý, J., 2013. Phase equilibria with hydrate formation in $\mathrm{H}_{2} \mathrm{O}+\mathrm{CO}_{2}$ mixtures modeled with reference equations of state. Fluid Phase Equil. 338, 100-113.

Klauda, J.B., Sandler, S.I., 2000. A fugacity model for gas hydrate phase equilibria. Ind. Eng. Chem. Res. 39, 3377-3386.

Klauda, J.B., Sandler, S.I., 2003. Phase behavior of clathrate hydrates : a model for single and multiple gas component hydrates. Chem. Eng. Sci. 58, $27-41$.

Kontogeorgis, G.M., Voustas, E.C., Yakounis, I.V., Tassios, D.P., 1996. An equation of state for associating fluids. Ind. Eng. Chem. Res. 35, 4310-4318.

Kvenvolden, K.A., 1998. Estimates of the methane content of worldwide gas-hydrate deposits. Japan National Oil Company: Tokyo, Japan. In Proceedings of the International Symposium of Japan National Oil Company, Methane Hydrates: Resources in the near Future? Panel Discussion Proceedings, Chiba City, Japan, Oct 20-22, 1998; p 1.

Lucia, A., 2010. A multi-scale Gibbs-Helmholtz Constrained cubic equation of state. J. Thermodyn. article id: 238365.

Lucia, A., Bonk, B.M., Waterman, R.R., Roy, A., 2012a. A multi-scale framework for multi-phase equilibrium flash. Comput. Chem. Eng. 36, 79-98.

Lucia, A., Bonk, B.M., 2012b. Molecular geometry effects and the Gibbs-Helmholtz Constrained equation of state. Comp. Chem. Eng. 37, 1-14.

Lucia, A., Henley, H., 2013. Thermodynamic consistency of the multi-scale GibbsHelmholtz Constrained equation of state. Chem. Eng. Res. Des. , 91, 1748-1759.

Lucia, A., Yang, F., 2003. Multivariable terrain methods. AIChE J. 49, 2553-2563.

MacDonald, G.J., 1990. The future of methane as an energy resource. Annu. Rev. Energy 15, 53-83. 
Martin, A., 2010. A simplified van der Waals-Platteeuw model of clathrate hydrates with multiple occupancy of cavities. J. Phys. Chem. B 114(29), 9602-9607.

Martin, M. G., Siepmann, J. I. 1998. Transferable potentials for phase equilibria. 1. United-atom description of n-alkanes, J. Phys. Chem. B 102 2569-2577.

Parrish, W.R., Prausnitz, J.M., 1972. Dissociation pressures of gas hydrates formed by gas mixtures. Ind. Eng. Chem. Proc. Des. Dev. 11, 26-35.

Peneloux, A., Rauzy, E., Freze, R., 1982. A consistent correction for Redlich-KwongSoave volumes. Fluid Phase Equil. 8, 7-23.

Peng, D.Y., Robinson, D.B., 1976. A new two-constant equation of state. Ind. Eng. Chem. Fund. 15, 59-64.

Salim, P.H., Trebble, M.A., 1994. Modeling of solid phases in thermodynamic calculations via translation of a cubic equation of state at the triple point. Fluid Phase Equil. 93, 75-99.

Sloan, E.D., Koh, C.A., 2007. Clathrate Hydrates of Natural Gases, $3^{\text {rd }}$ ed. CRC Press.

Smith, J.M., van Ness, H.C., Abbott, M.M., 2004. Chemical Engineering Thermodynamics. 7th Ed., McGraw-Hill, New York.

Soave, G., 1972. Equilibrium constants from a modified Redlich-Kwong equation of state. Chem. Eng. Sci. 27, 1197-1203.

van der Waals, J.H, Platteeuw, J.C., 1959. Clathrate Solutions. Advances in Chemical Physics 2, 1-5.

Voutsas, E.C., Boulougouris, G.C., Economou, I.G., Tassios, D.P., 2000.

Water/hydrocarbon phase equilibria using the thermodynamic perturbation theory. Ind. Eng. Chem. Res. 39, 797-804.

Wagner, W.A., Pruss, A., 2002. The IAPW formulation 1995 for the thermodynamic properties of ordinary water substance for general scientific use. J. Phys. Chem. Ref. Data 31, 387-535.

Yoon, J.H., Chun, M.K., Lee, H., 2002. Generalized model for predicting phase behavior of clathrate hydrate. AIChE J. 48, 1317-1330.

Zhdanov, R., Subbotin, O., Chen, L.-J., Belosludov, V., 2012. Theoretical description of methane hydrate equilibrium in a wide range of temperature and pressure. Int. J. Comp. Mat. Sci. Eng. 1(02), 1250017. 
CHAPTER 3 - Multiphase equilibrium flash with salt precipitation in systems with multiple salts

Published in Chemical Engineering Research and Design, January 2015

Angelo Lucia, Heath Henley and Edward Thomas

Chemical Engineering
University of Rhode Island

Kingston, RI 


\begin{abstract}
A new methodology for determining simultaneous chemical and phase equilibrium of mixtures of light gases and aqueous electrolyte solutions with the potential for multiple salt deposition is proposed. The novel aspects of this new approach include, but are not limited to, (1) a novel tearing algorithm for determining equilibrium ion solubility limits, (2) rigorous proof that the proposed tearing algorithm generates a Cauchy sequence and is therefore guaranteed to converge to the correct equilibrium ion solubility limits, (3) and a unique formulation of the combined chemical and multi-phase equilibrium flash problem that accounts for salt deposition but decouples the chemical and phase equilibrium aspects of the flash.

Examples from real EOR and $\mathrm{CO}_{2}$ sequestration applications are presented. Results clearly show that the proposed numerical approach is reliable, robust, and efficient and can be used to determine salt deposition in multi-phase flash problems. Several geometric illustrations and numerical details are used to elucidate key points of the proposed approach.
\end{abstract}




\subsection{Introduction: Motivation and Background}

Groundwater aquifers and seawater generally contain a number of ions such as $\mathrm{Na}^{+}, \mathrm{K}^{+}, \mathrm{Ca}^{2+}, \mathrm{Mg}^{2+}, \mathrm{Fe}^{2+}, \mathrm{Cl}^{-}, \mathrm{SO}_{4}{ }^{2-}, \mathrm{CO}_{3}{ }^{2-}$, and others. At high enough concentrations, these ions can combine and form salts and precipitate out of solution causing operational difficulties in a wide range of applications. Salt deposited on heat exchange equipment can cause poor heat transfer. A common example of this is scaling on a household water heater from 'hard' water (i.e., water with high levels of calcium, magnesium and carbonate ions). In enhanced oil recovery (EOR) operations, production water containing a wide range of ions is often re-injected into a reservoir in order to avoid the use of municipal water and/or costly water treatment. However, re-use of production water can result in salt deposition, which in turn can plug pores, block injection wells, and/or re-direct or sometimes stop flow through porous media. In $\mathrm{CO}_{2}$ sequestration, deposition of calcium carbonate can be either a blessing or a curse, depending on where deposition occurs. Obviously, it is desirable if deposition in $\mathrm{CO}_{2}$ sequestration occurs far from injection well bores. Salt deposition is also important for reservoir modelers to understand, predict, and quantify so that reservoir simulation results correctly reflect physics. In EOR and $\mathrm{CO}_{2}$ sequestration problems, multiple equilibrium phases often exist within a reservoir due to the presence of light gases and water. Thus, the quantification of salt precipitation when multiple salts can form must be considered in conjunction with multi-component, multi-phase equilibrium flash problem, which is a combined chemical and phase equilibrium problem.

\subsubsection{Organization of This Article}


In this article, a new equation-solving approach to determining simultaneous chemical and phase equilibrium for mixtures of light gases and aqueous electrolyte solutions with the potential for multiple salt deposition is described. Section 3.2 gives a brief summary of the relevant literature. Basic equations and formulations for equilibrium flash, equilibrium ion solubility limits, and the combined chemical and phase equilibrium problem of interest are described in section 3.3. Section 3.4 gives the details of a novel tearing strategy for determining equilibrium ion solubility limits. In particular, cation concentrations used as unknown variables in an inner loop that enforces mass balances for all species while anion concentrations are used as the outer loop variables to converge chemical equilibrium conditions. Section 3.5 presents numerical results for two isothermal, isobaric (TP) flash problems with salt deposition. Concluding remarks are given in section 3.6.

\subsection{Literature Survey}

The open literature on multi-phase flash abounds and dates back many years. Thus citation of all papers is not possible. Some of the more notable methodologies and articles for multiphase flash include the inside-out algorithm (Boston and Britt,1978), tangent plane analysis (Michelsen, 1982a,b), the negative flash (Whitson and Michelsen, 1989), the Mixed Integer Nonlinear Programming (MINLP) approach of McDonald and Floudas (1995), interval Newton-bisection methods (Stadtherr et al.,1995), homotopy-continuation (Sun and Seider, 1995), and the successive quadratic programming approach (Lucia et al., 2000). Notable methods and articles that address single and homogeneous multi-phase chemical reaction equilibrium include linear programming (White et al., 1958), an equation-tearing approach (Sanderson and Chien, 
1973), nonlinear programming (Castillo and Grossmann, 1981), and the work of Smith and Missen (1982).

Elementary information regarding heterogeneous chemical equilibrium, equilibrium solubility products, and common ion effects can be found in many standard textbooks on chemical engineering thermodynamics. The reader is referred to the textbooks by Sandler (1999) and Elliott and Lira (2012), which give basic theory for dilute solutions and/or common ion effects involving only a single common ion. In many practical situations, the problem of potential salt deposition can involve a large number of ions.

Although combined chemical and phase equilibrium is well studied in the chemical engineering literature, there is surprisingly little information in the open literature on equilibrium solubility and salt precipitation in the presence of multi-phase behavior and certainly no description of numerical methods for addressing the unique set of computational challenges that characterize these problems. In addition, there is very little experimental solubility data on compounds like calcium and magnesium carbonate because they are considered sparingly soluble, despite the fact that these salts play an important role in carbon mineralization and as a more permanent means of carbon sequestration.

On the other hand, there are empirical correlations for estimating properties of electrolyte solutions (e.g., Lam et al., 2008). There are also more rigorous approaches for determining the solubility of ions in solution and their associated properties such as the use of (1) Debye-Huckel theory, (2) Pitzer expansions, (3) equation of state models (i.e., variants of the electrolyte Predictive Soave-Redlich-Kwong (ePSRK) by Li et al., 
2001 and Kiepe et al., 2004), (4) variants of the SAFT equation (Behzadi et al., 2005), and (5) various activity coefficient models as studied by Raatikainen and Laaksonen (2005) and Mohs and Gmehling (2012). Moreover, there is a large body of experimental data for highly soluble chloride, nitrate and some sulfate salts; salts like $\mathrm{NaCl}, \mathrm{KCl}$, $\mathrm{Na}_{2} \mathrm{SO}_{4}$, etc. Unfortunately, all of the computational papers cited deal strictly with the determination of solubility. More importantly, none of the cited papers explicitly address the problem of combined chemical and phase equilibrium where multiple fluid phases and multiple solid salts can co-exist nor do they address the associated numerical issues that can arise.

\subsection{Problem Formulations}

The problem of interest in this work can be conveniently divided into two parts - equilibrium flash and salt deposition.

\subsection{Multi-phase Equilibrium Flash}

The approach to the multi-component, multi-phase isothermal, isobaric equilibrium (TP) flash problem used in this work in the absence of chemical equilibrium has been described in detail in the previous work of Lucia et al. (2012a, 2012b, 2013) and is based on finding the global minimum of the dimensionless Gibbs free energy. The necessary conditions for multiphase equilibrium are cast in the form of the equality of dimensionless chemical potential for all components in all phases. That is,

$\mu_{\mathrm{i}}^{1} / \mathrm{RT}=\mu_{\mathrm{i}}^{2} / \mathrm{RT}=\ldots=\mu_{\mathrm{i}}^{\mathrm{np}} / \mathrm{RT}, \quad \mathrm{i}=1, \ldots, \mathrm{n}_{\mathrm{c}}$

where $\mu$ denotes the chemical potential, the superscript $\mathrm{i}$ is a component index, $\mathrm{R}$ is the gas constant, $\mathrm{T}$ is absolute temperature, $\mathrm{n}_{\mathrm{c}}$ is the number of components, and $\mathrm{n}_{\mathrm{p}}$ is the number of fluid phases. Equation 3.1 is solved using a trust region strategy. Because 
light gases are present in the applications of interest, an equation of state approach is needed and thus we use the multi-scale Gibbs-Helmholtz Constrained (GHC) equation of state to determine all fluid properties. Of particular note is the recent proof by Lucia and Henley (2013) that the GHC equation of state satisfies conditions of thermodynamically consistency. We refer the reader to the articles by Lucia et al. (2012), Lucia and Bonk (2012), and Lucia and Henley (2013) for all details.

\subsubsection{Salt Deposition}

Salt deposition is a heterogeneous chemical equilibrium problem and its combination or coupling to multi-phase equilibrium flash has not been addressed to any great extent in the Process Systems Engineering (PSE) literature - particularly for cases where there are potentially a large number of salts that can form.

In general, salt deposition is approached by calculating and comparing equilibrium solubility products, $\mathrm{K}_{\mathrm{sp}}{ }^{\mathrm{j}}$, to actual ion solubility products, $\mathrm{Q}_{\mathrm{sp}}{ }^{\mathrm{j}}$, for all possible salts, $j=1, \ldots, n_{s}$, where $n_{s}$ denotes the number of molecular salts. That is, if the conditions

$\mathrm{Q}_{\mathrm{sp}}{ }^{\mathrm{j}}>\mathrm{K}_{\mathrm{sp}}{ }^{\mathrm{j}}$

then salt $\mathrm{j}$ will precipitate out of solution. Moreover, from equilibrium solubility limits one can readily determine how much of each salt will precipitate. In these applications, equilibrium solubility products are generally computed from standard Gibbs free energies of formation, $\Delta \mathrm{G}_{\mathrm{f}}{ }^{0}$, and adjusted for temperature using either a van't Hoff correction using heats of formation data, $\Delta \mathrm{H}_{\mathrm{f}}{ }^{0}$ and, if necessary, differences in heat capacities, $\Delta \mathrm{C}_{\mathrm{p}}$. The resulting chemical equilibrium formulation leads to a system of nonlinear equations of the form 
$\mathrm{F}(\mathrm{z})=0$

where the component functions can be a mixture of polynomial, linear, and transcendental equations and the unknown variables are ion concentrations.

The wide variety of possible ions and salts in many applications leads to challenges in automating the formulation and solution of salt deposition problems. However, there are two key equation-solving issues that need consideration (1) the basic formulation of the equations and variables and (2) an appropriate reduction strategy, when needed, that leads to a deterministic subset of equations that, when solved, gives a correct solution.

\subsubsection{Basic Chemical Equilibrium Formulations}

There are at least two different ways equations and unknown variables can be defined to determine equilibrium concentrations of ionic species in aqueous solution. For example, the dissociation of an ideal solution of calcium and magnesium carbonate can be written in the form of 2 quadratic equilibrium solubility equations and 1 linear mass balance constraint (from charge neutrality) given by

$$
\begin{aligned}
& \mathrm{F}_{1}(\mathrm{z})=\left[\mathrm{Ca}^{2+}\right]\left[\mathrm{CO}_{3}{ }^{2-}\right]-\mathrm{K}_{\mathrm{sp}}{ }^{1}=0 \\
& \mathrm{~F}_{2}(\mathrm{z})=\left[\mathrm{Mg}^{2+}\right]\left[\mathrm{CO}_{3}{ }^{2-}\right]-\mathrm{K}_{\mathrm{sp}}{ }^{2}=0 \\
& \mathrm{~F}_{3}(\mathrm{z})=\left[\mathrm{Ca}^{2+}\right]+\left[\mathrm{Mg}^{2+}\right]-\left[\mathrm{CO}_{3}{ }^{2-}\right]=0
\end{aligned}
$$

where the unknown variables are the concentrations of ionic species, $\left[\mathrm{c}_{\mathrm{j}}\right], \mathrm{j}=1,2,3$, typically in units of $\mathrm{mol} / \mathrm{kg} \mathrm{H} \mathrm{H}_{2} \mathrm{O}$. That is, $\mathrm{z}_{1}=\left[\mathrm{c}_{1}\right]=\left[\mathrm{Ca}^{2+}\right], \mathrm{z}_{2}=\left[\mathrm{c}_{2}\right]=\left[\mathrm{Mg}^{2+}\right]$, and $\mathrm{z}_{3}=$ $\left[c_{3}\right]=\left[\mathrm{CO}_{3}{ }^{2-}\right]$. For non-ideal solutions, one could replace the ion concentrations in eqs. 3.3 and 3.4 with ion activities. 
The equations governing the dissociation of these carbonate salts, eqs. 3.4 and 3.5, can also be written in the form

$\mathrm{F}_{1}(\mathrm{z})=\ln \left[\mathrm{Ca}^{2+}\right]+\ln \left[\mathrm{CO}_{3}{ }^{2-}\right]-\operatorname{lnK}_{\mathrm{sp}}{ }^{1}=0$

$\mathrm{F}_{2}(\mathrm{z})=\ln \left[\mathrm{Mg}^{2+}\right]+\ln \left[\mathrm{CO}_{3}^{2-}\right]-\ln \mathrm{K}_{\mathrm{sp}}^{2}=0$

$\mathrm{F}_{3}(\mathrm{z})=\ln \left\{\left[\mathrm{Ca}^{2+}\right]+\left[\mathrm{Mg}^{2+}\right]\right\}-\ln \left[\mathrm{CO}_{3}{ }^{2-}\right]=0$

where now the unknown variables are $\mathrm{z}_{\mathrm{j}}=\ln \left[\mathrm{c}_{\mathrm{j}}\right], \mathrm{j}=1,2,3$. This second formulation has 2 linear equations and 1 transcendental equation. Note that irrespective of formulation, the result is a set of nonlinear equations.

\subsubsection{Equation Reduction}

Since the salt deposition problem must consider the formation of all possible salts, the number unknowns, $\mathrm{n}_{\mathrm{C}}+\mathrm{n}_{\mathrm{A}}$, is always less than or equal to the number of possible salts, $n_{C} n_{A}$, when both $n_{C}$ and $n_{A}>1$. Here $n_{C}$ and $n_{A}$ denote the number of distinct cations and anions respectively. To illustrate equation reduction, consider an aqueous solution of $\mathrm{Na}^{+}, \mathrm{Ca}^{2+}, \mathrm{Cl}^{-}$and $\mathrm{SO}_{4}{ }^{2-}$ and their corresponding salts $\mathrm{NaCl}$, $\mathrm{Na}_{2} \mathrm{SO}_{4}, \mathrm{CaCl}_{2}$ and $\mathrm{CaSO}_{4}$. Writing equations similar to Eqs. 3.7 and 3.8 for all four salts and combining them by cation, we arrive at

$$
\begin{aligned}
& 3 \ln \left[\mathrm{Na}^{+}\right]=\ln \mathrm{K}_{\mathrm{sp}}{ }^{1}-\ln \left[\mathrm{Cl}^{-}\right]+\ln \mathrm{K}_{\mathrm{sp}}{ }^{3}-\ln \left[\mathrm{SO}_{4}{ }^{2-}\right] \\
& \ln \left[\mathrm{Ca}^{2+}\right]=\ln \mathrm{K}_{\mathrm{sp}}{ }^{2}-2 \ln \left[\mathrm{Cl}^{-}\right]+\ln \mathrm{K}_{\mathrm{sp}}{ }^{4}-\ln \left[\mathrm{SO}_{4}{ }^{2-}\right]
\end{aligned}
$$

which together with the mass balance constraints

$$
\begin{aligned}
& {\left[\mathrm{Cl}^{-}\right]=\left[\mathrm{Na}^{+}\right]+2\left[\mathrm{Ca}^{2+}\right]} \\
& {\left[\mathrm{SO}_{4}^{2-}\right]=1 / 2\left[\mathrm{Na}^{+}\right]+\left[\mathrm{Ca}^{2+}\right]}
\end{aligned}
$$


gives four equations in four unknowns, $\mathrm{z}_{1}=\ln \left[\mathrm{Na}^{+}\right], \mathrm{z}_{2}=\ln \left[\mathrm{Ca}^{2+}\right], \mathrm{z}_{3}=\ln \left[\mathrm{Cl}^{-}\right]$. and $\mathrm{z}_{4}$ $=\ln \left[\mathrm{SO}_{4}{ }^{2-}\right]$. Reduction strategies that also exploit complete dissociation of some salts are possible.

\subsubsection{Chemical Equilibrium and Equilibrium Solubility Products}

Equilibrium solubility products, $\mathrm{K}_{\mathrm{sp}}$, can be computed directly from Gibbs free energies of formation and related to the reaction equilibrium constant by assuming that the solid salt is a pure phase. For example

$\ln \mathrm{K}_{\mathrm{sp}}^{1}=\left[\Delta \mathrm{G}_{\mathrm{f}}^{0}\left(\mathrm{Ca}^{2+}\right)+\Delta \mathrm{G}_{\mathrm{f}}^{0}\left(\mathrm{CO}_{3}^{2-}\right)-\Delta \mathrm{G}_{\mathrm{f}}^{0}\left(\mathrm{CaCO}_{3}\right)\right] / \mathrm{RT}$

$\ln \mathrm{K}_{\mathrm{sp}}^{2}=\left[\Delta \mathrm{G}_{\mathrm{f}}^{0}\left(\mathrm{Mg}^{2+}\right)+\Delta \mathrm{G}_{\mathrm{f}}^{0}\left(\mathrm{CO}_{3}^{2-}\right)-\Delta \mathrm{G}_{\mathrm{f}}^{0}\left(\mathrm{MgCO}_{3}\right)\right] / \mathrm{RT}$

In general, given the salt dissociation reaction

$\mathrm{C}_{v C} \mathrm{~A}_{v A} \rightarrow v_{C} \mathrm{C}+v_{A} \mathrm{~A}$

where $\mathrm{C}$ and $\mathrm{A}$ denote cation and anion respectively and $v_{C}$ and $v_{A}$ are the associated stoichiometric numbers, the equilibrium solubility product of an ideal solution at standard conditions is given by

$\ln \mathrm{K}_{\mathrm{sp}}^{0}=\left[v_{C} \Delta \mathrm{G}_{\mathrm{f}}^{0}(\mathrm{C})+v_{A} \Delta \mathrm{G}_{\mathrm{f}}^{0}(\mathrm{~A})-\Delta \mathrm{G}_{\mathrm{f}}^{0}\left(\mathrm{C}_{v C} \mathrm{~A}_{v A}\right)\right] / \mathrm{RT}$

Values of $\Delta \mathrm{G}_{\mathrm{f}}{ }^{0}$ for a number of common ions and salts are listed in Table A1 in Appendix A.

\subsubsection{Nonideal Solutions}

When needed, mean ionic activity coefficients are used to account for non-ideal aqueous phase behavior. That is,

$\ln \mathrm{K}_{\mathrm{sp}}=\ln \mathrm{K}_{\mathrm{sp}}^{0}+\left(v_{C}+v_{A}\right) \ln \phi^{ \pm}$

where $\phi^{ \pm}$is the mean fugacity coefficient that represents non-ideal solution behavior

for a composite fluid consisting of all ions dissolved in the solvent. The variable $\phi^{ \pm}$in 
Eq. (3.18) takes the place of $\gamma^{ \pm}$in the usual representation of the product of the ion activities in electrolyte solutions. See Sandler (Eqs. 9.2-5 and 9.2-6, p. 668-669, 1999). The actual value of $\phi^{ \pm}$for any ionic species, $\mathrm{j}$, dissolved in water is determined by the simple ratio $\phi^{ \pm}=\left(\phi_{\mathrm{j}}{ }^{\mathrm{aq}} / \phi_{\mathrm{j}}{ }^{\mathrm{w}}\right)$, where $\phi_{\mathrm{j}}{ }^{\mathrm{aq}}$ and $\phi_{\mathrm{j}}{ }^{\mathrm{w}}$ represent the fugacity coefficient of $\mathrm{j}^{\text {th }}$ ion in an aqueous solution at the given concentration and the fugacity coefficient of the $\mathrm{j}^{\text {th }}$ ion in an aqueous phase at infinite dilution respectively and the same temperature and pressure. The value of $\ln \phi^{ \pm}$starts at an upper bound of 0 at infinite dilution and becomes more positive as the molality of the aqueous electrolyte solution increases.

In this work, we use the GHC equation to determine fugacity coefficients. However, the electrolyte Predictive SRK (ePSRK) equation of Kiepe et al. (2004), the Cubic Plus Association (CPA) equation of Kontogeorgis et al. (1996), or variants of the SAFT equation suitable for electrolyte solution (e.g., Behzadi et al., 2005) could alternatively be used to compute fugacity coefficients. Thus, the methodology presented here is not dependent on the EOS model.

\subsubsection{Temperature Effects}

When $\mathrm{T}$ is not too far from $\mathrm{T}_{0}=298.15 \mathrm{~K}$ and the heat of formation is constant, temperature effects can be included using heat of formation data, $\Delta \mathrm{H}_{\mathrm{f}}{ }^{0}$, and the van't Hoff equation

$\ln \mathrm{K}_{\mathrm{sp}}{ }^{\mathrm{T}}=\ln \mathrm{K}_{\mathrm{sp}}-\left(\Delta \mathrm{H}_{\mathrm{f}}{ }^{0} / \mathrm{R}\right)\left[1 / \mathrm{T}-1 / \mathrm{T}_{0}\right]$

A more rigorous approach requires the calculation of the heat of reaction as a function of temperature using heat capacity data and the integrals

$\Delta \mathrm{H}_{\mathrm{f}}=\int\left[\Delta \mathrm{H}_{\mathrm{f}}^{0}+\Delta \mathrm{C}_{\mathrm{p}}\right] \mathrm{dT}$

and 
$\ln \mathrm{K}_{\mathrm{sp}}{ }^{\mathrm{T}}=\ln \mathrm{K}_{\mathrm{sp}}+\int\left[\Delta \mathrm{H}_{\mathrm{f}} /\left(\mathrm{RT}^{2}\right)\right] \mathrm{dT}$

where $\Delta \mathrm{C}_{\mathrm{p}}=v_{C} \mathrm{C}_{\mathrm{p}}(\mathrm{C})+v_{A} \mathrm{C}_{\mathrm{p}}(\mathrm{A})-\mathrm{C}_{\mathrm{p}}\left(\mathrm{C}_{v C} \mathrm{~A}_{v A}\right)$. Values of $\Delta \mathrm{H}_{\mathrm{f}}^{0}$ used in this work are given in Table A1 in Appendix A.

\subsubsection{Combined Chemical and Phase Equilibrium}

When light gases are present and there is the possibility of ions in aqueous solution precipitating as molecular salts, the problem becomes a simultaneous chemical and phase equilibrium problem with interesting features. Of particular interest are the facts that

1) Light gases make it necessary to use an equation of state.

2) Ions and molecular salts are generally considered non-volatile so they do not exist in the vapor phase.

3) Molecular salts exist as solids and are not present in any fluid phase while ions are restricted to the aqueous liquid phase.

These problem characteristics make it difficult to write the necessary conditions for equilibrium as a simple set of equations defining the equality of chemical potentials of each species in all phases, as in eq. 3.1. Rather, it is considerably easier to decouple the chemical equilibrium conditions from the multi-phase equilibrium equations and solve each separately so that all conditions defining equilibrium are satisfied.

Our proposed algorithm for solving problems with multi-phase equilibrium and salt precipitation can be broken into three main steps:

1) Solve the multi-phase TP flash problem for a feed containing aqueous electrolytes. This can result in a number of different outcomes. 
a) If the flash solution has no aqueous liquid, then 'dry out' has occurred, all salts will precipitate, and the problem is solved.

b) If, however, the phase equilibrium solution has an aqueous liquid present that liquid can be either under-saturated, saturated or supersaturated depending on the amount of total aqueous liquid in the flash solution and the given ion concentrations. In this case the calculations must move to step 2.

2) Determine both equilibrium and ion solubility products for all possible salts as well as equilibrium solubility limits. Here again several results are possible.

a) Using eq. 3.2, if no precipitation is indicated, then the solution is undersaturated or saturated and the calculations finish.

b) If, on the other hand, precipitation of one or more molecular salts is indicated, then the amount of each salt that will precipitate must be calculated and the computations must move to step 3.

3) Re-solve the TP flash problem for a new flash solution. Because precipitation has occurred, the multi-phase TP flash results from step 1 will generally no longer satisfy equality of chemical potentials for the fluid phases. Therefore, a new feed must be calculated from the initial feed and the amounts of salt precipitates. The multi-phase TP flash is re-solved to high accuracy $\left(\|.\| \leq 10^{-10}\right)$ to ensure closure of the solution.

\subsection{A Tearing Strategy for Finding Equilibrium Solubility Limits for Multiple}

\section{Salts}

In this section, a novel tearing algorithm for determining the equilibrium solubility limits is presented. Remember, equilibrium solubility limits and equilibrium 
solubility products are needed in steps 2 and 3 of the overall algorithm for systems that involve multiple salts. This algorithm is preferred over Newton's method because it can be proved to be globally convergent under very mild conditions as shown in Appendices $\mathrm{B}$ and $\mathrm{C}$.

\subsubsection{General Equation Formulation}

The general formulation of equations used to define the equilibrium solubility limit problem is as follows.

1) Given $n_{C}$ distinct cations and $n_{A}$ distinct anions, write all possible chemical reactions in the form

$$
\left[\mathrm{C}_{\mathrm{i}}\right] v_{(i, j)}\left[\mathrm{A}_{\mathrm{j}}\right] v_{(i, n c+j)} \rightarrow v_{i, j} \mathrm{C}_{\mathrm{i}}+v i_{, n C+j} \mathrm{~A}_{\mathrm{j}}, \quad \mathrm{i}=1, \ldots, \mathrm{n}_{\mathrm{C}} ; \mathrm{j}=, \ldots, \mathrm{n}_{\mathrm{A}}
$$

where $\mathrm{C}_{\mathrm{i}}$ denotes $\mathrm{i}^{\text {th }}$ cation, $\mathrm{A}_{\mathrm{j}}$ denotes the $\mathrm{j}^{\text {th }}$ anion, and $v_{i, j}$ and $v_{i, n c+j}$ are the stoichiometric coefficients for the dissociation of the $\mathrm{k}^{\text {th }}$ salt, where $\mathrm{k}=(\mathrm{i}-1)^{*} \mathrm{n}_{\mathrm{A}}+\mathrm{j}$. The total number of possible molecular salts is $\mathrm{n}_{\mathrm{s}}=\mathrm{n}_{\mathrm{C}} \mathrm{n}_{\mathrm{A}}$.

2) Construct all equations defining the equilibrium solubility products for all chemical reactions. This gives

$$
\operatorname{lnK}_{\mathrm{sp}}{ }^{\mathrm{k}}=\left[v_{i, j} \Delta \mathrm{G}_{\mathrm{f}}^{0}\left(\mathrm{C}_{\mathrm{i}}\right)+v_{i, n c+j} \Delta \mathrm{G}_{\mathrm{f}}^{0}\left(\mathrm{~A}_{\mathrm{j}}\right)-\Delta \mathrm{G}_{\mathrm{f}}^{0}\left(\mathrm{C}_{v(i, j)} \mathrm{A}_{v(i, n c+j)}\right)\right] / \mathrm{RT}
$$

where $\mathrm{i}=1, \ldots, \mathrm{n}_{\mathrm{C}}, \mathrm{j}=1, \ldots, \mathrm{n}_{\mathrm{A}}$, and $\mathrm{k}=(\mathrm{i}-1) * \mathrm{n}_{\mathrm{A}}+\mathrm{j}$.

3) Adjust all chemical reactions for non-ideal solution behavior and temperature effects.

4) If necessary, reduce the number of equilibrium solubility product equations by summing all equations for the same cation and/or when possible exploiting complete dissociation of some salts.

5) Write all mass balance constraint equations that relate cations to anions for each salt. 


\subsubsection{Algorithmic Considerations}

The steps in Section 3.4.1 lead to a deterministic set of $\left(n_{C}+n_{A}\right)$ equations in $\left(\mathrm{n}_{\mathrm{C}}+\mathrm{n}_{\mathrm{A}}\right)$ unknowns, written in the general form $\mathrm{F}(\mathrm{z})=0$.

\section{A Novel Equation-Solving Algorithm}

Here the steps of a novel tearing algorithm are presented.

1) Input all necessary physical properties data (i.e., $\mathrm{T}, \mathrm{p}, \Delta \mathrm{G}_{\mathrm{f}}{ }^{0}, \Delta \mathrm{H}_{\mathrm{f}}{ }^{0}, \mathrm{C}_{\mathrm{p}}$ ) for all ionic and molecular salt species and set a convergence tolerance $\epsilon$. Typically $\epsilon=10^{-8}$ is used.

2) From a list of cations and anions, determine all possible salts and calculate all equilibrium solubility products, $\mathrm{K}_{\mathrm{sp}}$, using eqs. 3.16-20.

3) Formulate the resulting equations to be solved by performing all five formulation steps presented in section 3.4.1.

4) Partition the unknown variables, $\mathrm{z}=[\mathrm{x}, \mathrm{y}]$, where $\mathrm{x}$ denotes the $\ln \left[\mathrm{c}_{\mathrm{i}}\right], \mathrm{i}=1, \ldots, \mathrm{n}_{\mathrm{C}}$ and $\mathrm{y}=\ln \left[\mathrm{c}_{\mathrm{i}}\right], \mathrm{i}=\mathrm{n}_{\mathrm{C}}+1, . ., \mathrm{n}_{\mathrm{C}}+\mathrm{n}_{\mathrm{A}}$.

5) Set the iteration counter $k=0$ and initialize $\left[A_{j}\right]^{k}, j=1, \ldots, n_{A}$.

6) Rearrange the resulting solubility product equations in the form

$\mathrm{F}_{\mathrm{k}}(\mathrm{z})=\sum v_{k} \ln \left[\mathrm{C}_{\mathrm{i}}\right]=\sum \ln \mathrm{K}_{\mathrm{sp}}{ }^{\mathrm{k}}-\sum v_{n C+k} \ln \left[\mathrm{A}_{\mathrm{j}}\right], \quad \mathrm{k}=1, \ldots, \mathrm{n}_{\mathrm{C}}$

where the summation means summed over all like cations, accounting for complete dissociation. Note that Eq. 23 is a system of $n_{C}$ linear equations in $\ln \left[C_{i}\right], i=1, \ldots, n_{C}$.

7) Solve eq. 3.23 for $\ln \left[\mathrm{C}_{\mathrm{i}}\right]^{\mathrm{k}}, \mathrm{i}=1, \ldots, \mathrm{n}_{\mathrm{C}}$.

8) Compute $\left[\mathrm{C}_{\mathrm{i}}\right]^{\mathrm{k}}=\exp \left\{\ln \left[\mathrm{C}_{\mathrm{i}}\right]^{\mathrm{k}}\right\}$.

9) Set $\left[A_{j}\right]^{k}=1 / 2\left[A_{j}\right]^{k}, j=1, \ldots, n_{A}$. 
10) Solve all $n_{A}$ linear mass balance constraints for new values of anion concentrations, $\left[A_{j}\right]^{k+1}$, for $j=1, \ldots, n_{A}$.

11) If $\left\|\left[A_{j}\right]^{k+1}-\left[A_{j}\right]^{k}\right\|<\epsilon$, then stop. Else set $\left[A_{j}\right]^{k}=\left[A_{j}\right]^{k+1}, k=k+1$, and go to step 6 .

\section{Attributes of the Proposed Algorithm}

The advantages of the proposed tearing algorithm are four-fold. Specifically, the proposed algorithm

1) Only requires the solution of linear subsets of equations in steps 7 and 10 .

2) Is globally convergent for very large domains of attraction. See Appendices B and C.

3) Has a domain of attraction that can be quantified.

4) Has an asymptotic rate of convergence that is fast linear. That is, $\left\|z^{k+1}-z^{*}\right\|<c \| z^{k}$ $\mathrm{z}^{*} \|$, where $\mathrm{c} \rightarrow 0$ as $\mathrm{k} \rightarrow \infty$.

These facts are important because they show theoretically that it is straightforward to choose a starting point that is guaranteed to converge and converge quickly.

\subsubsection{Convergence Results}

Convergence results for the tearing algorithm depend on the salt reaction(s) and the initial values chosen for the anion concentrations. General results are not possible in the strictest sense. Appendices B presents convergence results for the proposed tearing algorithm for some simple cases. A number of illustrations supporting the convergence results in Appendix B are given in Appendix C.

\subsection{Numerical Examples}

In this section, two examples are presented that use the proposed numerical strategies given in sections 3.3 .3 and 3.4 .2 to solve multi-phase equilibrium flash 
problems in which the deposition of one or more salts is possible. The equation of state that is used in these computations is the multi-scale GHC equation of Lucia and coworkers. Table 3.1 gives a list of the conditions for the two example problems studied in this work.

Table 3.1: Example Problems Studied in This Work

\begin{tabular}{|c|c|}
\hline Example & Description \\
\hline 1 & $\mathrm{CO}_{2}, \mathrm{Ca}^{2+}, \mathrm{Mg}^{2+}, \mathrm{CO}_{3}{ }^{2-}, \mathrm{H}_{2} \mathrm{O}$ at $40^{\circ} \mathrm{C}$ and 10 bar \\
\hline 2 & $\mathrm{H}_{2}, \mathrm{O}_{2}, \mathrm{CO}, \mathrm{CH}_{4}, \mathrm{CO}_{2}, \mathrm{Na}^{+}, \mathrm{K}^{+}, \mathrm{Ca}^{2+}, \mathrm{Cl}_{-}, \mathrm{SO}_{4}{ }^{2-}, \mathrm{H}_{2} \mathrm{O}$ \\
& at $255^{\circ} \mathrm{C}$ and 18 bar \\
\hline
\end{tabular}

Example 1 is a simple model $\mathrm{CO}_{2}$ sequestration problem while Example 2 represents actual problems from a real enhanced oil recovery process in which production water is re-injected to cool an in situ burner and generate steam.

\subsubsection{Example 1}

This first example is a problem in understanding phase behavior in $\mathrm{CO}_{2}$ sequestration. Therefore, consider a mixture of $8 \mathrm{~mol} \% \mathrm{CO}_{2}, 0.03 \mathrm{~mol} \% \mathrm{Ca}^{2+}, 0.03$ $\mathrm{mol} \% \mathrm{Mg}^{2+}, 0.06 \mathrm{~mol} \% \mathrm{CO}_{3}{ }^{2-}$, and $91.88 \mathrm{~mol} \%$ water at $313.15 \mathrm{~K}$ and $10 \mathrm{bar}$. The corresponding molalities of the calcium, magnesium, and carbonate ions are 0.0181, 0.0181 , and $0.0362 \mathrm{~m}$ respectively. These molalities are very representative of ion concentrations in many reservoirs in Alberta, Canada. Because of the presence of $\mathrm{CO}_{2}$ at relatively low pressure, there will be vapor-liquid behavior and the levels of various ions in the feed suggest that calcium and/or magnesium salts may precipitate. Using the algorithmic strategy outlined in sections 3.3.3, 3.4.1 and 3.4.2, a phase equilibrium flash problem is solved first. Table 3.2 gives the results of this first flash.

Table 3.2: First Flash Solution for Example 1

\begin{tabular}{|c|c|c|}
\hline Quantity & Liquid & Vapor \\
\hline Mole fraction & & \\
\hline $\mathrm{CO}_{2}$ & 0.000436 & 0.999485 \\
\hline $\mathrm{H}_{2} \mathrm{O}$ & 0.998260 & 0.000515 \\
\hline
\end{tabular}




\begin{tabular}{|c|c|c|}
\hline $\mathrm{Ca}^{2+}$ & 0.000326 & 0 \\
\hline $\mathrm{Mg}^{2+}$ & 0.000326 & 0 \\
\hline $\mathrm{CO}_{3}^{2-}$ & 0.000652 & 0 \\
\hline Phase fraction & 0.920360 & 0.079640 \\
\hline Density $\left(\mathrm{kg} / \mathrm{m}^{3}\right)$ & 996.177 & 17.696 \\
\hline & \multicolumn{2}{|c|}{-4.728263} \\
\hline G/RT for VLE & \multicolumn{2}{|c|}{} \\
\hline
\end{tabular}

The next step of the overall algorithm is to determine equilibrium solubility limits, molalities, equilibrium solubility products $\left(\mathrm{K}_{\mathrm{sp}}\right)$, and ion solubility products $\left(\mathrm{Q}_{\mathrm{sp}}\right)$ using the proposed tearing algorithm and to determine which, if any, molecular salts precipitate.

Table 3.3: Iterative Values of All Ions Using the Proposed Tearing Algorithm

\begin{tabular}{|c|c|c|c|}
\hline Iteration & {$\left[\mathbf{C a}^{2+}\right]$} & {$\left[\mathbf{M g}^{\mathbf{2}}\right]$} & {$\left[\mathbf{C O}_{3}{ }^{2-}\right]$} \\
\hline 1 & $1.81253 \times 10^{-2}$ & $1.81253 \times 10^{-2}$ & $3.62506 \times 10^{-2}$ \\
\hline 2 & $8.46942 \times 10^{-8}$ & $1.32239 \times 10^{-4}$ & $1.81915 \times 10^{-2}$ \\
\hline 3 & $1.68772 \times 10^{-7}$ & $2.63516 \times 10^{-4}$ & $9.22758 \times 10^{-3}$ \\
\hline 4 & $3.32722 \times 10^{-7}$ & $5.19501 \times 10^{-4}$ & $4.87370 \times 10^{-3}$ \\
\hline 5 & $6.29956 \times 10^{-7}$ & $9.83591 \times 10^{-4}$ & $2.92896 \times 10^{-3}$ \\
\hline 6 & $1.04823 \times 10^{-6}$ & $1.63667 \times 10^{-3}$ & $2.28334 \times 10^{-3}$ \\
\hline 7 & $1.34462 \times 10^{-6}$ & $2.09944 \times 10^{-3}$ & $2.19206 \times 10^{-3}$ \\
\hline 8 & $1.40061 \times 10^{-6}$ & $2.18686 \times 10^{-3}$ & $2.19016 \times 10^{-3}$ \\
\hline 9 & $1.40182 \times 10^{-6}$ & $2.18876 \times 10^{-3}$ & $2.19016 \times 10^{-3}$ \\
\hline
\end{tabular}

Table 3.3 gives iterative results for the determination of the solubility limits for all ions using the tearing strategy proposed in sections 3.4.1 and 3.4.2, which are converged to an accuracy of $4.023 \times 10^{-11}$. Note that the outer loop iterate, $\mathrm{y}=\left[\mathrm{CO}_{3}{ }^{2-}\right]$, in Table 3.3 satisfies the conditions $\mathrm{y} \geq \sqrt{ }\left(\mathrm{K}_{\mathrm{sp}}{ }^{1}+\mathrm{K}_{\mathrm{sp}}{ }^{2}\right)=2.19016 \times 10^{-3} \mathrm{~mol} / \mathrm{kg} \mathrm{H} \mathrm{H}_{2} \mathrm{O}$ as predicted by the convergence theory in Appendix B. Values of the equilibrium solubility limits and ion molalities, as well as $\mathrm{K}_{\mathrm{sp}}$ and $\mathrm{Q}_{\mathrm{sp}}$ for both calcium carbonate and magnesium carbonate are given in Table 3.4.

Table 3.4: Equilibrium and Ion Solubility Products and Solubility Limits for Example 1

\begin{tabular}{|c|c|c|}
\hline Ion & Solubility Limit (mol//kg H2O) & Molality (mol/kg H2O) \\
\hline $\mathrm{Ca}^{2+}$ & $1.40182 \times 10^{-6}$ & $1.8125 \times 10^{-2}$ \\
\hline $\mathrm{Mg}^{2+}$ & $2.18876 \times 10^{-3}$ & $1.8125 \times 10^{-2}$ \\
\hline
\end{tabular}




\begin{tabular}{|c|c|c|}
\hline $\mathrm{CO}_{3}^{2-}$ & $2.19016 \times 10^{-3}$ & $3.6251 \times 10^{-2}$ \\
\hline $\mathbf{S a l t}$ & $\mathbf{K}$ sp & $\mathbf{Q}$ sp \\
\hline $\mathrm{CaCO}_{3}$ & $3.0702 \times 10^{-9}$ & $6.5705 \times 10^{-4}$ \\
\hline $\mathrm{MgCO}_{3}$ & $4.7937 \times 10^{-6}$ & $6.5705 \times 10^{-4}$ \\
\hline
\end{tabular}

From Table 3.4 it is straightforward to see that both calcium and magnesium carbonate will precipitate. Moreover, simple mass balance considerations show that the amounts of $\mathrm{CaCO}_{3}$ and $\mathrm{MgCO}_{3}$ that will precipitate are $2.99977 \times 10^{-4}$ and $2.63773 \times 10^{-4}$ moles/mole of feed. Finally, note that the results in Table 3.4 clearly show that the first VLE solution shown in Table 3.2 is supersaturated. The final step of the overall algorithm is to resolve the flash problem following salt precipitation and combine the results of the re-solved flash with the salt precipitation results. Table 3.5 gives the final numerical solution for this multi-phase flash/salt precipitation problem.

Table 3.5: Second and Global Flash Solution for Example 1

\begin{tabular}{|c|c|c|c|c|}
\hline Quantity & Liquid & Vapor & Solid $\mathrm{CaCO}_{3}$ & Solid $\mathrm{MgCO}_{3}$ \\
\hline \multicolumn{5}{|l|}{ Mole fraction } \\
\hline $\mathrm{CO}_{2}$ & 0.000436 & 0.999485 & 0 & 0 \\
\hline $\mathrm{H}_{2} \mathrm{O}$ & 0.999485 & 0.000515 & 0 & 0 \\
\hline $\mathrm{Ca}^{2+}$ & $2.522535 \times 10^{-8}$ & 0 & 0 & 0 \\
\hline $\mathrm{Mg}^{2+}$ & $3.938601 \times 10^{-5}$ & 0 & 0 & 0 \\
\hline $\mathrm{CO}_{3}^{2-}$ & $3.941124 \times 10^{-5}$ & 0 & 0 & 0 \\
\hline $\mathrm{CaCO}_{3}$ & 0 & 0 & 1 & 0 \\
\hline $\mathrm{MgCO}_{3}$ & 0 & 0 & 0 & 1 \\
\hline Phase fraction & 0.919797 & 0.079640 & $2.99977 \times 10^{-4}$ & $2.63773 \times 10^{-4}$ \\
\hline Density $\left(\mathrm{kg} / \mathrm{m}^{3}\right)$ & 994.262 & 17.696 & 2711.341 & 2958.181 \\
\hline G/RT VLE + salts & & & & \\
\hline
\end{tabular}

Note the following:

1) The dimensionless Gibbs free energy for the VLE + salts solution in Table 3.5 is 4.960854 and is lower than that for the supersaturated VLE flash solution shown in Table 3.2. 
2) All ion molalities in the VLE + salt flash solution correspond to saturated values of molality.

3) For slightly soluble salts like $\mathrm{CaCO}_{3}$ and $\mathrm{MgCO}_{3}$, there is very little change in the amount of vapor because there is essentially no boiling point elevation due to the presence of these salts. However, this is not the case for highly soluble salts as illustrated in the next example.

\section{Example 2}

The second example in this article is taken from a real EOR process for a reservoir located in Saskatchewan, Canada. The EOR process is $\mathrm{CO}_{2}$ plus steam injection, where the steam is generated from production water and the objective of this example is to determine if salts will precipitate in the well bore or near wellbore region. Table 3.6 gives the feed condition for this second example, which is taken from an actual analysis of production water from the reservoir.

Table 3.6: Feed Conditions for Example 2 at $255^{\circ} \mathrm{C}$ and 18 bar

\begin{tabular}{|c|c|}
\hline Species & Mole Fraction \\
\hline $\mathrm{CO}_{2}$ & 0.064966 \\
\hline $\mathrm{H}_{2} \mathrm{O}$ & 0.89793632 \\
\hline $\mathrm{Na}^{+}$ & 0.017692 \\
\hline $\mathrm{K}^{+}$ & 0.000122 \\
\hline $\mathrm{Ca}^{2+}$ & 0.000474 \\
\hline $\mathrm{Cl}^{-}$ & 0.018762 \\
\hline $\mathrm{SO}_{4}{ }^{2-}$ & $3.68 \times 10^{-7}$ \\
\hline
\end{tabular}

Note that the molalities of the dominant ions, $\mathrm{Na}^{+}$and $\mathrm{Cl}^{-}$, are 1.09 and $1.16 \mathrm{~m}$ respectively and the electro-neutrality of the aqueous mixture is $-7.36 \times 10^{-7}$, which is very close to zero. Moreover, because of the relatively higher molalities of $\mathrm{Na}^{+}$and $\mathrm{Cl}^{-}$ ions in the production water, it is not unreasonable to anticipate the precipitation of 
$\mathrm{NaCl}$. Table 3.7 gives results for the computation of the first VLE flash solution for this problem.

Table 3.7: Numerical Results for First Flash Solution for Example 2

\begin{tabular}{|c|c|c|}
\hline Quantity & Liquid & Vapor \\
\hline Mole fraction & & 0.131613 \\
\hline $\mathrm{CO}_{2}$ & 0.000144 & 0.868387 \\
\hline $\mathrm{H}_{2} \mathrm{O}$ & 0.926770 & 0 \\
\hline $\mathrm{Na}^{+}$ & 0.034900 & 0 \\
\hline $\mathrm{K}^{+}$ & 0.000241 & 0 \\
\hline $\mathrm{Ca}^{2+}$ & 0.000935 & 0 \\
\hline $\mathrm{Cl}^{-}$ & 0.037010 & 0.493059 \\
\hline $\mathrm{SO}_{4}^{2-}$ & $7.259 \times 10^{-7}$ & 9.183 \\
\hline Phase fraction & 0.506941 & \\
\hline Density $\left(\mathrm{kg} / \mathrm{m}^{3}\right)$ & 837.551 & \\
\hline \multicolumn{2}{|c|}{2.582986} \\
\hline G/RT for VLE & & \\
\hline
\end{tabular}

Note that the molalities of $\mathrm{Na}^{+}$and $\mathrm{Cl}^{-}$ions at this first flash solution are 2.0903 and $2.2167 \mathrm{~m}$ respectively and that they have essentially doubled compared to their molalities in the feed because roughly $50 \mathrm{~mol} \%$ of the feed has vaporized.

Equilibrium ion solubility limits and the actual solubility of all ions as well as values of $\mathrm{K}_{\mathrm{sp}}$ and $\mathrm{Q}_{\mathrm{sp}}$ for all six molecular salts are shown in Table 3.8. From Table 3.8, one can easily see that the equilibrium solubility product computations predict that $\mathrm{NaCl}$ will precipitate at the given conditions of temperature and pressure. Again, this is because approximately half of the aqueous liquid has been vaporized, leaving the remaining aqueous liquid incapable of accommodating all of the ions. The actual amount of $\mathrm{NaCl}$ that precipitates is $7.2830 \times 10^{-3}$ moles $/$ mole of feed. The equilibrium ion solubility limits shown in Table 3.8 converged to an accuracy of $5.575 \times 10^{-9}$ in 29 iterations. Table D1 in Appendix D gives the iterative values of all ions.

Table 3.8: Equilibrium and Ion Solubility Products and Solubility Limits for Example 2

\begin{tabular}{|c|c|c|}
\hline Ion & Solubility Limit (mol/kg H2O) & Molality (mol/kg Ho $\mathbf{~} \mathbf{~})$ \\
\hline $\mathrm{Na}^{+}$ & 1.2298 & 2.0903 \\
\hline $\mathrm{K}^{+}$ & 1.9928 & 0.014414 \\
\hline
\end{tabular}




\begin{tabular}{|c|c|c|}
\hline $\mathrm{Ca}^{2+}$ & 0.15787 & 0.056003 \\
\hline $\mathrm{Cl}^{-}$ & 3.5384 & 2.2167 \\
\hline $\mathrm{SO}_{4}{ }^{2-}$ & 1.7692 & 0.0000433 \\
\hline & & $\mathbf{Q}$ \\
\hline $\mathbf{S a l t}$ & $\mathbf{K}$ sp \\
\hline $\mathrm{NaCl}$ & 4.3516 & 4.6337 \\
\hline $\mathrm{KCl}$ & 7.0513 & 0.031953 \\
\hline $\mathrm{CaCl}_{2}$ & 1.9765 & 0.27520 \\
\hline $\mathrm{Na}_{2} \mathrm{SO}_{4}$ & 2.6759 & 0.000190 \\
\hline $\mathrm{K}_{2} \mathrm{SO}_{4}$ & 7.0259 & $9.0339 \times 10^{-9}$ \\
\hline $\mathrm{CaSO}_{4}$ & 0.27929 & $2.4350 \times 10^{-6}$ \\
\hline
\end{tabular}

The next step in the overall algorithm is to re-solve the VLE flash to determine the correct fluid phase equilibrium following precipitation. These results are shown in Table 3.9.

Table 3.9: Numerical Results for Second Flash Solution for Example 2

\begin{tabular}{|c|c|c|}
\hline Quantity & Liquid & Vapor \\
\hline Mole fraction & & \\
\hline $\mathrm{CO}_{2}$ & 0.000116 & 0.094998 \\
\hline $\mathrm{H}_{2} \mathrm{O}$ & 0.929367 & 0.905002 \\
\hline $\mathrm{Na}^{+}$ & 0.032645 & 0 \\
\hline $\mathrm{K}^{+}$ & 0.000383 & 0 \\
\hline $\mathrm{Ca}^{2+}$ & 0.001487 & 0 \\
\hline $\mathrm{Cl}^{-}$ & 0.036001 & 0 \\
\hline $\mathrm{SO}_{4}^{2-}$ & $1.1541 \times 10^{-6}$ & 0 \\
\hline Phase fraction & 0.316529 & 0.683471 \\
\hline Density $\left(\mathrm{kg} / \mathrm{m}^{3}\right)$ & 820.880 & 8.775 \\
\hline
\end{tabular}

The important point to note about the second flash solution is that the amount of aqueous liquid has changed significantly, dropping from a phase fraction of 0.506941 to 0.316529 , where now the molalities of $\mathrm{Na}^{+}$and $\mathrm{Cl}^{-}$are 1.9652 and $2.16727 \mathrm{~m}$ respectively. However, in our opinion, this makes perfect physical sense because the precipitation of $\mathrm{NaCl}$ has lowered the boiling point of the overall remaining fluid. This means that one must re-compute all ion solubility products, $\mathrm{Q}_{\mathrm{sp}}$, and compare them to their respective equilibrium solubility products, $\mathrm{K}_{\mathrm{sp}}$, to ensure no additional salt will precipitate. If we do this, we see that no additional precipitation is indicated and, in 
particular, the value of $\mathrm{Q}_{\mathrm{sp}}$ for $\mathrm{NaCl}$ is 4.2592 , which is just slightly less than the value of 4.3516 for $\mathrm{K}_{\mathrm{sp}}$ for $\mathrm{NaCl}$ shown in Table 8. That the values of $\mathrm{K}_{\mathrm{sp}}$ and $\mathrm{Q}_{\mathrm{sp}}$ for $\mathrm{NaCl}$ are not exactly equal has to do with the rather high sensitivity of molality to the amount of water. Table 3.10 gives the final combined chemical/phase equilibrium flash solution to this problem.

Table 3.10: Global Flash Solution for Example 2

\begin{tabular}{|c|c|c|c|}
\hline Quantity & Liquid & Vapor & Solid NaCl \\
\hline Mole fraction & & & \\
\hline $\mathrm{CO}_{2}$ & 0.000116 & 0.094998 & 0 \\
\hline $\mathrm{H}_{2} \mathrm{O}$ & 0.928849 & 0.905002 & 0 \\
\hline $\mathrm{Na}^{+}$ & 0.032885 & 0 & 0 \\
\hline $\mathrm{K}^{+}$ & 0.000385 & 0 & 0 \\
\hline $\mathrm{Ca}^{2+}$ & 0.001497 & 0 & 0 \\
\hline $\mathrm{Cl}^{-}$ & 0.036265 & 0 & 0 \\
\hline $\mathrm{SO}_{4}^{2-}$ & $1.1626 \times 10^{-6}$ & 0 & 0 \\
\hline $\mathrm{NaCl}$ & 0 & 0 & 1 \\
\hline Phase fraction & 0.314223 & 0.678494 & 0.007283 \\
\hline Density $\left(\mathrm{kg} / \mathrm{m}^{3}\right)$ & 820.880 & 8.775 & 2166.642 \\
\hline & \multicolumn{3}{l}{} \\
\hline G/RT VLE + salt & \multicolumn{3}{l}{} \\
\hline
\end{tabular}

Finally, note that the VLE + salt solution has a lower dimensionless Gibbs free energy than the supersaturated VLE flash solution shown in Table 3.7, as it should, and that it is lower by approximately the dimensionless Gibbs free energy of formation for $\mathrm{NaCl}$.

\subsection{Conclusions}

Combined chemical and phase equilibrium of mixtures involving light gases, aqueous electrolytes and the potential for solid salt precipitation were studied. A new tearing algorithm for determining equilibrium ion solubility limits was proposed and shown to generate a Cauchy sequence and therefore to be convergent under very mild conditions. A number of numerical and geometric illustrations of aqueous electrolyte 
solutions were presented that validate the robustness and convergence properties of the proposed tearing algorithm for finding equilibrium ion solubility limits. An overall multi-phase equilibrium flash algorithm that includes salt precipitation was also presented. Perhaps the most unique feature of this overall flash algorithm is that it decouples the chemical and phase equilibrium aspects of the flash problem. Two examples - one from $\mathrm{CO}_{2}$ sequestration and the other from EOR - were presented and used to illustrate the reliability and efficiency of the proposed multi-phase flash algorithm with salt precipitation.

\subsection{Acknowledgement}

This work was supported in part by a grant from the 'Petroleum Institute, Abu Dhabi' under Subaward Agreement No. 60371833-49954-B. 


\begin{tabular}{|c|c|}
\hline \multicolumn{2}{|c|}{ Nomenclature } \\
\hline A & - anion \\
\hline$[\mathrm{A}]$ & - anion concentration \\
\hline $\mathrm{C}$ & - cation \\
\hline$[\mathrm{C}]$ & - cation concentration \\
\hline$\left[\mathrm{c}_{\mathrm{j}}\right]$ & - concentration of the $\mathrm{j}^{\text {th }}$ ion \\
\hline $\mathrm{F}(\mathrm{z})$ & - set of nonlinear equations \\
\hline$\Delta \mathrm{G}_{\mathrm{f}}^{0}$ & - standard Gibbs free energy of formation \\
\hline $\mathrm{G}(\mathrm{y})$ & - fixed point map \\
\hline $\mathrm{G}^{\prime}(\mathrm{y})$ & - Jacobian matrix of fixed point map \\
\hline$\Delta \mathrm{H}_{\mathrm{f}}^{0}$ & - standard enthalpy of formation \\
\hline $\mathrm{K}_{\mathrm{sp}}$ & - equilibrium solubility product \\
\hline $\mathrm{n}_{\mathrm{c}}$ & - number of components \\
\hline $\mathrm{n}_{\mathrm{A}}, \mathrm{n}_{\mathrm{C}}$ & - number of distinct anions, cations \\
\hline $\mathrm{n}_{\mathrm{p}}$ & - number of fluid phases \\
\hline $\mathrm{n}_{\mathrm{s}}$ & - number of molecular salt phases \\
\hline $\mathrm{p}$ & - pressure \\
\hline $\mathrm{Q}_{\mathrm{sp}}$ & - ion solubility product \\
\hline $\mathrm{R}$ & - gas constant \\
\hline $\mathrm{T}, \mathrm{T}_{0}$ & - temperature, reference temperature \\
\hline$v_{A}, v_{C}$ & - stoichiometric numbers for anion, cation \\
\hline $\mathrm{X}$ & - vector of cation concentrations \\
\hline $\mathrm{y}$ & - vector of anion concentrations \\
\hline $\mathrm{z}$ & - vector of unknown variables \\
\hline \multicolumn{2}{|c|}{ Greek Symbols } \\
\hline$\phi, \phi \pm$ & - fugacity coefficient, mean fugacity coefficient \\
\hline$\gamma$ & - activity coefficient \\
\hline$\lambda$ & - eigenvalue \\
\hline$\mu$ & - chemical potential \\
\hline$\rho$ & - spectral radius \\
\hline \multicolumn{2}{|c|}{ Subscripts } \\
\hline 0 & - initial value \\
\hline c & - component \\
\hline A & - anion \\
\hline $\mathrm{C}$ & - cation \\
\hline $\mathrm{f}$ & - formation \\
\hline $\mathrm{i}$ & $-i^{\text {th }}$ component or $i^{\text {th }}$ unknown variable \\
\hline \multicolumn{2}{|c|}{ Superscripts } \\
\hline 0 & - standard state \\
\hline $\mathrm{k}$ & - iteration counter \\
\hline$*$ & - solution or fixed point \\
\hline
\end{tabular}




\section{Appendix A: Values of $\Delta \mathbf{G}_{\mathbf{f}}{ }^{0}$ and $\Delta \mathbf{H}_{\mathbf{f}}{ }^{0}$ for Some Common Ions and Salts}

The values of standard Gibbs free energies and enthalpies of formation (Sandler, 1999)

for the compounds studied in this article are given in Table A1.

Table A1: Values of $\Delta \mathbf{G}_{\mathbf{f}}{ }^{0}$ and $\Delta \mathbf{H}_{\mathrm{f}}{ }^{0}$ for Some Common Ions and Salts

\begin{tabular}{|c|c|c|}
\hline Ion or Salt & $\Delta \mathbf{G}_{\mathbf{f}}^{\mathbf{0}}(\mathbf{k J} / \mathbf{m o l})$ & $\Delta \mathbf{H}_{\mathbf{f}}{ }^{\mathbf{0}}(\mathrm{kJ} / \mathrm{mol})$ \\
\hline $\mathrm{Na}^{+}$ & -261.88 & -239.66 \\
\hline $\mathrm{K}^{+}$ & -282.28 & -251.21 \\
\hline $\mathrm{Ca}^{2+}$ & -553.04 & -542.96 \\
\hline $\mathrm{Mg}^{2+}$ & -456.01 & -461.96 \\
\hline $\mathrm{Cl}^{-}$ & -131.17 & -167.46 \\
\hline $\mathrm{SO}_{4}^{2-}$ & -741.99 & -907.51 \\
\hline $\mathrm{HCO}_{3}^{-}$ & -587.06 & -691.11 \\
\hline $\mathrm{CO}_{3}{ }^{2-}$ & -527.80 & -677.10 \\
\hline $\mathrm{NaCl}$ & -237.1 & -258.8 \\
\hline $\mathrm{KCl}$ & -408.3 & -435.8 \\
\hline $\mathrm{CaCl}_{2}$ & -748.1 & -795.8 \\
\hline $\mathrm{MgCl}_{2}$ & -591.8 & -641.3 \\
\hline $\mathrm{Na}_{2} \mathrm{SO}_{4}$ & -1265.2 & -1382.8 \\
\hline $\mathrm{K}_{2} \mathrm{SO}_{4}$ & -1316.4 & -1433.7 \\
\hline $\mathrm{CaSO}_{4}$ & -1320.3 & -1432.7 \\
\hline $\mathrm{MgSO}_{4}$ & -1173.6 & -1278.2 \\
\hline $\mathrm{Na}_{2} \mathrm{CO}_{3}$ & -1044.4 & -1130.7 \\
\hline $\mathrm{K}_{2} \mathrm{CO}_{3}$ & -1064.4 & -1150.2 \\
\hline $\mathrm{CaCO}_{3}$ & -1128.8 & -1206.9 \\
\hline $\mathrm{MgCO}_{3}$ & -1012.1 & -1095.8 \\
\hline
\end{tabular}




\section{Appendix B: Proof That $G(y)$ is a Contraction Mapping}

$\underline{\text { Salts with a Single Anion }}$

Consider the case of the dissociation of $\mathrm{NaCl}$ in water at $298.15 \mathrm{~K}$, described by the reaction $\mathrm{NaCl} \rightarrow \mathrm{Na}^{+}+\mathrm{Cl}^{-}$. From a partition the two unknowns $\mathrm{z}=\left\{\left[\mathrm{Na}^{+}\right],\left[\mathrm{Cl}^{-}\right]\right\}$into $\mathrm{x}=\left[\mathrm{Na}^{+}\right]$and $\mathrm{y}=\left[\mathrm{Cl}^{-}\right]$, we have the following iteration

$\mathrm{x}_{\mathrm{k}}=\mathrm{K}_{\mathrm{sp}} / \mathrm{y}_{\mathrm{k}}$

and

$\mathrm{y}_{\mathrm{k}+1}=1 / 2 \mathrm{y}_{\mathrm{k}}+1 / 2 \mathrm{x}_{\mathrm{k}}=1 / 2 \mathrm{y}_{\mathrm{k}}+1 / 2 \mathrm{~K}_{\mathrm{sp}} / \mathrm{y}_{\mathrm{k}}$

Equations B1and B2 follow easily from the definition of $\mathrm{K}_{\mathrm{sp}}$ and the iteration defined in the algorithm in section 4.2. Simple algebra gives the fixed-point iteration

$\mathrm{G}\left(\mathrm{y}_{\mathrm{k}}\right)=\mathrm{y}_{\mathrm{k}+1}=\left[\mathrm{y}_{\mathrm{k}}^{2}+\mathrm{K}_{\mathrm{sp}}\right] /\left(2 \mathrm{y}_{\mathrm{k}}\right)$

To prove convergence, we use the contraction mapping theorem given in Ortega and Rheinboldt ( $p, 120,1970$ ) which states that if $\mathrm{G}(\mathrm{y}): \mathrm{D} \subset \mathrm{R}^{\mathrm{n}} \rightarrow \mathrm{R}^{\mathrm{n}}$ is contractive on a closed set $\mathrm{D}_{0} \subset \mathrm{D}$, then $\mathrm{G}(\mathrm{y})$ converges to a unique fixed point in $\mathrm{D}_{0}$.

Theorem. Let the map $\mathrm{G}(\mathrm{y})$ be a continuous mapping defined by

$$
\mathrm{G}(\mathrm{y})=1 / 2 \mathrm{y}+1 / 2 \mathrm{x}=1 / 2 \mathrm{y}+1 / 2 \mathrm{~K}_{\mathrm{sp}} / \mathrm{y}=\left[\mathrm{y}^{2}+\mathrm{K}_{\mathrm{sp}}\right] /(2 \mathrm{y})
$$

Define the one-step, fixed point iteration by

$$
\mathrm{y}_{\mathrm{k}+1}=\mathrm{G}\left(\mathrm{y}_{\mathrm{k}}\right)=\left[\mathrm{y}_{\mathrm{k}}^{2}+\mathrm{K}_{\mathrm{sp}}\right] /\left(2 \mathrm{y}_{\mathrm{k}}\right)
$$

and let $\mathrm{D}_{0}=\left\{\mathrm{y}: \mathrm{y} \geq \sqrt{\mathrm{K}_{\mathrm{sp}}}\right\}$. Then for all $\mathrm{y}_{0} \in \mathrm{D}_{0}$, Eq. B5 converges to a unique fixed point, $\mathrm{y}^{*}$.

Proof. Write Eq. B5 for iteration k-1, which gives

$$
\mathrm{y}_{\mathrm{k}}=\mathrm{G}\left(\mathrm{y}_{\mathrm{k}-1}\right)=\left[\mathrm{y}_{\mathrm{k}-1}{ }^{2}+\mathrm{K}_{\mathrm{sp}}\right] /\left(2 \mathrm{y}_{\mathrm{k}-1}\right)
$$


Subtract Eq. B6 from Eq. B5 to get

$$
\left(\mathrm{y}_{\mathrm{k}+1}-\mathrm{y}_{\mathrm{k}}\right)=\left[\mathrm{y}_{\mathrm{k}}^{2}+\mathrm{K}_{\mathrm{sp}}\right] /\left(2 \mathrm{y}_{\mathrm{k}}\right)-\left[\mathrm{y}_{\mathrm{k}-1}{ }^{2}+\mathrm{K}_{\mathrm{sp}}\right] /\left(2 \mathrm{y}_{\mathrm{k}-1}\right)
$$

which is easily arranged into the form

$$
\left(y_{k+1}-y_{k}\right)=1 / 2\left(y_{k}-y_{k-1}\right)+1 / 2\left[K_{s p} /\left(y_{k-1} y_{k}\right)\right]\left(y_{k-1}-y_{k}\right)
$$

where now $\mathrm{K}_{\text {sp }}$ represents a mean value of the solubility product and easily derived using the mean value theorem. Taking the norm of both sides of Eq. B8 and using the triangle inequality gives

$$
\begin{aligned}
& \left\|\left(\mathrm{y}_{\mathrm{k}+1}-\mathrm{y}_{\mathrm{k}}\right)\right\|=\left\|1 / 2\left(\mathrm{y}_{\mathrm{k}}-\mathrm{y}_{\mathrm{k}-1}\right)+1 / 2\left[\mathrm{~K}_{\mathrm{sp}} /\left(\mathrm{y}_{\mathrm{k}-1} \mathrm{y}_{\mathrm{k}}\right)\right]\left(\mathrm{y}_{\mathrm{k}-1}-\mathrm{y}_{\mathrm{k}}\right)\right\| \\
& \quad \leq 1 / 2\left\|\left(\mathrm{y}_{\mathrm{k}}-\mathrm{y}_{\mathrm{k}-1}\right)\right\|+1 / 2\left[\mathrm{~K}_{\mathrm{sp}} /\left(\mathrm{y}_{\mathrm{k}-1} \mathrm{y}_{\mathrm{k}}\right)\right]\left\|\left(\mathrm{y}_{\mathrm{k}-1}-\mathrm{y}_{\mathrm{k}}\right)\right\|=\alpha\left\|\left(\mathrm{y}_{\mathrm{k}}-\mathrm{y}_{\mathrm{k}-1}\right)\right\|
\end{aligned}
$$

where $\alpha=1 / 2\left[1+\mathrm{K}_{\mathrm{sp}} /\left(\mathrm{y}_{\mathrm{k}-1} \mathrm{y}_{\mathrm{k}}\right)\right]$. However, if $\mathrm{y}_{\mathrm{k}} \geq \sqrt{\mathrm{K}}_{\mathrm{sp}}$, then $\alpha<1$. This means that $\mathrm{G}$ is contractive on $\mathrm{D}_{0}$, the sequence, $\left\{\mathrm{y}_{\mathrm{k}}\right\}$, formed by Eq. $\mathrm{B} 6$ lies in $\mathrm{D}_{0}$, is a Cauchy sequence, and converges to a limit point (a solution), $\mathrm{y}^{*}$ in $\mathrm{D}_{0}$.

\section{$\underline{\text { Remarks }}$}

1. One can actually get a tighter bound on $\alpha$ by foregoing the use of the triangle inequality, rearranging Eq. B7 using straightforward algebra, and invoking the condition $\mathrm{y}_{\mathrm{k}} \geq \sqrt{\mathrm{K}_{\text {sp }}}$ to arrive at the condition $\alpha=1 / 2\left[1-\mathrm{K}_{\mathrm{sp}} /\left(\mathrm{y}_{\mathrm{k}-1} \mathrm{y}_{\mathrm{k}}\right)\right]<1 / 2$.

2. Note that all large values of $y_{0}$ are guaranteed converge to $y^{*}$.

3. The results given by Eq. B9 holds for ideal and non-ideal aqueous electrolyte solutions alike since no restrictions have been placed on $\mathrm{K}_{\mathrm{sp}}$. This is a very important fact.

4. The results given by Eq. B9 also hold for any relevant temperature. 
5. The convergence result given by Eq. B9 also holds for the case of any number of cations and a single anion by replacing $\mathrm{K}_{\mathrm{sp}}$ with $\sum \mathrm{K}_{\mathrm{sp}}{ }_{\mathrm{i}}$, where the summation is over all cations.

\section{$\underline{\text { Two Cation, Two Anions }}$}

Consider the situation of an aqueous electrolyte solution of $\left[\mathrm{Na}^{+}\right],\left[\mathrm{Ca}^{2+}\right],\left[\mathrm{Cl}^{-}\right]$, and $\left[\mathrm{SO}_{4}{ }^{2-}\right]$. For this aqueous solution, it is possible to derive the iterative map given by

$$
\begin{aligned}
& \mathrm{G}_{1}\left(\mathrm{y}_{1, \mathrm{k}}\right)=\mathrm{y}_{1, \mathrm{k}+1}=1 / 2 \mathrm{y}_{1, \mathrm{k}}+1 / 2 \mathrm{~K}_{\mathrm{sp}}{ }^{1} / \mathrm{y}_{1, \mathrm{k}}+\mathrm{K}_{\mathrm{sp}}{ }^{3} /\left[\left(\mathrm{y}_{1, \mathrm{k}}\right)^{2}\right] \\
& \mathrm{G}_{2}\left(\mathrm{y}_{2, \mathrm{k}}\right)=\mathrm{y}_{2, \mathrm{k}+1}=1 / 5 \mathrm{y}_{2, \mathrm{k}}+2 / 5\left(\mathrm{~K}_{\mathrm{sp}}{ }^{2} / \mathrm{y}_{2, \mathrm{k}}\right)^{1 / 2}+2 / 5 \mathrm{~K}_{\mathrm{sp}}{ }^{4} / \mathrm{y}_{2, \mathrm{k}}
\end{aligned}
$$

where the corresponding salts are $\mathrm{NaCl}, \mathrm{Na}_{2} \mathrm{SO}_{4}, \mathrm{CaCl}_{2}$, and $\mathrm{CaSO}_{4}$ and the associated equilibrium solubility products are denoted by $\mathrm{K}_{\mathrm{sp}}{ }^{1}, \mathrm{~K}_{\mathrm{sp}}{ }^{2}, \mathrm{~K}_{\mathrm{sp}}{ }^{3}$, and $\mathrm{K}_{\mathrm{sp}}{ }^{4}$ respectively. In this illustration, the unknowns, $\mathrm{z}=\left\{\left[\mathrm{Na}^{+}\right],\left[\mathrm{Ca}^{2+}\right],[\mathrm{Cl}],\left[\mathrm{SO}_{4}{ }^{2-}\right]\right\}$, have been partitioned into $\mathrm{x}=\left\{\mathrm{x}_{1}, \mathrm{x}_{2}\right\}=\left\{\left[\mathrm{Na}^{+}\right],\left[\mathrm{Ca}^{2+}\right]\right\}$ and $\mathrm{y}=\left\{\mathrm{y}_{1}, \mathrm{y}_{2}\right\}=\left\{\left[\mathrm{Cl}^{-}\right],\left[\mathrm{SO}_{4}{ }^{2-}\right]\right\}$ and the iterative map, denoted $\mathrm{G}(\mathrm{y})$, has two components [i.e., $\mathrm{G}(\mathrm{y})=\mathrm{G}\left(\mathrm{y}_{1, k}, \mathrm{y}_{2, k}\right)=\left(\mathrm{G}_{1}\left(\mathrm{y}_{1, k}\right), \mathrm{G}_{2}\left(\mathrm{y}_{2, \mathrm{k}}\right)\right)$ ], as shown in Eqs. B10 and B11.

Using the same algebra as in the previous case of a single cation, we can write the following

$$
\begin{aligned}
& \left(\mathrm{y}_{1, \mathrm{k}+1}-\mathrm{y}_{1, \mathrm{k}}\right)=1 / 2\left[1-\mathrm{K}_{\mathrm{sp}}{ }^{1} /\left(\mathrm{y}_{1, \mathrm{k}-1} \mathrm{y}_{1, \mathrm{k}}\right)\right. \\
& \left.-2 \mathrm{~K}_{\mathrm{sp}}{ }^{3}\left(\mathrm{y}_{1, \mathrm{k}-1}+\mathrm{y}_{1, \mathrm{k}}\right) /\left(\mathrm{y}_{1, \mathrm{k}-1} \mathrm{y}_{1, \mathrm{k}}\right)^{2}\right]\left(\mathrm{y}_{1, \mathrm{k}}-\mathrm{y}_{1, \mathrm{k}-1}\right)
\end{aligned}
$$

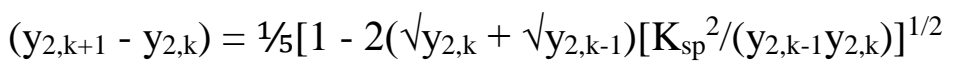

$$
\begin{aligned}
& \left.-2 \mathrm{~K}_{\mathrm{sp}}{ }^{4} /\left(\mathrm{y}_{2, \mathrm{k}-1} \mathrm{y}_{2, \mathrm{k}}\right)\right]\left(\mathrm{y}_{2, \mathrm{k}}-\mathrm{y}_{2, \mathrm{k}-1}\right)
\end{aligned}
$$

where, again, no assumptions on the equilibrium solubility products have been made with regard to ideal or non-ideal solution behavior and all values of $\mathrm{K}_{\mathrm{sp}}$ in Eqs. B12 and B13 represent mean values. 
From Eqs. B12 and B13 and the fact that both $1 / 2$ and $1 / 5<1$, it follows that

$$
\begin{aligned}
& \left\|\left(\mathrm{y}_{1, \mathrm{k}+1}-\mathrm{y}_{1, \mathrm{k}}\right)\right\|<\|\left[1-\mathrm{K}_{\mathrm{sp}}{ }^{1} /\left(\mathrm{y}_{1, \mathrm{k}-1} \mathrm{y}_{1, \mathrm{k}}\right)\right. \\
& \left.-2 \mathrm{~K}_{\mathrm{sp}}{ }^{3}\left(\mathrm{y}_{1, \mathrm{k}-1}+\mathrm{y}_{1, \mathrm{k}}\right) /\left(\mathrm{y}_{1, \mathrm{k}-1} \mathrm{y}_{1, \mathrm{k}}\right)^{2}\right] \mid\left\|\left(\mathrm{y}_{1, \mathrm{k}}-\mathrm{y}_{1, \mathrm{k}-1}\right)\right\| \\
& \left\|\left(\mathrm{y}_{2, \mathrm{k}+1}-\mathrm{y}_{2, \mathrm{k}}\right)\right\|<\|\left[1-2\left({\sqrt{\mathrm{y}_{2, \mathrm{k}}}}+{\sqrt{\mathrm{y}_{2, \mathrm{k}-1}}}\right)\left[\mathrm{K}_{\mathrm{sp}}{ }^{2} /\left(\mathrm{y}_{2, \mathrm{k}-1} \mathrm{y}_{2, \mathrm{k}}\right)\right]^{1 / 2}\right. \\
& \left.\quad-2 \mathrm{~K}_{\mathrm{sp}}{ }^{4} /\left(\mathrm{y}_{2, \mathrm{k}-1} \mathrm{y}_{2, \mathrm{k}}\right)\right] \mid\left\|\left(\mathrm{y}_{2, \mathrm{k}}-\mathrm{y}_{2, \mathrm{k}-1}\right)\right\|
\end{aligned}
$$

Since all $\mathrm{K}_{\mathrm{sp}}>0$ and all $\mathrm{y}>0$, Eqs. B14 and B15 are contractive if the following conditions hold

$$
\begin{aligned}
& \mathrm{K}_{\mathrm{sp}}{ }^{1} /\left(\mathrm{y}_{1, \mathrm{k}-1} \mathrm{y}_{1, \mathrm{k}}\right)+2 \mathrm{~K}_{\mathrm{sp}}{ }^{3}\left(\mathrm{y}_{1, \mathrm{k}-1}+\mathrm{y}_{1, \mathrm{k}}\right) /\left(\mathrm{y}_{1, \mathrm{k}-1} \mathrm{y}_{1, \mathrm{k}}\right)^{2}<1 \\
& \left(ل_{y_{2, k}}+{\sqrt{y_{2, k-1}}}\right)\left[K_{s p}{ }^{2} /\left(\mathrm{y}_{2, k-1} y_{2, k}\right)\right]^{1 / 2}+K_{s p}{ }^{4} /\left(y_{2, k-1} y_{2, k}\right)<1 / 2
\end{aligned}
$$

To go any further, we need to consider different situations. For example, consider the case where $\mathrm{K}_{\mathrm{sp}}{ }^{1}>\mathrm{K}_{\mathrm{sp}}{ }^{3}$ and $\mathrm{K}_{\mathrm{sp}}{ }^{4}>\sqrt{ } \mathrm{K}_{\mathrm{sp}}{ }^{2}$. Thus Eqs. B16 and B17 reduce to

$$
\begin{aligned}
& \mathrm{K}_{\mathrm{sp}}^{1}\left[1+2\left(\mathrm{y}_{1, \mathrm{k}-1}+\mathrm{y}_{1, \mathrm{k}}\right) /\left(\mathrm{y}_{1, \mathrm{k}-1} \mathrm{y}_{1, \mathrm{k}}\right)\right]<\left(\mathrm{y}_{1, \mathrm{k}-\mathrm{1}} \mathrm{y}_{1, \mathrm{k}}\right) \\
& \mathrm{K}_{\mathrm{sp}}{ }^{4}\left[1+\left({\sqrt{\mathrm{y}_{2, \mathrm{k}}}}+{\sqrt{\mathrm{y}_{2, \mathrm{k}-1}}}\right)\left(\mathrm{y}_{2, \mathrm{k}-1} \mathrm{y}_{2, \mathrm{k}}\right)^{1 / 2}\right]<(1 / 2)\left(\mathrm{y}_{2, \mathrm{k}-1} \mathrm{y}_{2, \mathrm{k}}\right)
\end{aligned}
$$

If $\mathrm{y}_{1, \mathrm{k}}>2$, for all $\mathrm{k}$, then $\left(\mathrm{y}_{1, \mathrm{k}-1}+\mathrm{y}_{1, \mathrm{k}}\right) /\left(\mathrm{y}_{1, \mathrm{k}-1} \mathrm{y}_{1, \mathrm{k}}\right)<1$. Similarly, if $\mathrm{y}_{2, \mathrm{k}}>1$ for all $\mathrm{k}$, then it follows that $\left({\sqrt{y_{2, k}}}+\sqrt{y} 2, k-1\right)\left(y_{2, k-1} y_{2, k}\right)^{1 / 2}<2\left(y_{2, k-1} y_{2, k}\right)$. Using these results in Eqs. B18 and $\mathrm{B} 19$ give

$$
\begin{aligned}
& 3 \mathrm{~K}_{\mathrm{sp}}{ }^{1}<\left(\mathrm{y}_{1, \mathrm{k}-1} \mathrm{y}_{1, \mathrm{k}}\right) \\
& \mathrm{K}_{\mathrm{sp}}{ }^{4}<\left(\mathrm{y}_{2, \mathrm{k}-1} \mathrm{y}_{2, \mathrm{k}}\right)
\end{aligned}
$$

Define $\mathrm{D}_{0}=\left\{\left(\mathrm{y}_{1, \mathrm{k}}, \mathrm{y}_{2, \mathrm{k}}\right): \mathrm{y}_{1, \mathrm{k}}>\sqrt{ }\left(3 \mathrm{~K}_{\mathrm{sp}}{ }^{1}\right)\right.$ and $\left.\mathrm{y}_{2, \mathrm{k}}>\sqrt{ }_{\mathrm{sp}_{\mathrm{sp}}}{ }^{4}\right\}$. Then the iterative map given by Eqs. B9 and B10 generates a Cauchy sequence, $\left\{\mathrm{y}_{1, k}, \mathrm{y}_{2, \mathrm{k}}\right\}$, that remains in $\mathrm{D}_{0}$ and converges to a fixed point $\mathrm{y}^{*}=\left(\mathrm{y}_{1} *, \mathrm{y}_{2}^{*}\right)$ in $\mathrm{D}_{0}$. Similar analysis can be applied to the other three cases (i.e., $\mathrm{K}_{\mathrm{sp}}{ }^{1}>\mathrm{K}_{\mathrm{sp}}{ }^{3}$ and $\mathrm{K}_{\mathrm{sp}}{ }^{4}<\sqrt{\mathrm{K}_{\mathrm{sp}}}{ }^{2} ; \mathrm{K}_{\mathrm{sp}}{ }^{1}<\mathrm{K}_{\mathrm{sp}}{ }^{3}$ and $\mathrm{K}_{\mathrm{sp}}{ }^{4}>\sqrt{ } \mathrm{K}_{\mathrm{sp}}{ }^{2}$; and $\mathrm{K}_{\mathrm{sp}}{ }^{1}<\mathrm{K}_{\mathrm{sp}}{ }^{3}$ and $\left.\mathrm{K}_{\mathrm{sp}}{ }^{4}<\sqrt{\mathrm{K}_{\mathrm{sp}}}{ }^{2}\right)$ 


\section{$\underline{\text { Remarks }}$}

Note that the results for this case are quite similar to those for the single cation case. In particular,

1. Note that all large values of $\mathrm{y}_{1,0}$ and $\mathrm{y}_{2,0}$ are guaranteed converge to $\mathrm{y}^{*}$.

2. The results given by Eq. B20 and B21 hold for ideal and non-ideal aqueous electrolyte solutions alike since no restrictions have been placed on any $\mathrm{K}_{\mathrm{sp}}$.

3. The results given by Eq. B20 1nd B21 also hold for any relevant temperature. 


\section{Appendix C: Illustrations of Convergence}

In this appendix, a number of illustrations are presented to support the proof of convergence in Appendix B.

Illustration 1

Table $\mathrm{C} 1$ gives all iterative values of $\mathrm{y}_{\mathrm{k}}, \mathrm{G}\left(\mathrm{y}_{\mathrm{k}}\right)$, and $\mathrm{x}_{\mathrm{k}}$ for $\mathrm{NaCl}$ at $298.15 \mathrm{~K}$ and 1 atm and clearly corroborates the convergence results given in Appendices B.

Table C1: Iterative Map for $\left[\mathrm{Na}^{+}\right]$and $\left[\mathrm{Cl}^{-}\right]$in Water at $298.15 \mathrm{~K}$

\begin{tabular}{|c|c|c|c|c|c|}
\hline & \multicolumn{2}{|c|}{ Outer Loop } & Inner Loop & & \\
\hline Iteration & $\mathbf{y}=[\mathbf{C l}-]$ & $\mathbf{G}(\mathbf{y})$ & $\mathbf{x}=\left[\mathbf{N a}^{+}\right]$ & $\left\|\mathbf{y}_{\mathbf{k}+\mathbf{1}}-\mathbf{y}_{\mathbf{k}}\right\|$ & $\alpha$ \\
\hline 0 & 83.2606 & 41.8524 & 0.44418 & 41.4082 & 0.49469 \\
\hline 1 & 41.8524 & 21.3680 & 0.88365 & 20.4844 & 0.47932 \\
\hline 2 & 21.3680 & 11.5494 & 1.73077 & 9.8186 & 0.42507 \\
\hline 3 & 11.5494 & 7.37578 & 3.20216 & 4.17362 & 0.28293 \\
\hline 4 & 7.37578 & 6.19495 & 5.01412 & 1.18083 & 0.09531 \\
\hline 5 & 6.19495 & 6.08241 & 5.96987 & 0.11254 & 0.00924 \\
\hline 6 & 6.08241 & 6.08137 & 6.08033 & 0.00104 & \\
\hline 7 & 6.08137 & 6.08137 & 6.08137 & & \\
\hline
\end{tabular}

Figure $\mathrm{C} 1$ demonstrates convergence for this example of $\mathrm{NaCl}$ where $\mathrm{K}_{\mathrm{sp}}=36.9830$ and the solution is $\mathrm{y}(*)=\left[\mathrm{Cl}^{-}\right]=6.08137 \mathrm{~mol} / \mathrm{kg} \mathrm{H} \mathrm{H}_{2} \mathrm{O}, \mathrm{x}^{*}=\left[\mathrm{Na}^{+}\right]=6.08137 \mathrm{~mol} / \mathrm{kg} \mathrm{H} 2 \mathrm{O}$ using only the last 6 iterates so the curvature of $G(y)$ in the neighborhood of the fixed point is evident. 


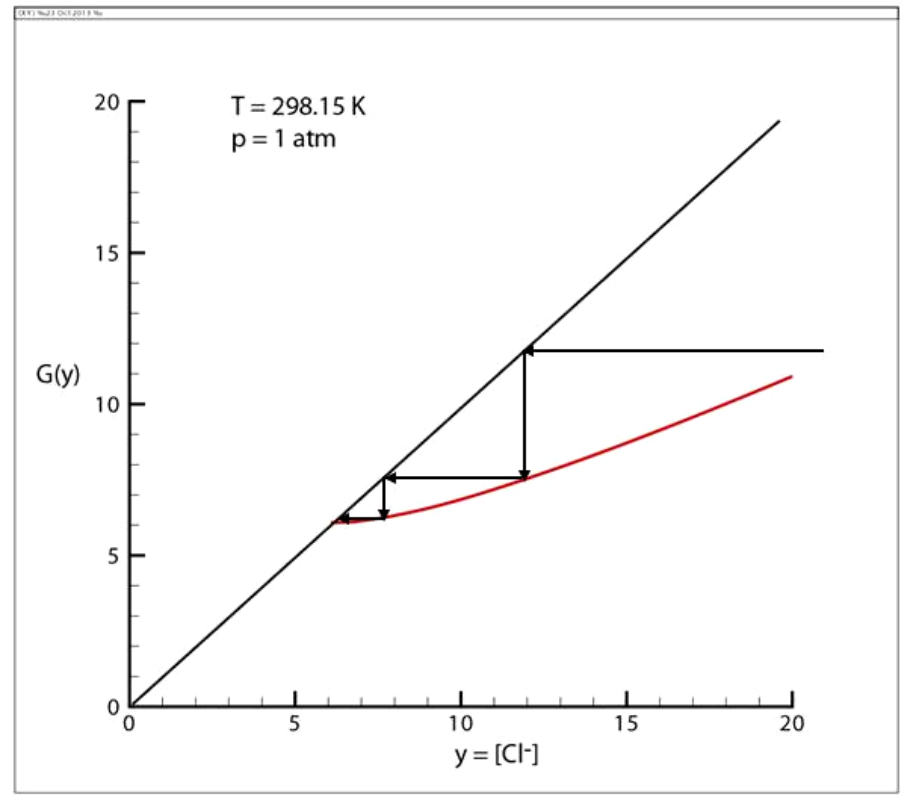

Figure C1: Iterative Map for Equilibrium Solubility of $[\mathrm{Na}+]=[\mathrm{Cl}-]$ in Water at $25{ }^{\circ} \mathrm{C}$

It also shows that the condition $\mathrm{G}^{\prime}\left(\mathrm{y}^{*}\right)=0$ is satisfied, which means asymptotic convergence is very fast.

\section{Illustration 2}

This second illustration shows that the proposed algorithm is convergent when common ion effects are present in the solution.

Table C2: Iterative Map for $\left[\mathrm{Ca}^{2+}\right],\left[\mathrm{Mg}^{2+}\right]$ and $\left[\mathrm{CO}_{3}^{2-}\right]$ at $303.15 \mathrm{~K}$ and $10 \mathrm{bar}$

\begin{tabular}{|c|c|c|c|c|c|c|}
\hline & \multicolumn{2}{|c|}{ Outer Loop } & \multicolumn{2}{|c|}{ Inner Loop } & & \\
\hline Iteration & $\mathbf{y}=\left[\mathbf{C O}_{\mathbf{3}^{2}}{ }^{-}\right]$ & $\mathbf{G}(\mathbf{y})$ & $\mathbf{x}^{\mathbf{1}}=\left[\mathbf{C a}^{\mathbf{2}}\right]$ & $\mathbf{x}^{\mathbf{2}}=\left[\mathbf{M g}^{\mathbf{2 +}}\right]$ & $\left\|\mathbf{y}_{\mathbf{k}+\mathbf{1}}-\mathbf{\mathbf { y } _ { \mathbf { k } }}\right\|$ & $\square$ \\
\hline 0 & 0.0111023 & 0.00429151 & $5.55115 \times 10^{-4}$ & $5.55115 \times 10^{-4}$ & 0.0051786 & 0.43695 \\
\hline 1 & 0.00429151 & 0.00311237 & $3.26713 \times 10^{-6}$ & 0.000746952 & 0.0022628 & 0.30887 \\
\hline 2 & 0.00311237 & 0.00288901 & $8.45221 \times 10^{-7}$ & 0.00193239 & 0.0006989 & 0.11790 \\
\hline 3 & 0.00288901 & 0.00288038 & $1.16544 \times 10^{-6}$ & 0.00266449 & 0.0000824 & 0.01456 \\
\hline 4 & 0.00288038 & 0.00288037 & $1.25554 \times 10^{-6}$ & 0.00287049 & 0.0000012 & 0 \\
\hline 5 & 0.00288037 & 0.00288037 & $1.25930 \times 10^{-6}$ & 0.00287910 & 0 & \\
\hline 6 & 0.00288037 & 0.00288037 & $1.25931 \times 10^{-6}$ & 0.02887911 & & \\
\hline
\end{tabular}


Therefore, consider the convergence of the proposed algorithm for the dissociation of $\mathrm{CaCO}_{3}$ and $\mathrm{MgCO}_{3}$ at $303.15 \mathrm{~K}$ and 10 bar. The unknowns $\mathrm{z}=\left\{\left[\mathrm{Ca}^{2+}\right],\left[\mathrm{Mg}^{2+}\right],\left[\mathrm{CO}_{3}{ }^{-}\right.\right.$ $\left.\left.{ }^{2}\right]\right\}$ are partitioned into $\mathrm{x}=\left\{\left[\mathrm{Ca}^{2+}\right],\left[\mathrm{Mg}^{2+}\right]\right\}$ and $\mathrm{y}=\left\{\left[\mathrm{CO}_{3}^{-2}\right]\right\}$. Remember, it is easily shown that the same convergence results in Appendix B hold for this case by simply replacing $\mathrm{K}_{\mathrm{sp}}$ with $\left(\mathrm{K}_{\mathrm{sp}}{ }^{1}+\mathrm{K}_{\mathrm{sp}}{ }^{2}\right)$, where $\mathrm{x}_{\mathrm{k}}{ }^{1}=\left[\mathrm{Ca}^{2+}\right], \mathrm{x}_{\mathrm{k}}{ }^{2}=\left[\mathrm{Mg}^{2+}\right]$, and $\mathrm{K}_{\mathrm{sp}}{ }^{1}$ and $\mathrm{K}_{\mathrm{sp}}{ }^{2}$ are the equilibrium solubility products for the dissociation of $\mathrm{CaCO}_{3}$ and $\mathrm{MgCO}_{3}$ respectively. The key equations that result for the case of 2 cations and 1 anion are

$$
\begin{aligned}
& \mathrm{G}\left(\mathrm{y}_{\mathrm{k}}\right)=\mathrm{y}_{\mathrm{k}+1}=\left[\mathrm{y}_{\mathrm{k}}^{2}+\left(\mathrm{K}_{\mathrm{sp}}{ }^{1}+\mathrm{K}_{\mathrm{sp}}^{2}\right)\right] /\left(2 \mathrm{y}_{\mathrm{k}}\right) \\
& \mathrm{G}^{\prime}\left(\mathrm{y}_{\mathrm{k}}\right)=1 / 2-1 / 2\left(\mathrm{~K}_{\mathrm{sp}}{ }^{1}+\mathrm{K}_{\mathrm{sp}}{ }^{2}\right) / \mathrm{y}_{\mathrm{k}}^{2}
\end{aligned}
$$

where $\mathrm{y}_{\mathrm{k}}=\left[\mathrm{CO}_{3}{ }^{-2}\right]$. The proof of linear convergence is the same and the results clearly identify the domain of attraction from which initial values that are guaranteed to converge can be chosen. That is, in this case, $\mathrm{D}_{0}=\left[\left(\sqrt{ }\left(\mathrm{K}_{\mathrm{sp}}{ }^{1}+\mathrm{K}_{\mathrm{sp}}{ }^{2}\right), \infty\right]\right.$. Table $\mathrm{C} 2$ gives iterative values of $\mathrm{y}_{\mathrm{k}}, \mathrm{G}\left(\mathrm{y}_{\mathrm{k}}\right), \mathrm{x}_{\mathrm{k}}{ }^{1}$ and $\mathrm{x}_{\mathrm{k}}{ }^{2}$ for $303.15 \mathrm{~K}$ and 10 bar at which $\mathrm{K}_{\mathrm{sp}}{ }^{1}=$ $3.6273 \times 10^{-9}$ and $\mathrm{K}_{\mathrm{sp}}{ }^{2}=8.2929 \times 10^{-6}$. Note that $\alpha<1 / 2$ and tends to 0 indicating fast linear convergence as shown in Appendix B. Figure C2 shows the iterations graphically as well as the fact that $G^{\prime}\left(y^{*}\right)=0$. 


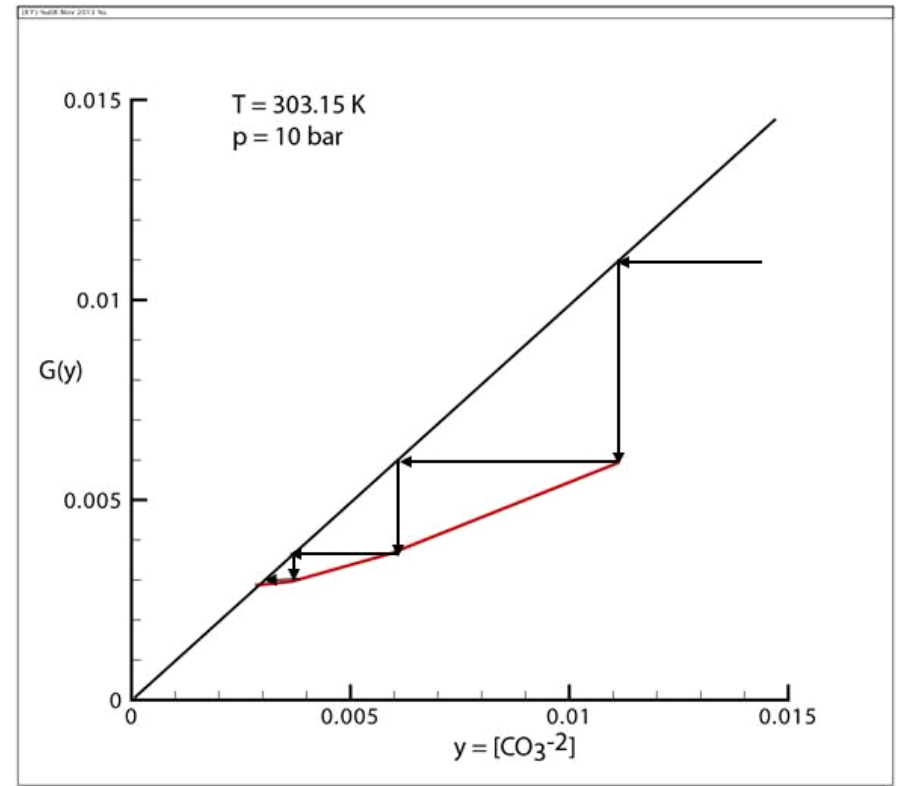

Figure C2: Iterative Map for Finding Equilibrium Solubility of $[\mathrm{Ca} 2+]=[\mathrm{Mg} 2+]=[\mathrm{CO} 2-]$ in Water at $30{ }^{\circ} \mathrm{C}$ and 10 bar

\section{$\underline{\text { Illustration } 3}$}

Consider an aqueous solution of $\left[\mathrm{Na}^{+}\right],\left[\mathrm{Ca}^{2+}\right],\left[\mathrm{Cl}^{-}\right]$, and $\left[\mathrm{SO}_{4}{ }^{2-}\right]$ at $323.15 \mathrm{~K}$ and $20 \mathrm{bar}$ with corresponding salts $\mathrm{NaCl}, \mathrm{Na}_{2} \mathrm{SO}_{4}, \mathrm{CaCl}_{2}$, and $\mathrm{CaSO}_{4}$ and equilibrium solubility products $\mathrm{K}_{\mathrm{sp}}{ }^{1}, \mathrm{~K}_{\mathrm{sp}}{ }^{2}, \mathrm{~K}_{\mathrm{sp}}{ }^{3}$, and $\mathrm{K}_{\mathrm{sp}}{ }^{4}$ respectively. Partition the unknowns $\mathrm{z}=\left\{\left[\mathrm{Na}^{+}\right]\right.$, $\left.\left[\mathrm{Ca}^{2+}\right],\left[\mathrm{Cl}^{-}\right],\left[\mathrm{SO}_{4}{ }^{2-}\right]\right\}$ into $\mathrm{x}=\left\{\mathrm{x}_{1}, \mathrm{x}_{2}\right\}=\left\{\left[\mathrm{Na}^{+}\right],\left[\mathrm{Ca}^{2+}\right]\right\}$ and $\mathrm{y}=\left\{\mathrm{y}_{1}, \mathrm{y}_{2}\right\}=\left\{\left[\mathrm{Cl}^{-}\right],\left[\mathrm{SO}_{4}{ }^{2-}\right.\right.$ ]\}. In this case, the iterative map, $\mathrm{G}(\mathrm{y})$, will have two components [i.e., $\mathrm{G}(\mathrm{y})=\mathrm{G}\left(\mathrm{y}_{1, k}\right.$, $\left.\left.\mathrm{y}_{2, \mathrm{k}}\right)=\left(\mathrm{G}_{1}\left(\mathrm{y}_{1, \mathrm{k}}\right), \mathrm{G}_{2}\left(\mathrm{y}_{2, \mathrm{k}}\right)\right)\right]$ and can be written in the form

$$
\begin{aligned}
& \mathrm{G}_{1}\left(\mathrm{y}_{1, \mathrm{k}}\right)=\mathrm{y}_{1, \mathrm{k}+1}=1 / 2 \mathrm{y}_{1, \mathrm{k}}+1 / 2 \mathrm{~K}_{\mathrm{sp}}{ }^{1 / \mathrm{y}_{1, \mathrm{k}}}+\mathrm{K}_{\mathrm{sp}}{ }^{3} /\left(\mathrm{y}_{1, \mathrm{k}}{ }^{2}\right) \\
& \mathrm{G}_{2}\left(\mathrm{y}_{2, \mathrm{k}}\right)=\mathrm{y}_{2, \mathrm{k}+1}=1 / 5 \mathrm{y}_{2, \mathrm{k}}+2 / 5\left(\mathrm{~K}_{\mathrm{sp}}{ }^{2} / \mathrm{y}_{2, \mathrm{k}}\right)^{1 / 2}+2 / 5 \mathrm{~K}_{\mathrm{sp}}{ }^{4} / \mathrm{y}_{2, \mathrm{k}}
\end{aligned}
$$


Table $\mathrm{C} 3$ presents iterative numerical results that illustrate convergence of the proposed tearing algorithm for this problem, where $\mathrm{K}_{\mathrm{sp}}{ }^{1}=8.2440, \mathrm{~K}_{\mathrm{sp}}{ }^{2}=1.4023, \mathrm{~K}_{\mathrm{sp}}{ }^{2}=7015.1$, and $\mathrm{K}_{\mathrm{sp}}{ }^{4}=144.74$.

Table C3: Iterative Map for $\left[\mathrm{Na}^{+}\right],\left[\mathrm{Ca}^{2+}\right],\left[\mathrm{Cl}^{-}\right]$and $\left[\mathrm{SO}_{4}{ }^{2-}\right]$ at $323.15 \mathrm{~K}$ and 20 bar

\begin{tabular}{|c|c|c|c|c|c|c|}
\hline & \multicolumn{2}{|c|}{ Outer Loop } & \multicolumn{2}{c|}{ Inner Loop } & & \\
\hline Iteration & $\mathbf{y}_{\mathbf{1}}=\left[\mathbf{C l}{ }^{-}\right]$ & $\mathbf{y}_{\mathbf{2}}=\left[\mathbf{S O}_{\mathbf{4}}{ }^{-}\right]$ & $\mathbf{x}_{\mathbf{1}}=\left[\mathbf{N a}^{+}\right]$ & $\mathbf{x}_{\mathbf{2}}=\left[\mathbf{C a}^{\mathbf{2}+}\right]$ & $\|\mathbf{y} \mathbf{k}+\mathbf{1}-\mathbf{y} \mathbf{k}\|$ & $\square$ \\
\hline 0 & $4.59711 \times 10^{4}$ & $3.76675 \times 10^{4}$ & 28.0302 & $4.59566 \times 10^{4}$ & 38041.58 & 0.3394 \\
\hline 1 & $2.29856 \times 10^{4}$ & $7.35531 \times 10^{3}$ & 0.001898 & 0.000114 & 12911.57 & 0.4543 \\
\hline 2 & $1.14928 \times 10^{4}$ & $1.47106 \times 10^{3}$ & 0.004089 & 0.000511 & 5865.668 & 0.4915 \\
\hline 3 & $5.74640 \times 10^{3}$ & $2.94218 \times 10^{2}$ & 0.008810 & 0.002286 & 2882.803 & 0.4986 \\
\hline 4 & $2.87322 \times 10^{3}$ & 58.8594 & 0.018980 & 0.010223 & 1437.309 & 0.4997 \\
\hline 5 & $1.43668 \times 10^{3}$ & 11.8248 & 0.040888 & 0.045713 & 718.1537 & 0.4990 \\
\hline 6 & 718.586 & 2.56332 & 0.087958 & 0.203968 & 358.3272 & 0.4954 \\
\hline 7 & 360.261 & 1.28714 & 0.184459 & 0.875866 & 177.5221 & 0.4936 \\
\hline 8 & 182.742 & 2.34660 & 0.292132 & 2.46540 & 87.62868 & 0.4765 \\
\hline 9 & 95.1205 & 3.46898 & 0.299847 & 3.59965 & 41.75232 & 0.4442 \\
\hline 10 & 53.4117 & 5.37490 & 0.327216 & 5.68778 & 18.54603 & 0.3952 \\
\hline 11 & 35.0148 & 7.72216 & 0.342760 & 8.13760 & 7.329437 & 0.3781 \\
\hline 12 & 28.0383 & 9.96918 & 0.349673 & 10.3561 & 2.771366 & 0.3690 \\
\hline 13 & 25.5745 & 11.2381 & 0.345824 & 11.3824 & 1.022564 & 0.3639 \\
\hline 14 & 24.7120 & 11.7874 & 0.342630 & 11.7534 & 0.372153 & 0.3599 \\
\hline 15 & 24.4034 & 11.9954 & 0.341102 & 11.8769 & 0.133941 & 0.3608 \\
\hline 16 & 24.2943 & 12.0731 & 0.340542 & 11.9223 & 0.048320 & 0.3580 \\
\hline 17 & 24.2545 & 12.1005 & 0.340318 & 11.9372 & 0.017300 & 0.3623 \\
\hline 18 & 24.2406 & 12.1108 & 0.340246 & 11.9432 & 0.006268 & 0.3414 \\
\hline 19 & 24.2354 & 12.1143 & 0.340215 & 11.9450 & 0.002140 & 0.4020 \\
\hline 20 & 24.2337 & 12.1156 & 0.340207 & 11.9459 & 0.000860 & 0.2599 \\
\hline 21 & 24.2330 & 12.1161 & 0.340202 & 11.9461 & 0.000224 & 0.6325 \\
\hline 22 & 24.2328 & 12.1162 & 0.340202 & 11.9462 & 0.000141 & 0.0000 \\
\hline 23 & 24.2327 & 12.1163 & 0.340201 & 11.9462 & 0.000000 & \\
\hline 24 & 24.2327 & 12.1163 & 0.340201 & 11.9462 & & \\
\hline
\end{tabular}




\section{Appendix D: Iterative Values of Ion Concentrations for Example 2}

Table D1 shows the iterative values of all ion concentrations for example 2.

Table D1: Iterative Map for $\left[\mathrm{Na}^{+}\right],\left[\mathrm{K}^{+}\right],\left[\mathrm{Ca}^{2+}\right],[\mathrm{Cl}-]$ and $\left[\mathrm{SO}_{4}{ }^{2-}\right]$ at $255{ }^{\circ} \mathrm{C}$ and 18 bar

\begin{tabular}{|c|c|c|c|c|c|}
\hline & \multicolumn{2}{|c|}{ Outer Loop } & \multicolumn{3}{|c|}{ Inner Loop } \\
\hline Iteration & $\mathbf{y}_{1}=\left[\mathrm{Cl}^{-}\right]$ & $\mathbf{y}_{2}=\left[\mathrm{SO}_{4}{ }^{2-}\right]$ & $\mathbf{x}_{1}=\left[\mathrm{Na}^{+}\right]$ & $\mathbf{x} \mathbf{2}=\left[\mathbf{K}^{+}\right]$ & $\mathbf{x} 3=\left[\mathrm{Ca}^{2+}\right]$ \\
\hline 0 & 116.708 & 92.4799 & 49.4355 & 80.1047 & 50.8298 \\
\hline 1 & 58.4892 & 18.6040 & 0.102563 & 0.166191 & 0.000661989 \\
\hline 2 & 29.5363 & 3.95414 & 0.220366 & 0.357078 & 0.00294508 \\
\hline 3 & 15.3883 & 1.28698 & 0.463699 & 0.751372 & 0.0126501 \\
\hline 4 & 8.83434 & 1.16954 & 0.837757 & 1.35749 & 0.0425598 \\
\hline 5 & 5.85840 & 1.38689 & 1.04066 & 1.68627 & 0.0777667 \\
\hline 6 & 4.51407 & 1.54527 & 1.12745 & 1.82691 & 0.107690 \\
\hline 7 & 3.94367 & 1.65837 & 1.18626 & 1.92220 & 0.132405 \\
\hline 8 & 3.70612 & 1.71910 & 1.21202 & 1.96395 & 0.146297 \\
\hline 9 & 3.60785 & 1.74765 & 1.22264 & 1.98115 & 0.152899 \\
\hline 10 & 3.56716 & 1.76012 & 1.22688 & 1.98803 & 0.155776 \\
\hline 11 & 3.55030 & 1.76540 & 1.22862 & 1.99084 & 0.156994 \\
\hline 12 & 3.54332 & 1.76761 & 1.22933 & 1.99199 & 0.157503 \\
\hline 13 & 3.54042 & 1.76853 & 1.22963 & 1.99247 & 0.157715 \\
\hline 14 & 3.53922 & 1.76891 & 1.22975 & 1.99267 & 0.157803 \\
\hline 15 & 3.53872 & 1.76907 & 1.22980 & 1.99275 & 0.157839 \\
\hline 16 & 3.53852 & 1.76914 & 1.22982 & 1.99278 & 0.157854 \\
\hline 17 & 3.53843 & 1.76917 & 1.22983 & 1.99280 & 0.157861 \\
\hline 18 & 3.53840 & 1.76918 & 1.22983 & 1.99280 & 0.157863 \\
\hline 19 & 3.53838 & 1.76918 & 1.22983 & 1.99281 & 0.157864 \\
\hline 20 & 3.53838 & 1.76918 & 1.22983 & 1.99281 & 0.157865 \\
\hline 21 & 3.53837 & 1.76918 & 1.22983 & 1.99281 & 0.157865 \\
\hline 22 & 3.53837 & 1.76919 & 1.22983 & 1.99281 & 0.157865 \\
\hline 23 & 3.53837 & 1.76919 & 1.22983 & 1.99281 & 0.157865 \\
\hline 24 & 3.53837 & 1.76919 & 1.22983 & 1.99281 & 0.157865 \\
\hline 25 & 3.53837 & 1.76919 & 1.22983 & 1.99281 & 0.157865 \\
\hline 26 & 3.53837 & 1.76919 & 1.22983 & 1.99281 & 0.157865 \\
\hline 27 & 3.53837 & 1.76919 & 1.22983 & 1.99281 & 0.157865 \\
\hline 28 & 3.53837 & 1.76919 & 1.22983 & 1.99281 & 0.157865 \\
\hline 29 & 3.53837 & 1.76919 & 1.22983 & 1.99281 & 0.157865 \\
\hline
\end{tabular}




\section{References}

Behzadi, B., Patel, B.H., Galindo, A., Ghotbi, C. (2005). Modeling electrolyte solutions with the SAFT-VR equation using Yukawa potentials and mean-spherical approximation. Fluid Phase Equilibria 236, 241-255.

Boston, J.F, Britt, H.I. (1978). A radically different formulation and solution of the single stage flash problem. Comput. Chem. Eng. 2, 109.

Castillo, J., Grossmann, I.E. (1981). Computation of phase and chemical equilibria. Comput. Chem. Eng. 5, 99.

Elliott, J.R., Lira, C.T. Introductory Chemical Engineering Thermodynamics. 2nd Ed., Prentice-Hall, Inc., New York (2012).

Kiepe, J., Horstmann, S., Fischer, K., Gmehling, J. (2004). Application of the PSRK model for systems containing strong electrolytes. Ind. Eng. Chem.Res.43, 6607-6615.

Kontogeorgis, G.M., Voutsas, E.C., Yakoumis, I.V., Tassios, D.P. (1996). An equation of state for associating fluids. Ind. Eng. Chem.Res.35, 4310-4318.

Lam, E.J., Alvarez, M.N., Galvez, M.E., Alvarez, E.B. (2008). A model for calculating the density of aqueous multi-component electrolyte solutions. J. Chil. Chem. Soc. 53, 1404-1409.

Li, J., Topphoff, M., Fischer, K., Gmehling, J. (2001). Prediction of gas solubilities in aqueous electrolyte systems using the predictive Soave-Redlich-Kwong model. Ind. Eng. Chem. Res. 40, 3703-3710.

Lucia, A. (2010). A multi-scale Gibbs Helmholtz constrained cubic equation of state. $J$. Thermodynamics: Special Issue on Advances in Gas Hydrate Thermodynamics and Transport Properties. Paper No. 238365.

Lucia, A., Bonk, B.M., Roy, A., Waterman, R.R. (2012). A multi-scale framework for multi-phase equilibrium flash. Comput. Chem. Engng. 36, 79-98.

Lucia, A., Bonk, B.M. (2012). Molecular geometry effects and the Gibbs-Helmholtz constrained equation of state. Comput. Chem. Engng. 37, 1-14.

Lucia, A., Henley, H. (2013). Thermodynamic consistency of the multi-scale GibbsHelmholtz constrained equation of state. Chem. Eng. Res. \& Des.91, 1748-1759.

Lucia, A., Padmanabhan, L., Venkataraman, S. (2000). Multiphase equilibrium flash calculations, Comput. Chem. Engng. 24, 2557-2569. 
McDonald, C.M., Floudas, C.A. (1995). Global optimization for the phase stability problem. AIChE J. 41, 1798-1814.

Michelsen, M.L. (1982a). The isothermal flash problem. I. stability. Fluid Phase Equilibria 9, 1-19.

Michelsen, M.L. (1982b). The isothermal flash problem. II. flash calculations. Fluid Phase Equilibria 9, 21-40.

Mohs, A., Gmehling, J. (2012). A revised LIQUAC and LIFAC model (LIQUAC/LIFAC) for the prediction of properties of electrolyte containing solutions. Fluid Phase Equilibria 337, 311-322.

Ortega, J.M., Rheinboldt, W.C. Iterative Solution of Nonlinear Equations in Several Variables. Academic Press, New York (1970).

Raatikainen, T., Laaksonen, A. (2005). Application of several activity coefficient models to water-organic-electrolyte aerosols of atmospheric interest. Atmos. Chem. Phys. 5, 2475-2495.

Sanderson, J.D., Chien, H.H.Y. (1973). Simultaneous chemical and phase equilibrium calculation. Ind. Eng. Chem. Proc. Des. Dev. 12, 81.

Sandler, S.I. 1999. Chemical and Engineering Thermodynamics. 3rd Edition. John Wiley \& Son, Inc. New York.

Smith, W.R., Missen, R.W. (1982). Chemical Reaction Equilibrium Analysis: Theory and Algorithms. J. Wiley \& Sons, Inc., New York, NY.

Stadtherr, M.A., Schnepper, C.A., Brennecke, J.F. (1995). Robust phase stability analysis using interval methods. AIChE Symp. Ser., 91, 356-359.

Sun, A.C., Seider, W.D. (1995). Homotopy-continuation for the stability analysis in global minimization of the Gibbs free energy. Fluid Phase Equilibria, 103, 213-249.

White, W.B., Johnson, S.M., Dantzig, G.B. (1958). Chemical equilibrium in complex mixtures. J. Chem. Phys. 28, 751-755.

Whitson, C.H., Michelsen, M.L. (1989). The negative flash. Fluid Phase Equilibria 53, 51-71. 
CHAPTER 4 - Constant pressure Gibbs ensemble Monte Carlo simulations for the prediction of structure I gas hydrate occupancy

Published in The Journal of Natural Gas Science and Engineering, September 2015

Heath Henley and Angelo Lucia

Chemical Engineering

University of Rhode Island

Kingston, RI 


\begin{abstract}
In this work, constant pressure Gibbs ensemble Monte Carlo (GEMC) simulations were applied as an alternative to grand canonical Monte Carlo (GCMC) simulations to calculate gas hydrate occupancy as function of temperature and pressure. Both rigid and flexible hydrate lattice models were investigated. GEMC structure I methane hydrate occupancy results using the flexible lattice model agree with experimentally measured values and van der Waals-Platteeuw (vdW-P) theory with AAD of $3.67 \%$ and $2.68 \%$ respectively whereas occupancy results using a rigid lattice model agree with the vdW-P model and literature data with an AAD of $1.02 \%$ and $2.78 \%$ respectively. The models are validated using occupancy results to predict methane hydrate dissociation pressures. The results compare favorably to previous results and experimental data. An AAD of $0.35 \%$ and $0.47 \%$ in predicted dissociation temperatures was obtained for the rigid and flexible hydrate lattice models, respectively.
\end{abstract}




\subsection{Introduction}

Gas hydrates are non-stoichiometric crystalline compounds composed of a network of hydrogen bonded water molecules forming cavities. Small guest molecules can occupy the cages, and in doing so stabilize the structure. The three most common naturally forming hydrate structures have been classified as structure I (sI), structure II (sII), and structure $\mathrm{H}(\mathrm{sH})$. This work is only concerned with sI hydrates. The cubic sI hydrate unit cell consists of two small $\left(5^{12}\right)$ and six large $\left(5^{12} 6^{2}\right)$ cavities. The notation $\mathrm{e}^{\mathrm{f}}$ denotes a polygon with $\mathrm{f}$ faces consisting of e edges, so that the sI small cages are polyhedra made of twelve pentagons, while the large sI cages are made of twelve pentagons and two hexagons. Since their discovery by Sir Humphrey Davies in 1810, gas hydrates have been of interest to the scientific community. They were later rediscovered by Hammerschmidt (1934) as the root cause of blockages in gas lines. Estimates made over the last decade concerning the amount of methane currently stored in gas hydrates vary widely $\left(3-120 \times 10^{15} \mathrm{~m}^{3} \mathrm{STP}\right)($ Sloan and Koh, 2007, Table 7.2, page 540); however even conservative estimates represent an enormous amount of energy. More recently, because of the estimated abundance of methane hydrate contained in permafrost basins and on the ocean bottom, gas hydrates are being studied as a potential fuel source (Li et al., 2013; Yuan et al., 2013) and a means of sequestering atmospheric $\mathrm{CO}_{2}$ (Park et al., 2006; Kvamme et al., 2007). The total equilibrium occupancy of the hydrate phase is important for determining storage capacity (for $\mathrm{CO}_{2}$ sequestration) or energy density (for methane production) of gas hydrates at differing conditions, both on the equilibrium curve and at conditions away from it. 
The theory developed by van der Waals and Platteeuw in 1958 is the basis for most of the common hydrate models being used today. Many modifications and models based on vdW-P theory (van der Waals and Platteeuw, 1958) have been developed over the last fifty years. An expanded derivation of the model and comprehensive survey of the relevant hydrate literature can be found in the textbook by Sloan and Koh (2007). Some modifications are outlined here. Parrish and Prausnitz (1972) adapted the model for calculation of dissociation pressures in mixed gas hydrate systems. A fugacity based model was presented by Klauda and Sandler (2000) that allowed for distortion of the hydrate lattice based on the type of guest molecule and removed the need for reference energy parameters for the empty hydrate lattice. A similar method was also developed by Ballard and Sloan (2002) and Jager et al. (2003). Many other modifications have been proposed, including allowing multiple cage occupancy (Klauda and Sandler, 2003; Martin, 2010), and adapting the model for use with highly accurate equations of state (Bandyopadhyay and Klauda, 2011; Martin and Peters, 2009; Kontogeorgis and Karakatsani, 2013). The vdW-P theory may be the most important theoretical tool that is currently available for studying the properties of gas hydrates. However, molecular simulations, both Monte Carlo and molecular dynamics simulations, are also a valuable tool for the study of gas hydrate properties. Gas hydrate structure can be determined by crystallographic experiments, therefore computer simulations have been carried out to study hydrate formation/dissociation, gas adsorption into the hydrate phase, and to test the assumptions made in development of vdW-P theory (for example: Tester et al., 1972; Sparks and Tester, 1992; Tanaka, 1998; Wierzchowski and Monson, 2007; Sizov and Piotrovskaya, 2007; Papadimitriou et al., 2008; Chakraborty and Gelb, 2012; 
Glavatskiy et al., 2012; Ravipati and Sudeep, 2013; Lasich et al., 2014). A distinct advantage of studying gas hydrate systems using molecular simulation is that it allows the study of hypothetical gas hydrate states (such as a zero-occupancy hydrate) or systems under conditions that would be difficult and/or expensive to study experimentally. The focus of this work is to use Monte Carlo simulations in the constant pressure Gibbs ensemble to determine fractional occupancy of simple hydrates of methane under varying conditions. It should be noted that the Gibbs ensemble is not being used in the usual way in this work, that is, to calculate direct coexistence conditions between two simulation boxes in thermodynamic contact. As described in Section 4.2, particle swap moves are only attempted for guest molecules between the two simulation boxes. This ensures that once equilibrium is reached, the guest molecules in the hydrate lattice and those in the gas phase will have equal chemical potentials. In this study we are interested in the occupancy at this point of equilibrium. Simulation results are compared to experimental data, calculations made by others in the literature, and vdW-P theory. Finally, the method is validated using the procedure developed by Lasich et al. (2014) to predict simple methane hydrate dissociation curves and heat of dissociation using fractional occupancy simulation results and vdW-P theory. The results of this procedure are also compared to experimental data.

The remaining organization of this article is as follows: Section 4.2 describes all computational details associated with the simulations and outlines a procedure for calculating dissociation conditions based on simulation results. All results are presented and discussed in Section 4.3 and then conclusions are drawn in Section 4.4.

\subsection{Procedure}


Constant pressure Gibbs ensemble Monte Carlo (GEMC) (Panagiotopoulos, 1987) simulations were performed to measure the equilibrium occupancy of pure structure 1 (sI) gas hydrates. The constant pressure Gibbs ensemble was preferred over the grand canonical ensemble (GCMC) because in this approach the pressure rather than the chemical potential is specified as an input parameter. In the grand canonical ensemble, the pressure must be calculated from the specified chemical potential either (1) using an EOS model, (2) determined during the simulation by calculating the molecular virial (Frenkel and Smit, 2001) or (3) by applying a method similar to Widom test particle insertion (Widom, 1963) in which test volume moves are attempted, but no volume move is ever actually applied to the system (Eppenga and Frenkel, 1984). Method 1 requires a choice of equation of state for the system of interest, and both of the later methods involve ensemble averages, and thus are subject to statistical uncertainty. Simulations in the Gibbs ensemble have been previously applied to study adsorption isotherms (eg. Bai et al., 2014; Demir and Ahunbay, 2014) but as far as we know this is the first application of the method to a gas hydrate system.

In this work, the simulations were initialized using two boxes, one containing an empty sI hydrate lattice and the other containing guest molecules. The box containing guest molecules was initialized to a simple cubic structure. Monte Carlo (MC) moves available to both boxes included translation and rotation of the molecule about the center of mass. Isotropic volume moves were available to the box containing only guest molecules, while anisotropic unit cell displacement moves were applied to the box containing the hydrate lattice. In addition, particle swap moves were available only to the guest molecules in the simulation, so that no water molecules were removed from 
the hydrate phase or inserted into the gas phase, but guest molecules could be removed from the gas phase and inserted into the hydrate phase and vice versa. In the rigid hydrate model, the rotation and translation moves were only applied to guest molecules, and no volume displacement was attempted on the box containing the hydrate phase. Volume displacement, unit cell displacement, and particle swap moves were all attempted with a frequency of 0.01 , while center of mass translation and rotation were attempted with frequencies 0.57 and 0.4 respectively. The simulations were first run in 'equilibration' mode where the maximum displacements (volume, unit cell, translation and rotation) were updated every $10 \mathrm{MC}$ cycles to achieve an acceptance ratio of 0.5 for each type of move. Properties were sampled in a 'production' mode in which the maximum displacements were updated four times during the simulation. A classical Lennard-Jones (LJ) potential was applied using Lorentz-Berthelot mixing rules for unlike sites. Long range electrostatic interactions were incorporated using Coulomb's law with the Ewald summation method. A LJ cutoff of 10 A was applied and the standard LJ tail correction was applied for distances greater than the LJ cutoff. For the Ewald summation five inverse space vectors were used in each direction and the electrostatic cutoff was allowed to adjust to half of the current box length. The simulation box containing the structure I hydrate lattice studied in this work was comprised of 8 unit cells $(2 \times 2 \times 2)$ (consisting of 368 water molecules). The TIP4P/Ew potential (Horn et al., 2004) was used for the hydrate phase water model in all simulations. The TraPPE-UA (Transferable Potentials for Phase Equilibrium - United Atom) (Martin \& Siepmann, 1998) model was used to represent methane in all simulations. Because the united atom model has only one LJ site and no charges, 
rotation moves were not applied to the methane molecules in either box. Model parameters that were used for methane and water are summarized in Table 4.1.

Table 4.1: Relevant Simulation Potential Parameters

\begin{tabular}{|c|c|c|c|}
\hline & $\frac{\boldsymbol{\epsilon}}{\boldsymbol{k}_{\boldsymbol{B}}}(\boldsymbol{K})$ & $\boldsymbol{\sigma}(\AA)$ & $\mathbf{q}(\mathbf{e})$ \\
\hline TIP4P/Ew & & & \\
\hline $\mathrm{O}^{*}$ & 81.8989 & 3.16435 & -1.0484 \\
\hline $\mathrm{H}$ & 0.0 & 0.0 & 0.5242 \\
\hline TraPPE-UA & & & 0.0 \\
\hline $\mathrm{CH}_{4}$ & 148.0 & 3.73 & 0.0 \\
\hline
\end{tabular}

* Oxygen charge placed on bisector of $\mathrm{HOH}$ angle (see Horn et al., 2004 for details)

\subsubsection{Computations}

All computations were performed using the open source Monte Carlo software MCCCS Towhee version 7.0.6 (Martin, 2013). Towhee input files for any of the simulations in this work will be made available by the authors on request. In addition, all relevant simulation details that would be required to reproduce the work are given in section 4.2.

\subsubsection{Validation of Method using Phase Equilibrium Computations}

Typically in the vdW-P model, hydrate occupancy is determined at a given temperature and pressure by the expression (assuming a simple hydrate system)

$\theta_{i}=\frac{C_{i} f}{1+C_{i} f}$

where the subscript $i$ refers to cavity type, $f$ is guest fugacity, and $C_{i}$ is the cavity Langmuir constant. Normally, a distinction is made between the small and large cavities in structure I hydrates when determining the Langmuir constant, but Lasich et al. (2014) have shown that it is possible to match experimental methane hydrate data without making such a distinction between the two cavity types. This is because methane exhibits one site adsorption behavior in the hydrate phase, filling both cavity types 
without preference (Glavatskiy et al., 2012). In general, Langmuir constants can be calculated from Kihara potential parameters, but commonly (for example: Parrish and Prausnitz, 1972; Munck et al., 1988) their temperature dependence is described by the following relationship as a function of the parameters $\mathrm{A}$ and $\mathrm{B}$ that are regressed to various data sources

$$
C=\frac{A}{T} \exp \left(\frac{B}{T}\right)
$$

From the work of van der Waals and Platteeuw (1958) and Parrish and Prausnitz (1972) the criterion for gas hydrate equilibrium is defined as

$\mu_{w}^{\alpha}=\mu_{w}^{H}$

where $\alpha$ refers to either liquid water or ice, depending on which phase is present at the current conditions. The hypothetical empty hydrate phase is chosen as a reference state, the difference in the chemical potential of water in the filled and empty hydrate at the given temperature and pressure can be expressed as

$\frac{\Delta \mu_{w}^{H}}{R T}=-\Sigma_{i}\left[v_{i} \ln \left(1-\Sigma_{j} \theta_{i j}\right)\right]$

where $v$ is the ratio of cavities of type $i$ to water molecules in a unit cell. The subscript $i$ runs over all cavity types and $j$ runs over components. The difference in chemical potential of water in the $\alpha$-phase (eg. liquid or ice) and the empty hydrate reference state can be expressed as

$\frac{\Delta \mu}{R T}=\frac{\Delta \mu^{0}}{R T_{R}}-\int_{T_{R}}^{T} \frac{\Delta H_{\alpha}}{R T^{2}} d T+\int_{0}^{P} \frac{\Delta V_{\alpha}}{R T} d P$

where $\Delta H_{\alpha}$ and $\Delta V_{\alpha}$ are the enthalpy difference and volume difference between the $\alpha$ phase and the empty hydrate reference phase. The volume difference is assumed to be constant over the temperature and pressure range of interest. The temperature 
dependence of the enthalpy difference is incorporated using the difference in isobaric heat capacity as

$\Delta H_{\alpha}=\Delta H_{\alpha}^{0}+\int_{T_{R}}^{T} \Delta C_{p \alpha} d T$

All of the required reference parameters can be found in the literature (Parrish and Prausnitz, 1972; Munck et al. 1988).

In the normal procedure that is followed using models based on vdW-P theory, the parameters A and B in equation (4.2) for the calculation of Langmuir constants, or Kihara potential parameters would be regressed to the experimental gas hydrate phase equilibrium data. In this work, following the procedure developed by Lasich et al. (2014), the parameters A and B were fit to gas hydrate occupancy data obtained using GEMC simulations. Then these parameters were used with equations (4.1-6) to calculate hydrate dissociation conditions. The equations were solved iteratively using Newton's method, and converged to a tolerance of $10^{-12}$.

\subsection{Results and Discussion}

\subsubsection{Simple structure I methane hydrate occupancy results}

In this section, results of simulations for pure structure I methane hydrate with both a rigid lattice and flexible lattice are described in detail. Figure 4.1 gives occupancy isobars as a function of temperature for each lattice model. All of the correct qualitative trends are observed in the simulation data depicted in Figure 4.1. That is, as temperature increases at constant pressure occupancy decreases, and increasing pressure at constant temperature forces more gas into the hydrate phase, increasing occupancy. A higher value of occupancy was obtained from the simulations with the rigid lattice than from simulations using the flexible lattice at the same temperature and pressure which is in 
agreement with results obtained by Sizov and Piotrovskoya (2007) using GCMC simulations. In the flexible model, the hydrate cavities are allowed to deform through both rotation moves and translation moves. The hydrate volume is also adjusted through anisotropic unit cell displacement moves. Disappearance or dissociation of the hydrate phase was not observed using the flexible model in the temperature and pressure range of interest, even though under some of the conditions studied the hydrate phase is hypothetical. The higher occupancy predicted by the rigid lattice model suggests that the distortion of the cavities in the flexible model makes some of them inaccessible to guest molecules. 

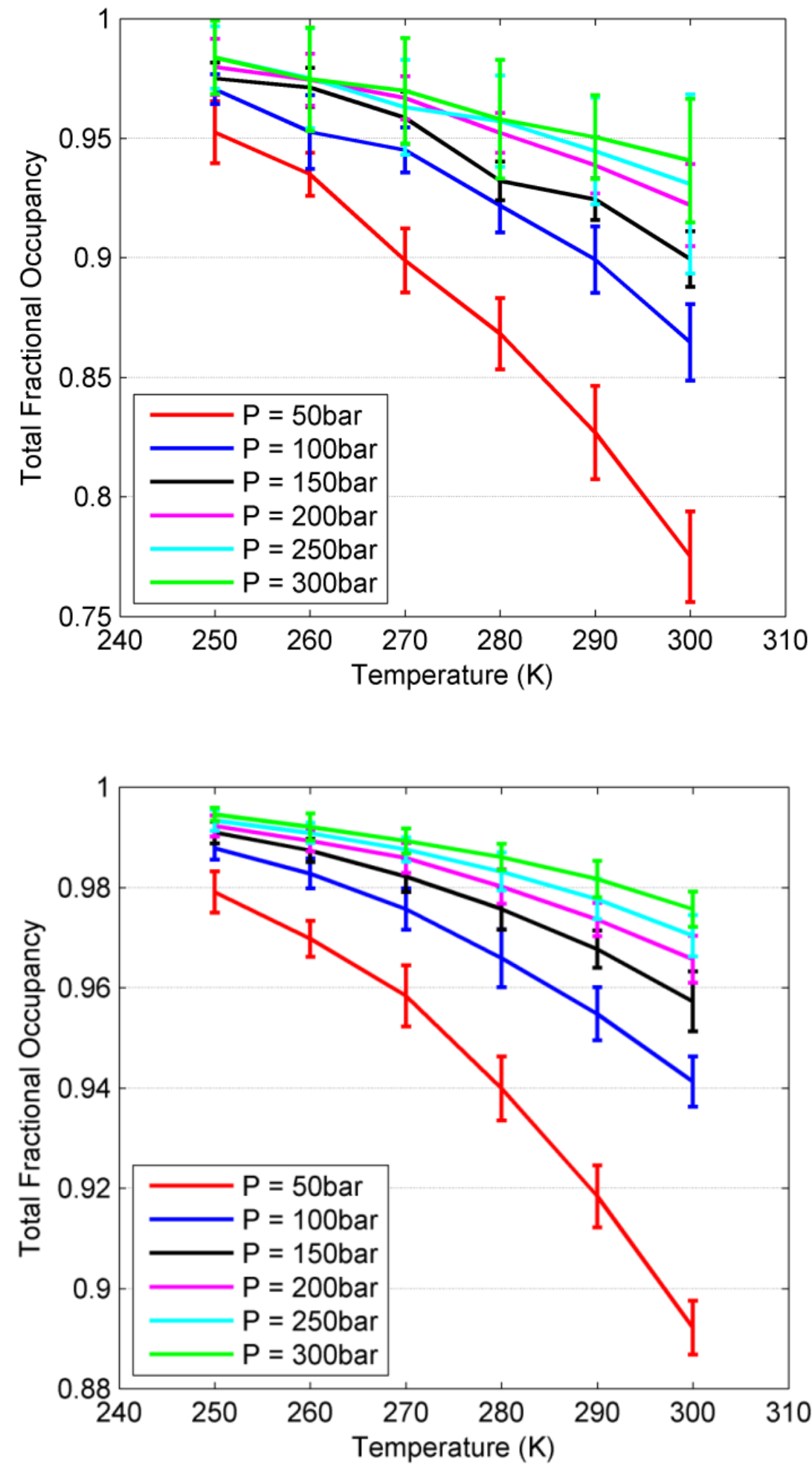

Figure 4.1: Occupancy Isobars for Pure Methane Hydrate from GEMC Simulations with: Top: Flexible Hydrate Lattice and Bottom: Rigid Hydrate Lattice 
The flexible hydrate model is a more rigorous description of the hydrate phase because in reality the hydrate lattice is distorted by the presence of guest molecules and changes in temperature and pressure (Klauda \& Sandler, 2000; Tse, 1987). A comparison of occupancy predicted by both models to experimental data (Uchida et al., 1999) is given in Table 4.2. Clearly the rigid hydrate model predicts occupancy more accurately over the range of the experimental data with an AAD of $2.78 \%$ compared to $3.67 \%$ with the flexible model. Similar results are obtained by Sizov and Piotrovskoya (2007) using SPC/E water and GCMC simulations. They suggest that at lower temperatures $(\mathrm{T}<200 \mathrm{~K})$, the flexible model will exhibit more ideal behavior and deviate less from the vdW-P model. Sizov and Piotrovskoya (2007) also suggest that their result, the flexible lattice resulting in lower occupancy and deviating from ideal behavior more strongly, may be due to "the peculiarities of SPC/E water behavior in gas hydrates." The reported melting point is $245.5 \mathrm{~K}$ (Vega et al., 2006) and $225 \pm 5 \mathrm{~K}$ (Bryk and Haymet, 2002), for TIP4P/Ew and SPC/E water respectively. Finally, Sizov and Piotrovskoya (2007) suggest that more accurate occupancy results may be obtained for the flexible lattice if a model that more accurately represents the melting point of ice is used.

Table 4.2: Experimental Methane Hydrate Occupancy vs. GEMC Occupancy

\begin{tabular}{|c|c|c|c|c|c|c|}
\hline $\mathbf{T}(\mathbf{K})$ & $\mathbf{P}(\mathbf{b a r})$ & $\boldsymbol{\theta}_{\exp }$ & $\boldsymbol{\theta}_{\text {gemc }}^{\boldsymbol{f}}$ & \% Error & $\boldsymbol{\theta}_{\text {gemc }}^{r}$ & \% Error \\
\hline 273.6 & 50.4 & 0.916 & $0.89 \pm 0.02$ & 3.06 & $0.95 \pm 0.02$ & 3.89 \\
\hline 273.6 & 63.7 & 0.918 & $0.90 \pm 0.02$ & 1.86 & $0.96 \pm 0.02$ & 4.25 \\
\hline 273.7 & 50.04 & 0.939 & $0.89 \pm 0.02$ & 5.43 & $0.95 \pm 0.02$ & 1.40 \\
\hline 273.8 & 50 & 0.946 & $0.89 \pm 0.02$ & 6.24 & $0.95 \pm 0.02$ & 0.54 \\
\hline 274.2 & 59.2 & 0.935 & $0.89 \pm 0.02$ & 4.29 & $0.95 \pm 0.02$ & 2.07 \\
\hline 275.3 & 61.3 & 0.929 & $0.89 \pm 0.02$ & 3.87 & $0.95 \pm 0.02$ & 2.53 \\
\hline 278.1 & 78.1 & 0.930 & $0.90 \pm 0.02$ & 3.26 & $0.96 \pm 0.02$ & 2.81 \\
\hline 278.3 & 80.08 & 0.916 & $0.90 \pm 0.02$ & 1.65 & $0.96 \pm 0.02$ & 4.47 \\
\hline
\end{tabular}




\begin{tabular}{|l|l|l|l|l|l|l|}
\hline 278.4 & 70.6 & 0.924 & $0.89 \pm 0.02$ & 3.40 & $0.95 \pm 0.02$ & 3.11 \\
\hline & & & & $\mathbf{3 . 6 7}$ & & $\mathbf{2 . 7 8}$ \\
\hline
\end{tabular}

Overall hydration number of the hydrate structure is simple to calculate from gas hydrate total occupancy information. A comparison between calculated methane gas hydrate hydration number and GEMC simulation results for methane hydrate is shown in Table 4.3. The data in Table 4.3 is taken directly from Anderson (2004) (see Table 6 on page 1124), and was calculated using a wide range of experimental hydrate dissociation data and the Clapeyron equation. The resulting AAD is $6.97 \%$ and $2.44 \%$ for the flexible and rigid lattice models respectively.

Table 4.3: Methane Gas Hydrate Hydration Number Calculated by Anderson (2004) versus Hydration Number Calculated from GEMC Results

\begin{tabular}{|c|c|c|c|c|c|c|}
\hline $\mathbf{T}(\mathbf{K})$ & $\mathbf{P}(\mathbf{b a r})$ & $\boldsymbol{n}_{\text {calc }}$ & $\boldsymbol{n}_{\text {flex }}$ & \% Error & $\boldsymbol{n}_{\text {rigid }}$ & \% Error \\
\hline 282 & 63.6 & $5.93 \pm 0.26$ & $6.58 \pm 0.08$ & 10.88 & $6.10 \pm 0.06$ & 2.86 \\
\hline 286 & 98.8 & $6.12 \pm 0.28$ & $6.34 \pm 0.07$ & 3.64 & $6.00 \pm 0.06$ & 1.96 \\
\hline 290 & 160.6 & $5.83 \pm 0.29$ & $6.20 \pm 0.07$ & 6.35 & $5.93 \pm 0.06$ & 1.79 \\
\hline 294 & 266.9 & $5.71 \pm 0.30$ & $6.11 \pm 0.06$ & 7.01 & $5.89 \pm 0.06$ & 3.16 \\
\hline & & & & $\mathbf{6 . 9 7}$ & & $\mathbf{2 . 4 4}$ \\
\hline
\end{tabular}

The rigid hydrate lattice model again seems to predict values that are in much better agreement both with experimentally measured values (Uchida et al., 1999), and the results of Anderson (2004). A comparison of the simulation results for both lattice models and predictions made by vdw-P theory for methane hydrate occupancy is shown in Figure 4.2. The figure illustrates that the flexible model tends to underestimate the occupancy, while the rigid model generally overestimates the occupancy compared to vdw-P theory. 


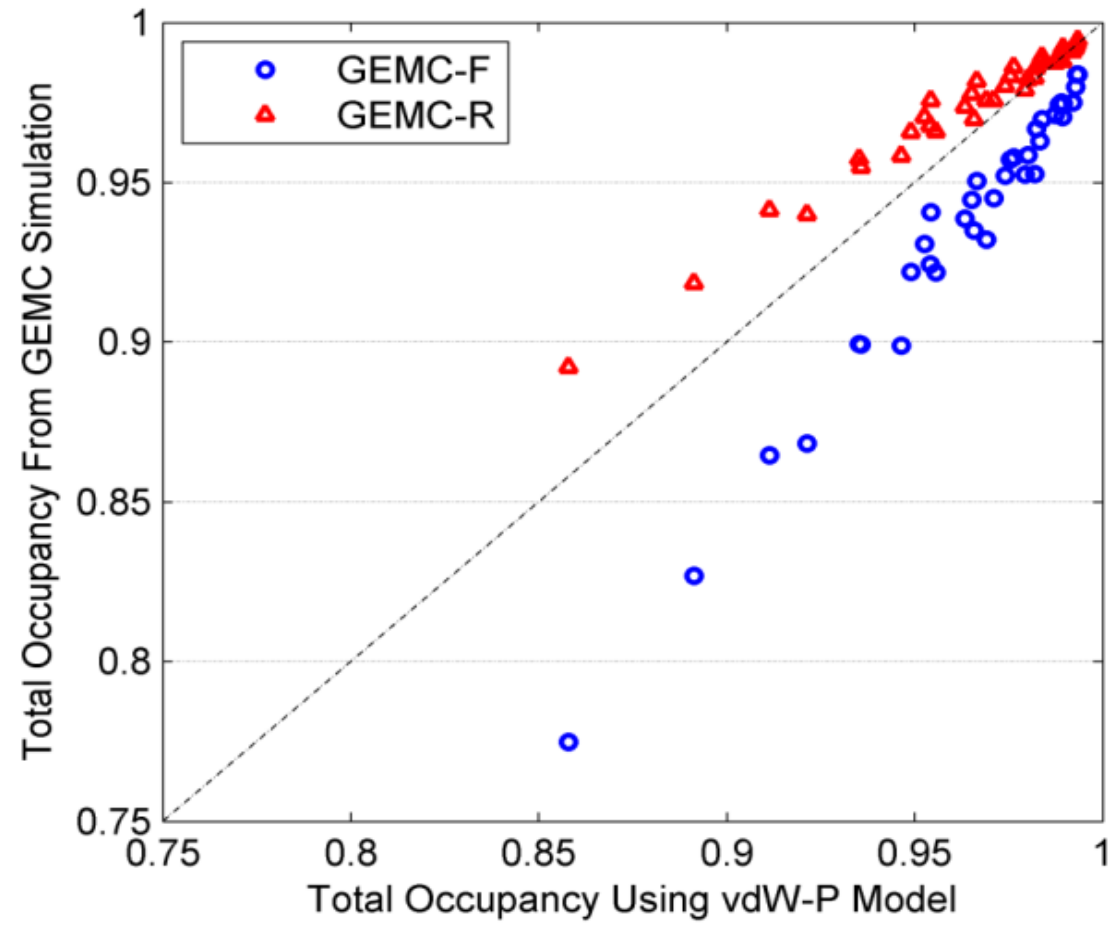

Figure 4.2: Total Methane Hydrate Occupancy From vdW-P Compared to GEMC Simulations. Red triangles: results from GEMC with a rigid hydrate lattice. Blue circles: results from GEMC with a flexible hydrate lattice.

\subsubsection{Methane Hydrate Phase Equilibrium Predictions}

The procedure described in Section 4.2.2 was used to calculate simple sI methane gas hydrate dissociation conditions. The governing equations were solved iteratively using Newton's method and converged to a tolerance of $10^{-12}$. The results for both the rigid and flexible model are compared to experimental data in Figure 4.3. From Figure 4.3, it is clear that although the more rigorous flexible description of the hydrate lattice results in occupancy values with a slightly higher deviation from vdW-P theory, calculation and experimental data, it does not strongly affect the predicted dissociation conditions. The resulting AAD in dissociation temperature predictions were $0.35 \%$ and $0.47 \%$ for the rigid and flexible models respectively. For comparison, Lasich et al., (2014 see Table 4, page 53) present results for AAD in predicted 
dissociation temperature using similar potential models and grand canonical simulations of $0.8-3.7 \%$. The smaller deviation from experimental dissociation temperatures in this work may be a direct result specifying pressure explicitly.

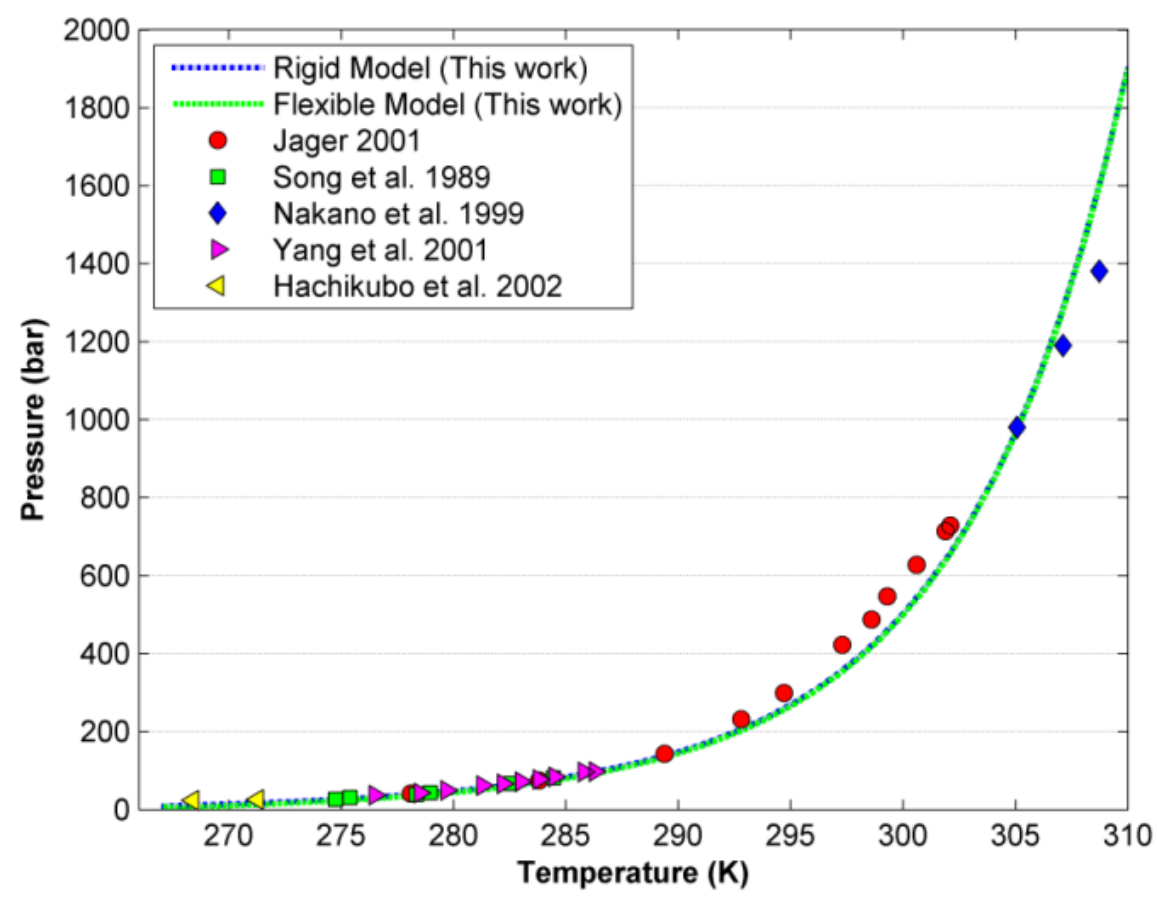

Figure 4.3: Pressure-Temperature Diagram for Simple Structure 1 Methane Hydrate - results from the rigid lattice model are indicated using a blue dotted line, while results from the flexible model are indicated with a solid green line, all other symbols represent experimental data

The heat of dissociation of the hydrate phase can be estimated using the ClausiusClapeyron equation

$\frac{d \ln P}{d\left(\frac{1}{T}\right)}=-\frac{\Delta H_{\text {diss }}}{Z R}$

Assuming that $\mathrm{Z}$ (the gas compressibility) is 1 over the range of interest $\Delta H_{\text {diss }}$ can be easily obtained by plotting $\ln P$ versus $\frac{1}{T}$ (see figure 4.4 ). 


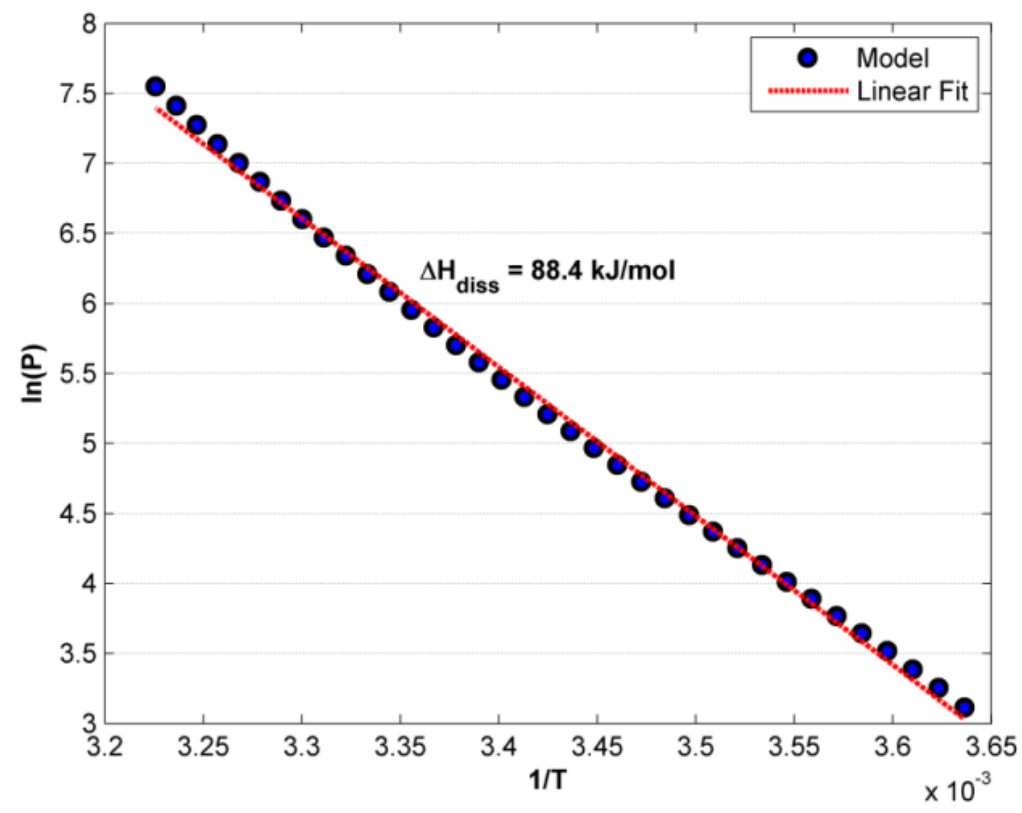

Figure 4.4: $\operatorname{Ln}(p)$ versus (1/T) and a Linear Fit used with Equation (4.7) to Determine the Heat of Dissociation

The resulting value for $\Delta H_{\text {diss }}$ is $88.4 \mathrm{~kJ} / \mathrm{mol}$, in error of about $63 \%$ from the experimentally measured values of $54.19 \pm 0.28 \mathrm{~kJ} / \mathrm{mol}$ reported by Handa and coworkers (1986) and $53.5 \pm 1.3 \mathrm{~kJ} / \mathrm{mol}$ reported by Anderson (2004). One possible cause of the strong deviation is the assumption that $Z=1$ in equation (4.7), which is not valid at high pressures and it essentially removes any temperature dependence of the heat of dissociation. Anderson (2004) discusses the weaknesses associated with making such an assumption for methane hydrate systems, and performs calculations in which this assumption is removed. The assumption is retained in this work for simplicity, and to facilitate comparisons between this method and the work of Lasich and coworkers (2014). Our result using the same procedure (equation 4.7) for determining enthalpy of dissociation is slightly better than the results obtained by Lasich et al. (2014) for all of the combinations of water and methane potentials that were used (see table 5, pg 53, Lasich et al., 2014). They report values from grand canonical Monte Carlo simulations 
that range from $102.5-114.6 \mathrm{~kJ} / \mathrm{mol}$. We believe that using eight unit cells in the simulation box, thereby increasing the resolution of the occupancy calculations, is the main reason why our method compares favorably to other work in the literature for predicting dissociation curves and enthalpies of dissociation using similar potential models and conditions.

\subsection{Conclusions}

The following conclusions were drawn from the results presented and discussed in section 4.3:

- Simulation of sI gas hydrate occupancy using the constant pressure Gibbs ensemble is an attractive alternative to the grand canonical ensemble because pressure, instead of fugacity or chemical potential, is given as an input parameter. This removes the need to calculate the pressure using an appropriate equation of state model, calculation of the molecular virial, or test volume moves. The main disadvantage of the constant pressure Gibbs ensemble compared to the grand canonical ensemble is the simulations are more computationally expensive because of the need to calculate interactions in both the box containing the hydrate lattice, and the fluid phase. However, this allows the calculation of properties for the fluid phase in equilibrium with the hydrate phase, and will be much more interesting in an extension of the work in which a mixture of guests is introduced. Another common disadvantage occurs when dealing with dense phases (high pressure and/or low temperature) or bigger molecules; in this case the acceptance rate of particle swap moves can be rather low. Biasing techniques have been developed to deal with this situation (Snurr 
et al., 1993). However, in this work they were not needed as acceptance rates of the particle swap moves, though low, were manageable (0.3-1.1\%). It is possible that in order to efficiently sample with a more complicated guest molecule in the simulation biasing techniques will be required, and if so they will be implemented in future work.

- The results of the simulations for sI methane hydrate can be used along with the procedure suggested by Lasich et al. (2014) and the vdW-P model to predict methane hydrate dissociation conditions. Deviation in predicted dissociation temperatures from this work compare favorably to those obtained by Lasich et al (2014) using similar potential models and GCMC simulations, suggesting that either the use of eight unit cells in the simulation box (resulting in higher resolution in occupancy) or the inclusion of pressure as an input parameter increases the accuracy of the results. The results of Papdimitriou et al. (2008) showed that in a GCMC simulation framework the number of unit cells included in the simulation does not affect the results. However, the simulations from this work were rerun using a single unit cell and the resulting occupancy was systematically higher (by as much as $5 \%$ at higher temperatures) than the occupancy predicted using eight cells. Therefore, the increased accuracy of the results is likely due to a combination of both including pressure explicitly and using a larger number of unit cells. Using a single unit cell also presents an issue because the lattice parameter, and thus the box size for the simulation box containing the hydrate phase, is 12.03 Angstroms. This limits the possible length for the Lennard-Jones cutoff to $\leq 6.015$ Angstroms because it must be less than 
half of the box size to be consistent with the minimum image convention (Allen and Tildesley, 1991). This leads to fewer important interactions being considered in the single cell simulation. For example, the average distance between guest molecules in a structure I hydrate is $~ 6$ Angstroms (Sloan and Koh, 2007), which may explain why the occupancy results from single cell simulations are systematically higher. That is, the interactions between guest molecules with guests in neighboring cavities and beyond, as well as with water molecules past the first coordination shell, are not being properly accounted for.

Another attractive aspect of the constant pressure Gibbs ensemble is that it is easy to imagine including additional simulation boxes. For example, a box could be added containing a liquid-like phase in a mixed hydrate system to study hydrate occupancy with a vapor and liquid phase in thermodynamic equilibrium. Future work on this project will involve the study of simple sI hydrates of $\mathrm{CO}_{2}$, mixed structure I hydrates of $\mathrm{CO}_{2}+\mathrm{CH}_{4}$, the addition of another simulation box to simulate mixed hydrate - vapor - liquid equilibrium, and finally structure II hydrates. 


\section{Nomenclature}

$C$ - Langmuir constant

$C_{P}$ - Isobaric heat capacity

GCMC - Grand canonical Monte Carlo

GEMC - Gibbs ensemble Monte Carlo

$H$ - Enthalpy

$P$ - Pressure

$R$ - Gas Constant

$T$ - Temperature

$V$ - Volume

$Z$ - Compressibility factor

$\underline{\text { Greek }}$

$\mu$-Chemical potential

$\theta$ - Occupancy 


\section{References}

Anderson, G. K. (2004). Enthalpy of dissociation and hydration number of methane hydrate from the Clapeyron equation. The Journal of Chemical Thermodynamics, 36(12), 1119-1127. doi:10.1016/j.jct.2004.07.005

Ballard, A. L., \& Jr, E. D. S. (2002). The next generation of hydrate prediction I . Hydrate standard states and incorporation of spectroscopy. Fluid Phase Equilibria, 197, 371-383.

Bai, P., Ghosh, P., Sung, J. C., Kohen, D., Siepmann, J. I., \& Snurr, R. Q. (2014). A computational study of the adsorption of n-perfluorohexane in zeolite BCR-704. Fluid Phase Equilibria, 366, 146-151. doi:10.1016/j.fluid.2013.07.018

Bandyopadhyay, A. A., \& Klauda, J. B. (2011). Gas Hydrate Structure and Pressure Predictions Based on an Updated Fugacity-Based Model with the PSRK Equation of State. Industrial \& Engineering Chemistry Research, 50(1), 148-157. doi:10.1021/ie100440s

Bivins, R. L., Herrick, C. C., \& Tester, J. W. (1972). Use of Monte Carlo in Calculating the Thermodynamic Properties of Water Clathrates. AIChE Journal, $18(6)$.

Bryk, T., \& Haymet, a. D. J. (2002). Ice 1h/water interface of the SPC/E model: Molecular dynamics simulations of the equilibrium basal and prism interfaces. The Journal of Chemical Physics, 117(22), 10258. doi:10.1063/1.1519538

Chakraborty, S. N., \& Gelb, L. D. (2012). A Monte Carlo simulation study of methane clathrate hydrates confined in slit-shaped pores. The Journal of Physical Chemistry. B, 116(7), 2183-97. doi:10.1021/jp205241n

Demir, B., \& Ahunbay, M. G. (2014). Prediction of perfluorohexane adsorption in BCR-704 zeolite via molecular simulation. Fluid Phase Equilibria, 366, 152158. doi:10.1016/j.fluid.2013.07.009

Glavatskiy, K. S., Vlugt, T. J. H., \& Kjelstrup, S. (2012). Toward a possibility to exchange $\mathrm{CO} 2$ and $\mathrm{CH} 4$ in sI clathrate hydrates. The Journal of Physical Chemistry. B, 116(12), 3745-53. doi:10.1021/jp2119586

Hachikubo, A., Miyamoto, A., Hyakutake, K., Abe, K., \& Shoji, H. (2002). Phase equilibrium studies on gas hydrates formed from various guest molecules and powder ice. The Fourth International Conference on Gas Hydrates. Yokohama, Japan. 357-360.

Hammerschmidt, E. G. (1934). Gas Hydrates in Natural Gas Transmission Lines. Industrial \& Engineering Chemistry, 1(4), 851-855. 
Handa, Y. P. (1986). Compositions, enthalpies of dissociation, and heat capaities in the range 85 to $270 \mathrm{~K}$ for clathrate hydrates of methane, ethane, propane, and enthalpy of dissociation of isobutane hydrate as determined by a heat-flow calorimeter. Journal of Chemical Thermodynamics, 18, 915-921.

Horn, H. W., Swope, W. C., Pitera, J. W., Madura, J. D., Dick, T. J., Hura, G. L., \& Head-Gordon, T. (2004). Development of an improved four-site water model for biomolecular simulations: TIP4P-Ew. The Journal of Chemical Physics, 120(20), 9665-78. doi:10.1063/1.1683075

Jager, M. D., Ballard, A. L., \& Sloan, E. D. (2003). The next generation of hydrate prediction II. Dedicated aqueos phase fugacity model for hydrate prediction. Fluid Phase Equilibria, 211(1), 85-107. doi:10.1016/S0378-3812(03)00155-9

Karakatsani, E. K., \& Kontogeorgis, G. M. (2013). Thermodynamic Modeling of Natural Gas Systems Containing Water. Industrial \& Engineering Chemistry Research, 52, 3499-3513.

Klauda, J. B., \& Sandler, S. I. (2000). A Fugacity Model for Gas Hydrate Phase Equilibria. Industrial \& Engineering Chemistry Research, 39, 3377-3386.

Klauda, J. B., \& Sandler, S. I. (2003). Phase behavior of clathrate hydrates : a model for single and multiple gas component hydrates. Chemical Engineering Science, $58,27-41$.

Kvamme, B., Graue, a., Buanes, T., Kuznetsova, T., \& Ersland, G. (2007). Storage of $\mathrm{CO} 2$ in natural gas hydrate reservoirs and the effect of hydrate as an extra sealing in cold aquifers. International Journal of Greenhouse Gas Control, 1(2), 236246. doi:10.1016/SI750-5836(06)00002-8

Li, S., Zhang, L., Jiang, X., \& Li, X. (2013). Hot-brine Injection for the Dissociation of Natural Gas Hydrates. Petroleum Science and Technology, 31(13), 1320-1326. doi:10.1080/10916466.2012.716887

Martin, M. G. (2013). MCCCS Towhee: a tool for Monte Carlo molecular simulation. Molecular Simulation, 39(14-15), 1212-1222. doi:10.1080/08927022.2013.828208

Martin, M. G., \& Siepmann, J. I. (1998). Transferable Potentials for Phase Equilibria. 1. United-Atom Description of $\mathrm{n}$-Alkanes. Journal of Physical Chemistry B, 5647(97), 2569-2577.

Munck, J., Skjold-Jørgensen, S., \& Rasmussen, P. (1988). Computations of the formation of gas hydrates. Chemical Engineering Science, 43(10). Retrieved from http://www.sciencedirect.com/science/article/pii/0009250988800101 
Nakamura, T., Makino, T., Sugahara, T., \& Ohgaki, K. (2003). Stability boundaries of gas hydrates helped by methane-structure- $\mathrm{H}$ hydrates of methylcyclohexane and cis-1,2-dimethylcyclohexane. Chemical Engineering Science, 58(2), 269-273. doi:10.1016/S0009-2509(02)00518-3

Nakano, S., Moritoki, M., \& Ohgaki, K. (1999). High-Pressure Phase Equilibrium and Raman Microprobe Spectroscopic Studies on the Methane Hydrate System. Journal of Chemical \& Engineering Data, 44(2), 254-257. doi:10.1021/je980152y

Papadimitriou, N. I., Tsimpanogiannis, I. N., Papaioannou, A. T., \& Stubos, a. K. (2008). Monte Carlo study of sII and sH argon hydrates with multiple occupancy of cages. Molecular Simulation, 34(10-15), 1311-1320. doi:10.1080/08927020802101734

Panagiotopoulos, A. Z. (1987). Direct determination of phase coexistence properties of fluids by Monte Carlo simulation in a new ensemble. Molecular Physics, 61(4), 813-826. doi:10.1080/00268970110097866

Park, Y., Kim, D.-Y., Lee, J.-W., Huh, D.-G., Park, K.-P., Lee, J., \& Lee, H. (2006). Sequestering carbon dioxide into complex structures of naturally occurring gas hydrates. Proceedings of the National Academy of Sciences of the United States of America, 103(34), 12690-4. doi:10.1073/pnas.0602251103

Parrish, W. R., \& Prausnitz, J. M. (1972). Dissociation Pressures of Gas Hydrates Formed by Gas Mixtures. Industrial \& Engineering Chemistry Research, 11(1), 26.

Platteeuw, J. C. ., \& Waals, J. H. van der. (1958). Thermodynamic Properties of Gas Hydrates. Molecular Physics, 1(1), 91-96.

Ravipati, S., \& Punnathanam, S. N. (2013). Calculation of Chemical Potentials and Occupancies in Clathrate Hydrates through Monte Carlo Molecular Simulations. The Journal of Physical Chemistry C, 117(36), 18549-18555. doi:10.1021/jp405771u

Sizov, V. V, \& Piotrovskaya, E. M. (2007). Computer simulation of methane hydrate cage occupancy. The Journal of Physical Chemistry. B, 111(11), 2886-90. doi:10.1021/jp0658905

Snurr, R. Q., Bell, A. T., \& Theodorou, D. N. (1993). Prediction of Adsorption of Aromatic Hydrocarbons in Silicate from Grand Canonical Monte Carlo Simulations with Biased Insertions. Journal of Physical Chemistry, 97, 13742 13752. 
Song, K. Y., \& Kobayashi, R. (1989). Final hydrate stability conditions of a methane and propane mixture in the presence of pure water and aqueous solutions of methanol and ethylene glycol. Fluid Phase Equilibria, 47(2-3), 295-308. doi:10.1016/0378-3812(89)80181-5

Tanaka, H. (1998). A novel approach to the stability of clathrate hydrates: grandcanonical MC simulation. Fluid Phase Equilibria, 144(1-2), 361-368. doi:10.1016/S0378-3812(97)00280-X

Tse, J. S. (1987). Thermal expansion of the clathrate hydrate of ethylene oxide and tetrahydrofuran. Journal de Physique, 48(3).

Uchida, T., Hirano, T., Ebinuma, T., Narita, H., Gohara, K., Mae, S., \& Matsumoto, R. (1999). Raman spectroscopic determination of hydration number of methane hydrates. AIChE Journal, 45(12), 2641-2645. doi:10.1002/aic.690451220

Vega, C., Abascal, J. L. F., \& Nezbeda, I. (2006). Vapor-liquid equilibria from the triple point up to the critical point for the new generation of TIP4P-like models: TIP4P/Ew, TIP4P/2005, and TIP4P/ice. The Journal of Chemical Physics, 125(3), 34503. doi:10.1063/1.2215612

Widom, B. (1963). Some Topics in the Theory of Fluids. The Journal of Chemical Physics, 39(11), 2808. doi:10.1063/1.1734110

Wierzchowski, S. J., \& Monson, P. A. (2007). Calculation of free energies and chemical potentials for gas hydrates using Monte Carlo simulations. The Journal of Physical Chemistry. B, 111(25), 7274-82. doi:10.1021/jp068325a

Yang, S. O., Cho, S. H., Lee, H., \& Lee, C. S. (2001). Measurement and prediction of phase equilibria for water + methane in hydrate forming conditions. Fluid Phase Equilibria, 185(1-2), 53-63. doi:10.1016/S0378-3812(01)00456-3

Yuan, Q., Sun, C.-Y., Liu, B., Wang, X., Ma, Z.-W., Ma, Q.-L., .. Zhang, K. (2013). Methane recovery from natural gas hydrate in porous sediment using pressurized liquid CO2. Energy Conversion and Management, 67, 257-264. doi:10.1016/j.enconman.2012.11.018 


\title{
CHAPTER 5 - Fully compositional and thermal reservoir simulation
}

Published in Computers and Chemical Engineering, April 2014

\author{
Rustem Zaydullin and Denis V. Voskov \\ Department of Energy Resources Engineering \\ Stanford University \\ Palo Alto, CA
}

Scott C. James

$E^{x}$ ponent, Inc.

320 Goddard, Suite 200

Irvine, CA 92618

\author{
Heath Henley \\ Department of Chemical Engineering \\ University of Rhode Island
}

Kingston, RI 02881

Angelo Lucia

FlashPoint LLC

Narragansett, RI 02882 


\begin{abstract}
Fully compositional and thermal reservoir simulation capabilities are important in oil exploration and production. There are significant resources in existing wells and in heavy oil, oil sands, and deep-water reservoirs. This article has two main goals: (1) to clearly identify chemical engineering sub-problems within reservoir simulation that the PSE community can potentially make contributions to and (2) to describe a new computational framework for fully compositional and thermal reservoir simulation based on a combination of the Automatic Differentiation - General Purpose Research Simulator (AD-GPRS) and the multiphase equilibrium flash library (GFLASH). Numerical results for several chemical engineering sub-problems and reservoir simulations for two EOR applications are presented. Reservoir simulation results clearly shows that the Solvent Thermal Resources Innovation Process (STRIP) outperforms conventional steam injection using two important metrics - sweep efficiency and oil recovery.
\end{abstract}




\subsection{Introduction}

Modeling and simulation to predict long-term performance of oil recovery methods (i.e., reservoir simulation) is a topic dating back to the 1950 s, late 1960 s, and the early 1970s (see Douglas Jr. et al., 1959; Price and Coats, 1974; Todd et al., 1972). Early reservoir models (e.g., black-oil reservoir models) were typically based upon rigorous mass balance equations for key species (oil, water, and gas) but only used approximate phase equilibrium (e.g., no oil dissolved in the water phase) and/or neglected energy balances. Nevertheless, by 1981, reservoir simulation had reached a level of maturity to warrant the first Society of Petroleum Engineers (SPE) Comparative Solutions Project on 3-D Black Oil Reservoir Simulation (Odeh, 1981), in which seven different companies participated. To date, there have been ten separate comparative solution projects sponsored by the SPE with topics that include three-phase behavior, steam injection, horizontal wells, and effective grid generation and up-scaling techniques. These Comparative Solutions Projects papers are useful for readers new to the reservoir simulation or those simply interested in learning more about challenging issues in this area.

Today, reservoir simulation has reached a point where advanced concepts such as dual-porosity models, rigorous phase behavior, energy balance considerations, fully implicit time stepping with Newton's method to solve the reservoir model equations at each time step, iterative linear solvers, finite difference, and/or analytical Jacobian matrices (to name a few) are common modeling components. 
There remains considerable oil in place (OIP) in many reservoirs that are either in current operation or have been shutdown (often with infrastructure remaining in place). There are also large amounts of fossil fuels in heavy oil, oil sands, and deep sea reservoirs - but these hydrocarbons are more challenging and more costly to produce. An increase in production of just $1 \%$ represents a $\$ 25$ B opportunity. Many oil producers are considering enhanced oil recovery (EOR) methods such as steam injection and in situ $\mathrm{CO}_{2}+$ steam injection (i.e., Solvent Thermal Resource innovative Process - or STRIP) as a means of increasing recovery. Modeling STRIP, and other advanced EOR methods necessarily requires both fully compositional and thermal reservoir flow simulation capabilities, something that remains challenging.

Perhaps it is not surprising that various aspects (or sub-problems) of fully compositional and thermal reservoir modeling and simulation are, in many ways, similar to modeling and equation-solving task associated with the kinds of chemical processes with which the PSE community and readership of Computers \& Chemical Engineering are familiar. These sub-problems include

1. Multi-phase equilibrium or flash.

2. Chemical reaction equilibrium.

3. Combined chemical and phase equilibrium.

4. Adiabatic flame temperature determination.

5. Heat and mass transfer in porous media.

6. Models consisting of differential-algebraic equations (DAEs).

7. Nonlinear equation-solving using Newton and trust region methods.

8. Iterative linear equations solving. 
Thus it is our opinion that chemical engineers, particularly those in the process systems engineering (PSE) community, are in a unique position to make significant contributions to various aspects of reservoir simulation.

In this paper, we present an advanced reservoir modeling and simulation framework for fully compositional and thermal reservoir simulation and subsequently apply this simulation framework to a comparative study of steam injection and STRIP in EOR applications. We also identify those sub-problems that are, in our opinion, problems that the PSE community can contribute to. Accordingly, this paper is organized as follows. Section 5.2 gives an overview of the relevant literature. In Section 5.3, a generalized reservoir model is presented; it includes model equations for both the reservoir and the bulk-phase length scales. Coupling between the reservoir and other constitutive equations needed to close the model (e.g., multi-phase equilibrium flash, viscosity correlations, Darcy's law, porosity, slip, capillary pressure, etc.) are also described. In Section 5.4, details that describe how model equations are formulated and solved at various computational levels are given. Specific algorithmic features of the coupled methodology are also presented. In Section 5.5, steam injection and STRIP are introduced along with common metrics used to evaluate thermal EOR methods. In Section 5.6, several relevant sub-problems are presented and solved prior to the application of this new reservoir simulation framework to two separate reservoir examples that demonstrate modeling and simulation capabilities while quantifying the reliability and computational efficiency of the proposed approach. A quantitative comparison of steam injection and STRIP is provided for the first reservoir simulation example using common performance metrics. The second example compares the 
performance of a modified compositional space adaptive tabulation (CSAT) with the conventional multiphase flash. Finally, in Section 5.7 conclusions of this work are drawn and future needs are highlighted while in Section 5.8 some additional subproblems of interest to the PSE community are identified.

\subsection{Literature Survey}

The main focus of this article is numerical reservoir simulation, which comprises a vast body of literature and thus it is not possible to survey all relevant scientific papers. Therefore in this section only a summary of those papers and numerical methods directly relevant to the modeling and simultaneous solution of numerical reservoir models is presented. We refer the reader to the book by Peaceman (2000) for an introduction to the fundamentals of reservoir modeling and simulation and a description of some of the earlier underlying numerical methods that have been used. A secondary focus of this manuscript is to identify sub-problems within a larger reservoir simulation that are clearly within the skill set of process systems engineers.

Some of the earliest work in numerical reservoir simulation dates back to 1959 and the pioneering work of Douglas Jr. et al. (1959), who developed numerical methods for the simultaneous solution of time dependent two-phase flow problems in one and two spatial directions. Governing partial differential equations (PDEs) describing conservation of mass and flow were converted to nonlinear algebraic equations using difference approximations and the resulting nonlinear algebraic model equations were then solved using various numerical methods including alternating-directions implicit, Jacobi iteration, successive over-relaxation, Gauss-Seidel iteration, and other 
established techniques. We refer the reader to the book by Ortega and Rheinboldt (1970) for a comprehensive description of these numerical methods. The work of Douglas Jr. et al. (1959) was later extended to three spatial dimensions by Coats et al. (1967) and three-phase flow problems by Peery and Herron (1969) and Sheffield (1969). Other journal articles that address additional physics in reservoir simulations and solve model equations simultaneously include those by Snyder (1969), Settari and Aziz (1974), and Trimble and McDonald (1981). Key differences among many of the early approaches to reservoir simulations reside largely in model formulation and the methods used to solve the resulting algebraic model equations. These differences persist today. Note that all of the topics that have just been described are topics that are very familiar to the PSE community - dynamical equations describing conservation of mass and energy, differencing, and nonlinear equation solving.

Current state-of-the-art reservoir simulation has moved to two basic nonlinear formulations - a natural formulation (Coats, 1980) and a molar formulation (Acs, 1985). Large sets or subsets of nonlinear algebraic equations result from discrete representations of the governing PDEs that describe the spatial and temporal evolution of the system. The most commonly used approaches for discrete representation are finite-difference or finite-volume approximations on structured or unstructured grids. The resulting algebraic equations are generally solved simultaneously using variants of Newton's method, although various forms of model reductions are also used. In the natural formulation, pressure, temperature, saturation, and all phase compositions for all grid blocks comprise the set of unknown variables. In the molar formulation, which is probably the formulation that is more familiar to engineers in the PSE community, 
pressure, temperature, and overall compositions (or total component mass) are the unknown variables. While there are many approaches to model formulation and solution, some of the more commonly used methods differentiate by temporal discretizations - Fully Implicit Method(FIM), IMplicit Pressure Explicit Saturation (IMPES), IMplicit Pressure and SATuration (IMPSAT), and Adaptive Implicit Methods (AIM).

For the description of different solution techniques that follows, we use the natural formulation in a reservoir application in which the pressures, saturations, and phase compositions for all grid blocks are the unknown variables. In the FIM, all pressures, saturations, and compositions of all phases are computed simultaneously at each time step. One of the key advantages of the FIM is that it is unconditionally stable. In contrast, the IMPES methodology treats all terms that depend on saturation and compositions, except the transient terms, as explicit functions of these variables. This allows saturation and composition to be decoupled from the pressure, resulting in a smaller subset of equations to be solved simultaneously, which reduces overall computational demand. However, because IMPES involves some explicit terms, integration may not be numerically stable in regions where volumetric flows are large. As a result, the computational time saved by reducing the size of the system of nonlinear equations can often be offset by smaller time stepping and, in the worst case, can lead to model failure. IMPSAT is similar IMPES, except that IMPSAT treats pressures and saturation variables for all grid blocks implicitly and phase compositions for all grid blocks explicitly. AIM, on the other hand, is intended to marry the best characteristics of FIM, IMPSAT, and IMPES by switching between different solution methods using 
one or more prescribed metrics, as solution stability demands. For example, AIM might use the spectral radius of a transformation matrix in the residuals of the mass conservation equations to decide when to switch from FIM in regions where instabilities in IMPES are likely and use IMPES everywhere else (Cao, 2002). A good survey of the numerical characteristics of FIM, IMPES, and AIM is given by Marcondes et al. (2009).

Regardless of the formulation, many current solution methods use some form of iterative linear equation solving (e.g., GMRES or other Krylov subspace methods) with pre-conditioning to solve the linear system of equations that determines the Newton correction to the variables at each time step.

\subsection{Reservoir Model Equations}

The equations describing the time evolution of fluid compositions, temperatures, and pressures in a reservoir comprise a set of coupled, nonlinear PDEs that describe conservation of mass, energy, and momentum. In addition, various thermo-physical properties, equilibrium (or non-equilibrium) behavior of fluid phases, properties of porous media, and well configuration specifications are included as algebraic constraints to the governing PDEs. In this article, the governing PDEs are represented in discrete form using finite-volume discretization and when used with additional constraints that form a large set of nonlinear algebraic equations. In this section, the reservoir equations as well as other constitutive equations are described.

\subsubsection{Reservoir Model Equations in General Form}


The nonlinear time-dependent PDEs that represent conservation of mass and energy in a reservoir are given by

$\frac{\partial}{\partial t}\left(\phi \sum \rho^{k} x_{i}^{k} S^{k}\right)-\sum \nabla\left(\rho^{k} x_{i}^{k} V^{k}+S^{k} J_{i}^{k}\right)-Q_{i}=0, i=1, \ldots, C$

and

$\frac{\partial}{\partial t}\left[(1-\phi) \rho_{M} U_{M}+\phi\right]-\sum \nabla\left(\rho^{k} H^{k} V^{k}+S^{k} G^{k}\right)-Q_{E}=0$

where $\phi$ is the porosity of the porous media, $\rho$ denotes molar density, $x$ is composition in mole fraction, $S$ is saturation, $V$ is volumetric flow, $J$ is molar diffusion flux, which is usually ignored for large scale applications, and $Q_{i}$ is a mass source or sink term. In eq. (5.2), $U$ denotes internal energy, $H$ is enthalpy, $G$ is heat conduction flux, $Q_{E}$ is an energy source or sink term, and the summation is also over all phases $k=1, \ldots, P$. The subscript $i$ denotes a given component while the superscript $k$ denotes a given phase. $C$ is the total number of components in the mixture and $P$ is the total number of phases. The subscript $M$ in eq. (5.2) denotes the porous media whereas the symbol $\nabla$ denotes the gradient of a vector.

\subsubsection{Phase Equilibrium in General Form}

Phase equilibrium in any given finite volume (also referred to as a cell or grid block) is described by the equality of partial fugacities for all components in all phases, clearly a topic on which publications in the chemical engineering literature abound. In particular, 
$f_{i}^{1}=f_{i}^{2}=\cdots=f_{i}^{k}, i=1, \ldots, C ; k=1, \ldots, P$

where $f_{i}^{k}$ denotes the partial fugacity of component $i$ in phase $k$ and is given by

$f_{i}^{k}=x_{i}^{k} \varphi_{i}^{k} p$

where $x$ denotes the mole fraction, $\varphi$ denotes the fugacity coefficient of component $i$ in phase $k$, and $p$ is pressure.

Conservation of mass within any grid block is represented by a set of component mass balance equations

$F z_{i}-\sum \rho^{k} S^{k} x_{i}^{k}=0, i=1, \ldots, C$

where $F$ and $z_{i}$ are the total density and mole fraction of component $i$ in the cell. Note that there is some overlap in symbols because standard notation in reservoir engineering and chemical engineering thermodynamics use the same symbol to denote different quantities. We caution the reader to pay careful attention to context so the meaning of a symbol is clear.

Finally, in the natural formulation, eqs. (5.1) - (5.3) are solved simultaneously and do not require a separate solution to the flash problem. For the molar formulation, overall composition, temperature, and pressure of a given finite volume are specified, and, as a consequence, eqs. (5.3) through (5.5), which constitute the classical isothermal, isobaric $(T p)$ flash problem, must be solved separately for the number and type of equilibrium phases and their corresponding compositions and densities. 


\subsubsection{Equation of State}

The topic of equations of state is intimately familiar to the PSE and thermodynamics communities of chemical engineering and, in general, equations of state (EOS) are required to model reservoir fluids. This is because some of the components (e.g, $\mathrm{CH}_{4}, \mathrm{~N}_{2}, \mathrm{CO}_{2}$ ) and/or mixtures of components can be supercritical at various conditions of temperature and pressure in a reservoir. Using an EOS, all phase properties (i.e., density, fugacity coefficients, fugacities, chemical potentials, enthalpies, etc.) can be readily computed. Furthermore, cubic equations are preferred over more complex equations like Statistical Associating Fluid Theory because they have a lower computational overhead and provide results that are within acceptable accuracy. As described later in this article, our implementation provides the user with a number of more commonly used cubic EOS.

\subsubsection{Other Constitutive Equations}

Other constitutive equations are also needed to close the numerical model and allow proper integration of eqs. (5.1) and (5.2). These constitutive equations include Darcy's Law, heat conduction, and when relevant, diffusion equations - again all topics familiar to the PSE community in traditional applications such as heat and mass transfer in catalyst pellets, non-equilibrium models in multi-stage distillation as well as more recent applications in bio-medical modeling and simulation of the brain, and others.

\subsubsection{Darcy's Law}


Darcy's law describes the volumetric flow of each phase, $V^{k}$, through porous media and is given by

$V^{k}=-\left(\frac{K R_{i}^{k} \rho^{k} x_{i}^{k}}{\mu^{k}}\right) \nabla\left(p+\rho^{k} x_{i}^{k} g z\right)$

where $K$ is an intrinsic rock or soil permeability, $R$ is relative permeability, $\mu$ is viscosity, $g$ is the acceleration due to gravity, and $z$ is the coordinate in the direction of gravity.

\subsubsection{Heat Conduction Equations}

The heat conduction equation is

$G^{k}=-K^{k} \nabla T$

where $K^{k}$ is the conduction coefficient for phase $k$ and $T$ is absolute temperature.

\subsubsection{Equation Coupling}

The conservation of mass and energy, flow, and conduction through porous media described by eqs. (5.1)-(5.7), and the equations describing the conservation of mass, conservation of energy with heat losses to the surroundings, phase equilibrium, and holdup in injection and production wells form a large system of nonlinear algebraic equations that are strongly coupled. In a hierarchical sense, the EOS lies at the innermost level of the computations and provides the phase densities. Phase densities are used to calculate fugacity coefficients, and fugacities to determine the type and amounts of each phase present in a grid block (i.e., by solving the traditional chemical engineering $T p$ 
flash). Calculated phase densities and composition from the flash are then used to determine the unknown variables at the reservoir level (e.g., pressures, saturations, and temperatures) as well as heat conduction fluxes, and the flow of phases through the porous media.

\subsection{Implementation}

As noted in the literature survey, a variety of computer implementations and methods of solving the model equations described in Section 5.3 are possible. In this subsection, we describe the specific implementation of the reservoir model, well models, and constitutive equations associated with heat conduction. The reservoir modeling system is called Automatic Differentiation - General Purpose Research Simulator (AD-GPRS). AD-GPRS was originally developed and is currently maintained by the SUPRI-B group in the Energy Resources Engineering Department at Stanford University. It enjoys widespread use throughout the reservoir and petroleum engineering communities. AD-GPRS is written in $\mathrm{C}++$. The EOS and flash calculations are implemented in a suite of FORTRAN programs called GFLASH, which was developed and is maintained by A. Lucia, and may be of particular relevance to the PSE community.

\subsubsection{AD-GPRS}

AD-GPRS is an advanced reservoir simulator with wide ranging capabilities that include

1) flexible treatment of all nonlinear physics, 
2) a fully thermal-compositional formulation for any number of phases,

3) multi-phase CSAT for the efficient and robust computation of phase behavior,

4) a variety of discretization schemes in time and space,

5) thermal geo-mechanical modeling with the presence of fractures,

6) a fully coupled, thermal, multi-segmented well model with drift-flux, and

7) an adjoint-based optimization module.

There are, of course, many details associated with AD-GPRS (Voskov and Zhou., 2012); here we only summarize its main features.

\subsubsection{Formulations}

Both natural and molar formulations are available in AD-GPRS (Voskov and Tchelepi, 2012). Regardless of formulation, the primary dynamical model equations describing the time evolution of material and energy in a reservoir given by eqs. (5.1) and (5.2) are appended with a number of constraint equations to form a differential algebraic equation (DAE) system. The algebraic constraint equations include

1) fugacity constraints [i.e., eq. (5.3)].

2) summation equations for the mole fractions in each phase.

$$
1-\sum_{i=1}^{C} x_{i}^{k}=0
$$

3) saturation summation equations

$$
1-\sum_{k=1}^{P} S^{k}=0
$$

4) volume balance constraints when total mass variables are used

$$
\phi \rho_{T} V-\sum_{i=1}^{C} n_{i}=0
$$


Equations (5.1), (5.2), (5.3), (5.6), (5.7), (5.8), (5.9), and (5.10) comprise a DAE representation of the reservoir equations.

\subsubsection{Discretization}

The DAE system described by Eqs. (5.1), (5.2), (5.3), (5.6), (5.7), (5.8), (5.9), and (5.10), is converted into a set of nonlinear algebraic equations using finite volume spatial and temporal discretization. Note that Eqs. (5.1), (5.2), (5.3), (5.6), (5.7), and (5.8) are essentially the same equations used to model traditional steady and unsteadystate chemical processes.

\section{$\underline{\text { Spatial Discretization }}$}

Spatial representation of a reservoir in discrete form in AD-GPRS uses the Multi-Point Flux Approximation to account for the geometry of fluxes across interfaces (see Zhou et al., 2011 for details). Consider the flux across the interface shared by two cells, denoted by $j$ and $j_{1}$, and assume that the normal vector at the interface has an orientation that points into cell $j$. The overall flux of component i from $j_{1}$ to $j$ is given by

$F^{j, j_{1}}=\sum_{k} x_{i}^{k} \rho^{k} \lambda^{k}\left(\Phi^{j, j_{1}}\right)^{k}$

where $\lambda^{k}$ is the mobility of phase $k$. Here all quantities except $\left(\Phi^{j, j_{1}}\right)^{k}$ are taken in upstream of flow direction. $\left(\Phi^{j, j_{1}}\right)^{k}$ is called the geometric part of the flux of phase $k$ and is approximated by

$$
\left(\Phi^{j, j_{1}}\right)^{k}=\sum \theta^{j, j_{1}}\left(p_{j}^{k}-p_{j_{1}}^{k}+g\left(\gamma^{j, j_{1}}\right)^{k} d^{j}\right)
$$


where the summation in eq. (5.12) is over the number of data points associated with the flux across interface $\left\{j, j_{1}\right\}$ (only one for a Two-Point Flux Approximation), $\theta^{j^{,} j_{1}}>0$ is the transmissibility coefficient average on interface $\left\{j, j_{1}\right\}, d^{j}$ is the depth of cell $j$, and $\left(\gamma^{j, j 1}\right)^{k}$ is the mass density of phase $k$ averaged at the interface $\left\{j, j_{1}\right\}$.

Similarly heat (energy) flux can be expressed as

$E^{j, j_{1}}=\sum_{k}\left\{\rho^{k} H^{k} \lambda^{k}\left(\Phi^{j, j_{1}}\right)^{k}+S^{k} \kappa^{k} \theta_{g}^{j, j_{1}}\left(T_{j}-T_{j_{1}}\right)\right\}$

where $\theta_{g}^{j, j_{1}}$ is the geometrical part of the transmissibility coefficient assuming TwoPoint Flux Approximation (TPFA) for the conduction term (Voskov and Zhou., 2012).

$\underline{\text { Temporal Discretization }}$

Temporal discretization by implicit integration is unconditionally stable. ADGPRS has a number of the commonly used temporal discretizations - FIM, IMPES, IMPSAT, and AIM. As noted in section 5.2, each of these methods represents a different approach where different unknown variables and equations are treated either explicitly or implicitly. In AD-GPRS, FIM, IMPES, and IMPSAT are all considered special cases of AIM. Finally, Courant-Friedrich-Lewy (CFL) stability criteria are used to adaptively determine the level of implicitness in solving the model equations.

\subsubsection{Solution of Nonlinear Algebraic Equations}

The Newton-Raphson method is used where a Jacobian matrix is assembled and a linear system of equations solved for each iteration. The relations, other than the mass 
conservation equations, are treated as constraints that are local to a grid block (cell). To minimize the size of the global linear system, a Schur-complement procedure is applied to the full Jacobian matrix of each block to express the primary (mass conservation) equations as a function of the primary variables only $(\mathrm{CaO}, 2002)$. After the size of the system is reduced, the resulting global linear system of equations is solved for the primary variables. An iterative linear equation solver with pre-conditioning is used to solve the linear system.

After the linear system is solved, the computed changes in the primary variables are used with the secondary equations to obtain changes in the secondary variables locally in each grid block. Next, the nonlinear variables can be updated using different strategies and safeguards to ensure that the solution remains within physical boundaries. Convergence of Newton-Raphson iteration depends on several aspects that include (1) any corrections to updated variables that employ safeguards, (2) various chopping strategies for different unknowns, and (3) the choice of time step. Several strategies for updating variables and time step choice are implemented in AD-GPRS (Voskov and Zhou., 2012).

\title{
5.4.1.4 Phase Behavior Computations
}

In this section, we describe different approaches to phase behavior computations in AD-GPRS, which include the use of intermittent flash solutions and CSAT.

\author{
$\underline{\text { Intermittent Flash Problem Solutions }}$
}


For phase behavior computations, AD-GPRS uses a two-stage procedure. In the first stage, the number of phases that exist in each cell is determined. This can be obtained using Gibbs energy minimization or phase stability analysis (Michelsen, 1982a). In the second stage, flash calculations are performed to determine the compositions of the existing phases (Michelsen, 1982b). At both stages a combination of Successive Substitution Iteration and Newton's method is used.

As an alternative to this two-stage strategy, a generalization of the negative-flash based approach of Whitson and Michelsen (1989) can be used (Iranshahr et al., 2010). Here it is assumed that the number of phases present is the maximum possible, and then eqs. (5.3) and (5.5) are solved, allowing for phase fraction $V^{k}$ to be less than zero, or greater than one. When the phase fractions of a converged negative flash procedure are negative, fewer existing phases are assumed and a similar procedure for this reduced system may be required (Iranshahr et al., 2010).

\section{$\underline{\text { Compositional Space Adaptive Tabulation (CSAT) }}$}

Solving flash problems for all grid blocks over all nonlinear iterations and time steps is computational demanding. To improve the performance of phase behavior computation in reservoir simulation, the CSAT approach originally developed by Voskov and Tchelepi (2009a,b) is used. CSAT adaptively stores a discrete set of tielines at different pressures and temperatures to represent phase behavior during reservoir simulation. This collection of tie-lines is interpolated and used to look up the phase state of the mixture at a particular pressure and temperature. In addition, the 
number of tie lines can be collected adaptively based on the specific attributes of a compositional solution during a reservoir simulation.

CSAT completely replaces the need for phase stability tests and provides good initial guesses for the standard $T p$ flash computations.

\section{Compositional Space Parameterization (CSP)}

The compositional space parameterization (CSP) method (Voskov and Tchelepi, 2009a; Zaydullin et al., 2013) is based on casting the nonlinear governing equations (1) and (2), including thermodynamic phase equilibrium constraints (3), in terms of the tiesimplex $(\gamma)$ space. During a simulation, the $\gamma$ space is adaptively discretized using supporting tie-lines. The coefficients for the governing system of equations, including the phase compositions, densities, and mobilities, are computed using multi-linear interpolation in the discretized space.

Using the CSP methodology, phase behavior computations can be replaced by an iteration-free look-up table procedure during the course of a reservoir simulation, removing the need for standard EOS computations (phase stability and flash). Also, it is important to note that the error associated with multi-linear interpolation is bounded and decreases with grid (or $\gamma$ space) refinement (Zaydullin et al., 2013) and therefore only a limited number of supporting tie-lines are needed for the accurate representation of phase behavior. That, in turn, leads to significant gains in computational efficiency. 
Tie-lines or tie-simplexes needed for CSAT and CSP can be parameterized using the generalized negative flash procedure (Iranshahr et al., 2010) or using GFLASH (Section 5.4.2).

\subsubsection{GFLASH}

GFLASH is a FORTRAN suite that models and solves the traditional chemical engineering multi-phase, multi-component isothermal, isobaric ( $T p$ ) flash problem. That is, given an overall composition for a fluid mixture, $z$, a temperature, $T$, and pressure, $p$, GFLASH determines the number of phases that exist at equilibrium and their corresponding compositions, fugacities, densities, and enthalpies. In this section, formulations, overall solution strategies, and methods of solution are described.

\subsubsection{Equations of State}

A number of the commonly used cubic EOS with and without volume translation are implemented in GFLASH. The EOS available include the

1) Soave-Redlich-Kwong (SRK) equation (Soave, 1972),

2) SRK with the Peneloux volume translation (SRK+) equation (Péneloux et al., 1982),

3) Predictive SRK (PSRK) equation (Holderbaum and Gmehling, 1991),

4) Electrolyte PSRK (ePSRK) equation (Kiepe et al., 2004),

5) Peng-Robinson (PR) equation (Peng and Robinson, 1976),

6) volume translated PR (VTPR) equation (Ahlers and Gmehling, 2001; Ahlers and Gmehling, 2002), and 
7) multi-scale Gibbs-Helmholtz Constrained (GHC) equation (Lucia et al., 2012).

\section{Formulation and Solution}

All EOS are formulated as cubic polynomials in compressibility factor, $z$, in the complex plane in the form

$f(z)=c_{1} z^{3}+c_{2} z^{2}+c_{3} z+c_{4}=0$

The resulting single variable function, $f(z)$, is solved using Newton's method in the complex plane to find any root to an accuracy of $|f(z)| \leq 10^{-12}$. The cubic polynomial is then deflated to a quadratic equation, which is solved using the quadratic formula to determine the other two roots. This approach removes the need to use an accurate initial guess for Newton's method, guarantees that all three roots will always be found, and is actually faster than using the analytical solution to a cubic polynomial.

\section{$\underline{\text { Root Assignment }}$}

Correctly determining which root is liquid and which root is vapor is as important, if not more important, than computing roots to EOS and is particularly challenging under harsh conditions (i.e., high $T$ and high $p$ ). The current approach used to assign roots in GFLASH is as follows: For a set of roots given by $\left\{z_{1}, z_{2}, z_{3}\right\}$, where any root has the complex variable form $z_{k}=a_{k} \pm b_{k}, k=1,2,3$, we define

$$
z^{L}=\min \left\{\left|z_{k}\right|\right\} \text { and } z^{V}=\max \left\{\left|z_{k}\right|\right\}
$$


where $\left|z_{k}\right|$ denotes the complex absolute value function given by $\left|z_{k}\right|=\sqrt{a_{k}^{2}+b_{k}^{2}}$ and the superscripts $\mathrm{L}$ and $\mathrm{V}$ denote liquid and vapor respectively. Phase densities are easily computed from the compressibility factors, $z^{L}$ and $z^{V}$, using the expression

$\rho=\frac{p}{z R T}$

\subsubsection{Flash Problem Formulations and Method of Solution}

The flash problem is really two problems - a phase stability problem and a phase equilibrium problem. In GFLASH, the formulations of the phase stability and phase equilibrium conditions use the dimensionless Gibbs free energy of mixing, $\Delta G / R T$, and the dimensionless Gibbs free energy, $G / R T$, respectively.

$\underline{\text { Phase Stability }}$

Minima in $\Delta G / R T$ often turn out to be inexpensive and good approximations for points of tangency. The necessary conditions for a minimum in $\Delta G / R T$ are formulated in terms of the equality of dimensionless chemical potentials, $\mu_{i}, i=1, \ldots, C$. For the phase split (or phase stability) problem, which is always a two-phase determination, the model equations are given by

$F(x)=\frac{\left[\left(\mu_{1}-\mu_{i}^{0}\right)-\left(\mu_{C}-\mu_{C}^{0}\right)\right]}{R T}, i=1, \ldots, C-1$

where the superscript 0 denotes standard state and the unknown variables in eq. (5.17) are the mole fractions, $x_{i}, i=1, \ldots, C-1$, of a single hypothetical phase. Note that 
this formulation of the phase split problem results from the projection of the dimensionless Gibbs free energy of mixing onto the summation equation [i.e., eq. (5.8)].

\section{$\underline{\text { Phase Equilibrium }}$}

Phase equilibrium equations are also formulated in terms of dimensionless chemical potentials using projection onto the conservation of mass equations. Conservation of mass for the phase equilibrium problem is given by

$n_{i}-\sum n_{i}^{k}=0, i=1, \ldots, C$

where $n_{i}$ is the overall moles of component $i$ in the system and is fixed, $n_{i}^{k}$ is the number of moles of $i^{\text {th }}$ component in the $k^{\text {th }}$ phase, and the summation in eq. (5.18) is over all phases. Note that the phase equilibrium problem is formulated in terms of mole numbers, not mole fractions, because it is a way of exploiting many of the useful mathematical properties of partial molar quantities.

Phase equilibrium is defined by the equality of dimensionless chemical potentials given by

$\mu_{i}^{1} /_{R T}=\mu_{i}^{2} /_{R T}=\cdots=\mu_{i}^{k} /_{R T}, \quad i=1, \ldots, C ; k=1, \ldots, P$

for any number of total phases, P. Equation (5.19) is expressed in the form

$F\left(n_{i}^{1}, n_{i}^{2}, \ldots, n_{C}^{P}\right)=\left(\mu_{i}^{1} /_{R T}-\mu_{i}^{k} /_{R T}\right)=0, \quad i=1, \ldots, C ; k=1, \ldots, P$ 
and then projected onto the mass balance constraints in eq. (5.18) to reduce the size of the phase equilibrium problem and to ensure that conservation of mass is satisfied at each iteration.

\section{Other Modeling Capabilities in GFLASH}

GFLASH also has the capability of solving chemical reaction equilibrium problems and combined chemical and phase equilibrium problems, topics that are both familiar to the PSE community and important in various applications of EOR. For example, in applications of STRIP, partial oxidation of methane is used to generate in situ $\mathrm{CO}_{2}$ and steam. In other EOR applications, where production water is re-used in order to defray the high cost of purchasing municipal water or expensive water

treatment, salt precipitation in the presence of multiple fluid phases, which is a combined chemical and phase equilibrium problem, can be a serious operational problem. These sub-problems are also solved by Gibbs free energy minimization within the GFLASH framework.

\section{Method of Solution}

GFLASH uses a trust region method to solve both the phase stability and phase equilibrium model equations. This methodology is a simple version of the terrain methodology developed by Lucia and Feng (2003). When applied to phase stability and phase equilibrium, we restrict the terrain method to look for only one stationary point in each of $\Delta G / R T$ and $G / R T$ respectively. 
In addition, when solving flash problems, GFLASH alternates between phase stability and phase equilibrium sub-problems, maintaining a monotonically decreasing sequence of values of $G / R T$ until a global minimum identifying the number and type of phases as well as their associated mole numbers is found. Phase stability problems [i.e, eq. (5.17)] are solved to an accuracy of $\|F(x)\|_{2} \leq 10^{-6}$, where $\|\cdot\|_{2}$ denotes the 2norm or Euclidean norm. In contrast, phase equilibrium problems (eq. 5.20) are solved to an accuracy of $\|F(n)\|_{2} \leq 10^{-4}$ for two-phase equilibria and $10^{-5}$ for three-phase equilibria.

\subsubsection{The Connection Between CSAT and GFLASH}

In this section, we describe the connection between rigorous phase stability and flash computations using GFLASH and CSAT. We also describe the interface between ADGPRS and GFLASH.

\subsubsection{Conventional phase behavior computations}

The number and types of phases (or phase state) of a mixture in a given grid block can vary. For example, for mixtures that exhibit three-phase behavior, there are seven different possible phase states - three single phase states (i.e., water-rich liquid, vapor, or oil-rich liquid), three different two-phase states (i.e., LLE, water-rich VLE, or oilrich VLE), or vapor-liquid-liquid equilibrium (VLLE). Thus, the phase state as well as all corresponding phase compositions need to be determined for every grid block on each Newton iteration. For the natural formulation, a three-step procedure is usually used for these computations: 
1. For any grid block, the current phase state is determined using a phase stability test.

2. If the current phase state is different from one on a previous Newton iteration, flash computations are performed to obtain phase compositions.

3. Phase properties (i.e., fugacities, densities, enthalpies, etc.) are obtained using known phase compositions.

Because of the complexity of the ADGPRS-GFLASH interface, both a phase stability test and flash computations are performed simultaneously in the current model framework realization.

\subsubsection{Phase behavior computations with CSAT}

As noted, CSAT can significantly improve the time required for phase behavior computations in fully compositional reservoir simulation (Voskov and Tchelepi, 2009a; Voskov and Tchelepi, 2009b). The general multiphase implementation of CSAT (Iranshahr et al., 2010; Voskov and Tchelepi, 2009b) is a two-step procedure:

1. Computation of supporting tie-simplexes (i.e., tie-triangles for three-phase systems).

2. Parameterization of tie-simplex subspace (tie-triangle planes for three-phase systems).

In the original CSAT implementation of Iranshahr et al. (2010), a generalization of the negative-flash idea (Whitson and Michelsen, 1989) for Step 1 and geometrical parameterization (i.e.,. tracking tie-lines from each side of a tie-triangle) for Step 2 was used. While this approach proves to be robust for challenging three-phase systems, it 
requires some preliminary knowledge of a multiphase mixture under investigation because the geometry of tie-simplex subspace can be quite complicated.

In this work, we have used a different strategy. First, we use GFLASH to provide fugacities for given pressure, temperature, and phase compositions and the generalized negative flash approach (Iranshahr et al., 2010) is used to find a supporting tie-simplex for the CSAT procedure. Next, an extension of the tie-simplex is adaptively discretized and GFLASH determines the phase state of a model cell. Finally, the collection of tiesimplexes and their extensions are interpolated for a particular pressure and temperature and used to look up the phase state of the mixture.

\subsubsection{AD-GPRS/GFLASH Interface}

Because AD-GPRS is written in C++ and GFLASH is a FORTRAN suite, the proposed modeling and simulation framework is necessarily mixed language and therefore an interface is needed to communicate information between the two programs. The interface program is described in Appendix A.

\subsection{Thermal EOR Methodologies}

In this section, steam injection and STRIP are introduced along with common performance metrics used to evaluate thermal EOR methods. We refer the reader to the work of Aziz et al. (1987), which is the $4^{\text {th }}$ SPE Comparative Solution Project: Comparison of Steam Injection Simulators, for an introduction to steam injection and associated simulation challenges.

\subsubsection{Steam Injection}


Steam injection is generally implemented using surface facilities to generate superheated steam, which is injected into a reservoir through a well. The entering steam heats the formation and lowers oil viscosity, which allows the oil to flow more easily to production wells. In all steam injection methods, surface generation of steam suffers from a number of disadvantages, not the least of which is energy losses (up to 50\%) to the walls of the injection well.

\subsubsection{Solvent Thermal Resource Innovation Process (STRIP)}

STRIP, which has been developed by RII North America, is an environmentally friendly approach to EOR, which is typically deployed into existing wells, so there is little or no disruption of land. Unlike other steam injection processes, STRIP generates steam and $\mathrm{CO}_{2}$ by in situ combustion of methane in oxygen, which eliminates energy losses to the injection well and delivers steam directly to the formation. STRIP also provides a co-solvent, $\mathrm{CO}_{2}$, which is well known to enhance oil recovery by swelling oil and lowering viscosity. The STRIP burner can be placed in a number of configurations, but in this work the STRIP burner resides in a vertical section of the injection well. Because the combustion temperature can approach $3,000^{\circ} \mathrm{C}$, the STRIP burner is typically cooled using production water, significantly reducing and often removing the need for municipal water. The nominal composition of lumped gases entering a reservoir formation is around $10 \mathrm{~mol} \%$, with roughly $6.7 \mathrm{~mol} \%$ being $\mathrm{CO}_{2}$.

\subsubsection{Performance Metrics}

Several common metrics are used to evaluate the performance of a thermal EOR methodology. These metrics include (1) sweep and (2) oil recovery, which, of course, is of primary interest. 


\subsection{Numerical Examples}

In this section, two reservoir simulation examples are presented to elucidate key points, to compare the performance of steam injection and STRIP, and to demonstrate the reliability and computational efficiency of the numerical tools in GFLASH and AD-

GPRS. However, prior to presenting results for reservoir simulation with STRIP, a number of traditional chemical engineering sub-problems needed to be solved, including a chemical equilibrium problem, an adiabatic flame temperature problem, and a salt precipitation problem, to clarify and quantify various aspects of the reservoir simulations.

\subsubsection{Example 1: Chemical Equilibrium of STRIP Combustion}

As noted, STRIP generates in situ $\mathrm{CO}_{2}$ and steam by partial oxidation of methane. In a typical application, the reactants are fuel-rich and thus there are a number of 'major' syngas by-products such as $\mathrm{H}_{2}$ and $\mathrm{CO}$, and un-reacted methane and $\mathrm{O}_{2}$ in addition to the $\mathrm{CO}_{2}$ and steam. However, the composition of the combustion product stream is a function of both the $\mathrm{O}_{2} / \mathrm{CH}_{4}$ ratio and the reaction temperature, the latter of which we do not know. The $\mathrm{O}_{2} / \mathrm{CH}_{4}$ ratio, which is denoted by $\mathrm{r}$, is an operational decision based on extensive laboratory experimentation and can vary between at 1.6 and 1.9 depending on the application. Note that the stoichiometric ratio of oxygen/methane for complete combustion is 2 and thus STRIP combustion is fuel-rich and thus will produce some syngas $\left(\mathrm{H}_{2}\right.$ and $\left.\mathrm{CO}\right)$.

The governing equations for this single vapor phase chemical equilibrium problem are 
$\min \frac{G}{R T}=\sum_{i=1}^{C} n_{i} \mu_{i} / R T$

subject to mass balances for hydrogen, oxygen, and carbon

$\sum_{i=1}^{n} a_{i j} n_{i}=A_{j}, j=1, \ldots, J$

where $J$ is the number of atomic species, $A_{j}$ is the total amount of atom $j$ in the system, and $a_{i j}$ is the number of $j^{t h}$ atoms in the $i^{\text {th }}$ molecular compound. For this example, using a basis of 1 mole of $\mathrm{CH}_{4}$, the mass balances are

hydrogen: $2 n_{\mathrm{H} 2}+0 n_{\mathrm{O} 2}+0 n_{\mathrm{CO}}+4 n_{\mathrm{CH} 4}+0 n_{\mathrm{CO} 2}+2 n_{\mathrm{H} 2 \mathrm{O}}=4$

oxygen: $\quad 0 n_{\mathrm{H} 2}+2 n_{\mathrm{O} 2}+1 n_{\mathrm{CO}}+0 n_{\mathrm{CH} 4}+2 n_{\mathrm{CO} 2}+1 n_{\mathrm{H} 2 \mathrm{O}}=2 r$

carbon: $0 n_{\mathrm{H} 2}+0 n_{\mathrm{O} 2}+1 n_{\mathrm{CO}}+1 n_{\mathrm{CH} 4}+1 n_{\mathrm{CO} 2}+0 n_{\mathrm{H} 2 \mathrm{O}}=r$

Figure 5.1 shows the effect of reaction temperature on the composition of STRIP combustion products for temperatures between 300 and $3100{ }^{\circ} \mathrm{C}$ at 20 bar. Note that above about $1000{ }^{\circ} \mathrm{C}$, there is very little change in the composition of the combustion products. 


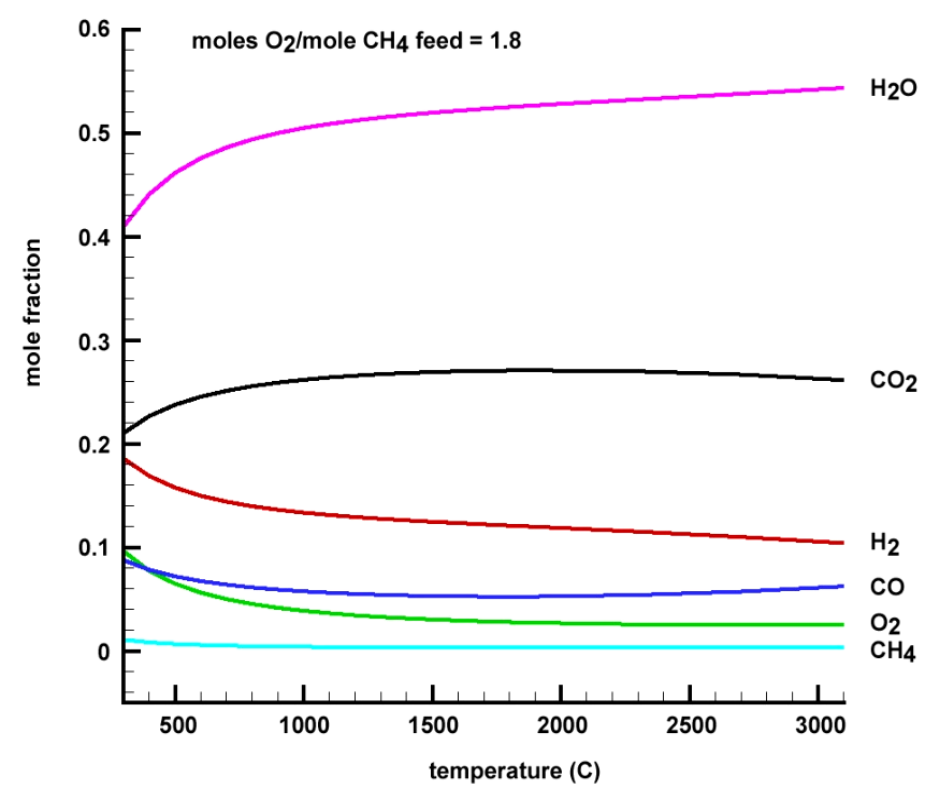

Figure 5.1: STRIP Combustion Product Composition vs. Temperature for a Fuel-Rich Burner Table 5.1 gives the details of a single chemical equilibrium computation for $2500{ }^{\circ} \mathrm{C}$ at 20 bar for an oxygen-to-methane ratio of 1.8. Note that there is a significant amount of 'major' by-product gases, about $20 \mathrm{~mol} \%$, and a net production of 0.269696 moles.

Table 5.1: Numerical Results for Chemical Equilibrium of STRIP Combustion

\begin{tabular}{|c|c|c|}
\hline Chemical Species & Feed Mole Fractions & Product Gas Mole Fractions \\
\hline $\mathbf{H}_{\mathbf{2}}$ & 0 & 0.133035 \\
\hline $\mathbf{O}_{\mathbf{2}}$ & 0.6428571 & 0.028308 \\
\hline $\mathbf{C O}$ & 0 & 0.042660 \\
\hline $\mathbf{C H}_{\mathbf{4}}$ & 0.3571428 & 0.002809 \\
\hline $\mathbf{C O}_{\mathbf{2}}$ & 0 & 0.280303 \\
\hline $\mathbf{H}_{\mathbf{2}} \mathbf{O}$ & 0 & 0.512884 \\
\hline Total Moles & 2.8 & 3.069696 \\
\hline
\end{tabular}

\subsection{Example 2: Adiabatic Flame Temperature}

While Fig. 5.1 gives chemical equilibrium results for a wide range of combustion temperatures, the actual temperature of the combustion products for a given set of 
conditions should be estimated using an adiabatic flame temperature calculation and is coupled to the previous chemical equilibrium problem because the temperature and composition are interdependent. However, because product gas compositions are relatively weak functions of temperature above about $1000{ }^{\circ} \mathrm{C}$, we can effectively decouple the problems and solve the adiabatic flame temperature problem using the product gas compositions shown in Table 1. The corresponding problem formulation, which is rather simple and can be found in several undergraduate level thermodynamics textbooks, is shown in eq. (5.26).

$0=\Delta H_{R}^{0}+\sum_{i=1}^{C} \int_{T_{0}}^{T} n_{i} C_{p, i} d T$

where $\Delta H_{R}^{0}$ is the standard heat of reaction, $T_{0}$ is a reference temperature and equal to $25{ }^{\circ} \mathrm{C}$, and $C_{p, i}$ is the heat capacity for the $i^{t h}$ component. Data for $\Delta H_{R}^{0}$ and $C_{p, i}$ are given in Appendix B. The calculated adiabatic flame temperature for an oxygen-tomethane ratio of 1.6 is $3343.975{ }^{\circ} \mathrm{C}$.

\subsubsection{Example 3: Salt Precipitation}

Use of production water in EOR processes can reduce the cost of purchasing municipal water or operating an on-site water treatment plant and concomitantly lower environmental impact. The main challenge associated with the use of production water is the presence of ions and the potential for salt precipitation. To lower the potential for precipitation, production water can be mixed with clean water. In the case of STRIP, production water is mixed with in situ generated steam for two purposes - to generate additional steam and to cool the STRIP combustion burner. Table 5.2 gives an 
illustration of the compositions of production water and the combined feed for a STRIP application to a real reservoir in Saskatchewan, Canada before and after mixing. Note that production water analyses are generally reported as molality, whereas mass or mole fractions are generally used in flash calculations.

Table 5.2: Composition of Production Water and Combined Feed for STRIP

\begin{tabular}{|c|c|c|}
\hline Chemical Species & $\begin{array}{c}\text { Production Water } \\
\text { Molality }\left(\mathrm{mol} / \mathrm{kg} \mathrm{H}_{2} \mathrm{O}\right)\end{array}$ & $\begin{array}{c}\text { Mole Fractions of } \\
\text { Combined Feed }\end{array}$ \\
\hline $\mathbf{H}_{2}$ & 0 & 0.016793 \\
\hline $\mathbf{O}_{2}$ & 0 & 0.003229 \\
\hline $\mathrm{CO}$ & 0 & 0.006459 \\
\hline $\mathrm{CH}_{4}$ & 0 & 0.000388 \\
\hline $\mathrm{CO}_{2}$ & 0 & 0.043532 \\
\hline $\mathrm{Na}^{+}$ & 1.100299 & 0.017692 \\
\hline $\mathbf{K}^{+}$ & 0.007587 & 0.000122 \\
\hline $\mathrm{Ca}^{2+}$ & 0.029479 & 0.000474 \\
\hline $\mathrm{Cl}^{-}$ & 1.166844 & 0.018762 \\
\hline $\mathrm{SO}_{4}{ }^{2-}$ & 0.000023 & $3.68 \times 10^{-7}$ \\
\hline $\mathrm{H}_{2} \mathrm{O}$ & 0.983278 & 0.892549 \\
\hline Total & & 1.000000 \\
\hline
\end{tabular}

The real concern regarding precipitation comes from the fact that the combustion products from STRIP are very hot and thus the amount of liquid available to dissolve ions, even after mixing, might be quite small if too much vaporization occurs. Remember, the main purpose of STRIP is to inject enough steam and $\mathrm{CO}_{2}$ into the reservoir for improved oil recovery. What this means is that the desired fluid stream entering the reservoir (i.e., at the injection well bore) should have a relatively high vapor fraction, say between 0.7 and 0.8 . To determine whether or not salt precipitation will occur, we must therefore solve a combined chemical and phase equilibrium flash problem at high temperature. Salt precipitation is a heterogeneous chemical equilibrium 
problem and must be determined by comparing equilibrium solubility products, $K_{s p}$, to ion solubility products, $Q_{s p}$, for all possible molecular salts as shown in eq. (5.24).

$K_{s p}^{k}>Q_{s p}^{k}$, then aqueous liquid is under-saturated with molecular salt k

$K_{s p}^{k}=Q_{s p}^{k}$, then aqueous liquid is saturated with molecular salt $\mathrm{k}$

$K_{s p}^{k}<Q_{s p}^{k}$, then the aqueous liquid is super-saturated with salt k

For $k=1, \ldots, n_{s}$

where $n_{s}$ is the number of molecular salts. In this example, there are six possible molecular salts: $\mathrm{NaCl}, \mathrm{KCl}, \mathrm{CaCl}_{2}, \mathrm{Na}_{2} \mathrm{SO}_{4}, \mathrm{~K}_{2} \mathrm{SO}_{4}$ and $\mathrm{CaSO}_{4}$. The standard Gibbs free energy and enthalpy of formation data used to compute $K_{s p}$ is shown in Appendix B. Moreover, it is entirely possible to compute multi-phase equilibrium flash solutions that are supersaturated and meta-stable; thus simultaneously satisfying conditions of multi-phase and chemical equilibrium is quite challenging. Table 5.3 shows a metastable VLE flash solution for the combined feed in Table 5.2 at $255{ }^{\circ} \mathrm{C}$ and 18 bar computed using the GHC equation of state.

Table 5.3: Meta-stable Flash Solution to Combined Chemical and Phase Equilibrium Problem

\begin{tabular}{|c|c|c|c|}
\hline Quantity & $\begin{array}{c}\text { Mole Fractions of } \\
\text { Combined Feed }\end{array}$ & Aqueous Liquid & Vapor \\
\hline $\mathbf{H}_{\mathbf{2}}$ & 0.016793 & $7.9788 \times 10^{-7}$ & 0.033336 \\
\hline $\mathbf{O}_{\mathbf{2}}$ & 0.003229 & $2.8861 \times 10^{-6}$ & 0.006408 \\
\hline $\mathbf{C O}$ & 0.006459 & $7.7968 \times 10^{-7}$ & 0.012821 \\
\hline $\mathbf{C H}_{4}$ & 0.000388 & $1.7858 \times 10^{-7}$ & 0.000770 \\
\hline $\mathbf{C O}_{2}$ & 0.043532 & $9.0811 \times 10^{-5}$ & 0.086332 \\
\hline $\mathbf{N a}^{+}$ & 0.017692 & 0.033586 & 0 \\
\hline $\mathbf{K}^{+}$ & 0.000122 & 0.000247 & 0 \\
\hline $\mathbf{C a}^{2+}$ & 0.000474 & 0.000961 & 0 \\
\hline $\mathbf{C l}^{-}$ & 0.018762 & 0.038027 & 0 \\
\hline $\mathbf{S O}^{2-}$ & $3.68 \times 10^{-7}$ & $7.4585 \times 10^{-7}$ & 0 \\
\hline
\end{tabular}




\begin{tabular}{|c|c|c|c|}
\hline $\mathbf{N a C l}$ & 0 & 0 & 0 \\
\hline $\mathbf{H}_{2} \mathbf{O}$ & 0.892549 & 0.924811 & 0.860333 \\
\hline Phase Fraction & 1.000000 & 0.496276 & 0.503724 \\
\hline Density (kg/m $\left.\mathbf{m}^{\mathbf{3}}\right)$ & & 831.985 & 8.464 \\
\hline G/RT & 2.53535 & \multicolumn{2}{|c|}{2.496677} \\
\hline
\end{tabular}

Note that the supersaturated VLE solution has a lower value of G/RT than the single phase solution. Table 5.4 gives the values of $K_{s p}$ and $Q_{s p}$ for all six molecular salts at aqueous liquid phase conditions given in Table 5.3. Note that Table 5.4 clearly shows that $K_{s p}^{N a C l}<Q_{s p}^{N a C l}$ and therefore $N a C l$ will precipitate. The molar amount that will precipitate, $S_{\mathrm{NaCl}}$, is easily computed using the following mass balance

$S_{\mathrm{NaCl}}=F x_{\mathrm{NaCl}}-[c]_{N a^{+}}\left(n_{\mathrm{H} 2 \mathrm{O}} M W_{\mathrm{H} 2 \mathrm{O}}\right) / 1000$

where $F x_{\mathrm{NaCl}}$ is the molar amount of $\mathrm{NaCl}$ in the feed, $[c]_{\mathrm{Na}^{+}}$is the solubility limit of $\mathrm{Na}^{+}$in the aqueous liquid, $n_{\mathrm{H} 2 \mathrm{O}}$ is the number of moles of water in the aqueous liquid, and $M W_{H 2 O}$ is the molecular weight of water.

Table 5.4: Equilibrium and Ion Solubility Products for Example 3

\begin{tabular}{|c|c|c|}
\hline Molecular Salt & $\boldsymbol{K}_{\boldsymbol{s p}}$ & $\boldsymbol{Q}_{\boldsymbol{s p}}$ \\
\hline $\boldsymbol{N a C l}$ & 4.3516 & 4.9124 \\
\hline $\boldsymbol{K C l}$ & 7.0513 & 0.033875 \\
\hline $\boldsymbol{C a C l} \boldsymbol{2}_{\mathbf{2}}$ & 1.9765 & 0.30040 \\
\hline $\boldsymbol{N a}_{\mathbf{2}} \boldsymbol{S O}_{\mathbf{4}}$ & 2.6759 & 0.000207 \\
\hline $\boldsymbol{K}_{\mathbf{2}} \boldsymbol{S O}_{\mathbf{4}}$ & 7.0259 & $9.8612 \times 10^{-9}$ \\
\hline $\boldsymbol{C a S O}_{\mathbf{4}}$ & 0.27929 & $2.5815 \times 10^{-6}$ \\
\hline
\end{tabular}

Table 5.5 gives the global minimum vapor-liquid-solid equilibrium solution for the same combined feed conditions and there are several important points to note regarding this equilibrium solution.

1. The VLE + salt solution has a lower dimensionless Gibbs free energy than either the single phase solution or the supersaturated VLE solution. 
2. The STRIP criterion of 0.7 - 0.8 vapor fraction has been met in the final solution.

3. Salt precipitation is potentially a serious concern in this application of STRIP unless production water is mixed with clean water.

Table 5.5: Global Minimum Solution to Combined Chemical and Phase Equilibrium Problem

\begin{tabular}{|c|c|c|c|c|}
\hline Quantity & $\begin{array}{l}\text { Mole Fractions of } \\
\text { Combined Feed }\end{array}$ & Aqueous Liquid & Vapor & Solid Salt \\
\hline $\mathbf{H}_{2}$ & 0.016793 & $6.8490 \times 10^{-7}$ & 0.023735 & 0 \\
\hline $\mathbf{O}_{2}$ & 0.003229 & $2.3922 \times 10^{-6}$ & 0.004563 & 0 \\
\hline $\mathrm{CO}$ & 0.006459 & $6.4952 \times 10^{-7}$ & 0.009129 & 0 \\
\hline $\mathrm{CH}_{4}$ & 0.000388 & $1.4567 \times 10^{-7}$ & 0.000548 & 0 \\
\hline $\mathrm{CO}_{2}$ & 0.043532 & $7.1298 \times 10^{-5}$ & 0.061500 & 0 \\
\hline $\mathbf{N a}^{+}$ & 0.017692 & 0.033746 & 0 & 0 \\
\hline $\mathbf{K}^{+}$ & 0.000122 & 0.000419 & 0 & 0 \\
\hline $\mathrm{Ca}^{2+}$ & 0.000474 & 0.001629 & 0 & 0 \\
\hline $\mathrm{Cl}^{-}$ & 0.018762 & 0.037426 & 0 & 0 \\
\hline $\mathrm{SO}_{4}{ }^{2-}$ & $3.68 \times 10^{-7}$ & $1.2654 \times 10^{-6}$ & 0 & 0 \\
\hline $\mathrm{NaCl}$ & 0 & 0 & 0 & 1.000000 \\
\hline $\mathrm{H}_{2} \mathrm{O}$ & 0.892549 & 0.926701 & 0.900524 & 0 \\
\hline Phase Fraction & 1.000000 & 0.290190 & 0.701886 & 0.007924 \\
\hline Density $\left(\mathrm{kg} / \mathrm{m}^{3}\right)$ & & 813.901 & 8.245 & 2166.642 \\
\hline G/RT & 2.53535 & & 1.80108 & \\
\hline
\end{tabular}

\subsubsection{Example 4: Flash Level Reliability Testing}

A high level of reliability is needed at the flash level for successful reservoir simulations. Even a single failure in one grid block can cause the entire reservoir simulation to fail. To ensure reliability at the flash level, several phase diagrams similar to the ones shown in Fig. 5.2 and covering the entire composition space are usually generated using GFLASH for a number of different temperatures and pressures prior to running a reservoir simulation. Typically, a composition interval of 0.005 is used for 
each independent composition. Thus, for a three-component mixture, roughly 20,000 composition points are generated for each temperature and pressure.
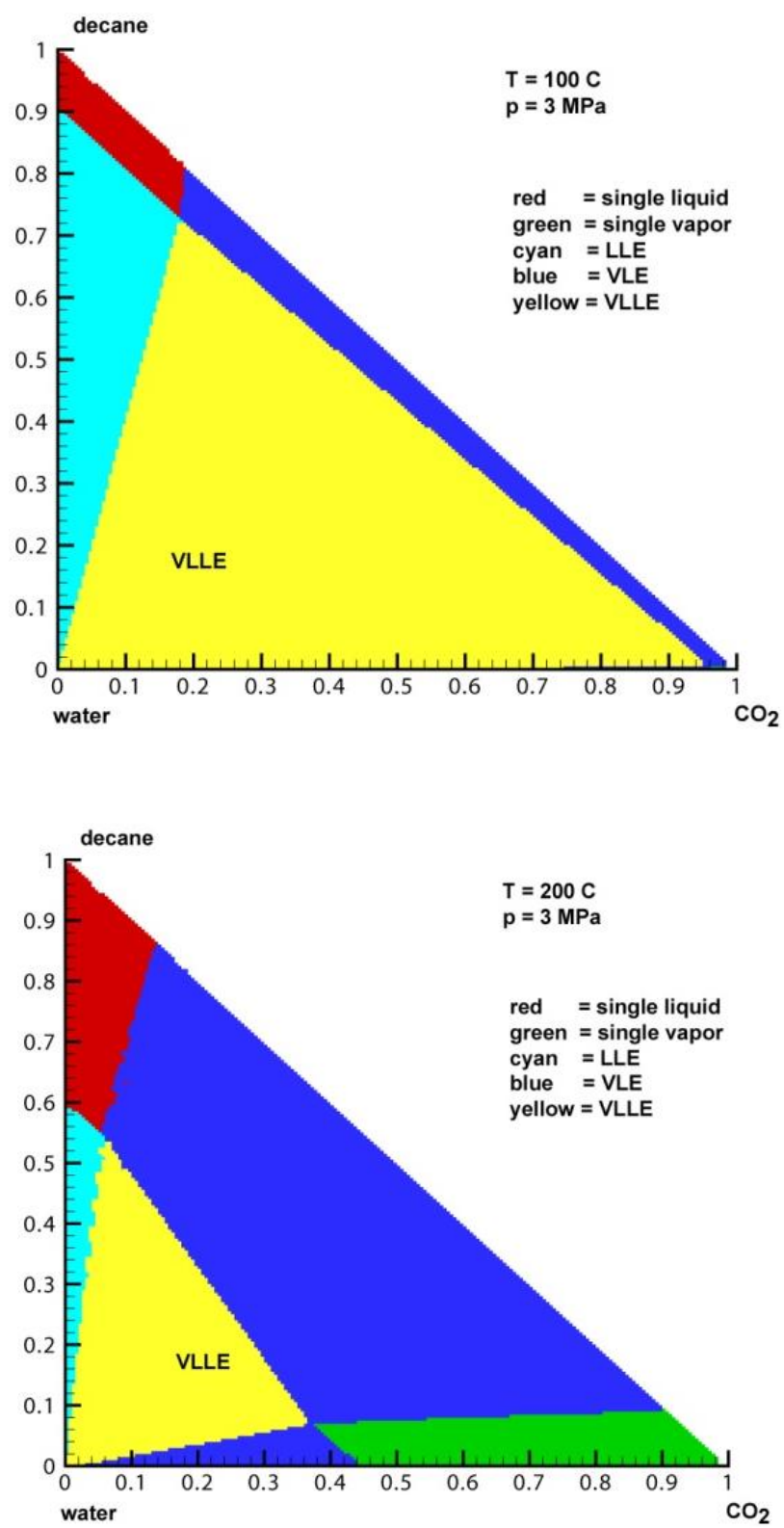

Figure 5.2: $\mathrm{CO}_{2}$-Decane-Water Phase Behavior at $100{ }^{\circ} \mathrm{C}$ and $200{ }^{\circ} \mathrm{C}$ and 30 bars

This is to ensure that phase boundaries are smooth and that changes in V-only, L-only, VLE, LLE, and VLLE regions make physical sense. Table 5.6 gives computational details for the rigorous flash tests. 
Table 5. 6: Statistics for Rigorous Flash Solutions for $\mathrm{CO}_{2}$-Decane-Water at 30 bars Using GFLASH

\begin{tabular}{|c|c|c|}
\hline & $\mathrm{T}=373 \mathrm{~K}$ & $\mathrm{~T}=473 \mathrm{~K}$ \\
\hline No. of Problems & 19,532 & 19,532 \\
\hline No. of Liquid-Only Solutions & 687 & 1559 \\
\hline No. of Vapor-Only Solutions & 5 & 11,720 \\
\hline No. of VLE Solutions & 1876 & 682 \\
\hline No. of LLE Solutions & 3207 & 3796 \\
\hline No. of VLLE Solutions & 13,757 & $3,255,481$ \\
\hline No. of Function Calls & $2,114,553$ & $7,709,004$ \\
\hline No. of EOS Solves & $5,448,233$ & 26.5 \\
\hline Total Solve Time (CPU sec) & 38.7 & \\
\hline
\end{tabular}

\subsubsection{Example 5: Comparison of Steam Injection and STRIP}

This first EOR example compares model results for steam injection and STRIP for a 3D heterogeneous reservoir formation containing light oil. Input data are listed in Table 5.7. In EOR applications it is typical to 'lump' components to reduce computational costs; thus for STRIP all light gases were treated as $\mathrm{CO}_{2}$, which is the solvent of interest.

In this example, the model is based on a fragment of the up-scaled SPE10 porosity and permeability fields (see Christie and Blunt, 2001). Here we used a grid size of $30 \times 60 \times 3 \mathrm{~m}^{3}$ with a uniform grid block volume of $12 \times 6 \times 1.2 \mathrm{~m}^{3}$. The injection and production wells were placed at opposite corners of the reservoir. A single component, n-decane, was used to model the oil and the EOS used was the SRK equation. Steam injection was modeled using an injection stream of $1 \mathrm{~mol} \% \mathrm{CO}_{2}$ and $99 \mathrm{~mol} \%$ steam while STRIP, which contains more $\mathrm{CO}_{2}$ from combustion, injected 10 mol\% $\mathrm{CO}_{2}$ and $90 \mathrm{~mol} \%$ water. The heat and water input were the same for steam injection and STRIP so an equitable comparison could be made. 
Table 5.7: Input Data for Example 5

\begin{tabular}{|c|c|}
\hline Quantity & Value \\
\hline Reservoir Dimensions & $360 . \times 360 . \times 3.6 \mathrm{~m}^{3}$ \\
\hline Initial Reservoir $\boldsymbol{T}$ and $\boldsymbol{P}$ & $290 \mathrm{~K}, 31 \mathrm{bar}$ \\
\hline Initial reservoir composition & $1 \mathrm{~mol}^{2} \mathrm{CO}_{2}, 74 \mathrm{~mol} \%$ oil, $25 \mathrm{~mol} \%$ water \\
\hline Porosity, Rock Heat Capacity & $0.197 \%$ (average), $2.35 \times 10^{6} \mathrm{~J} / \mathrm{m}^{3} \mathrm{~K}$ \\
\hline Permeability (Upscaled SPE10) & 5 orders of magnitude in permeability variations \\
\hline Injection Conditions & water rate $15 \mathrm{~m}^{3} /$ day \\
& heat rate $1.3 \times 10^{10} \mathrm{~J} /$ day (steam at $518 \mathrm{~K}$ ) \\
\hline Injection Composition & $10 \% \mathrm{CO}_{2}, 90 \%$ water (STRIP) \\
& $1 \% \mathrm{CO}_{2}, 99 \%$ water (steam injection) \\
\hline Production Well $\boldsymbol{P}$ & 3.45 bar \\
\hline Time Horizon & 2,000 days \\
\hline
\end{tabular}

\subsubsection{Main Simulation Results}

The performance of steam injection and STRIP are compared using the metrics of sweep and oil recovery.

\section{$\underline{\text { Sweep Efficiency }}$}

The sweep efficiency can be deduced from oil saturation at the end of the operating period. Figure 5.3 shows the oil saturation in the reservoir for steam injection and STRIP after 2,000 days of operation. 

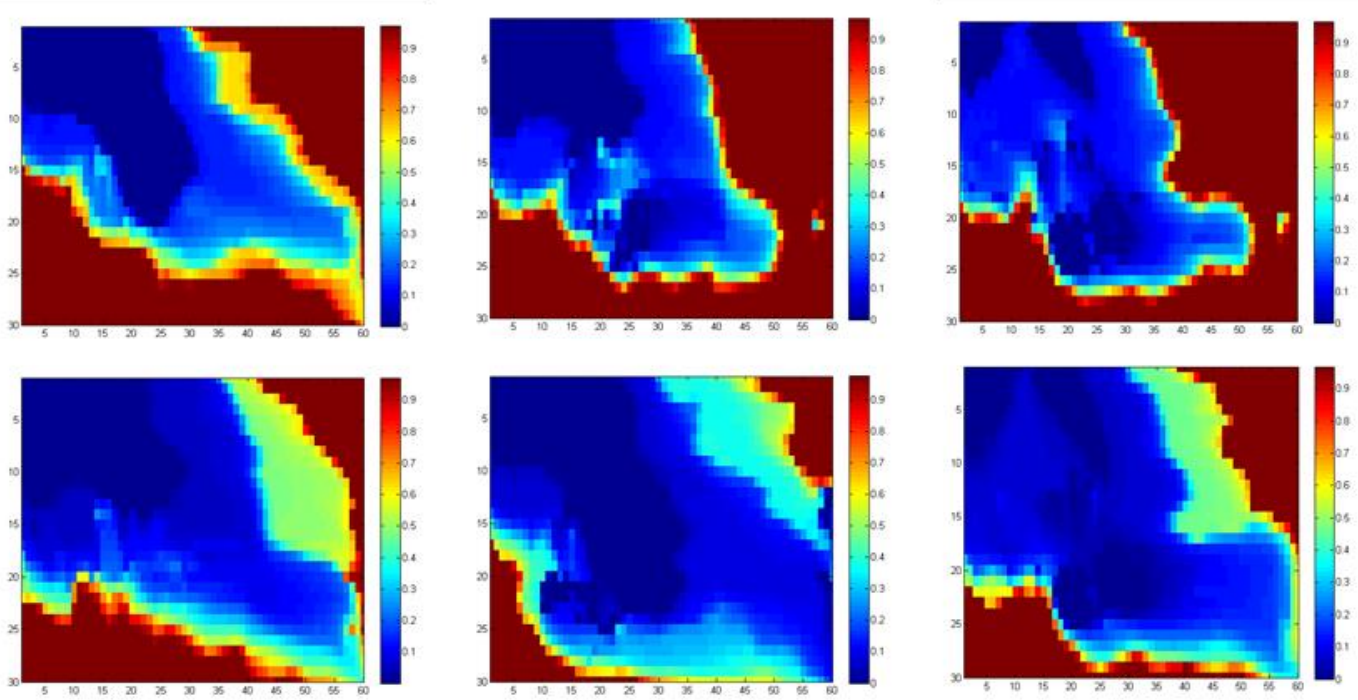

Figure 5.3: Oil Saturation for Steam Injection (upper) and STRIP (lower) for Example 5

Note that the blue regions are much larger for STRIP than for steam injection, indicating that STRIP removes more oil. One can also make more quantitative measures of sweep efficiency using the following expression

$\eta=\frac{V_{o i l}^{\Delta}}{V}$

where $\eta$ denotes the sweep ratio, $V_{\text {oil }}^{\Delta}$ is the porous volume for which the oil composition has changed by $1 \%$ or more and $V$ is the total porous volume available to the oil. Figure 5.4 shows quantitative results for sweep ratio for steam injection and STRIP as a function of time. The sweep ratios for steam injection and STRIP after 2,000 days of operation are $60 \%$ and $83 \%$, respectively. Clearly the sweep ratio of STRIP is superior to steam injection. 


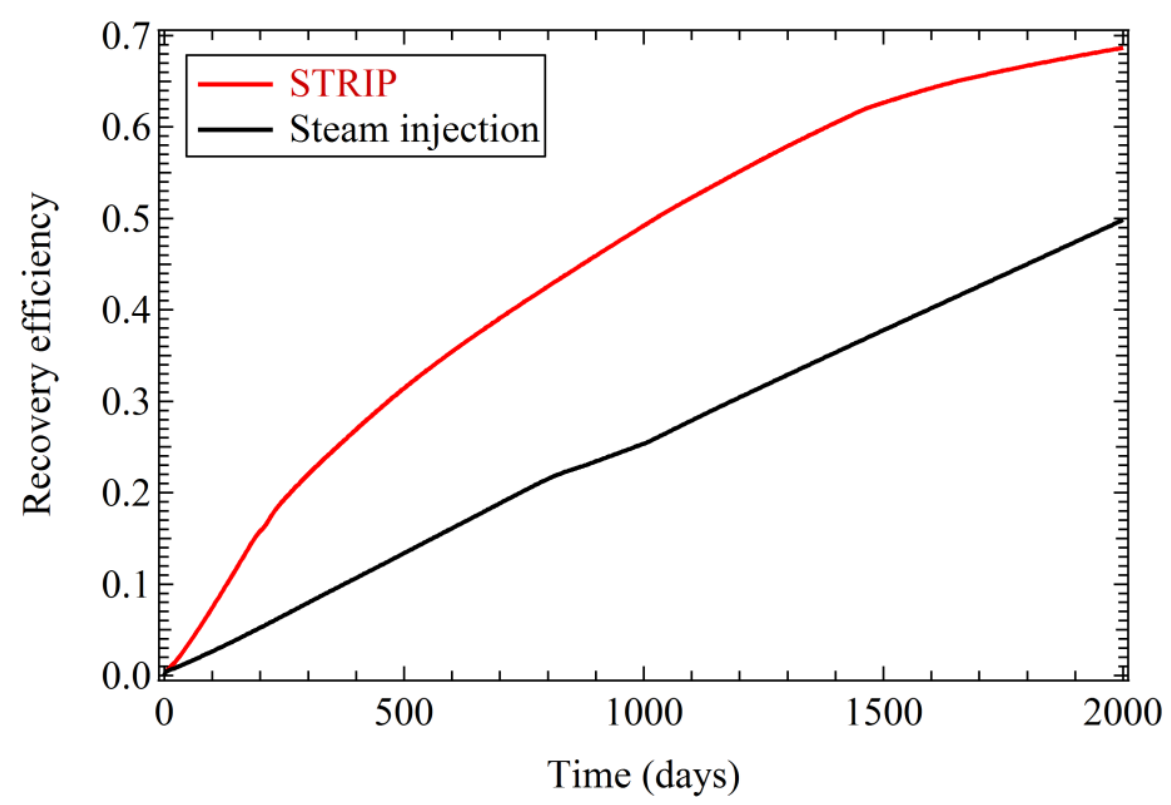

Figure 5.4: Sweep Ratio for Steam Injection and STRIP for Example 5

\section{Oil Production}

Figure 5.5 shows the total cumulative oil recovered during 2,000 days of operation of steam injection and STRIP.

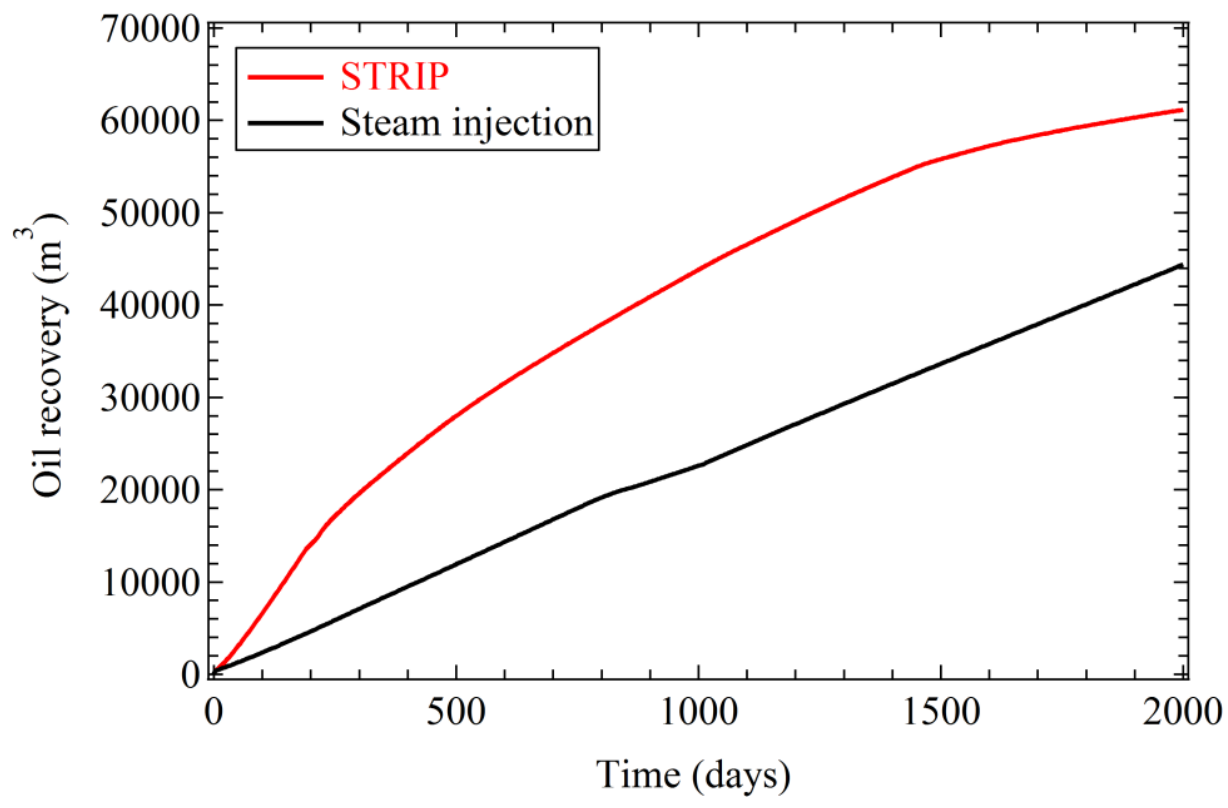


Figure 5.5: Oil Recovery for Steam Injection and STRIP for Example 5

To compare oil recovery, the Original Oil in Place (OOIP) at surface conditions, which is a common assumption in the petroleum industry, must be computed. OOIP is calculated using formula

$\mathrm{OOIP}=\sum_{\text {all blocks }} \frac{V \phi S_{\text {oil }}}{B_{\text {oil }}}$

where $V$ is the block volume, $S_{\text {oil }}$ is oil saturation, and $B_{o i l}$ is the surface-to-reservoir formation volume factor. Here again, STRIP outperforms steam injection - recovering $16,764 \mathrm{~m}^{3}(105,442$ barrels) more oil and leaving less OIP after 2,000 days. Table 5.8 summarizes the performance of steam injection and STRIP for this first example.

Table 5.8: Summary of Steam Injection and STRIP Performance for Example 5

\begin{tabular}{|c|c|c|c|}
\hline & Steam injection & STRIP & Improvement with STRIP \\
\hline${\text { Operation }(\text { days })^{*}}$ & 2000 & 2000 & \\
\hline & & & \\
\hline OOIP $\left(\mathrm{m}^{3}\right)$ & 89,051 & 89,051 & \\
\hline Oil produced $\left(\mathrm{m}^{3}\right)$ & 44,380 & 61,144 & 16,764 \\
\hline$\%$ oil recovered & $50 \%$ & $69 \%$ & $38 \%$ \\
\hline Sweep efficiency & $60 \%$ & $83 \%$ & $27.4 \%$ \\
\hline
\end{tabular}

\subsubsection{Example 6: Comparisons between Conventional EOS and CSAT}

This second example compares a conventional reservoir simulation approach, which uses an EOS, to one that uses CSAT. For this example, pore volumes and permeability fields were taken from the upper layer of the original SPE10 model (Christie and Blunt, 2001). The simulations were performed using an initial reservoir composition of $1 \mathrm{~mol} \% \mathrm{CO}_{2}, 49 \mathrm{~mol} \%$ n-decane, $20 \mathrm{~mol} \%$-hexadecane, and $30 \mathrm{~mol} \%$ 
water and the initial reservoir pressure and temperature were 31 bar and $300 \mathrm{~K}$, respectively. One injection and one production well were placed at opposite corners of the reservoir. The injection well operates under constant pressure and constant temperature conditions of 60 bars and $500 \mathrm{~K}$. The STRIP injection fluid consisted of 15 $\mathrm{mol} \% \mathrm{CO}_{2}$, and $85 \mathrm{~mol} \%$ water. The production well was set to a constant pressure of 3.45 bars. Input data for this example are shown in Table 5.9.

Table 5.9: Input Data for STRIP Simulation of Example 6

\begin{tabular}{|c|c|}
\hline Quantity & Value \\
\hline Reservoir Dimensions & $365 \times 670 \times 0.6096 \mathrm{~m}^{3}$ \\
\hline Initial Reservoir $\boldsymbol{T} \& \boldsymbol{P}$ & $300 \mathrm{~K}, 31 \mathrm{bars}$ \\
\hline Initial Reservoir Composition & $1 \mathrm{~mol}^{2} \mathrm{CO}_{2}, 49 \mathrm{~mol}^{2} \mathrm{C}_{10}, 20 \mathrm{~mol}^{2} \mathrm{C}_{16}, 30 \mathrm{~mol} \%$ \\
water \\
\hline Average Porosity & 0.1945 \\
\hline Permeability (SPE10, upper layer)* & 8 orders of permeability variations \\
\hline Injection $\boldsymbol{T}$ \& $\boldsymbol{P}$ & $500 \mathrm{~K}, 60$ bar \\
\hline Injection Composition & $15 \% \mathrm{CO}_{2}, 85 \%$ water \\
\hline Production Well $\boldsymbol{P}$ & 3.45 bar \\
\hline Time Horizon & 7,000 days \\
\hline
\end{tabular}

*Taken from Christie and Blunt (2001)

\subsubsection{Main Simulation Results}

The details of the performance of STRIP are discussed along with the features of the simulator.

\section{$\underline{\text { Sweep Efficiency }}$}

Oil and gas saturations provide enough information to quantify sweep efficiency. Figure 5.6 shows the oil and gas saturation in the reservoir for STRIP after 7,000 days of operation, where the $\mathrm{x}$ and $\mathrm{y}$ axes denote grid blocks and the color bar shows saturations. 


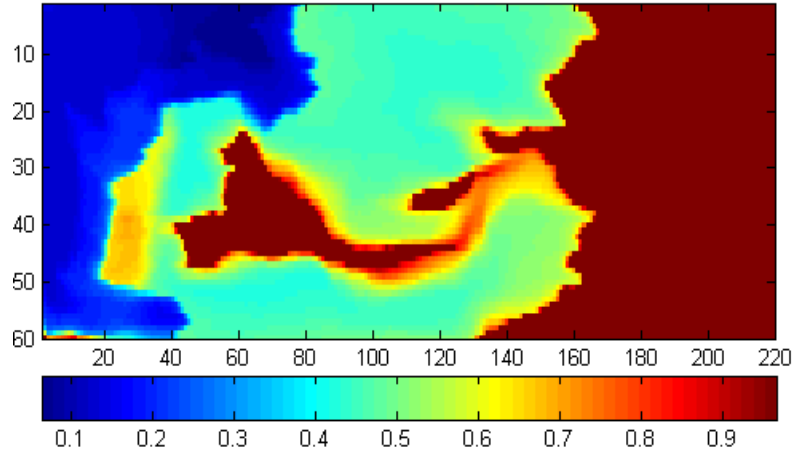

(a) Oil saturation (EOS)

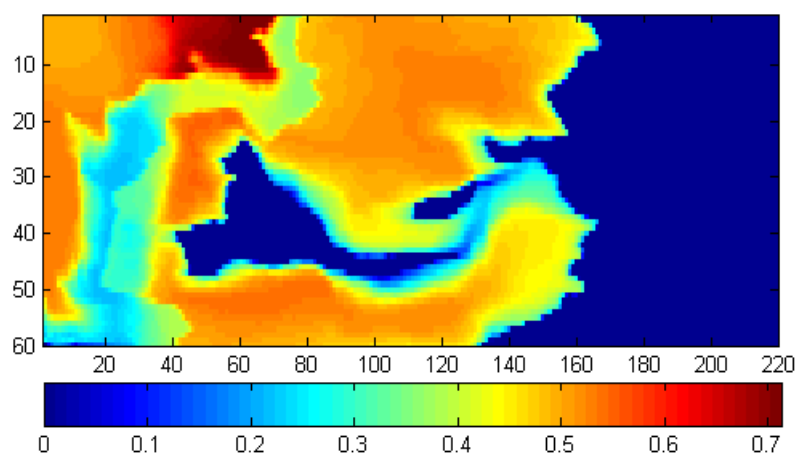

(c) Gas saturation (EOS)

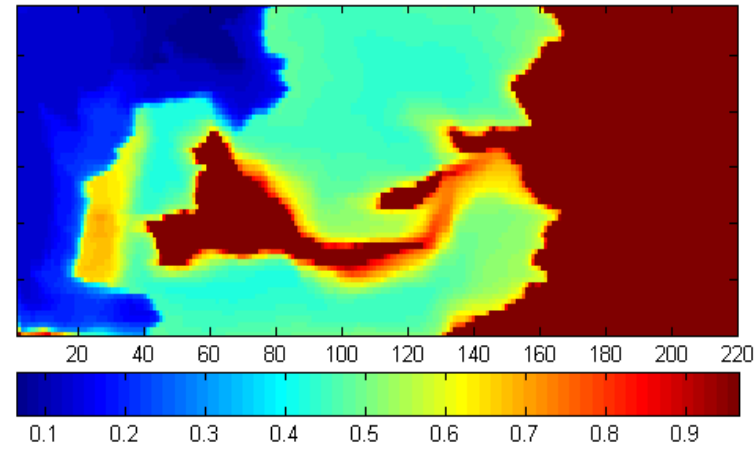

(b) Oil saturation (CSAT)

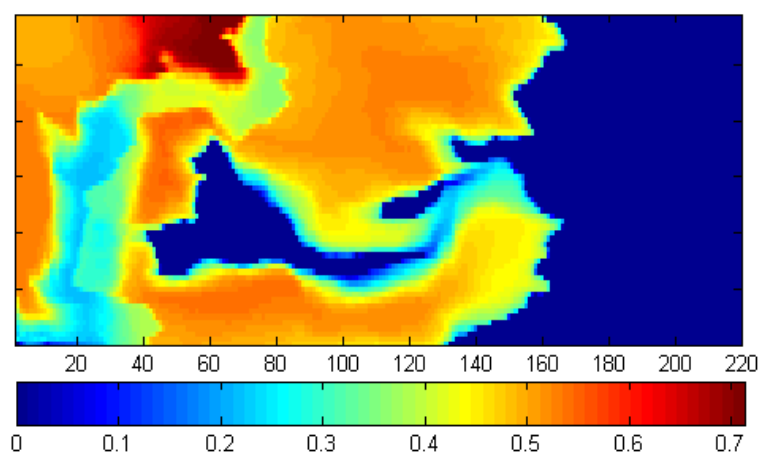

(d) Gas saturation (CSAT)

Figure 5.6: Oil and Gas Saturation Distributions for EOS and CSAT Simulations after 7000 Days

As expected, both CSAT and GFLASH provide identical results for gas and oil saturation. This is because CSAT only skips phase identification and rigorous flash computations when compositions are far from phase boundaries.

\section{$\underline{\text { Simulation Statistics }}$}

Table 5.10 summarizes the simulation statistics for this example and shows that rigorous flash solutions take the bulk of the computer time for the conventional EOS approach. CSAT, on the other hand, significantly decreases the number of EOS solves and, therefore, reduces total flash solution time by almost two orders of magnitude. 
Table 5.10: Statistics for STRIP Reservoir Simulation of Example 6

\begin{tabular}{|c|c|c|}
\hline & AD-GPRS/GFLASH & AD-GPRS/GFLASH/CSAT \\
\hline Time Horizon (days) & 7000 & 7000 \\
\hline Average Time Step (days) & 4.9 & 4.9 \\
\hline Model Formulation & Natural Variables & Natural Variables \\
\hline Number of Grid Blocks & 13,200 & 13,200 \\
\hline No. of Equations/Grid Block & 2+P-1+(C-1)P & $2+\mathrm{P}-1+(\mathrm{C}-1) \mathrm{P}$ \\
\hline Equation Solving Methodology & $\begin{array}{c}\text { Fully Implicit Method } \\
\text { (FIM) }\end{array}$ & Fully Implicit Method (FIM) \\
\hline Total No. of Newton Iterations & & 4140 \\
\hline Total No. of EOS Solves & $44,028,736$ & 499,693 \\
\hline $\begin{array}{c}\text { Total Flash Solution Time (CPU } \\
\text { sec) }\end{array}$ & 270,830 & 3869 \\
\hline Total Simulation Time (CPU sec) & 345,659 & 79,710 \\
\hline
\end{tabular}

\subsection{Conclusions}

A new methodology for reservoir simulation was presented. This new modeling and simulation framework consists of AD-GPRS, the Automatic Differentiation General Purpose Research Simulator, a general multi-phase equilibrium flash suite, GFLASH, and a Compositional Space Adaptive Tabulation (CSAT) approach. The fundamental PDE model equations and methods of solution for the resulting nonlinear algebraic equations at the reservoir length scale were provided. Modeling, equationsolving, and numerical details for four separate chemical engineering problems at the flash level of the computations were also presented to raise awareness in the PSE community with regard to reservoir simulation. Coupling of the flash and reservoir equations was described. CSAT and the interface between AD-GPRS, which is written in $\mathrm{C}++$, and GFLASH, which is a FORTRAN program suite, were also described. Two numerical reservoir simulation examples were presented to highlight the accuracy, reliability, and computational efficiency of AD-GPRS/GFLASH, including two threephase reservoir simulation examples with and without the use of CSAT for a highly 
heterogeneous reservoir formation and for three- and four-component system. Comparisons of steam injection and STRIP in Example 5 clearly demonstrate the superiority of the Solvent Thermal Resource Innovation Process in terms of sweep and oil recovery. Example 6 demonstrates that the AD-GPRS/GFLASH/CSAT framework reduces the simulation time by two orders of magnitude without losses in accuracy or reliability.

\subsection{Coda}

In addition to the chemical engineering sub-problems described in this work, there are also others, including sub-problems that require

(1) The characterization of oils with many components.

(2) Development of better methods for determining viscosity and relative permeability in harsh conditions.

(3) Understanding chemical EOR methods and the associated phase equilibrium in the presence of surfactants and other chemical additives.

(4) The determination of asphaltene precipitation.

(5) Reaction kinetics models for gas hydrate formation and $\mathrm{CO}_{2}$ sequestration.

(6) Improved numerical methods for flash and for solving 'stiff' DAE systems.

In our opinion, the PSE community is ideally positioned to make contributions in these and other areas as they relate to reservoir simulation. 


\section{Appendix A: C++ Interface for AD-GPRS/GFLASH}

The $\mathrm{C}++$ interface for communicating information between AD-GPRS and GFLASH is divided into two sections: a definition section and an execution section.

The definition section, which defines essential variable information, is shown below and is self-explanatory.

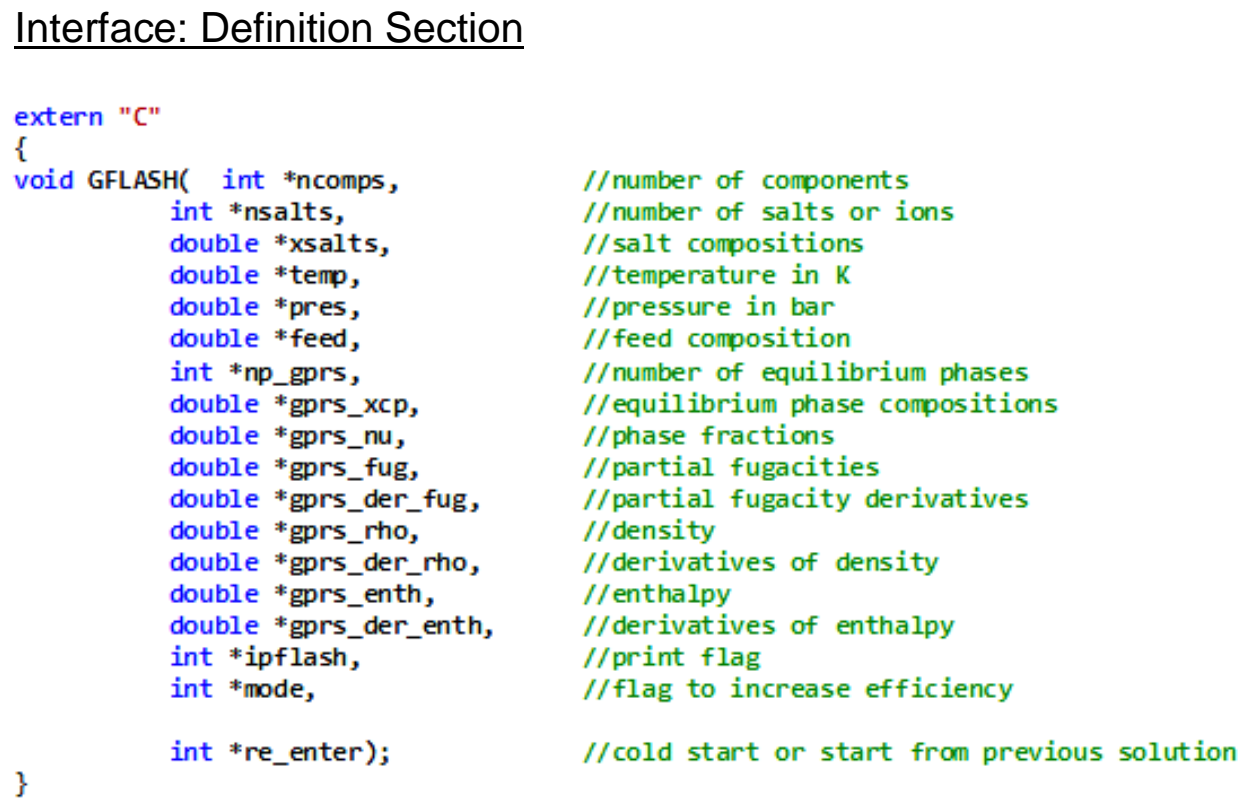

During execution, AD-GPRS passes GFLASH the number of components (ncomps), the temperature (temp), pressure (pres), and the feed composition (feed) for a given grid block. GFLASH returns the number of equilibrium phases (np_gprs), the phase compositions (gprs_xcp), the equilibrium phase partial fugacities (gprs_fug), their pressure, temperature and composition derivatives (gprs_der_fug), equilibrium phase 
densities (gprs_rho), densities derivatives (gprs_der_rho), equilibrium phase enthalpies (gprs_enth), and associated phase enthalpy derivatives (gprs_der_enth).

One variable that need some clarification is the integer variable RE_ENTER, which provides re-entry facilities in GFLASH, is defined as follows:

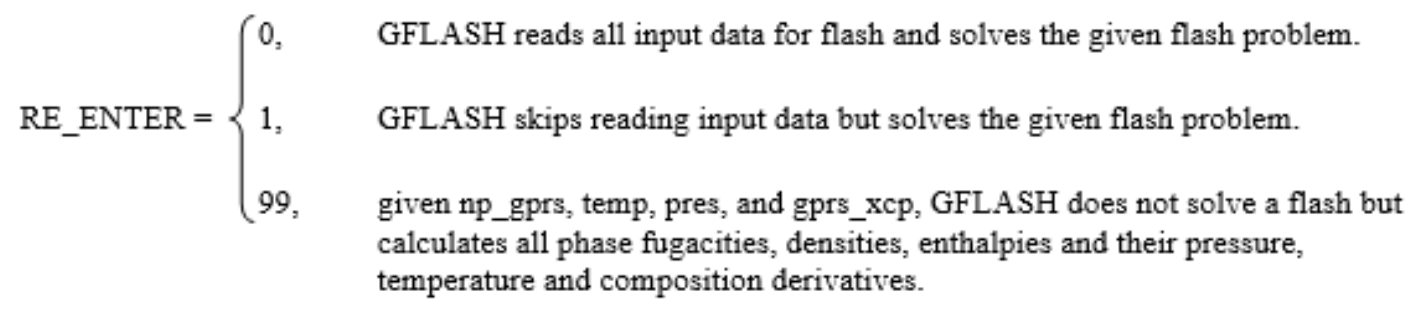

RE_ENTER gives AD-GPRS complete control of GFLASH and is an important feature for reducing computational workload. RE_ENTER allows AD-GPRS to determine when it is necessary to solve a rigorous flash problem for a given grid block or when to skip solving the flash for that grid block. More specifically, when the rigorous solution of a flash problem is needed, AD-GPRS sets RE_ENTER $=0$ or 1 and GFLASH solves a rigorous flash problem. As a result, the fugacity constraints for the given grid block are satisfied for the conditions of temperature, pressure and equilibrium phase compositions for the grid block and communicated back to AD-GPRS. On the other hand, when the temperature, pressure and equilibrium phase compositions for that grid block change but it is anticipated that the number of equilibrium phases in that grid block is unlikely to change, then AD-GPRS ask GFLASH to simply evaluate fugacities, densities, enthalpies, and their derivatives without solving a flash problem by setting RE_ENTER $=99$. This approach works because AD-GPRS includes fugacity and other constraints in the equation set for a given time step, it converges the fugacity conditions 
defining equilibrium along with the conservation of mass and energy equations whether or not they are satisfied at the beginning of the time step.

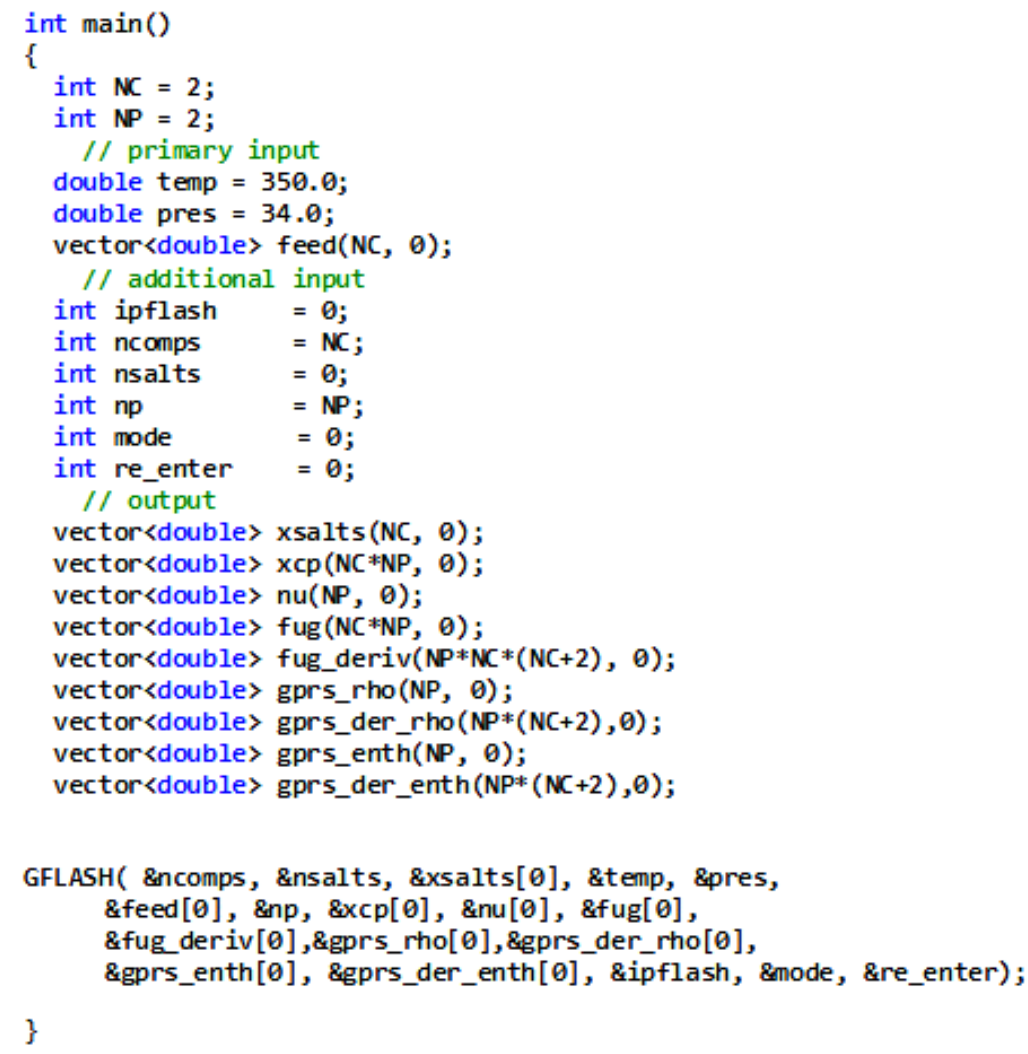




\section{Appendix B: Standard Gibbs Free Energy, Standard Heat of Formation, and}

\section{Ideal Gas Heat Capacity Data}

The standard heat of reaction, $\Delta H_{R}^{0}$, is calculated using standard heats of formation data, $\Delta H_{f, i}^{0}$, plus the simple equation

$\Delta H_{R}^{0}=\sum_{i=1}^{p r o d} n_{i} \Delta H_{f, i}^{0}-\sum_{i=1}^{r e a c t} n_{i} \Delta H_{f, i}^{0}$

Pure component ideal gas heat capacities are computed using a polynomial in temperature of the form

$C_{p, i}=A_{i} T+B_{i} T^{2}+C_{i} T^{3}+D_{i} T^{4}$

Table B1 gives the heat of formation data, which was taken from Appendix IV in Sandler (1999), and ideal gas heat capacity coefficient data, which has units of $\mathrm{J} / \mathrm{mol}$, taken from Reid et al. (1987).

Table B1: Standard Heat of Formation and Ideal Gas Heat Capacity Data

\begin{tabular}{|c|c|c|c|c|c|}
\hline Species & $\begin{array}{c}\Delta \boldsymbol{H}_{\boldsymbol{f}}^{\mathbf{1}} \\
(\mathbf{k J} / \mathbf{m o l})\end{array}$ & $\boldsymbol{A}$ & $\boldsymbol{B}$ & $\boldsymbol{C}$ & $\boldsymbol{D}$ \\
\hline $\boldsymbol{H}_{\mathbf{2}}$ & 0 & 27.14 & $9.274 \times 10^{-3}$ & $-1.381 \times 10^{-5}$ & $7.645 \times 10^{-9}$ \\
\hline $\boldsymbol{O}_{\mathbf{2}}$ & 0 & 28.11 & $-3.680 \times 10^{-6}$ & $1.746 \times 10^{-5}$ & $-1.065 \times 10^{-8}$ \\
\hline $\boldsymbol{C O}$ & -110.5 & 30.87 & $-1.285 \times 10^{-2}$ & $2.789 \times 10^{-5}$ & $-1.272 \times 10^{-8}$ \\
\hline $\boldsymbol{C H}_{\mathbf{4}}$ & -74.5 & 19.25 & $5.213 \times 10^{-2}$ & $1.197 \times 10^{-5}$ & $-1.132 \times 10^{-8}$ \\
\hline $\boldsymbol{C O}_{2}$ & -393.5 & 19.80 & $7.344 \times 10^{-2}$ & $-5.602 \times 10^{-5}$ & $1.715 \times 10^{-8}$ \\
\hline $\boldsymbol{H}_{\mathbf{2}} \boldsymbol{O}(\boldsymbol{g})$ & -241.8 & 32.24 & $1.924 \times 10^{-3}$ & $1.055 \times 10^{-5}$ & $-3.596 \times 10^{-9}$ \\
\hline
\end{tabular}

Table B2 shows the standard Gibbs free energy and heat of formation data needed for computing equilibrium solubility products of molecular salts. Some of the data was taken from Sandler (1999) while the remaining data was taken from the CRC Handbook of Chemistry and Physics.

Table B2: Standard Gibbs Free Energy and Heat of Formation Data

\begin{tabular}{|c|c|c|}
\hline Species & $\Delta \boldsymbol{G}_{\boldsymbol{f}}^{\mathbf{0}}(\mathbf{k J} / \mathbf{m o l})$ & $\Delta \boldsymbol{H}_{\boldsymbol{f}}^{\mathbf{0}}(\mathbf{k J} / \mathbf{m o l})$ \\
\hline $\boldsymbol{N a}^{+}$ & -261.88 & -239.66 \\
\hline $\boldsymbol{K}^{+}$ & -282.28 & -251.21 \\
\hline $\boldsymbol{C a}^{\mathbf{2 +}}$ & -553.04 & -542.96 \\
\hline
\end{tabular}




\begin{tabular}{|c|c|c|}
\hline $\boldsymbol{C l}^{-}$ & -131.17 & -167.46 \\
\hline $\boldsymbol{S O}_{\mathbf{4}}^{\mathbf{2 -}}$ & -741.99 & -907.51 \\
\hline $\boldsymbol{N a C l}$ & -384.1 & -411.2 \\
\hline $\boldsymbol{K} \boldsymbol{C l}$ & -408.3 & -435.8 \\
\hline $\boldsymbol{C a C \boldsymbol { I } _ { \mathbf { 2 } }}$ & -748.1 & -795.8 \\
\hline $\boldsymbol{N a}_{\mathbf{2}} \boldsymbol{S O}_{\mathbf{4}}$ & -1265.2 & -1382.8 \\
\hline $\boldsymbol{K}_{\mathbf{2}} \boldsymbol{S O}_{\mathbf{4}}$ & -1316.4 & -1433.7 \\
\hline $\boldsymbol{C a S O _ { \mathbf { 4 } }}$ & -1320.3 & -1432.7 \\
\hline
\end{tabular}




\section{Nomenclature}

\begin{tabular}{|c|c|}
\hline$a_{i j}$ & number of atoms $\mathrm{j}$ in molecule $\mathrm{i}$ \\
\hline$A_{j}$ & total amount of atom $\mathrm{j}$ \\
\hline$B_{\text {oil }}$ & oil surface-to-reservoir formation volume factor \\
\hline$c_{1}, c_{2}, c_{3}, c_{4}$ & coefficients of cubic EOS \\
\hline$[c]$ & equilibrium ion solubility limit \\
\hline$C$ & total number of components \\
\hline$C_{p, i}$ & ideal gas heat capacity for $i^{t h}$ component \\
\hline$f_{i}$ & partial fugacity of component $\mathrm{i}$ in solution \\
\hline$F$ & total density \\
\hline$g$ & acceleration due to gravity \\
\hline G & heat conduction flux \\
\hline$\Delta G_{f}^{0}$ & standard Gibbs free energy of formation \\
\hline$H$ & enthalpy \\
\hline$\Delta H_{f}^{0}$ & standard heat of formation \\
\hline$\Delta H_{R}^{0}$ & standard heat of reaction \\
\hline$K, K^{k}$ & intrinsic rock or soil permeability, thermal conductivity \\
\hline$K_{s p}$ & equilibrium solubility product \\
\hline$k_{i j}$ & binary interaction parameters \\
\hline$M$ & mass source or sink term \\
\hline$M W$ & molecular weight \\
\hline$n, n_{i}$ & vector of mole numbers, $i^{\text {th }}$ component mole number \\
\hline$p, p_{c}$ & pressure, critical pressure \\
\hline$P$ & total number of phases \\
\hline$Q$ & energy source or sink term \\
\hline$Q_{s p}$ & ion solubility product \\
\hline$r$ & oxygen-to-methane ratio \\
\hline$R$ & universal gas constant, relative permeability \\
\hline$S$ & saturation or amount of salt precipitate \\
\hline$t$ & time \\
\hline$T, T_{c}, T_{j m}$ & absolute temperature, critical temperature, transmissibility coefficient \\
\hline$U$ & internal energy \\
\hline$V$ & volumetric flow, volume of grid block \\
\hline$x, x_{i}$ & vector of liquid phase mole fractions, $\mathrm{i}^{\text {th }}$ component liquid mole fraction \\
\hline$Z$ & $\begin{array}{l}\text { coordinate in direction of gravity, compressibility factor, vector of feed } \\
\text { compositions }\end{array}$ \\
\hline
\end{tabular}

\section{Greek symbols}

$\begin{array}{ll}\phi & \text { porosity } \\ \varphi_{i}, \varphi_{M} & \text { partial fugacity coefficient of component } \mathrm{i}, \text { mixture fugacity coefficient } \\ \Phi & \text { geometric part of flux }\end{array}$




$\begin{array}{ll}\gamma & \text { mass density at interface } \\ \eta & \text { sweep ratio } \\ k & \text { permeability } \\ \lambda & \text { mobility } \\ \mu & \text { viscosity, chemical potential } \\ \rho & \text { density }\end{array}$

\section{Superscripts}

$\begin{array}{ll}k & \text { phase index } \\ L & \text { liquid } \\ V & \text { vapor }\end{array}$

\section{Subscripts}

$\begin{array}{ll}0 & \text { standard state } \\ C & \text { critical property } \\ C & \text { number of components } \\ i & \text { component or summation index } \\ M & \text { porous media }\end{array}$




\section{References}

Acs, G. (1985). General purpose compositional model, Soc. Pet. Eng. J. 25, 543.

Ahlers, J., Gmehling, J. (2001). Development of a universal group contribution equation of state. 1. Prediction of liquid densities for pure compounds with a volume translated Peng-Robinson equation of state. Fluid Phase Equil. 191, 177.

Ahlers, J., Gmehling, J. (2002). Development of a universal group contribution equation of state. 2. Prediction of vapor-liquid equilibria for asymmetric systems. Industrial \& Engineering Chemistry Research 41, 3489.

Aziz, K., Ramesh, A.B. Woo, P.T. (1987). Fourth SPE comparative solution project: comparison of steam injection simulators. JPT 39, 1576.

Cao H. (2002). Development of Techniques for General Purpose Simulators, Ph.D. Thesis, Stanford University.

Christie M. and Blunt M (2001). Tenth SPE comparative solution project: A comparison of upscaling techniques.SPE Reservoir Evaluation and Engineering 4, 308.

Coats, K.H. (1980). An equation of state compositional model. Soc. Pet. Eng. J. 1, 363.

Coats, K.H., Nielsen, R.L., Terhune, M.H., Weber, A.G. (1967). Simulation of threedimensional, two-phase flow in oil and gas reservoirs. Trans. Am. Inst. Min. Metall. Pet. Eng. 237, 377.

Douglas, J., Peaceman, D.W., Rachford, H.H. (1959). A method of calculating multidimensional immiscible displacement. Trans. Am. Inst. Min. Metall. Pet. Eng. 216, 297.

Holderbaum, Th., Gmehling, J. (1991). PSRK: A group-contribution equation of state based on UNIFAC. Fluid Phase Equilibria 70, 251.

Iranshahr, A., Voskov, D.V., Tchelepi, H.A. (2010). Generalized Negative-Flash Method for Multiphase Multicomponent Systems. Fluid Phase Equilibria 2, 299.

Kiepe, J., Horstmann, S., Fischer, K., Gmehling, J. (2004). Application of the PSRK model for systems containing strong electrolytes. Industrial Engineering Chemistry Research 43, 6607.

Lucia, A., Bonk, B.M., Waterman, R.R., Roy, A. (2012). A multi-scale framework for multi-phase equilibrium flash. Comput. Chem. Engng. 36, 79. 
Lucia, A., Feng, Y. (2003). Multivariable terrain method. AIChE J. 49, 2553.

Marcondes, F., Maliska, C.R., Zambaldi, M.C. (2009). A comparative study of implicit and explicit methods using unstructured Voronoi meshes in petroleum reservoir simulation. J. Braz. Soc. Mech. Sci. Eng. 31, 353.

Michelsen, M.L. (1982a) The isothermal flash problem. Part I. Stability. Fluid Phase Equilibria 1,9.

Michelsen, M.L. (1982b). The isothermal flash problem. Part II. Phase-split calculation. Fluid Phase Equilibria 1, 9.

Odeh, A.S. (1981). Comparison of solutions to a three-dimensional black oil reservoir simulation problem. JPT 33, 13.

Ortega, J.M., Rheinboldt, W.C. (1970). Iterative solution of nonlinear equations in several variables. SIAM, Philadelphia, PA.

Peaceman, D.W. (2000). Fundamentals of numerical reservoir simulation. Elsevier Scientific Publishing Co., Amsterdam, The Netherlands.

Peery, J.H., Herron, E.H. (1969). Three-phase reservoir simulation. Trans. Am. Inst. Min. Metall. Pet. Eng. 246, 211.

Peneloux, A., Rauzy, E., Freze, R. (1982). A consistent correction for Redlich-KwongSoave volumes. Fluid Phase Equilibria 8, 7.

Peng, D.Y., Robinson, D.B. (1976). A new two-constant equation of state. Industrial Engineering Chemistry Fundamentals 15, 59.

Price H.S., Coats, K.H. (1974). Direct methods in reservoir simulation. Trans. Am. Inst. Min. Metall. Pet. Eng. 257, 295.

Reid, R., Prausnitz, J.M., Poling, B.E. (1987). The Properties of Gases and Liquids. 4th Ed., McGraw-Hill Co., New York, NY.

Sandler, S.I. (1999). Chemical and Engineering Thermodynamics. 3rd Ed., John Wiley \& Sons, Inc., New York, NY.

Settari, A., Aziz, K. (1974). A computer model for two-phase coning simulation. Soc. Pet. Eng. J. 14, 221.

Sheffield, M. (1969). Three-phase fluid flow including gravitational, viscous and capillary forces. Trans. Am. Inst. Min. Metall. Pet. Eng. 257, 232.

Snyder, L.J. (1969). Two-phase reservoir flow calculations. Soc. Pet. Eng. J. 9, 170. 
Soave, G. (1972). Equilibrium constants from a modified Redlich-Kwong equation of state. Chemical Engineering Science 27, 1197.

Todd, M.R., O'Dell, P.M., Hirasaki, G.J. (1972). Methods for increased accuracy in numerical reservoir simulation. Trans. Am. Inst. Min. Metall. Pet. Eng. 253, 515.

Trimble, R.H., McDonald, A.E. (1976). A strongly coupled, implicit well coning model. Soc. Pet. Eng. 4th Symposium on Numerical Simulation of Reservoir Performance. Los Angeles, CA, SPE Paper No. 5738.

Voskov D., Tchelepi H. (2012). Comparison of nonlinear formulations for two-phase multi-component EOS-based simulation. J. Pet. Sci. Eng. 82-83, 101.

Voskov, D, Tchelepi, H. (2009a). Compositional space parameterization: Theory and application for immiscible displacements. Soc. Pet. Eng. J. 14, 431.

Voskov, D, Tchelepi, H. (2009b). Compositional space parameterization: Multicontact miscible displacement and extension to multiple phases. Soc. Pet. Eng. J. 14, 441.

Voskov, D., Zhou, Y. (2012). Technical description of AD-GPRS. Stanford University, Stanford, CA.

Whitson, C., Michelsen, M.L. (1989). The negative flash. Fluid Phase Equilibria 53, 51.

Zaydullin R., Voskov D.V., Tchelepi, H.A. (2013). Formulation and solution of compositional displacements in tie-simplex space. 2013 SPE Reservoir Simulation Symposium, Society of Petroleum Engineers, The Woodlands, TX.

Zhou, Y., Tchelepi, H.A., Mallison, B.T. (2011). Automatic differentiation framework for compositional simulation on unstructured grids with multi-point discretization schemes. In SPE Reservoir Simulation Symposium. SPE141592, February 2011 
CHAPTER 6 - Fully compositional multi-scale reservoir simulation of various $\mathrm{CO}_{2}$ sequestration mechanisms

Published in Computers and Chemical Engineering, January 2017

Denis V. Voskov

Department of Geoscience \& Engineering

Delft University of Technology

Stevinweg 1, 2628 CN Delft, Netherlands

\author{
Heath Henley \& Angelo Lucia \\ Department of Chemical Engineering \\ University of Rhode Island
}

Kingston, RI 02881 


\begin{abstract}
A multi-scale reservoir simulation framework for large-scale, multiphase flow with mineral precipitation in $\mathrm{CO}_{2}$-brine systems is proposed. The novel aspects of this reservoir modeling and simulation framework are centered around the seminal coupling of rigorous reactive transport with full compositional modeling and consist of (1) thermal, multi-phase flow tightly coupled to complex phase behavior, (2) the use of the Gibbs-Helmholtz Constrained (GHC) equation of state, (3) the presence of multiple homogeneous/heterogeneous chemical reactions, (4) the inclusion of mineral precipitation/dissolution, and (5) the presence of homogeneous/heterogeneous formations. The proposed modeling and simulation framework is implemented using the ADGPRS/GFLASH system. A number of examples relevant to $\mathrm{CO}_{2}$ sequestration including salt precipitation and solubility/mineral trapping are presented and geometric illustrations are used to elucidate key attributes of the proposed modeling framework.
\end{abstract}




\subsection{Introduction}

\subsubsection{Background and motivation}

Thermal multiphase flow and compositional reactive transport in porous media is the basis for simulation of almost all energy and environment-related industrial processes. The development of a simulation framework capable of modeling this class of problems on a continuous scale has been an important task in both the reservoir engineering and hydrology communities. Reservoir engineers usually deal with problems involving thermal multiphase flow and multi-component transport tightly coupled with complex phase behavior (Zaydullin et al., 2014). These problems include different enhanced oil recovery processes such as steam or gas injection. Usually, chemical reactions are not treated as having a first-order impact on these models.

On the other hand, the hydrology community has been concerned with subsurface modeling of multiple components and multiple chemical reactions. The work by Lichtner (1985) laid the theoretical foundation for continuum models for mass transport and chemical interactions. Current chemical models include a wide variety of different reactions, including dissolution-precipitation and adsorption-desorption (Steefel et al., 2005). However, these models mostly deal with only the aqueous phase in slightly heterogeneous reservoirs. Reactive transport modeling in subsurface hydrology has never been fully coupled with equilibrium phase behavior of complex hydrocarbon mixtures in highly heterogeneous formations, despite some recent attempts (Flemisch et al., 2011). Due to the emerging interest in complicated subsurface dynamic processes like $\mathrm{CO}_{2}$ sequestration, methane hydrate recovery, and geothermal processes, there is a growing need in integrating full chemical reaction modeling capabilities with 
compositional reservoir simulation (Marchand and Knabner, 2014; Farshidi, 2016). Any heterogeneous structure of subsurface formations and the multiple scales of governing processes requires implicit time approximation for numerical solutions to be unconditionally stable on simulation time steps appropriate for the problem of interest.

The main purpose of this study was to develop, for the first time, capabilities for reactive transport modeling in subsurface hydrology fully coupled to equilibrium phase behavior of complex mixtures in highly heterogeneous formations within a numerical reservoir simulator. We tested our framework on a problem of particular practical importance $-\mathrm{CO}_{2}$ sequestration in aqueous aquifers. One of the major challenges in modeling this class of problems is accurate representation of dissolution trapping (Elenius et al., 2014 and Elenius et al., 2015). Macroscopic dissolution rates can be enhanced significantly by gravity-driven currents (up to an order of magnitude). This complex behavior is strongly affected by many factors, including the chemical composition of the brine, different impurities in the injection stream of $\mathrm{CO}_{2}$, changes in pressure and temperature, and simultaneous chemical reactions. In addition, small scale precipitation and dissolution of minerals impacts the dynamics of gravity-driven flows and, in turn, effects the dissolution as well. This work is the first attempt to create a universal tool for predictive reservoir simulation of $\mathrm{CO}_{2}$ sequestration in aqueous aquifers that takes into account all of the complex mechanisms that effect the macroscopic dissolution rate. This dissolution rate can then be used in a realistic, largescale reservoir model using simplified physical models (Gasda et al., 2011 and Lagasca, 2014) to predict the dynamics of $\mathrm{CO}_{2}$ trapping for medium time scales (i.e., tens to a hundred thousand years). 


\subsubsection{EOS modeling}

Additional complexity in compositional modeling stems from phase behavior computations. An Equation of State (EoS) model is usually employed to describe the phase behavior of the multi-component system (Lake, 1989). For given temperature, pressure, and overall composition, EoS computations define the phase state and composition of each phase (Michelsen, 1982a and Michelsen, 1982b). Since iterative EoS computations must be performed for each computational grid block in the reservoir and for each global nonlinear iteration, they can constitute a significant fraction of the total computational cost, even though several schemes exist to speed up these computations in the natural variable formulation (Rasmussen et al., 2006, Iranshahr et al., 2013 and Zaydullin et al., 2016).

Another challenge is related to the accuracy of the EoS for systems involving simultaneous phase and chemical equilibrium for homogeneous and heterogeneous chemical reactions. There are no journal articles in the open literature that consider all of these problem attributes together. Many models use correlations instead of rigorous EoS computations to determine fluid properties and equilibrium. For example, the fluid property module, ECO2N (Pruess and Spycher, 2007) was specifically designed for geological $\mathrm{CO}_{2}$ sequestration in conjunction with the TOUGH2 reservoir simulator. This model considers the simple system of $\mathrm{NaCl}-\mathrm{CO}_{2}$-water and (1) treats the $\mathrm{CO}_{2}$ phase as a pure phase and uses tabulated correlation instead of an EoS for the $\mathrm{CO}_{2}$ molar volume, (2) uses a temperature correlation to determine whether $\mathrm{NaCl}$ precipitates or not, which ignores the presence of $\mathrm{CO}_{2}$, and (3) does not take into account the reaction of $\mathrm{CO}_{2}+\mathrm{H}_{2} \mathrm{O}$ to form either carbonate or bicarbonate ions or the presence of $\mathrm{Ca}^{+}$ions. 
Most successful thermodynamic models are either activity coefficient models (e.g. NRTL, UNIQUAC or EOS models [Redlich-Kwong (RK) equation (Redlich and Kwong, 1949), Soave-Redlich-Kwong (SRK) equation (Soave, 1972), Peng-Robinson (PR) equation (Peng and Robinson, 1976), Statistical Associating Fluid Theory (SAFT), Huang and Radosz, 1990; Cubic Plus Association (CPA), Kontogeorgis et al., 1996; etc.] and are not directly applicable to aqueous electrolyte system. However, thermodynamic models have also been developed for electrolyte solutions (see Prausnitz et al., 1998) including Pitzer equations (Pitzer, 1977), the electrolyte NRTL equation (Chen and Song, 2005), the electrolyte Predictive SRK (ePSRK) equation (Kiepe et al., 2004), the GHC equation (Lucia et al., 2015), the eCPA equation (MariboMogensen et al., 2015), and variants of Statistical Associating Fluid Theory or SAFT (Chapman et al., 1989). Unfortunately, many of the rigorous EoS models such as the recent modifications for the activity coefficient part of the ePSRK model, LIQUAC/LIFAC, by Mohs and Gmehling (2013) mention salt precipitation but present no results illustrating capabilities and do not consider simultaneous homogeneous chemical reactions. The electrolyte Cubic Plus Association (eCPA) model of MariboMogensen et al. (2015), on the other hand, only considers phase equilibrium of electrolyte mixtures and no chemical reactions. Finally, the recent electrolyte version of SAFT (Zhao et al., 2007) does not consider solid precipitation either.

\subsection{Modeling}

In this section, the GHC EOS and numerical reservoir simulator, ADGPRS, are briefly discussed and advantages of each are highlighted.

\subsubsection{GHC Equation of State}


The GHC EOS (Lucia, 2010) is a recent modification of the SRK (Soave, 1972)

EOS that constrains the energy parameter, a, to satisfy the Gibbs-Helmholtz equation and uses Monte Carlo simulations to incorporate molecular length scale information. In particular, the energy parameter in the GHC EOS for pure components is given by equation (6.1).

$a(T, p)=\left(0.42748 * \frac{R^{2} T_{c}}{p_{c}}+\frac{b U^{D L}}{T_{c} \ln (2)}+\frac{2 b R \ln \left(T_{c}\right)}{\ln (2)}\right) T-\frac{b U^{D L}}{\ln (2)}-\left(\frac{2 b R}{\ln (2)}\right) T \ln (T)$

where $p_{c}$ and $T_{c}$ are critical properties, $b$ is the molecular co-volume parameter, and $R$ is the gas constant, and $U^{D}$ is the molecular scale internal energy of departure at the given temperature and pressure. Pure component $U^{D}$ is determined a priori over wide ranges of temperature and pressure using Monte Carlo molecular simulation, stored in look up tables, and readily up-scaled to bulk phase EOS calculations using eq. (6.1). The novel features of the GHC equation include the use of molecular information in the energy parameter expression and the estimation of $\mathrm{b}$ from pure component density data. The details of the derivation of the GHC EOS, the extension to non-electrolyte and electrolyte mixtures can be found in the literature (Lucia, 2010; Lucia et al., 2012a,b; Lucia et al., 2015). It is important to note that the GHC EOS only uses parameters based on pure component properties (e.g., mixture critical properties from Kay's rules) and pure component Monte Carlo molecular simulation (mixture $U^{D}$ from a linear mixing rule), even in systems containing electrolytes, and is truly predictive.

\subsubsection{Monte Carlo simulation details}

Application of the multi-scale GHC EOS requires prior knowledge of pure component internal energy of departure for the components in the system at relevant conditions. Monte Carlo molecular simulations in the isobaric-isothermal ensemble are 
used to generate the necessary information a priori and create lookup tables. The specific details of the simulation change based on the component and molecular model being used, however generally a 6-12 Lennard-Jones potential is used to account for van der Waals interactions, along with the recommended cut off (depending on the model) and tail corrections. The Coulomb potential with an Ewald summation is used to account for electrostatic interactions. A cubic box with periodic boundary conditions is used in all bulk fluid simulations. Standard center of mass translation and rotation moves, as well as isotropic volume moves are applied. Simulations are run in equilibration mode for a number of cycles (depending on the system) in which the maximum displacement and rotation are frequently adjusted to maintain $50 \%$ acceptance rates of translation and rotation moves, respectively. The system is then switched to production mode, in which the maximum displacement and rotation are fixed, for sampling. Typically, four parallel sets are run for the same system and the results are averaged. References for the simulation parameters for the components used in this work can be found Table B3. Simulations are typically run either using the open source Towhee MCCCS software (Martin, 2013) or an in-house FORTRAN program. MC simulation runtimes can range from a few hours to a few days, depending on the complexity of the molecular model, the number of particles included in the simulation, and the potential model(s) used.

\subsubsection{GFLASH}

The GFLASH library is a multi-component, multiphase, isothermal, isobaric (TP) flash calculation program written in FORTRAN. Given an overall composition, temperature, and pressure of a fluid mixture, GFLASH has the capability to determine the number of existing phases at equilibrium and calculate their compositions, densities, 
enthalpies, fugacities, and all property derivatives with respect to pressure, temperature, and composition. The main capabilities and details are outlined in previous publications (Zaydullin et al., 2014; Lucia, et al., 2015). The main reasons for the use of GFLASH in this work are the implementation of (1) a robust stability and flash algorithm and (2) the GHC EOS, and (3) the capability to handle simultaneous phase and homogeneous/heterogeneous chemical reaction equilibrium with mineral deposition/dissolution.

\subsubsection{Description of Reaction Equilibrium Model}

A full detailed description of the numerical methods used for solving the equilibrium reactions for molecular salt formation included in this work can be found in the paper by Lucia et al. (2014). For the examples studied in this work, the formation/dissolution of solid salts was limited to $\mathrm{NaCl}, \mathrm{Na}_{2} \mathrm{CO}_{3}, \mathrm{CaCl}_{2}$, and $\mathrm{CaCO}_{3}$, described by the following reactions:

$$
\begin{aligned}
& \mathrm{NaCl}_{(s)} \leftrightarrow \mathrm{Na}_{(a q)}^{+}+\mathrm{Cl}_{(a q)}^{-} \\
& \mathrm{Na}_{2} \mathrm{CO}_{3(s)} \leftrightarrow 2 \mathrm{Na}_{(a q)}^{+}+\mathrm{CO}_{3(a q)}^{2-} \\
& \mathrm{CaCl}_{2(s)} \leftrightarrow \mathrm{Ca}_{(a q)}^{2+}+2 \mathrm{Cl}_{(a q)}^{-} \\
& \mathrm{CaCO}_{3(s)} \leftrightarrow \mathrm{Ca}_{(a q)}^{2+}+\mathrm{CO}_{3}^{2-}{ }_{(a q)}
\end{aligned}
$$

In addition, the following reaction of dissolved carbon dioxide with water to generate carbonate ion was included:

$$
\mathrm{CO}_{2}+3 \mathrm{H}_{2} \mathrm{O} \leftrightarrow 2 \mathrm{H}_{3} \mathrm{O}_{(a q)}^{+}+\mathrm{CO}_{3(a q)}^{2-}
$$

Reaction (6.6) was obtained by summing the reactions in the carbonate series, and equilibrium concentrations of carbonic acid and bicarbonate ion, which were not of interest in the examples studied. Also, the formation of hydronium ion, and therefore 
changes in $\mathrm{pH}$ due to the dissolution of $\mathrm{CO}_{2}$, were neglected. This is because Soong and coworkers (2004) have found that brine with a $\mathrm{pH}$ of 11 produces the most $\mathrm{CaCO}_{3}$ when reacted with $\mathrm{CO}_{2}$. Therefore, it is assumed that the original $\mathrm{pH}$ of formation brine was high enough to fully support $\mathrm{CaCO}_{3}$ precipitation. For a brine solution with $\mathrm{pH}$ of 11 , the change in $\mathrm{pH}$ due to the amount of $\mathrm{CO}_{3}{ }^{2-}$ produced from $\mathrm{CO}_{2}$ in the examples in this study was, in fact, negligible, as shown in Appendix A. The equilibrium constants for the reactions were calculated from tabulated standard Gibbs free energies of formation data and corrected for temperature using tabulated standard enthalpies of formation and the van't Hoff equation. See Appendix B.

The primary goals of this study were (1) to demonstrate that the coupled ADGPRS/GFLASH software system has the capability to accurately model mixtures in which minerals dissolve and/or precipitate and (2) to show that ADGPRS/GFLASH can accurately model $\mathrm{CO}_{2}$ sequestration with residual, dissolution, and mineral trapping.

\subsubsection{ADGPRS}

The reservoir modeling software used in this work is called Automatic Differentiation General Purpose Research Simulator (ADGPRS) and was developed and maintained by SUPRI-B research group at Stanford University. ADGPRS is written mainly in $\mathrm{C}++$, and widely used throughout the reservoir and petroleum engineering communities because of its wide-ranging capabilities, which include (Zaydullin et al., 2014):

1. Flexible treatment of all nonlinear physics.

2. A fully thermal-compositional formulation for any number of phases.

3. Multi-phase CSAT for efficient and robust computation of phase behavior. 
4. A variety of spatial and temporal discretization schemes.

5. Thermal geo-mechanical modeling including the effects of fractures.

6. A fully coupled, thermal, multi-segmented well model with drift-flux.

7. An adjoint-based optimization module.

The details of ADGPRS, including (1) available variable formulations (Voskov and Tchelepi, 2012; Zaydullin et al., 2012), (2) discretization schemes (Zhou et al., 2011), (3) solution methods for the system of linear and nonlinear equations (Voskov, 2011; Tchelepi and Zhou, 2013), and (4) various approaches for phase behavior computations (Iranshahr et al., 2010; Iranshahr et al., 2013) can be found in the literature cited. An overview of the topics previously listed is given in a previous paper (Zaydullin et al., 2014) and is not included here.

\subsubsection{Coupling ADGPRS/GFLASH for compositional systems}

Interfacing GFLASH with ADGPRS results in a fully implicit and fully coupled treatment of the flow and transport through porous media, as well as rigorous, EOSbased phase/chemical equilibrium. GFLASH determines the equilibrium compositions of all phases using rigorous Gibbs free energy minimization along with the density of the fluid phases and provides accurate densities for the fluid phases without the need for empirical correlations such as volume translation and binary interaction parameters. ADGPRS/GFLASH has been successfully used to compare different enhanced oil recovery (EOR) methods in both light and heavy oil reservoirs. The details of the interface can be found in the literature (Zaydullin et al., 2014; Voskov et al., 2016).

\subsubsection{ADGPRS/GFLASH Architecture}


Fig. 6.1 clearly illustrates the architecture of the ADGPRS/GFLASH modeling framework, with a focus on the flow of information in the GFLASH library.

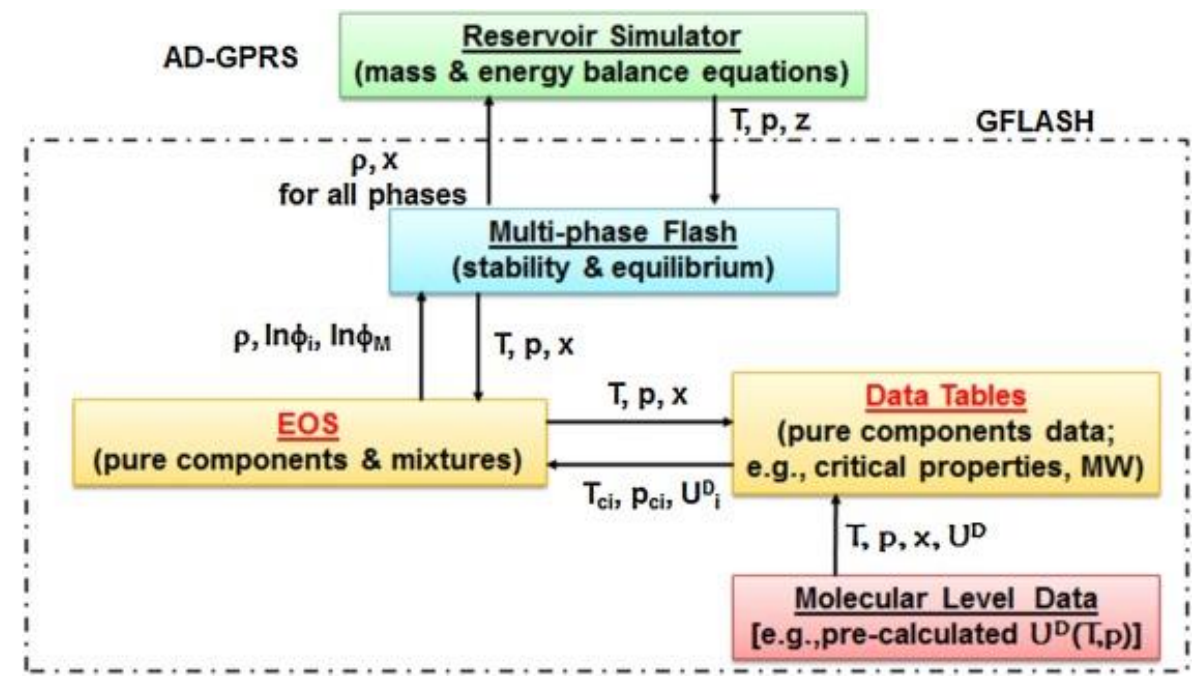

Figure 6.1: Information Flowchart for AD-GPRS/GFLASH Framework

Fluid densities and fugacities, as well as chemical reaction equilibrium constraints and their derivatives for the fluids in each grid block in the reservoir model, are calculated at given conditions (temperature, pressure and composition) and returned to the simulator. As described in Section 6.2.1, the molecular level information required to use the GHC equation of state is obtained a priori and stored in pure component look-up tables for the components of interest. To perform EOS based calculations the pure component $\mathrm{U}^{\mathrm{D}}$ values for all components in the mixture are read from the look-up tables and, if necessary, interpolated to the conditions of interest. It is important to note the GHC EOS requires no adjustable parameters at the EOS level. Critical properties for all components used in this work are listed in B.1, as well as the values of the molecular co-volumes for the GHC EOS. See Lucia et al. (2012) and Lucia et al. (2015) respectively for additional information regarding the implementation of the GHC EOS and the multiphase flash algorithm and handling of salt precipitation within GFLASH.

\subsection{Natural formulation for reactive systems with precipitation and dissolution}


The basic information flow between ADGPRS and GFLASH is given in Fig. 6.1. Specifically, for each grid block in the reservoir ADGPRS passes the current estimate of the temperature, pressure and overall composition of that block to GFLASH. GFLASH, in turn, uses that information to determine the number of equilibrium phases, their amounts and compositions, in this case using the GHC equation of state, and returns this information to ADGPRS. Many of these details are described in previous publications (Zaydullin et al., 2014; Voskov et al., 2016). In this section, specific modifications for the treatment of flow and transport in the presence of chemical (equilibrium) reactions and details of the coupling between ADGPRS and GFLASH are described. For problems with precipitation and dissolution with equilibrium reactions, new (solid) phases must be introduced into the general natural variables logic (Voskov and Tchelepi, 2012; Zaydullin et al., 2014).

\subsubsection{Governing equations}

The typical governing equations for $\mathrm{CO} 2$ sequestration include conservation of mass for each species and closure assumptions and constraints. The mass conservation equations for isothermal compositional systems can be written as

$\frac{\partial}{\partial t}\left(\phi \sum_{k=1}^{P} \rho^{k} x_{i}^{k} S^{k}\right)-\Sigma_{k=1}^{P} \nabla\left(\rho^{k} x_{i}^{k} V^{k}+S^{k} J_{i}^{k}\right)-q_{i}=\Sigma_{l=1}^{R} r^{l} v_{i}^{l}$, for $\mathrm{i}=1, \ldots, \mathrm{C}$

where $\mathrm{P}$ is the number of co-existing thermodynamic phases, $\mathrm{R}$ is the number of reactions, and $\mathrm{C}$ is the number of species. Also, $\phi$ is the porosity of the porous media, $\rho$ is molar density, $\mathrm{x}$ denotes composition in mole fraction, $\mathrm{S}$ is phase saturation, $\mathrm{V}$ is volumetric (Darcy) flow, $\mathrm{J}$ is molar diffusion flux, q denotes a mass source or sink term, $\mathrm{r}$ is reaction rate, and $\mathrm{v}$ are stoichiometric coefficients.

\subsubsection{Rearrangement of equations}


Eq. (6.7) can be written in the general matrix form given by

$\frac{\partial \boldsymbol{a}}{\partial t}+\boldsymbol{I}+q=V \boldsymbol{r}$

where a corresponds to an accumulation vector of length $C, \mathbf{I}$ is a $\mathrm{C}$ vector of fluxes, $\mathbf{q}$ is the well source term vector, also of length $\mathrm{C}, \mathbf{r}$ is the reaction rate vector of length $\mathrm{Q}$, and $\mathbf{V}$ is a CxQ stoichiometric matrix.

Following the logic described in Farshidi et al. (2013), we introduce the ExC matrix, E, which represents the stoichiometry for each element associated with the reactions of each species. In general, this matrix can be determined by solving the equations

$E \times V=0$

Multiplying Eq. (6.8) by E gives E element mass conservation equations of the form

$\frac{\partial E \boldsymbol{a}}{\partial t}+E \boldsymbol{I}+E q=0$

To close the system, an additional $\mathrm{C}-\mathrm{E}$ independent equilibrium constraints are needed and take the form

$K_{s p}(T, P)-Q_{s p}(\boldsymbol{x}, T, P)=0$

where the multi-phase flash procedure described in Section 6.2.2 is used to define the equilibrium solubility product, $K_{s p}(T, P)$, using Gibbs free energies of formation and the identity of the minerals that precipitate. The ion solubility product, $Q_{s p}(x, T, P)$, on the other hand, is defined using the actual ion concentrations in the brine determined from the GHC equation of state.

\subsubsection{Mineral precipitation}

When mineral precipitation is controlled by chemical equilibrium, a procedure is needed to account for the appearance and/or disappearance of solids. Since precipitation only 
occurs when the ion solubility product for any particular salt exceeds its equilibrium solubility product, a more general form of eq. (6.10) is needed.

$Q_{s p}(x, T, P)>K_{s p}(T, P) ;$ precipitation

$Q_{s p}(\boldsymbol{x}, T, P)>K_{s p}(T, P) ;$ precipitation

Once the potential for precipitation is identified, new conservation equations for those mineral components and mineral phases of the form

$\frac{\partial a_{c}}{\partial t}=r_{c}$

must be added to the original system given in eq. (6.8). Additional unknown variables must also be added to the set of unknowns corresponding to the concentrations of the solid species. Finally, the matrix E should be modified and include a new rate corresponding to the reaction for the precipitated mineral, see Farshidi (2016) for details.

\subsubsection{Illustrative example}

In this section, a simple example is presented to illustrate the extension of the compositional AD-GPRS/GFLASH framework to reactive systems with five components and three phases as shown in Table 6.1.

Table 6.1: Presence of Components in Phases

\begin{tabular}{|c|c|c|c|c|c|}
\hline Phase/Components & $\mathrm{H} 2 \mathrm{O}$ & $\mathrm{CO} 2$ & $\mathrm{Ca} 2+$ & $\mathrm{CO} 2-$ & $\mathrm{CaCO} 3$ \\
\hline 1. Brine & $\mathrm{x}$ & $\mathrm{x}$ & $\mathrm{X}$ & $\mathrm{x}$ & - \\
\hline 2. Gas & $\mathrm{x}$ & $\mathrm{x}$ & - & - & - \\
\hline 3. Mineral & - & - & - & - & $\mathrm{x}$ \\
\hline
\end{tabular}

For simplicity, we assume that the brine phase always exists. Treatment of the disappearance of water or brine phases can be found in Farshidi (2016). For the 
illustrative example, there are only four possible combinations of co-existing phases, as shown in Table 6.2.

Table 6.2: Status Table and Equations for Brine- $\mathrm{CO}_{2}$ System

\begin{tabular}{|c|c|c|c|c|}
\hline Status & Number of phases & \multicolumn{3}{|c|}{ Array of existing phases } \\
\hline & & Brine & Gas & Solid \\
\hline 1 & 1 & $\mathrm{X}$ & - & - \\
\hline 2 & 2 & $\mathrm{X}$ & $\mathrm{x}$ & - \\
\hline 3 & 2 & $\mathrm{X}$ & - & $\mathrm{x}$ \\
\hline 4 & 3 & $\mathrm{X}$ & $\mathrm{x}$ & $\mathrm{x}$ \\
\hline
\end{tabular}

The matrix $\mathbf{E}$ for this example is

$E=\left[\begin{array}{llll}1 & 0 & 0 & 0 \\ 0 & 1 & 0 & 0 \\ 0 & 0 & 1 & 0 \\ 0 & 0 & 0 & 1\end{array}\right]$

when solid phase does not precipitate and

$E=\left[\begin{array}{lllll}1 & 0 & 0 & 0 & 0 \\ 0 & 1 & 0 & 0 & 0 \\ 0 & 0 & 1 & 0 & 1 \\ 0 & 0 & 0 & 1 & 1\end{array}\right]$

when solid precipitates and correspond to statuses 3 and 4 . For the matrices shown in Eqs. (6.14) and (6.15), each row corresponds to an element (i.e., carbon, hydrogen, oxygen, etc.) while each column corresponds to a component (i.e., molecular or ionic species). Finally, a correct set of unknowns (and equations) can be easily constructed for each combination of phases shown in Table 6.2.

\subsection{Numerical results and discussion}

In this section, numerical results for four separate $\mathrm{CO}_{2}$ sequestration examples are presented to illustrate the robustness of the proposed methodology in capturing the 
correct physics of solubility and mineral trapping, carbonate chemistry, and mineral precipitation and dissolution.

\subsubsection{Example 1 - Large scale model with solid precipitation and dissolution}

This first example is a simple reservoir model with the fluid system of $\mathrm{CO}_{2}-\mathrm{H}_{2} \mathrm{O}-\mathrm{Ca}^{2+}-$ $\mathrm{Na}^{+}-\mathrm{Cl}^{-} \mathrm{CO}_{3}{ }^{2-}$. For the conditions shown in Table 6.3, there are many different equilibrium phase states possible (i.e., VLE, VLLE, LLE, SLE, SLLE, etc.), depending on temperature, pressure and composition throughout the reservoir. The main purpose of this example was to demonstrate the ability of the ADGPRS/GFLASH system to model solid precipitation and dissolution; therefore, carbonate chemistry was not included and represents a system in which a $\mathrm{CO}_{2}$-rich injection stream is introduced into a formation containing a single-phase brine. It is set up in a $50 \times 50 \times 1$ grid to study horizontal propagation of the injection stream.

Table 6.3: Initial Conditions for 50 x 50 x 1 Example

\begin{tabular}{|c|c|c|}
\hline & Injection conditions & Reservoir \\
\hline p (bar), T (K) & 240,350 & 220,350 \\
\hline Species & Mole Fraction & Mole Fraction \\
\hline $\mathrm{CO}_{2}$ & 0.979997 & 0.0005 \\
\hline $\mathrm{H}_{2} \mathrm{O}$ & 0.02 & 0.9943 \\
\hline $\mathrm{Na}^{+}$ & 0.000002 & 0.002 \\
\hline $\mathrm{Ca}^{2+}$ & $1.00 \mathrm{E}-13$ & 0.0004 \\
\hline $\mathrm{Cl}^{-}$ & $1.00 \mathrm{E}-13$ & 0.0028 \\
\hline $\mathrm{CO}_{3}{ }^{2-}$ & 0.000001 & $1.00 \mathrm{E}-13$ \\
\hline Minerals & Concentration $\left(\mathrm{kmol} / \mathrm{m}^{3}\right)$ & Concentration $\left(\mathrm{kmol} / \mathrm{m}^{3}\right)$ \\
\hline $\mathrm{NaCl}$ & 0 & 1.2 \\
\hline $\mathrm{CaCl}_{2}$ & 0 & 0 \\
\hline $\mathrm{Na}_{2} \mathrm{CO}_{3}$ & 0 & 0 \\
\hline $\mathrm{CaCO}_{3}$ & 0 & 0 \\
\hline
\end{tabular}


As shown in Table 6.3, the injection feed contained an elevated carbonate composition due to higher carbon dioxide composition. Transmissibility in both the $\mathrm{x}$ and y directions was set to $10.0\left(\mathrm{~m}^{3} / \mathrm{day} / \mathrm{bar}\right)$. A formation porosity of 0.18 was used and simulations were conducted isothermally (energy balance neglected) at a temperature of $350 \mathrm{~K}$. In addition, the GHC EOS was used to evaluate all densities, fugacities, and required derivatives and all salt equilibrium and ion solubility calculations were performed by GFLASH. A natural variable formulation, in which pressure, saturations, and component phase compositions were the independent variables, was used for the simulations using ADGPRS.

This particular example contained an injection well in the lower left corner, and a production well in the upper right-hand corner. As shown in Table 6.3, the reservoir was initialized with solid $\mathrm{NaCl}$ in each block and a fluid with a composition different than the composition of the injected fluid.

As the simulation of this first example progressed, the pressure changed until supercritical $\mathrm{CO}_{2}$ broke into the production well in the upper right-hand corner. Also, the flow of $\mathrm{CO}_{2}$ from the injection block caused an increase in $\mathrm{CO}_{2}$ composition in many blocks of the reservoir, eventually causing a second $\mathrm{CO}_{2}$ rich phase to appear in the system (see Fig. 6.2). Fig. 6.3, on the other hand, shows the equilibrium phase state (i.e., LLE, SLLE, VLE, etc.) of each block in the system as the simulation evolved. Clearly, Fig. 6.3 shows that as fluid flowed out of the feed block into the reservoir, $\mathrm{NaCl}$ dissolved before the $\mathrm{Ca}^{2+}$ in the reservoir could react with $\mathrm{CO}_{3}{ }^{2-}$ from the feed block to form $\mathrm{CaCO}_{3}$. 

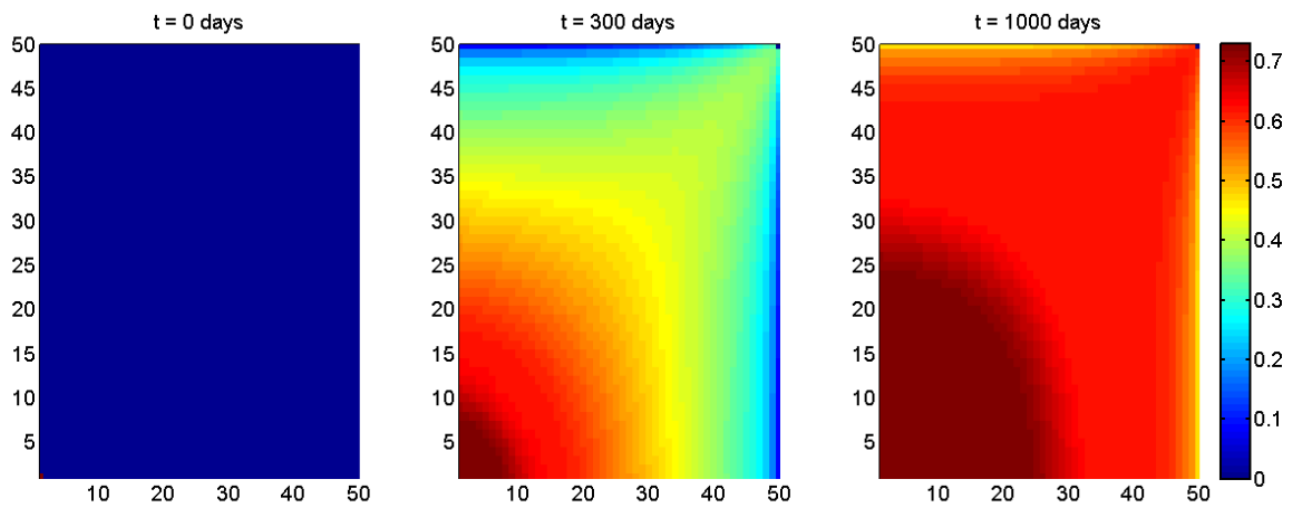

Figure 6.2: Saturation Distribution of CO2-rich Phase
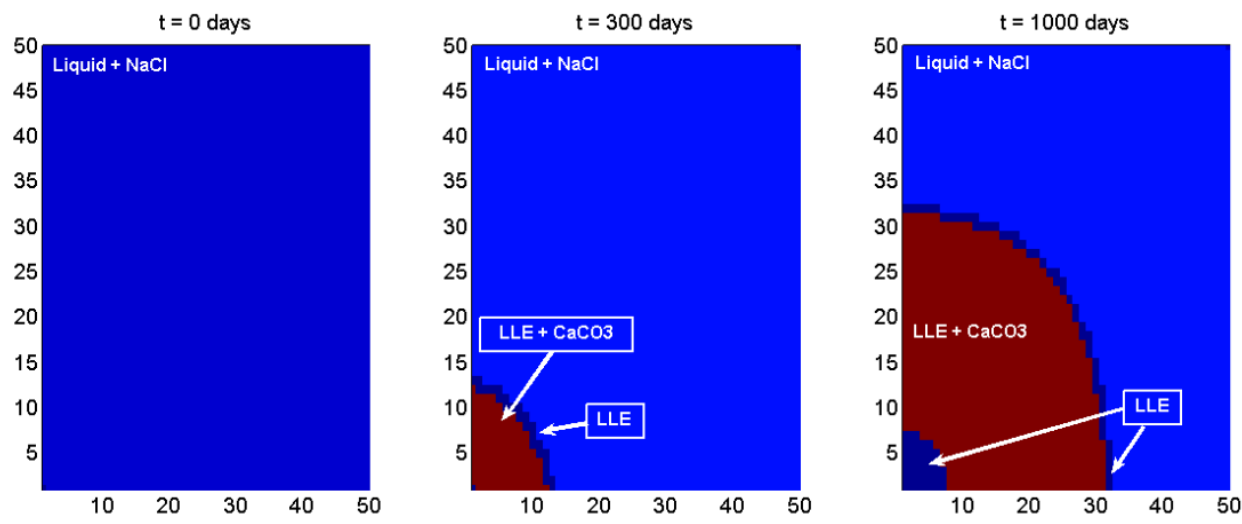

Figure 6.3: Distribution of Equilibrium Phase State

This example clearly illustrates the capabilities of the ADGPRS/GFLASH system to model both mineral dissolution $(\mathrm{NaCl})$ and precipitation $\left(\mathrm{CaCO}_{3}\right)$ using a rigorous EOS-based treatment of the phase equilibrium. Some current reservoir simulation frameworks rely on tabulated K-values (e.g., CMG STARS) while others, like the ECO2N module (Pruess and Spycher, 2007) in the TOUGH2 simulator, use correlations to determine the vapor-liquid equilibrium instead of a rigorous EOS-based flash calculation.

\subsubsection{Example 2 - Large scale simulation of $\mathrm{CO}_{2}$ injection}

The purpose of this second example was to demonstrate that the coupled ADGPRS/GFLASH system could successfully model $\mathrm{CaCO}_{3}$ precipitation/dissolution. 
This second example focused on buoyancy driven vertical migration of a $\mathrm{CO}_{2}$ plume, which is a key feature of many carbon sequestration studies, the use of approximate carbonate chemistry, and its impact on the precipitation of $\mathrm{CaCO}_{3}$ as described in Section 6.2.2.1. Here we assume that the $\mathrm{CO}_{2}$ plume is trapped in the geological formation and monitor short time-scale mineralization processes. This example used the same fluid system that was used in Example 1 with conditions shown in Table 6.4. More specifically, the reservoir in this example was homogeneous with a porosity of 0.18 and discretized with a $25 \times 1 \times 25$ grid. The grid spacing was also homogeneous and set to $8 \mathrm{~m}$ in each direction, with absolute permeability equal to $150 \mathrm{mD}$ and $220 \mathrm{mD}$ in the $\mathrm{x}$ and $\mathrm{z}$ directions respectively. This system was first equilibrated to approximate hydrostatic equilibrium so that the pressure in the initial system varied with depth from 250 bar to 270 bar. Pure $\mathrm{CO}_{2}$, which was less dense than the surrounding reservoir fluid, was injected into the middle block in the bottom row of the reservoir. The increased amount of $\mathrm{CO}_{2}$ that dissolved in reservoir brine resulted in an increase in dissolved carbonate ions in the aqueous phase, and under the model conditions defined in this example, also resulted in the precipitation of $\mathrm{CaCO}_{3}$. As this $\mathrm{CO}_{2}$ plume rose, it was observed that the amount of dissolved $\mathrm{CO}_{2}$ in the aqueous phase in the blocks near the plum increased. This, in turn, led to the generation of $\mathrm{CO}_{3}{ }^{2-}$, which then reacted with dissolved $\mathrm{Ca}^{2+}$ in the reservoir to form solid $\mathrm{CaCO}_{3}$.

Table 6.4: Initial Conditions for 25 x 1 x 25 Example

\begin{tabular}{|c|c|c|}
\hline & Injection conditions & Reservoir \\
\hline Quantity & Value & Value \\
\hline $\mathrm{p}$ (bar), $\mathrm{T}(\mathrm{K})$ & 280,350 & $250-270,350$ \\
\hline & & \\
\hline Species & Mole Fraction & Mole Fraction \\
\hline
\end{tabular}




\begin{tabular}{|c|c|c|}
\hline $\mathrm{CO}_{2}$ & 0.43 & $1.00 \mathrm{E}-05$ \\
\hline $\mathrm{H}_{2} \mathrm{O}$ & 0.569979 & 0.999689 \\
\hline $\mathrm{Na}^{+}$ & $1.00 \mathrm{E}-13$ & $1.00 \mathrm{E}-13$ \\
\hline $\mathrm{Ca}^{2+}$ & $1.00 \mathrm{E}-13$ & $1.00 \mathrm{E}-04$ \\
\hline $\mathrm{Cl}^{-}$ & $1.00 \mathrm{E}-13$ & $2.00 \mathrm{E}-04$ \\
\hline $\mathrm{CO}_{3}^{2-}$ & $1.00 \mathrm{E}-13$ & $1.00 \mathrm{E}-13$ \\
\hline \multicolumn{3}{|c|}{} \\
\hline \multicolumn{3}{|c|}{} \\
\hline Mineral & Concentration $\left(\mathbf{k m o l} / \mathbf{m}^{3}\right)$ & Concentration $\left(\mathbf{k m o l} / \mathbf{m}^{3}\right)$ \\
\hline $\mathrm{NaCl}^{2}$ & 0 & 0 \\
\hline $\mathrm{CaCl}_{2}$ & 0 & 0 \\
\hline $\mathrm{Na}_{2} \mathrm{CO}_{3}$ & 0 & 0 \\
\hline $\mathrm{CaCO}_{3}$ & 0 & 0 \\
\hline
\end{tabular}

Fig. 6.4 shows the $\mathrm{CO}_{2}$-rich phase saturation at selected time steps, while Figs. 6.5 and 6.6 show the concentration of $\mathrm{CO}_{2}$ in the brine phase and amount of precipitated $\mathrm{CaCO}_{3}$ respectively. 

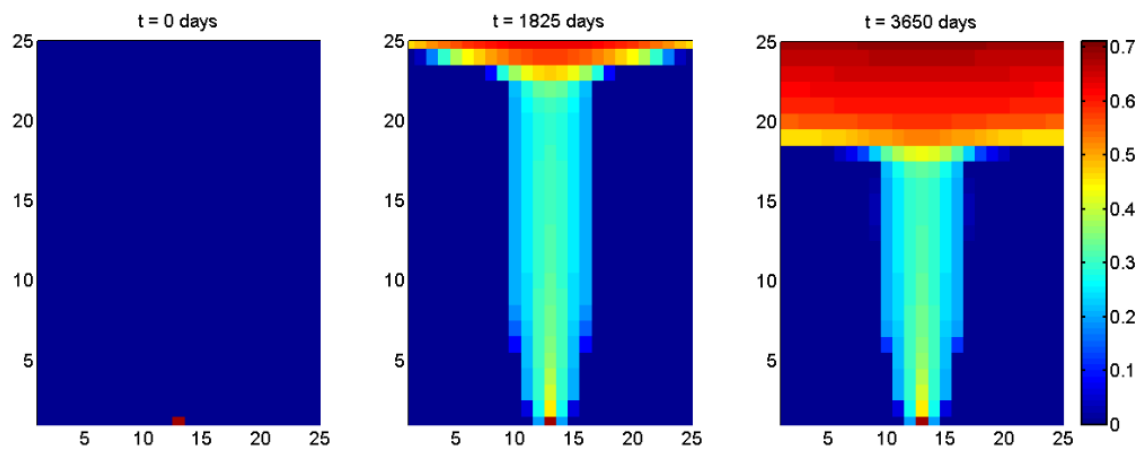

Figure 6.4: Saturation distribution of $\mathrm{CO}_{2}$-rich phase
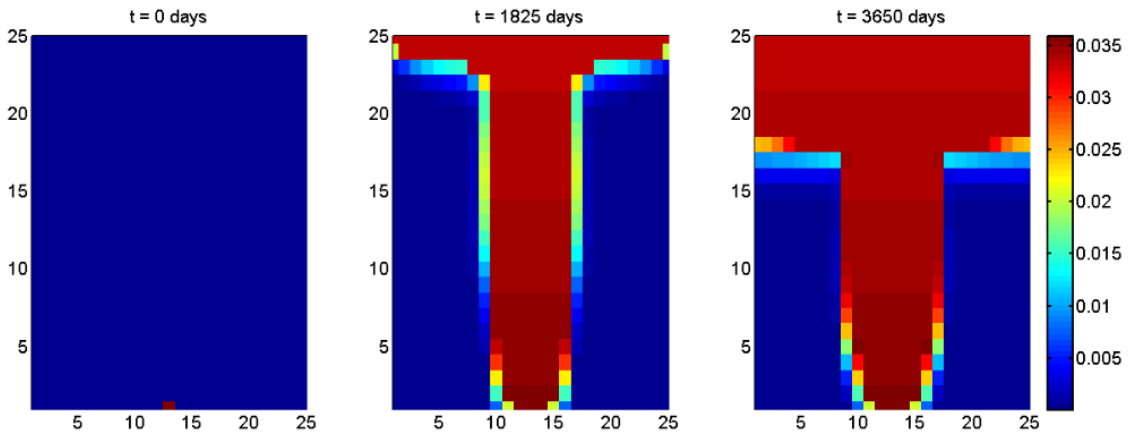

Figure 6.5: Distribution of $\mathrm{CO}_{2}$ mole fraction in the brine phase
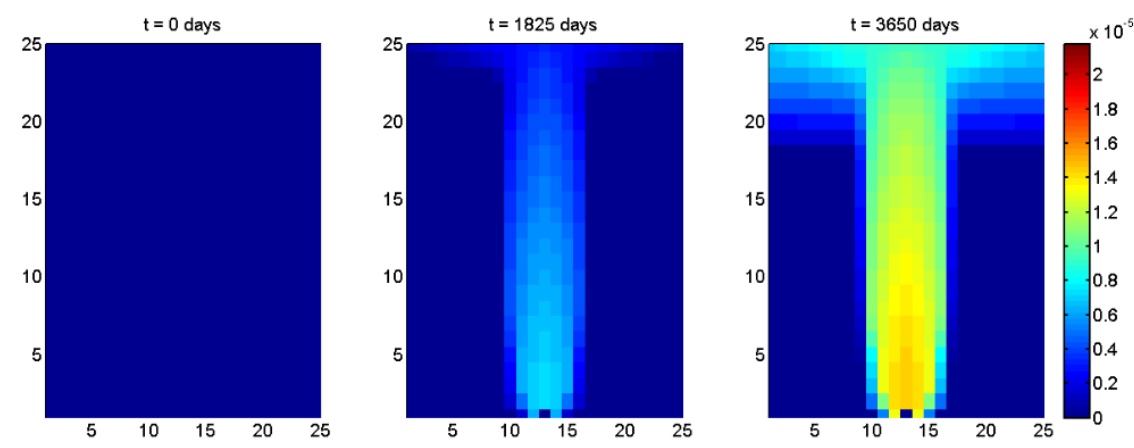

Figure 6.6: Distribution of Precipitated $\mathrm{CaCO}_{3}\left(\mathrm{kmol} / \mathrm{m}^{3}\right)$

It is clear from Figs. 6.4-6.6 that the $\mathrm{CO}_{2}$ plume migrates upward, causing an increase dissolved $\mathrm{CO}_{2}$ in the brine phase, leading to precipitation of $\mathrm{CaCO}_{3}$. Moreover, in this example the only source of $\mathrm{CO}_{3}{ }^{2-}$ ions was the equilibrium reaction between dissolved carbon dioxide and water and the resulting precipitation of $\mathrm{CaCO}_{3}$ in the reservoir clearly illustrates that the coupled ADGPRS/GFLASH system has the capability to model salt precipitation in the presence of carbonate chemistry. 


\subsubsection{Example 3 - Small scale model with solubility trapping}

In this section, we use a simulation model from Elenius et al. (2015) to estimate the small-scale dissolution rate of $\mathrm{CO}_{2}$. The rectangular 2D domain has dimensions $100 \times$ $50 \mathrm{~m}$ with resolution $\Delta \mathrm{x}=\Delta \mathrm{z}=0.5 \mathrm{~m}$, constant porosity $\varphi=0.15$ and permeability $\mathrm{k}=$ $100 \mathrm{mDarcy}$. There are no flow boundary conditions on the top and sides of the domain and an open downward boundary with a low permeability ( $\mathrm{kb}=0.1 \mathrm{mDarcy})$. This model represents the trailing part of a large-scale plume with a capillary transient zone and the diffusion of dissolved $\mathrm{CO}_{2}$ through the bedrock. Here instead of using the simplified correlations for properties of $\mathrm{CO}_{2}$ and brine as was done in Elenius et al. (2015), we used the GHC EOS for property evaluation at different thermodynamic conditions to account for the presence of aqueous ions. Table 6.5 gives the initial compositions for the model. We used an initial pressure distribution starting from $\mathrm{p}=$ 240 bar at the lower part of the model and constant temperature $\mathrm{T}=345 \mathrm{~K}$. No minerals initially precipitated in the model.

Table 6.5: Initial Composition in Lower Region for Example 3

\begin{tabular}{|c|c|}
\hline Component & $\begin{array}{c}\text { Mole fraction in lower } \\
\text { region (single phase) }\end{array}$ \\
\hline $\mathrm{CO}_{2}$ & $1.00 \mathrm{E}-09$ \\
\hline $\mathrm{H}_{2} \mathrm{O}$ & 0.999500149 \\
\hline $\mathrm{Na}^{+}$ & $1.00 \mathrm{E}-04$ \\
\hline $\mathrm{Ca}^{2+}$ & $1.00 \mathrm{E}-04$ \\
\hline $\mathrm{Cl}^{-}$ & $3.00 \mathrm{E}-04$ \\
\hline $\mathrm{CO}_{3}{ }^{2-}$ & $1.00 \mathrm{E}-12$ \\
\hline
\end{tabular}

Due to molecular diffusion, the initial portion of $\mathrm{CO}_{2}$ in the plume starts dissolving in the brine, and the difference in density of the brine with the dissolved $\mathrm{CO}_{2}$ (since it is heavier than the original brine) initiates the formation of unstable fingers of 
$\mathrm{CO}_{2}$-rich brine. These fingers enhance the dissolution rate of $\mathrm{CO}_{2}$ several fold and significantly increase the trapping capability of the aquifer due to the higher dissolution. The numerical simulation of this process requires very fine resolution of the simulation grid which makes it prohibitive for a full field simulation (Elenius et al., 2015). Small scale models can predict $\mathrm{CO}_{2}$ dissolution rate quite accurately, which can be used in various up-scaling models (Gasda et al., 2011; Lagasca, 2014) to predict the migration distance of the $\mathrm{CO}_{2}$ plume in a large aquifer over medium time-scale (tens to one hundred thousand years). The left part of Fig. 6.7 shows the composition of $\mathrm{CO}_{2}$ in the brine phase at different times. In the right part of Fig. 6.7 is shown the dissolution rate of $\mathrm{CO}_{2}$ as a function of time (years). The dissolution rate and trend are similar to ones reported in Elenius et al. (2015).

\section{Example 4 - Small scale model with combined solubility/mineral trapping}

It is believed that due to the time-scale of chemical reactions in brine- $\mathrm{CO}_{2}$ systems, mineral trapping does not affect the early stages of the $\mathrm{CO}_{2}$ sequestration process. However, small-scale precipitation may affect dissolution trapping due to the change in the dynamics of the instabilities. Precipitation and dissolution can change the porosity, which in turn can affect diffusion and the formation of fingers. In the presence of a capillary transient zone, this process will be coupled to phase behavior and become quite challenging to predict without a reliable simulation tool. Any inaccuracy in the

prediction of the small-scale dissolution rate can change the predicted capacity of aquifers used for a large-scale sequestration several fold (see the example in Elenius et al., 2015). Here we present unique simulation results where the physics of all $\mathrm{CO}_{2}$ trapping mechanisms are taken into account. 

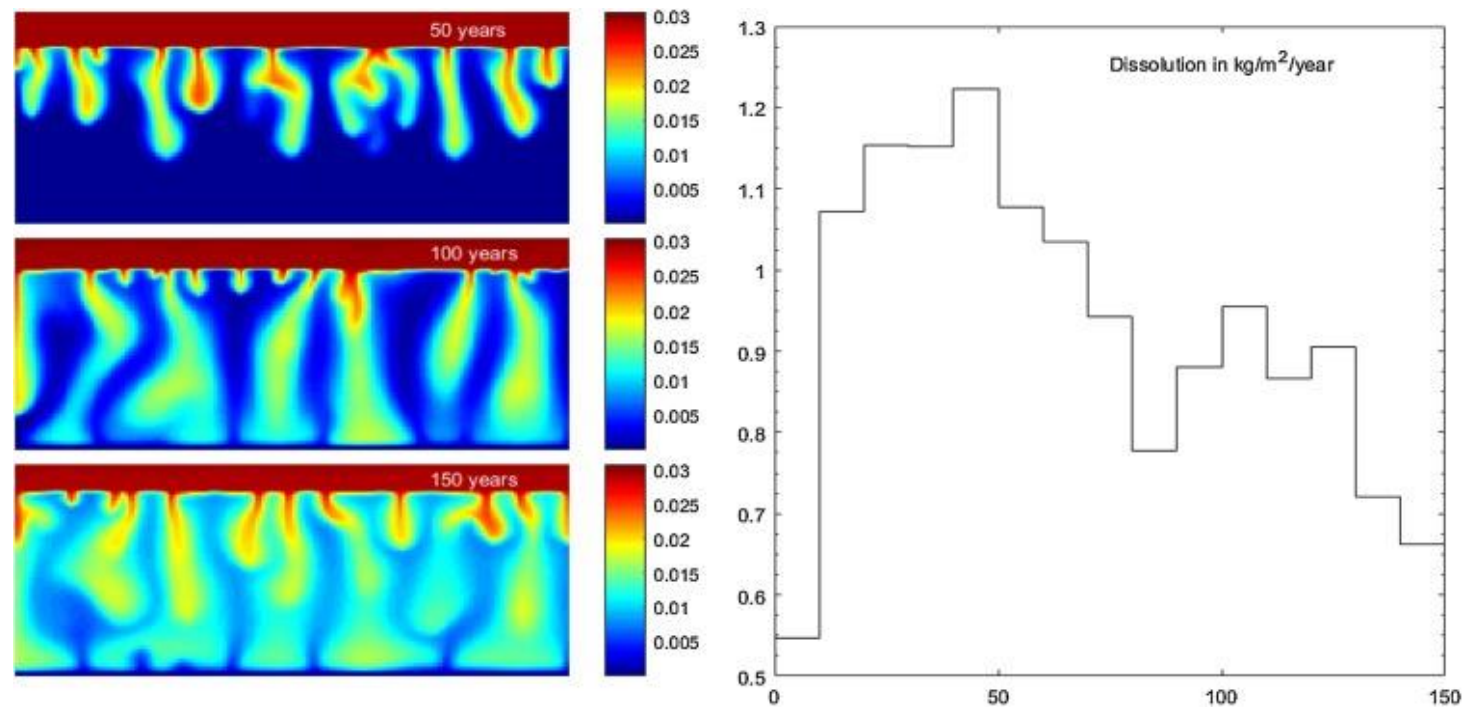

Figure 6.7: Distribution of $\mathrm{CO}_{2}$ in Brine at Different Times and Macroscopic Dissolution Rate of $\mathrm{CO}_{2}$ as a Function of Time for Simulation at $\mathrm{T}=345 \mathrm{~K}$

For the simulation of $\mathrm{CO}_{2}$ fingering in the presence of chemical precipitation, the second type of small-scale model from Elenius et al. (2015) was used. In this model, the entire two-phase region was located in the high volume area, which maintains the original $\mathrm{CO}_{2}$ profile. This model represents the leading part of the $\mathrm{CO}_{2}$ plume. For simplicity we used the same configuration and composition of the plume as in the previous simulation, but increased the temperature to $\mathrm{T}=380 \mathrm{~K}$, which decreased the $\mathrm{CO}_{2}$ solubility to $\mathrm{xCO}_{2}=0.016$. At conditions described in Table 6.5 , the higher concentration of $\mathrm{CO}_{2}$ triggers the carbonate reaction (Eq. (6.6)), which increases the concentration of carbonate ion and, in turn, initiates precipitation of $\mathrm{CaCO}_{3}$ based on Eq. (6.5).

The influence of chemical precipitation on the generation of fingers is shown in Fig. 6.8. The top figures correspond to the concentration of $\mathrm{CO}_{2}$ in brine at different simulation times. This distribution is shown for the reference case where the precipitated mineral is changing (decreasing) the porosity based on a constant mineral volume (see Appendix B) and permeability of the reservoir using the Kozeny-Carman equation. The 
resulting porosity changes at different times are shown in the middle row of Fig. 6.8. The lower row of Fig. 6.8 shows the absolute difference in concentrations between the reference simulation shown in the upper row and the simulation without an update in porosity and permeability.
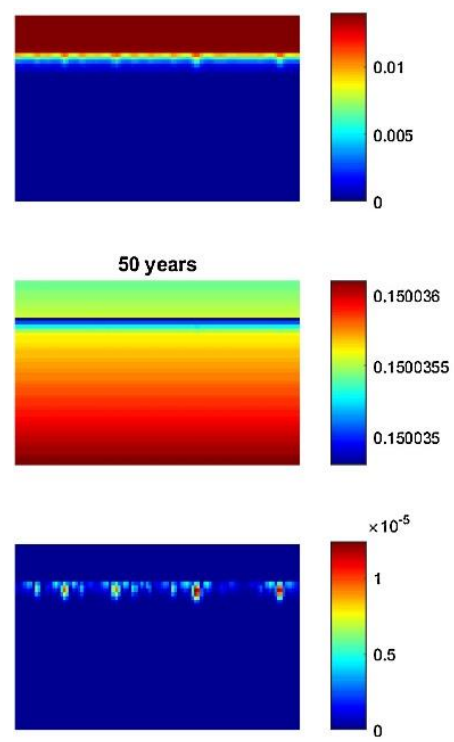
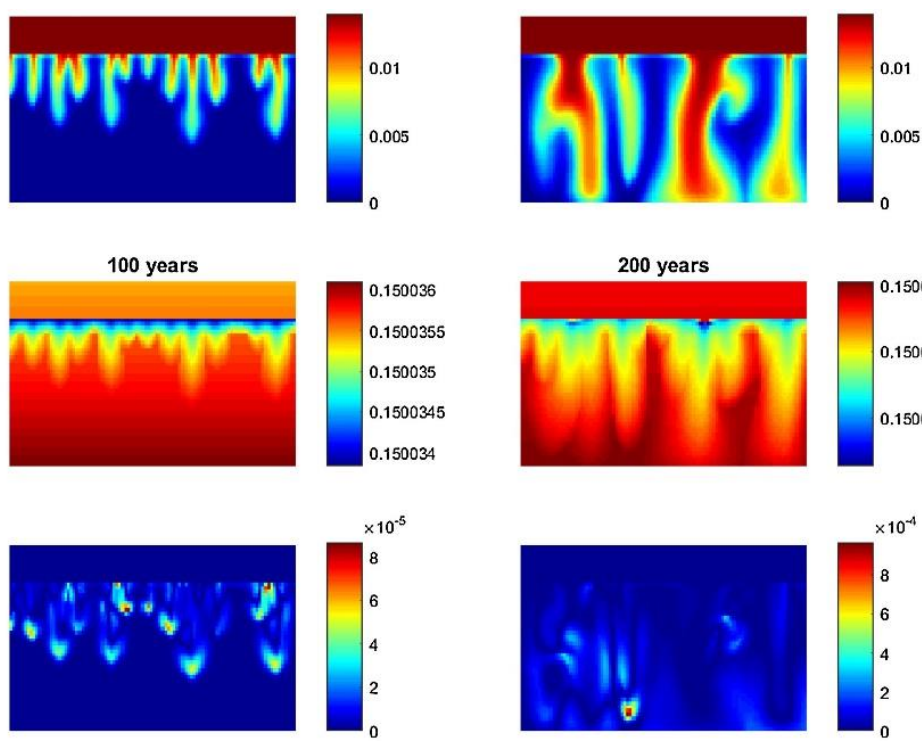
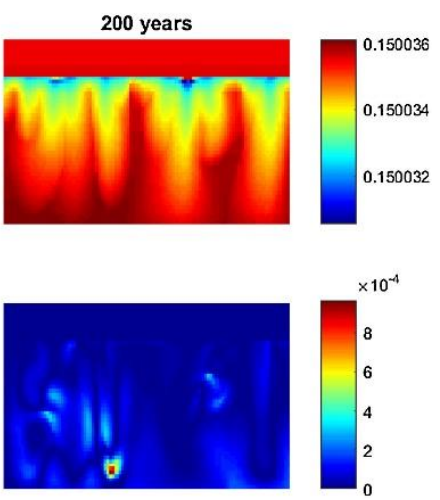

Figure 6.8: Small-Scale Simulation Results with $\mathrm{CaCO}_{3}$ Precipitation: (upper row) overall $\mathrm{CO}_{2}$ composition; (middle row) porosity changes; (lower row) difference in $\mathrm{CO}_{2}$ composition for cases with and without porosity and permeability update.

Note that the difference in $\mathrm{CO}_{2}$ distribution is insignificant and clearly suggests that the influence of early-time mineralization can be ignored in the accurate estimation of the $\mathrm{CO}_{2}$ dissolution rate for the system studied. However, this does not guarantee that at different thermodynamic or chemical reaction conditions, the same conclusion will hold.

In the next simulation the same system is kept, but amplify the molar volume of minerals to update the porosity 1000 fold. It can be seen in Fig. 6.9 that the porosity variation in this case is more significant due to the larger pore volume occupied by minerals resulting from precipitation. In this case, the dynamics of the fingering process have changed, which affects the subsequent macroscopic dissolution rate. 

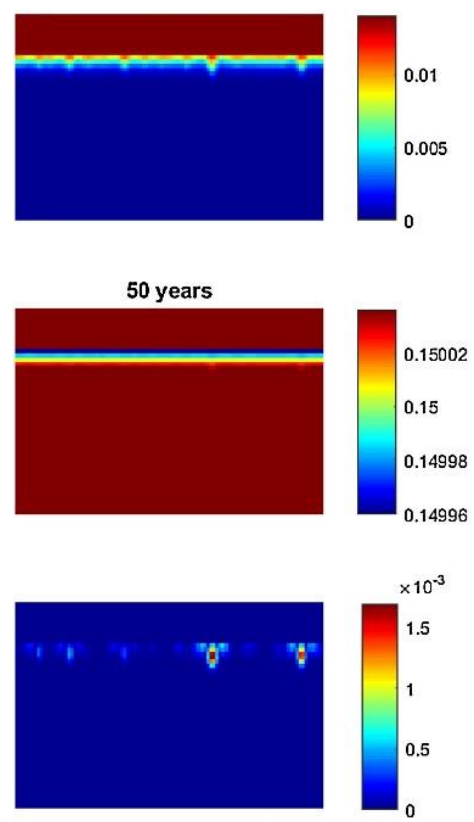
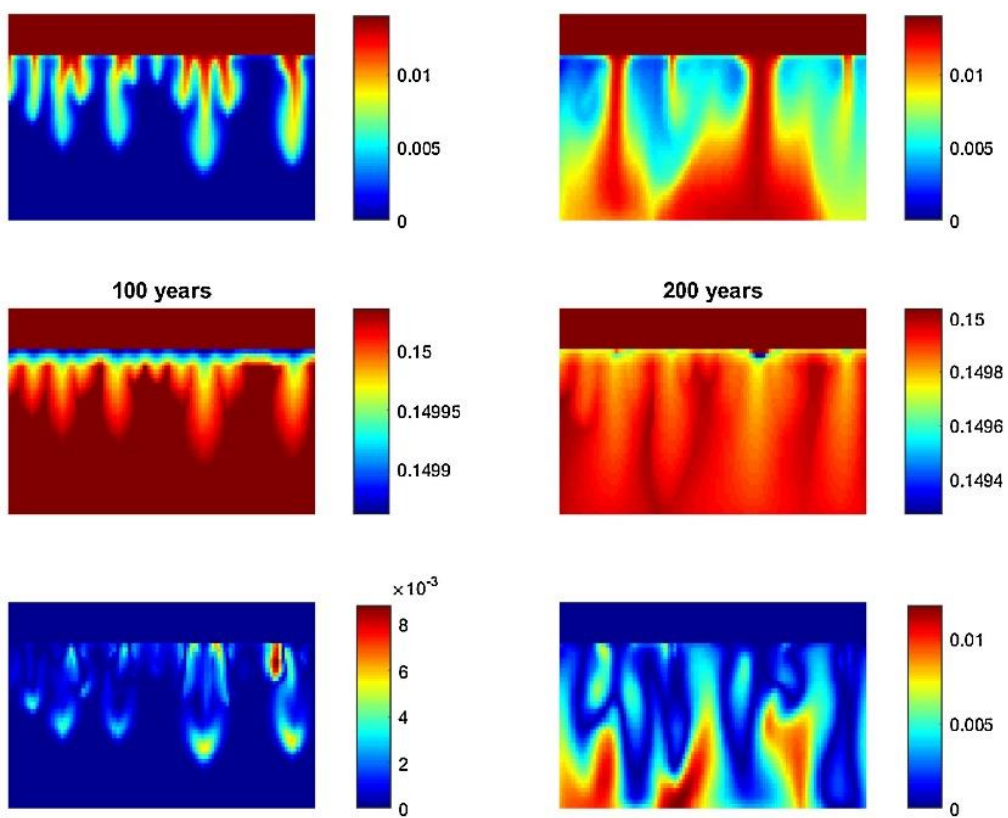

Figure 6.9: Small-Scale Simulation Results with $\mathrm{CaCO}_{3}$ Precipitation at Magnified Molar

Volume: (upper row) overall $\mathrm{CO}_{2}$ composition; (middle row) porosity changes; (lower row) difference in $\mathrm{CO}_{2}$ composition for the previous case and the case with magnified molar volume.

Obviously, the last case is hypothetical since the molar volume of $\mathrm{CaCO}_{3}$ for the porosity update is unrealistically large.

In the next simulation, we assume the presence of $\mathrm{NaCl}$ with an initial concentration $\mathrm{C}_{\mathrm{NaCl}}=1 \mathrm{kmol} / \mathrm{m}^{3}$ and the same under-saturated brine. The dynamics of the instability completely changes in this case, and no fingers are formed in the reservoir formation. See Fig. 6.10. Here, the increase in porosity due to the dissolution of $\mathrm{NaCl}$ in the diffusion zone and the reduction of solubility due to the presence of $\mathrm{Na}+$ and $\mathrm{Cl}-$ ions stabilizes the $\mathrm{CO}_{2}$-brine interface and prevents fingers from growing. 

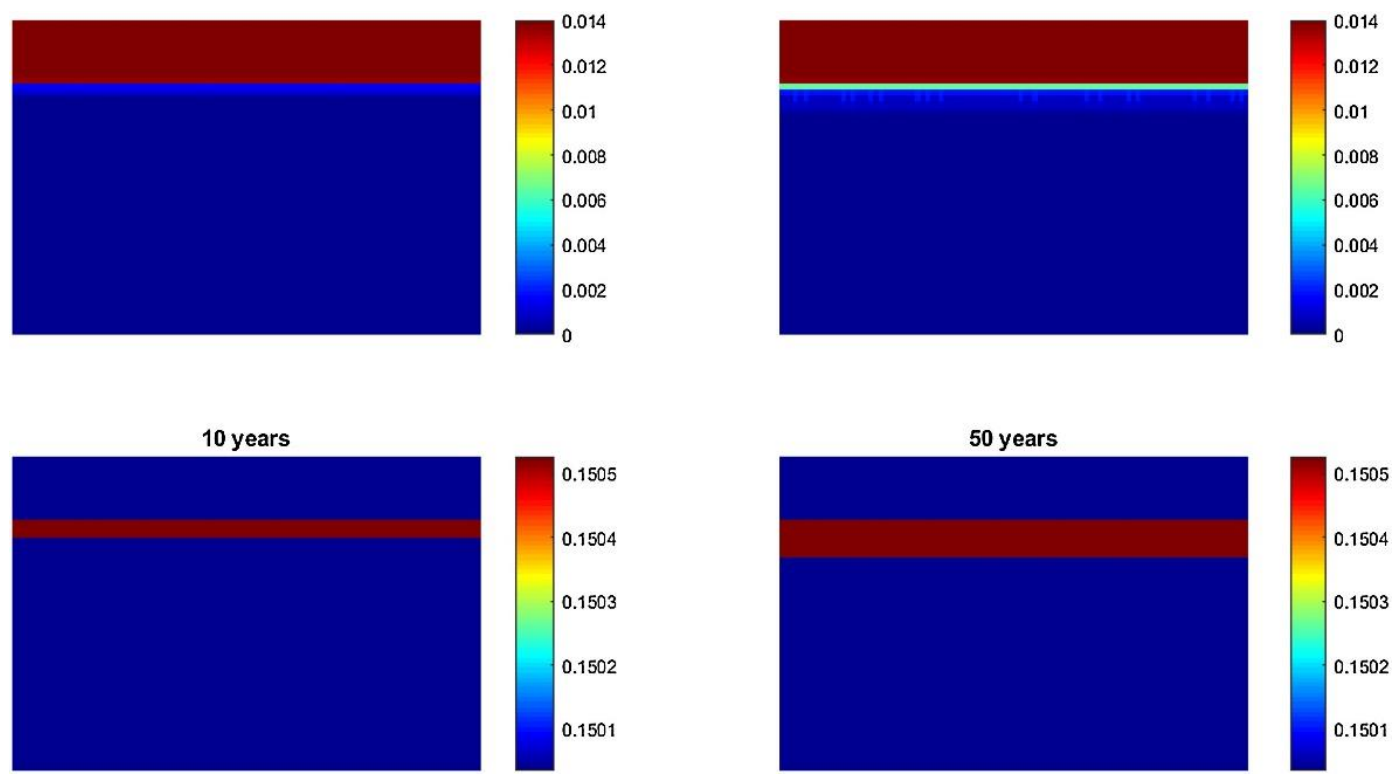

Figure 6.10: Small-Scale Simulation Results with $\mathrm{CaCO}_{3}$ Precipitation and $\mathrm{NaCl}$ Dissolution: (upper row) overall $\mathrm{CO}_{2}$ composition; (lower row) porosity changes.

\subsection{Conclusion}

A multi-scale framework for modeling and simulating reactive transport in subsurface hydrology with fully coupled equilibrium phase behavior of complex mixtures in homogeneous to highly heterogeneous reservoir formations was developed. The key attributes of this numerical reservoir simulation framework include the capabilities to model (1) simultaneous chemical/phase equilibrium, (2) homogeneous and heterogeneous chemical reactions, (3) aqueous electrolytes, and (4) mineral precipitation/dissolution. Simultaneous multi-component, multi-phase/chemical equilibrium was modeled using a combination of the multi-scale Gibbs-Helmholtz constrained (GHC) equations of state to describe the behavior of all fluid phases and Gibbs free energies and enthalpies of formation to predict equilibrium solubility products. Precipitation was identified using comparisons of equilibrium and ion solubility products. Governing partial differential conservation and constraint equations 
were solved using a fully implicit method (FIM). All modeling capabilities were implemented in the coupled software system ADGPRS/GFLASH.

Four different types of processes related to subsurface $\mathrm{CO}_{2}$ sequestration were used to test the efficacy of the proposed framework. Using the multi-component mixture $\mathrm{CO}_{2}$ and brine with dissolved ion $\mathrm{Na}^{+}, \mathrm{Ca}^{2+}, \mathrm{Cl}^{-}$and $\mathrm{CO}_{3}{ }^{2-}$, the first example demonstrated that the modeling framework successfully predicted the formation and dissolution of solid salts $\mathrm{NaCl}$ and $\mathrm{CaCO}_{3}$ throughout an isothermal and homogeneous reservoir formation in the presence of brine and a $\mathrm{CO}_{2}$-rich super-critical fluid. The second example was similar to the first but also included two additional modeling challenges (1) the equilibrium reaction between $\mathrm{CO}_{2}$ and water to form carbonate and hydronium, $\mathrm{H}_{3} \mathrm{O}^{+}$, ions and (2) vertical migration of a $\mathrm{CO}_{2}$ plume. Therefore, this example was used to demonstrate combined homogeneous/heterogeneous chemical reactions, salt dissolution, buoyancy driven flow, and simultaneous phase and chemical equilibrium. It was also shown that the carbonate chemistry resulted in insignificant changes in the initial $\mathrm{pH}$ of the reservoir, which was assumed to be 11. Accordingly, $\mathrm{pH}$ changes were neglected in this second example. Here again, numerical results showed that the proposed framework was capable of successfully modeling all of the relevant physics. The third and fourth examples were used to demonstrate that ADGPRS/GFLASH can capture all of the higher fidelity physics of the interplay between residual, solubility, and mineral trapping in the presence of unstable $\mathrm{CO}_{2}$ fingers, which enhance the macro-scale $\mathrm{CO}_{2}$ solubility in brine, following buoyancydriven flow of $\mathrm{a}_{2}$ plume. 
Accurate modeling of all physics in this work (i.e., rigorous, complex EOSbased simultaneous phase and chemical equilibrium involving homogeneous and heterogeneous reactions) is essential for developing a high-fidelity model for carbon sequestration in any reservoir-specific environment. To our knowledge there is no software system currently available with all of these capabilities. The use of a rigorous EOS allows us to treat impurities such as $\mathrm{O}_{2}, \mathrm{Ar}, \mathrm{SO}_{2}, \mathrm{CH}_{4}, \mathrm{~N}_{2}, \mathrm{H}_{2} \mathrm{~S}$, etc. Impurities can have strong effects on the density of the $\mathrm{CO}_{2}$-rich phase as well as the solubility of $\mathrm{CO}_{2}$ in the aqueous phase, which in turn can affect the migration and spread of the injected $\mathrm{CO}_{2}$ plume and $\mathrm{CO}_{2}$ storage capacity ( $\mathrm{Sin}, 2015$ ). Therefore, the next phase of this work will include the development of models that include impact of impurities on $\mathrm{CO}_{2}$ sequestration.

\subsection{Acknowledgements}

We acknowledge financial support from the Petroleum Institute and Abu Dhabi National Oil Company. We also acknowledge the SUPRI-B program at Stanford University for permission to use ADGPRS and Sara Farshidi and Maria Elenius for helpful discussions.

\section{Appendix A - pH Change due to $\mathrm{CaCO}_{3}$ formation}

Let the $\mathrm{pH}$ of the brine solution be 11. It is demonstrated that the amount of hydronium ion produced is small so that associated changes in $\mathrm{pH}$ can be neglected.

The maximum $\mathrm{CaCO}_{3}$ concentration obtained in examples in this work was $\sim 1.3 \times 10^{-3}$ $\mathrm{mol} / \mathrm{L}$. From reactions (5) and (6), the concentration of hydronium ion corresponding to this amount of $\mathrm{CaCO}_{3}$ is $\left[\mathrm{H}_{3} \mathrm{O}^{+}\right]=2.6 \times 10^{-3} \mathrm{~mol} / \mathrm{L}$. Also, the equilibrium constant for the dissociation of water into hydronium and hydroxide ions at $350 \mathrm{~K}$ and 250 bar using 
linear interpolation is $\mathrm{Kw}=1 \times 10^{-12.58}$ (see, Bandura and Lvov, 2006). At a pH of 11, the initial hydroxide concentration is

$\left[\mathrm{OH}^{-}\right]=\frac{k_{w}}{\left[\mathrm{H}_{3} \mathrm{O}^{+}\right]}=0.0263 \frac{\mathrm{mol}}{\mathrm{L}}$

Hydronium ions from the reaction between $\mathrm{CO}_{2}$ and water react with hydroxide ions, resulting in a change in hydroxide concentration given by

$\left[\mathrm{OH}^{-}\right]=0.0263-2.6 \times 10^{-3}=0.0237 \frac{\mathrm{mol}}{\mathrm{L}}$

Finally, the new equilibrium hydronium ion concentration is

$\left[\mathrm{H}_{3} \mathrm{O}^{+}\right]=\frac{K_{w}}{\left[\mathrm{OH}^{-}\right]}=1.11 \times 10^{-11}$

which corresponds to a $\mathrm{pH}$ of 10.95 .

Therefore, for the examples studied in this article, the amount of hydronium ion produced as carbonate ion is formed does not significantly change the $\mathrm{pH}$ of the formation brine.

\section{Appendix B: Fluid and Rock Properties}

Table B.1: Critical properties

\begin{tabular}{|c|c|c|c|}
\hline Component & $\mathrm{T}_{\mathrm{c}}(\mathrm{K})$ & $\mathrm{P}_{\mathrm{c}}(\mathrm{bar})$ & $\mathrm{b}_{\mathrm{GHC}}\left(\mathrm{cm}^{3} \mathrm{bar} / \mathrm{mol}\right)$ \\
\hline $\mathrm{CO}_{2}$ & 304.20 & 73.80 & 28.169 \\
\hline $\mathrm{H}_{2} \mathrm{O}$ & 647.37 & 221.20 & 16.363 \\
\hline
\end{tabular}

Table B.2: Enthalpy and Gibbs free energy of formation data

\begin{tabular}{|c|c|c|}
\hline Component & $\Delta H_{f}(\mathrm{~kJ} / \mathrm{mol})$ & $\Delta G_{f}(\mathrm{~kJ} / \mathrm{mol})$ \\
\hline $\mathrm{NaCl}$ & -411.2 & -384.1 \\
\hline $\mathrm{CaCl}_{2}$ & -795.8 & -748.1 \\
\hline $\mathrm{Na}_{2} \mathrm{CO}_{3}$ & -11130.7 & -1044.4 \\
\hline $\mathrm{CaCO}_{3}$ & -1206.9 & -1128.8 \\
\hline
\end{tabular}

A Corey-type relative permeability model was used to define the relative permeability as a function of saturation (Eqs. B1-B3), the parameters are given in Table B.3.

$S_{p e}=\frac{S_{p}-S_{p r}}{1-S_{p r}-S_{o r}}$ 
$k_{p r}=\left(S_{p e}\right)^{n_{p}}$

$k_{o r}=\left(1-S_{p e}\right)^{n_{o}}$

In the third example, the residual water and $\mathrm{CO}_{2}$ saturations were each set to 0.2 , and the relative permeability and saturation distribution were determined by specifying a static pressure distribution in each phase (see Elenius et al., 2014, Elenius et al., 2015) to create a capillary transition zone at the interface between the two phases.

Table B.3: Additional Parameters

\begin{tabular}{|c|c|c|c|}
\hline & Parameter & Value & Description \\
\hline \multirow{2}{*}{$\begin{array}{c}\text { Common for all } \\
\text { examples }\end{array}$} & $\mathrm{C}_{\mathrm{r}}$ & $1.0 \mathrm{e}-06$ 1/bar & rock compressibility \\
\cline { 2 - 4 } & $\mathrm{N}_{\mathrm{p}}$ & 2 & aqueous phase exponent \\
\cline { 2 - 4 } & $\mathrm{N}_{\mathrm{o}}$ & 2 & $\mathrm{CO}_{2}$-rich phase exponent \\
\hline \multirow{2}{*}{ Example \#1 } & $\mathrm{S}_{\mathrm{pr}}$ & 0.0 & aqueous phase residual saturation \\
\cline { 2 - 4 } & $\mathrm{S}_{\mathrm{or}}$ & 0.0 & $\mathrm{CO}_{2}$-rich phase residual saturation \\
\hline \multirow{2}{*}{ Examples \#2-4 } & $\mathrm{S}_{\mathrm{pr}}$ & 0.2 & aqueous phase residual saturation \\
\cline { 2 - 4 } & $\mathrm{S}_{\mathrm{or}}$ & 0.2 & $\mathrm{CO}_{2}$-rich phase residual saturation \\
\hline
\end{tabular}

The viscosities of the brine phase and the $\mathrm{CO}_{2}$-rich phase were assumed to be constant in all examples in this work. Values of 0.511 and $0.061 \mathrm{cP}$ were chosen for the brine and $\mathrm{CO}_{2}$ phases, respectively, based on values used in a similar study (Elenius et al., 2015). 


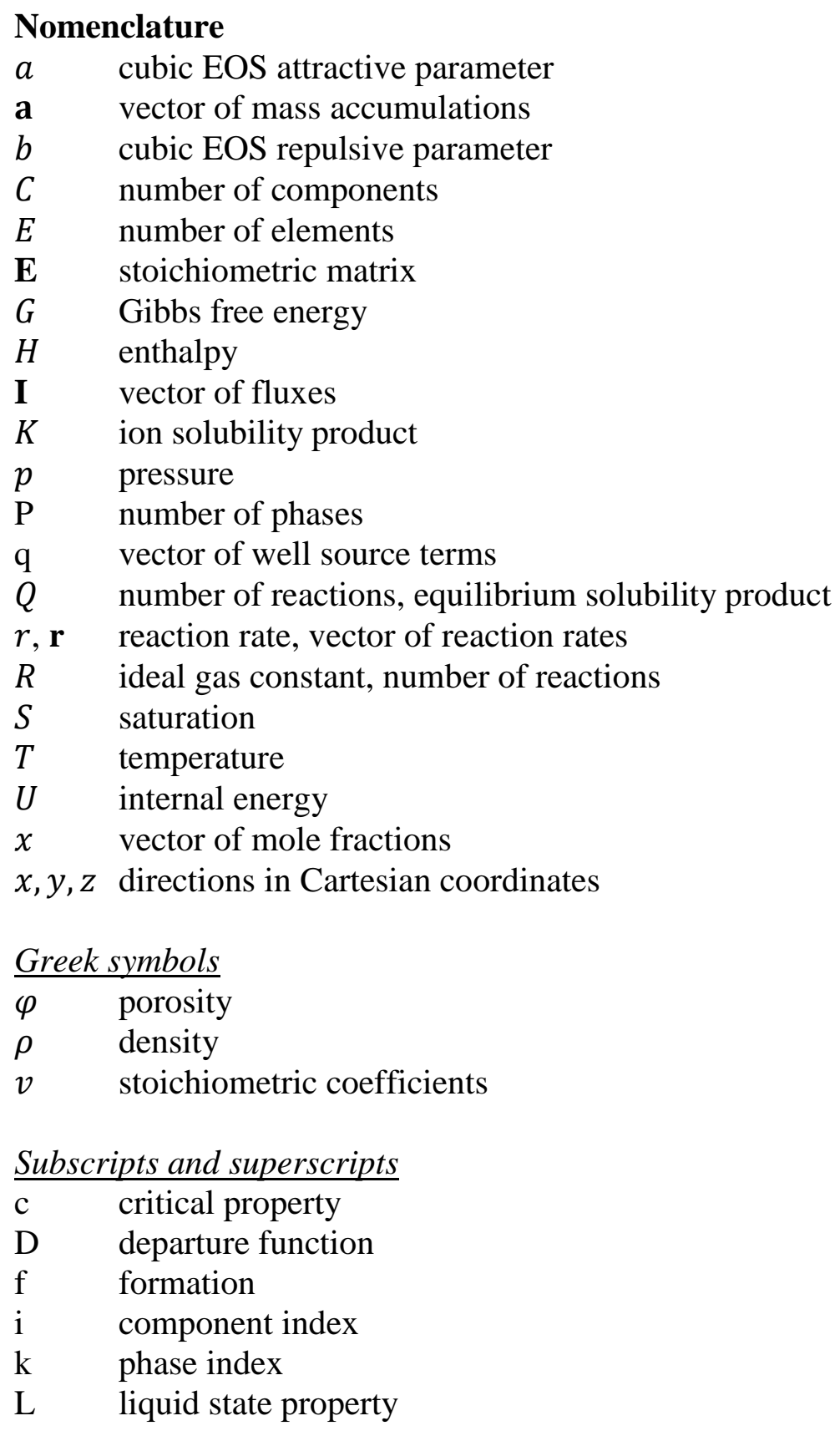




\section{References}

Bachu, S., \& Adams, J. J. (2003). Sequestration of $\mathrm{CO}_{2}$ in geological media in response to climate change: capacity of deep saline aquifers to sequester $\mathrm{CO}_{2}$ in solution. Energy Conversion and Management, 44(20), 3151-3175. doi:10.1016/S0196-8904(03)00101-8

Bandura, A. V., \& Lvov, S. N. (2006). The ionization constant of water over wide ranges of temperature and density. Journal of Physical and Chemical Reference Data, 35(1), 15-30. doi:10.1063/1.1928231

Celia, M. a., \& Nordbotten, J. M. (2009). Practical modeling approaches for geological storage of carbon dioxide. Ground Water, 47(5), 627-638. doi:10.1111/j.1745-6584.2009.00590.x

Chen, C., \& Song, Y. (2005). Extension of Nonrandom Two-Liquid Segment Activity Coefficient Model for Electrolytes. Ind. Eng. Chem. Res., 44(1), 8909-8921. doi:10.1021/ie049463u

Elenius, M. T., Nordbotten, J. M., \& Kalisch, H. (2014). Convective mixing influenced by the capillary transition zone. Computational Geosciences, 18(3-4), 417-431. doi:10.1007/s10596-014-9415-1

Elenius, M. T., Voskov, D. V., \& Tchelepi, H. A. (2015). Interactions between gravity currents and convective dissolution. Advances in Water Resources, 83, 77-88. doi:10.1016/j.advwatres.2015.05.006

Farshidi, S. F., Fan, Y., Durlofsky, L. J., \& Tchelepi, H. A. (2013). Chemical reaction modeling in a compositional reservoir-simulation framework. In proceeding: SPE Reservoir Simulation Symposium. doi:10.2118/163677-MS

Farshidi, S. (2016). Compositional reservoir simulation-based reactive-transport formulations, with application to $\mathrm{CO} 2$ storage in sandstone and ultramafic formations. PhD Thesis, Stanford University.

Huang, S. H., \& Radosz, M. (1990). Equation of state for small, large, polydisperse and associating molecules. Ind. Eng. Chem. Res., 29, 2284-2294. doi:10.1021/ie00107a014

Iranshahr, a., Voskov, D., \& Tchelepi, H. A. (2010). Generalized negative-flash method for multiphase multicomponent systems. Fluid Phase Equilibria, 299(2), 272-284. doi:10.1016/j.fluid.2010.09.022

Iranshahr, A., Voskov, D.V., Tchelepi, H.A. (2013). Tie-simplex based compositional space parameterization: Continuity and generalization to multiphase systems. AIChE J. 59 (5), pp. 1684-1701. doi:10.1002/aic.13919 
Kaszuba, J. P., Janecky, D. R., \& Snow, M. G. (2003). Carbon dioxide reaction processes in a model brine aquifer at $200{ }^{\circ} \mathrm{C}$ and 200 bars: implications for geologic sequestration of carbon. Applied Geochemistry, 18(7), 1065-1080. doi:10.1016/S0883-2927(02)00239-1

Kiepe, J., Horstmann, S., Fischer, K., \& Gmehling, J. (2004). Application of the PSRK model for systems containing strong electrolytes. Industrial \& Engineering Chemistry Research, 43(1), 6607-6615.

Kim, J., Tchelepi, H. A., \& Juanes, R. (2009). Stability , Accuracy and efficiency of sequential methods for coupled flow and geomechanics. Society of Petroleum Engineers.

Kontogeorgis, G. M., Voutsas, E. C., Yakoumis, I. V., \& Tassios, D. P. (1996). An equation of state for associating fluids. Industrial \& Engineering Chemistry Research, 35(11), 4310-4318. doi:10.1021/ie9600203

Lucia, A. (2010). A multiscale Gibbs-Helmholtz Constrained cubic equation of state. Journal of Thermodynamics, 2010, 1-10. doi:10.1155/2010/238365

Lucia, A., Henley, H., \& Thomas, E. (2014). Multiphase equilibrium flash with salt precipitation in systems with multiple salts. Chemical Engineering Research and Design, 93(May), 662-674. doi:10.1016/j.cherd.2014.04.034

Leung, D. Y. C., Caramanna, G., \& Maroto-Valer, M. M. (2014). An overview of current status of carbon dioxide capture and storage technologies. Renewable and Sustainable Energy Reviews, 39, 426-443. doi:10.1016/j.rser.2014.07.093

Maribo-Mogensen, B., Thomsen, K., \& Kontogeorgis, G. M. (2015). An electrolyte CPA equation of state for mixed solvent electrolytes. AIChE Journal, 61(9), 2933-2950. doi:10.1002/aic.14829

Peng, D.-Y., \& Robinson, D. B. (1976). A new two-constant equation of state. Industrial \& Engineering Chemistry Fundamentals, 15(1), 59-64. doi:10.1021/i160057a011

Pitzer, K. S. (1977). Electrolyte theory-improvements since Debye and Huckel. Accounts of Chemical Research, 10(11), 371-377. doi:10.1021/ar50118a004

Redlich, O., \& Kwong, J. N. S. (1949). On the thermodynamics of solutions. V. An equation of state. Fugacities of gaseous solutions. Chemical Reviews, 44(1), 233 244.

Soave, G. (1972). Equilibrium Constants from a modified Redlich-Kwong equation of state. Chemical Engineering Science, 27(6), 1197-1203. 
Soong, Y., Goodman, A. L., McCarthy-Jones, J. R., \& Baltrus, J. P. (2004). Experimental and simulation studies on mineral trapping of $\mathrm{CO} 2$ with brine. Energy Conversion and Management, 45(11-12), 1845-1859. doi:10.1016/j.enconman.2003.09.029

Tchelepi, H., \& Zhou, Y. (2013). Multi-GPU parallelization of nested factorization for solving large linear systems. In proceeding: SPE Reservoir Simulation Symposium. doi:10.2118/163588-MS

Van Der Zwaan, B., \& Smekens, K. (2009). CO2 capture and storage with leakage in an energy-climate model. Environmental Modeling and Assessment, 14(2), 135148. doi:10.1007/s10666-007-9125-3

Voskov, D., Zaydullin, R., \& Lucia, A. (2016). Heavy oil recovery efficiency using SAGD, SAGD with propane co-injection and STRIP-SAGD. Computers \& Chemical Engineering, 88, 115-125. doi:10.1016/j.compchemeng.2016.02.010

Voskov, D. V., \& Tchelepi, H. A. (2012). Comparison of nonlinear formulations for two-phase multi-component EoS based simulation. Journal of Petroleum Science and Engineering, 82-83, 101-111. doi:10.1016/j.petrol.2011.10.012

Voskov, D.V. (2011). An extended natural variable formulation for compositional simulation based on tie-line parameterization, Transport in Porous Media, 92(3), 541-557. doi:10.1007/s11242-011-9919-2

Xu, T., Apps, J. A., \& Pruess, K. (2005). Mineral sequestration of carbon dioxide in a sandstone-shale system. Chemical Geology, 217(3-4), 295-318. doi:10.1016/j.chemgeo.2004.12.015

Xu, T., Spycher, N., Sonnenthal, E., Zhang, G., Zheng, L., \& Pruess, K. (2011). Tough react version 2.0: A simulator for subsurface reactive transport under nonisothermal multiphase flow conditions. Computers and Geosciences, 37(6), $763-$ 774. doi:10.1016/j.cageo.2010.10.007

Zaydullin, R., Voskov, D., \& Tchelepi, H. A. (2012). Nonlinear formulation based on an equation-of-state free method for compositional flow simulation. Society of Petroleum Engineers. doi:10.2118/146989-PA

Zaydullin, R., Voskov, D. V., James, S. C., Henley, H., \& Lucia, A. (2014). Fully compositional and thermal reservoir simulation. Computers \& Chemical Engineering, 63, 51-65. doi:10.1016/j.compchemeng.2013.12.008 
CHAPTER 7 - Fully compositional ground water simulation using AD-GPRS and GFLASH

In preparation for submission to Environmental Modelling and Software

Heath Henley \& Angelo Lucia

Department of Chemical Engineering

University of Rhode Island

Kingston, RI 02881 


\begin{abstract}
Automatic Differentiation General Purpose Research Simulator (AD-GPRS) is a numerical reservoir modeling and simulation tool developed by the SUPRI-B group at Stanford University. It has been used to simulate a wide variety of industrial processes, including enhanced oil recovery and carbon dioxide sequestration processes. It has recently been coupled with GFLASH fluid property library developed by Prof. Lucia at University of Rhode Island. Some of the basic features of the ADGPRS/GFLASH system are (1) a fully compositional treatment of the fluid mixture in the reservoir, (2) the ability to use rigorous EOS-based phase equilibrium calculations, and (3) the choice of a wide range of cubic equations in the van der Waals family for determining fluid density as a function composition, pressure, and temperature. While some of these features are usually not needed in the state-of-the-art groundwater simulators, there are cases in which their inclusion would better represent the physics of the system. In this work, a contaminated groundwater flow example for a reservoir in central Rhode Island is presented to highlight the utility of AD-GPRS for groundwater simulation problems. Our numerical results provide a qualitative match of numerical simulations generated using MODFLOW and also show how contaminants in the watershed can be easily tracked using AD-GPRS. Finally, some of the remaining challenges for the application of the AD-GPRS/GFLASH system to groundwater problems are discussed.
\end{abstract}




\subsection{Introduction}

Understanding the flow of pure fluids and their mixtures in porous media is of interest to a wide variety of practical applications including oil and gas exploration/recovery, carbon dioxide sequestration, and ground water flow. Several software tools exist that allow one to solve the set of partial differential equations governing fluid flow in porous media numerically. However, despite some of the underlying similarities in the physics of model development, most of these tools are specific to the application problem. The two software packages that are of interest in this work are Automatic Differentiation General Purpose Research Simulator (ADGPRS) (Voskov \& Zhou, 2012) and MODFLOW-2005 (Harbaugh, 2005), developed by the SUPRI-B group at Stanford University and US Geological Survey (USGS), respectively.

AD-GPRS is a numerical reservoir simulator built around Automatic Differentiation (AD) technology. Originally developed as a hydrocarbon reservoir simulator, AD-GPRS currently has advanced features which allow the user to model complex physical phenomena and represents the state-of-the-art in reservoir simulation. Recently, AD-GPRS has been adapted for modeling $\mathrm{CO}_{2}$ sequestration application (Voskov et al., 2017) such as $\mathrm{CO}_{2}$ injection into a deep saline aquifer, where mineralization of $\mathrm{CO}_{2}$ can impact the dissolution rate of $\mathrm{CO}_{2}$ and hence affect the storage capacity of the formation.

MODFLOW is a mature open source numerical groundwater simulation program developed by USGS. It has been used to study the interaction between ground and surface water, the long and short-term effects of pumping, and the change in the 
water table as a function of variations in seasonal inflow and outflow. MODFLOW has a wide user base, and many extensions have been developed to add features to the basic MODFLOW package. Including the ability to adjust for variable density fluid flow (a posteriori), track particles originating in some point source for a given system, and include many different boundary conditions representing surface features such as rivers and streams.

The tools and extensions developed for MODFLOW are very useful for studying groundwater systems. However, the main MODFLOW package makes several major assumptions about the composition of the fluid and its physical properties, which limit its applicability. The specific assumptions include that (1) the fluid is a single component (water), (2) the density of the fluid is independent of pressure, temperature or composition, and (3) the fluid is stable in a single phase (liquid) state. For many cases, these assumptions are completely reasonable. However, in systems where pressure change is expected to be large, or additional phases may be present in the system, these assumptions are not adequate to represent the physics of the system. For example, a carbon sequestration example was recently presented in Voskov et al. (2017) using ADGPRS in which the variation in density with composition and pressure strongly effects the dissolution rate $\mathrm{CO}_{2}$ from a supercritical carbon dioxide phase into a brine phase. In contrast, the advanced features implemented in AD-GPRS allow the study of groundwater systems in which density variation due to pressure or fluid composition may strongly affect the results, multiple phases may be present, and/or the distribution of the fluid composition at a given time step is of interest to the user. 
Due to differences in the formulation of the model equations, implementation, and availability of various boundary conditions, a direct comparison between MODFLOW and AD-GPRS is not feasible. Therefore, the purpose of this study is to demonstrate the efficacy of using AD-GRPS to model groundwater flow in a realistic groundwater system, to highlight the advantages gained from using AD-GPRS in these systems, and to identify the weaknesses and/or challenges that should be overcome to apply AD-GPRS to these systems more efficiently. To accomplish these goals, a simulation model for the AD-GPRS simulator was developed using a previously developed MODFLOW model as a guide. The reservoir model used in this study is the Big River Management area in central Rhode Island, published in the USGS report of Masterson and Granato (2012).

\subsection{Procedure}

The AD-GPRS reservoir simulator (Voskov and Zhou, 2012) developed by the SUPRI-B group at Stanford University was used in the work. AD-GPRS is a state-ofthe-art, multi-phase, fully thermal and compositional reservoir simulation program. It has been used to simulate many industrial processes including steam injection and steam injection with propane co-injection for enhanced oil recovery (Zaydullin et al. 2014; Voskov et al., 2016), in situ $\mathrm{CO}_{2}$-steam co-injection for heavy oil recovery, and plume migration in carbon dioxide sequestration in the presence of convective dissolution and gravity currents (Elenius et al., 2015; Voskov et al., 2017). In this work, AD-GPRS is used to model and perform fully compositional simulations of groundwater flow. Treating the groundwater flow problem in this way enables one to study problems in which the composition of the formation water is not constant throughout the reservoir. 
Thus, it is possible to monitor the concentration of any one species in the mixture at any location in the model at any given time step.

In this section, we will briefly highlight some of the features of the software used in this work and discuss the development of the simulation model using the published MODFLOW model of the Big River Management area as a guide. Fluid properties were calculated using a program developed by Professor A. Lucia at URI called GFLASH, which has been interfaced with AD-GPRS.

\section{AD-GPRS Overview}

The subsurface flow numerical simulation program used in this work is called ADGPRS. AD-GPRS is a simulation program written primarily in $\mathrm{C}++$ and maintained by the SUPRI-B project at Stanford University. It is used extensively in the reservoir engineering community due its wide-ranging capabilities, which include

1. Flexible treatment of all nonlinear physics.

2. A fully thermal-compositional formulation for any number of phases.

3. Multi-phase CSAT for efficient and robust computation of phase behavior.

4. A variety of spatial and temporal discretization schemes.

5. Thermal geo-mechanical modeling including the effects of fractures.

6. A fully coupled, thermal, multi-segmented well model with drift- flux.

7. An adjoint-based optimization module.

A more detailed overview of the capabilities listed above is given in a previous article by Zaydullin et al., (2014). Additional details regarding the implementation of AD-GPRS can be found in the open literature. For example, different options for the choice of independent variables (e.g., natural versus molar formulation) can be found in 
Voskov and Tchelepi (2012), discretization schemes are described in Zhou et al. (2011), Voskov (2011) gives a description of the methods for solving non-linear and linear systems of equations, and the many approaches for fluid phase behavior computations are presented in the work of Iranshahr et al. (2013).

\section{$\underline{\text { GFLASH Overview }}$}

The GFLASH software developed by Professor A. Lucia was used for all the fluid properties calculations in this work. GFLASH is a FORTRAN program suite which given temperature, pressure, and overall mixture composition calculates the number of equilibrium phases and their compositions, along with their respective densities, fugacities, enthalpies. Several commonly used cubic equations of state (EOS) models are implemented in GFLASH including Soave-Redlich-Kwong (SRK) equation (Soave, 1972), the Peng-Robinson (PR) equation (Peng \& Robinson, 1979), and the Gibbs-Helmholtz constrained (GHC) equation of Lucia et al. (2012). For this work, the GHC EOS was used exclusively because it predicts the density of water more accurately than the traditional cubic equations of state (Lucia et al., 2012) and because it is applicable to aqueous electrolyte solutions. Neither the SRK nor PR equations can treat aqueous electrolytes. Additional information about the methodologies in GFLASH for the solution of the classical isothermal, isobaric flash problem can be found in the literature (Lucia, 2000), as can more information on the GHC EOS model (Lucia et al., 2012).

Converting the MODFLOW Model

The AD-GPRS model used in this work was developed from the input files from a MODFLOW study of the Big River Management area in Rhode Island (Maserson \& 
Granato, 2012). Most of the data from of the original $512 \times 232 \times 7$ MODFLOW were simply converted into the required units for AD-GPRS and re-represented in AD-GPRS input file format. However, because of the additional computational complexity of the AD-GPRS simulator, the size of the original MODFLOW was reduced by a factor of 0.25 in the horizontal dimensions to yield a $128 \times 58 \times 7$ model. The actual dimensions of the entire model were left unchanged. That is, the dimensions of the scaled blocks were increased so that the same volume used in the MODFLOW model was represented by the AD-GPRS model. The number of layers in the vertical dimension remained unchanged. In reducing the size of the model, the properties were averaged accordingly. Finally, the locations of the wells and inflows into the model were taken directly from the MODFLOW input files transformed into the corresponding locations in the ADGPRS model. The resulting AD-GPRS model locations are indicated in Fig. 7.1.

\subsection{Results and Discussion}

Simulation results using the model described in the previous section are detailed in this section for three distinct cases. In the first case, the inflows and outflows to/from the active model area represent rivers or streams entering or exiting the model area. There is no other pumping/injection in the model. The second case is a modification of the first in which pumping is performed at designated locations for a period of 5 days. The effects of pumping at a specified rate for 5 days is analyzed. This type of analysis is important to determine amount of pumping that is acceptable for an aquifer of interest, and to understand the effects of pumping on the water level in the surrounding areas. Finally, the third example aim to highlights the utility of running a fully compositional simulation by introducing a contaminant into one or more of the inflows. The 
composition distribution can then be analyzed over time to understand the spread of contaminant, the potential size of the contaminated area, and possible remediation strategies.

\section{Example 1: Simple case with no pumping}

This case was initialized using the same initial pressure distribution as the MODFLOW model. Locations of inflows and outflows across the boundary of the model area were also adapted from the MODFLOW model. The simulation was run for 1000 days in AD-GPRS to allow it to reach steady state and for hydrostatic equilibrium to be reached. The composition of the fluid in the reservoir is given in Table 7.1. The GHC EOS was used to calculate the fluid density as a function of pressure and the necessary derivatives.

Table 7.1: Fluid Mixture Mole Fraction

\begin{tabular}{|c|c|}
\hline Species & Mole Fraction \\
\hline $\mathrm{n}$-Octane & $1.00000 \mathrm{e}-10$ \\
\hline Water & $0.999984 \mathrm{e} 0$ \\
\hline $\mathrm{Na}^{+}$ & $4.60000 \mathrm{e}-06$ \\
\hline $\mathrm{Ca}^{2+}$ & $1.70000 \mathrm{e}-06$ \\
\hline $\mathrm{Mg}^{2+}$ & $7.40000 \mathrm{e}-07$ \\
\hline $\mathrm{Cl}^{-}$ & $4.24000 \mathrm{e}-06$ \\
\hline $\mathrm{HCO}_{3}^{-}$ & $3.40000 \mathrm{e}-06$ \\
\hline $\mathrm{SO}_{4}{ }^{2-}$ & $9.20000 \mathrm{e}-07$ \\
\hline
\end{tabular}

Figure 7.1 shows the equilibrated pressure distribution after 1000 days; the approximate inflow (red circles) and outflow (grey circles) locations are marked on the figure for reference. Note that in the first case, there was no pumping from the wells, all inflow and outflow sources were located on the top model layer, and the pumping wells were located in the fifth layer as in the MODFLOW model. 


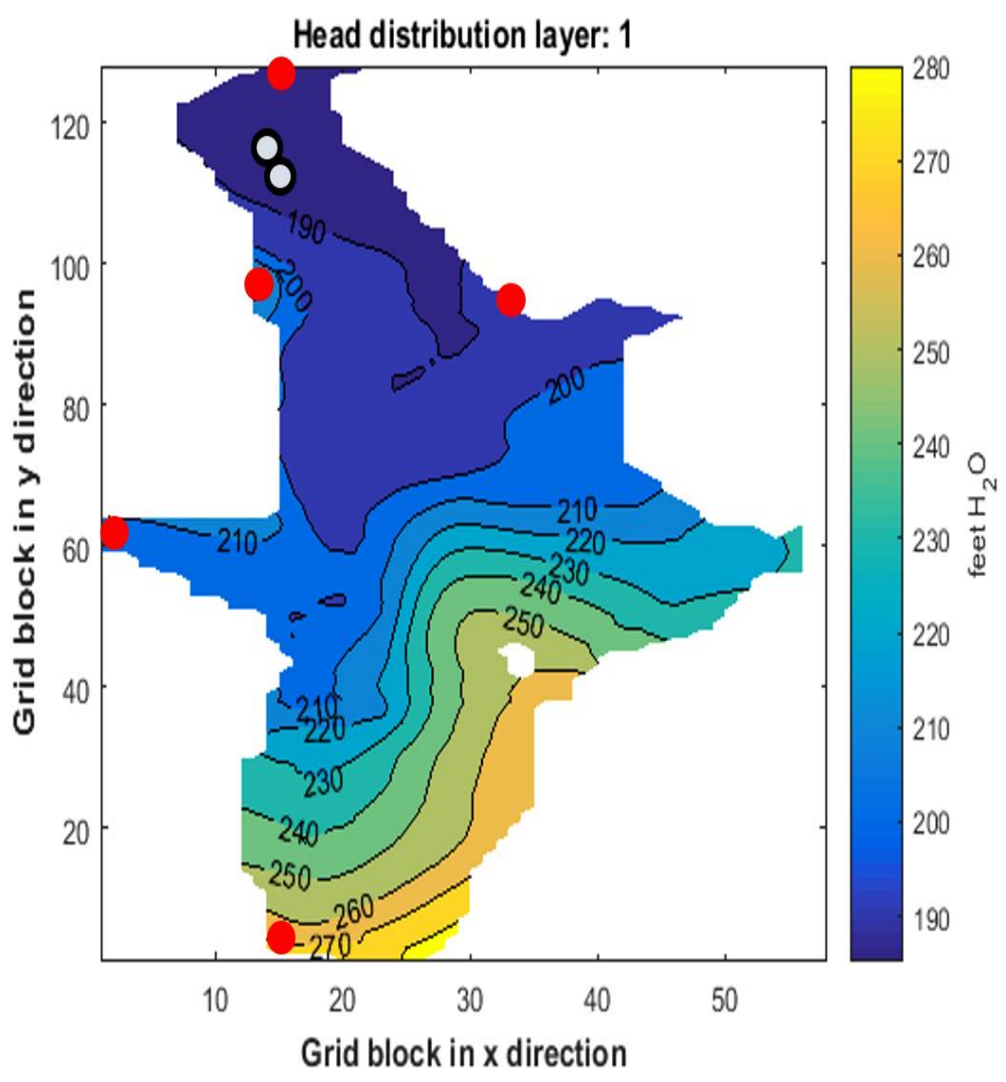

Figure 7.1: Equilibrated Head (no pumping)

The results from the 1000 day equilibration simulations with no pumping depicted in

Fig. 7.1 were used to initialize a second simulation in which water was pumped out of the system at the two production wells (the gray dots in Fig. 7.1) for 5 days. Note that the results using AD-GPRS/GFLASH shown in Fig. 7.1 are in qualitative agreement with those shown in Fig. 9 of Maserson \& Granato (2012).

Example 2: Pumping response in 5 days

The model parameters for this example are exactly the same as in the previous example, with the exception that the two production wells were added at the locations indicated in Fig. 7.1. Figures 7.2 and 7.3 show the change in head after pumping for 5 days in layers 1 and 2 respectively. 


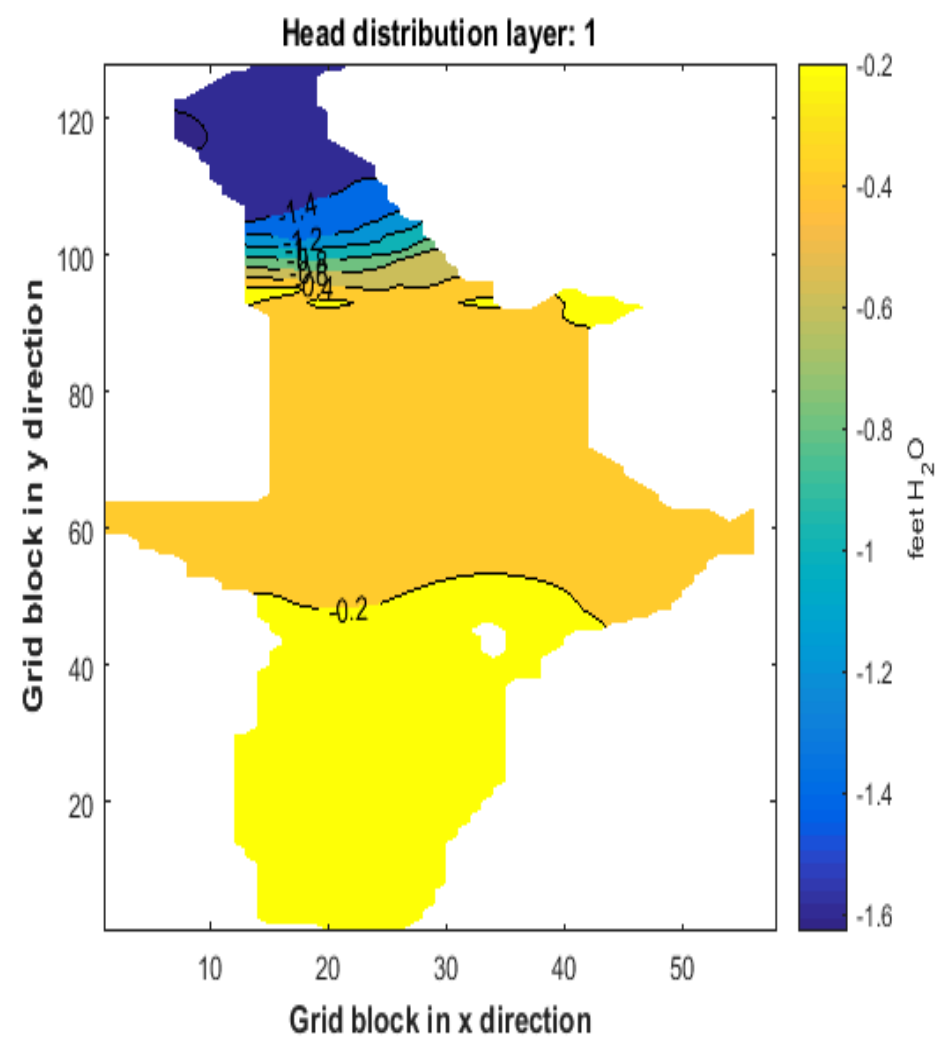

Figure 7.2: Layer 1 head distribution change after 5 days of pumping at an average of $190 \mathrm{gpm}$ The well rates were adjusted throughout the simulation to keep a constant bottom hole pressure of 3 bar at each production well. The average rate of production for each well over the time horizon for the simulation was approximately 190 gpm.

It is clear from Figs. 7.2 and 7.3 that the areas closest to the wells experience a greater decrease in head due to sustained pumping. The distribution and magnitude of the response of the formation to water production can be an important metric for determining maximum allowable production rates, since it can be used to predict the effects that sustained pumping will have on water level in different areas of the formation. To highlight the effects of pumping on water level, additional simulation runs were carried out with modified average pumping rates. Figures 7.4 and 7.5 show results after 5 days of pumping at average rates of $800 \mathrm{gpm}$ and $1000 \mathrm{gpm}$, respectively. 


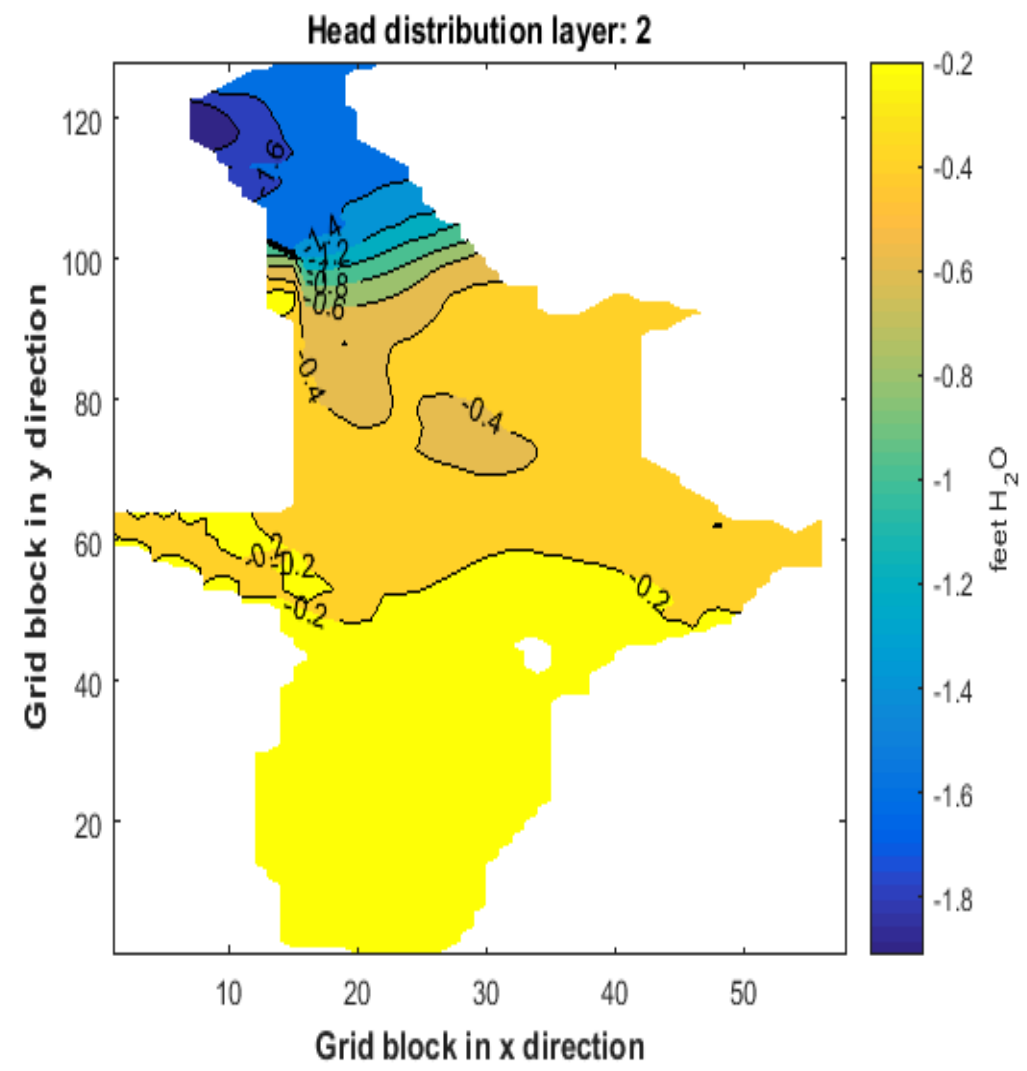

Figure 7.3: Layer 2 head distribution change after 5 days of pumping at average rate of $190 \mathrm{gpm}$
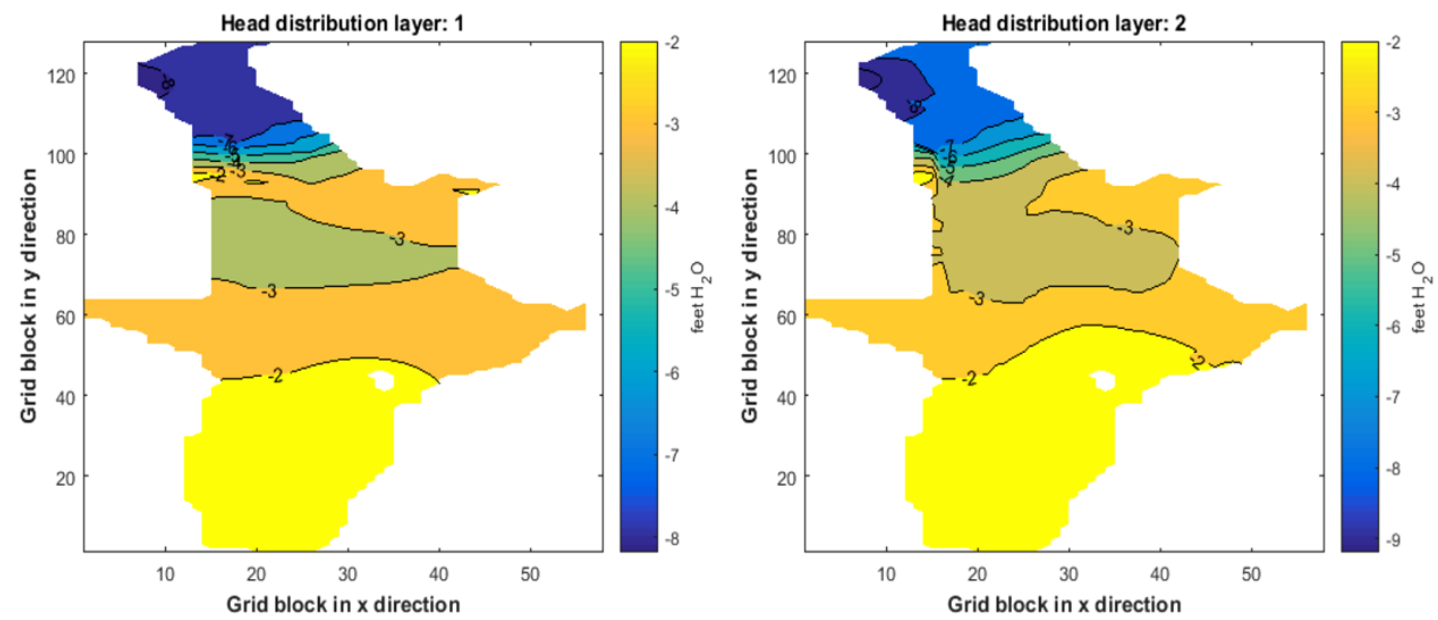

Figure 7.4: Change in head after pumping for 5 days at $800 \mathrm{gpm}$ : layer 1 (left); layer 2 (right) 

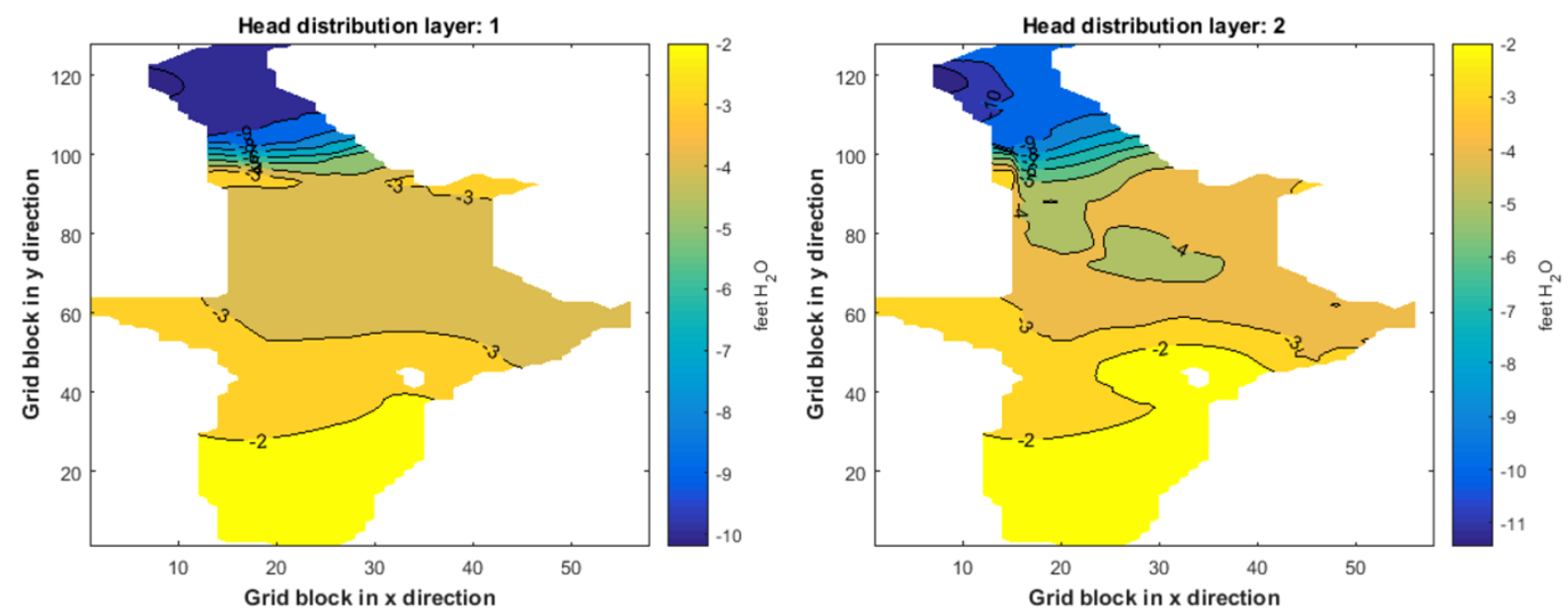

Figure 7.5: Change in head after pumping for 5 days at 1000 gpm: layer 1 (left); layer 2 (right)

Example 3: Contaminant flow

Compositional simulation capabilities implemented in AD-GPRS facilitate the study of the spatial distribution of contaminant as a function of time. As an illustration of this functionality, two example cases are presented. In the first case, a small amount of n-octane is introduced into all the source blocks while in the second case, contaminant is introduced into only one source block. Both examples use the same model and initialization as the previous examples, with exception of the concentration of contaminant in the injection stream. Figure 7.6 shows the contaminant distribution after 5000 days of simulation in the case in which all sources to the model contain contaminant, while Fig. 7.7, on the other hand, shows the case in which only one source is contaminated. 


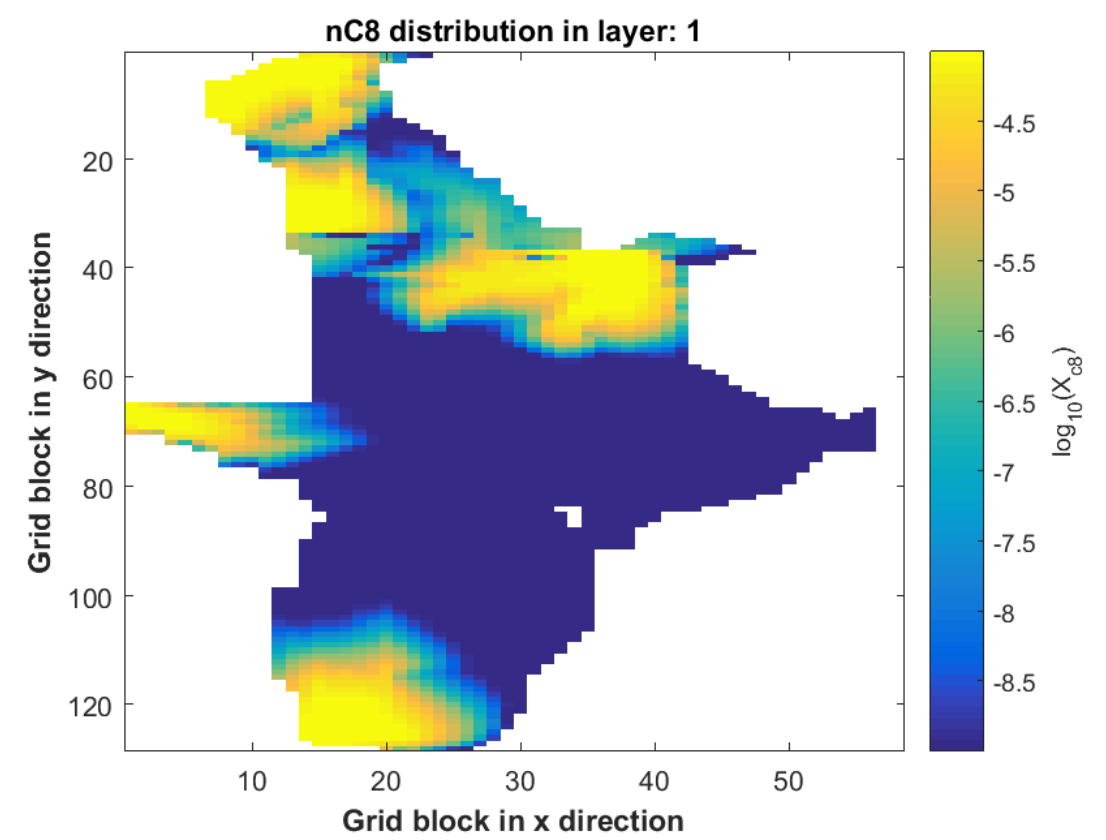

Figure 7.6: Contaminant Distribution After 5000 Days (all sources)

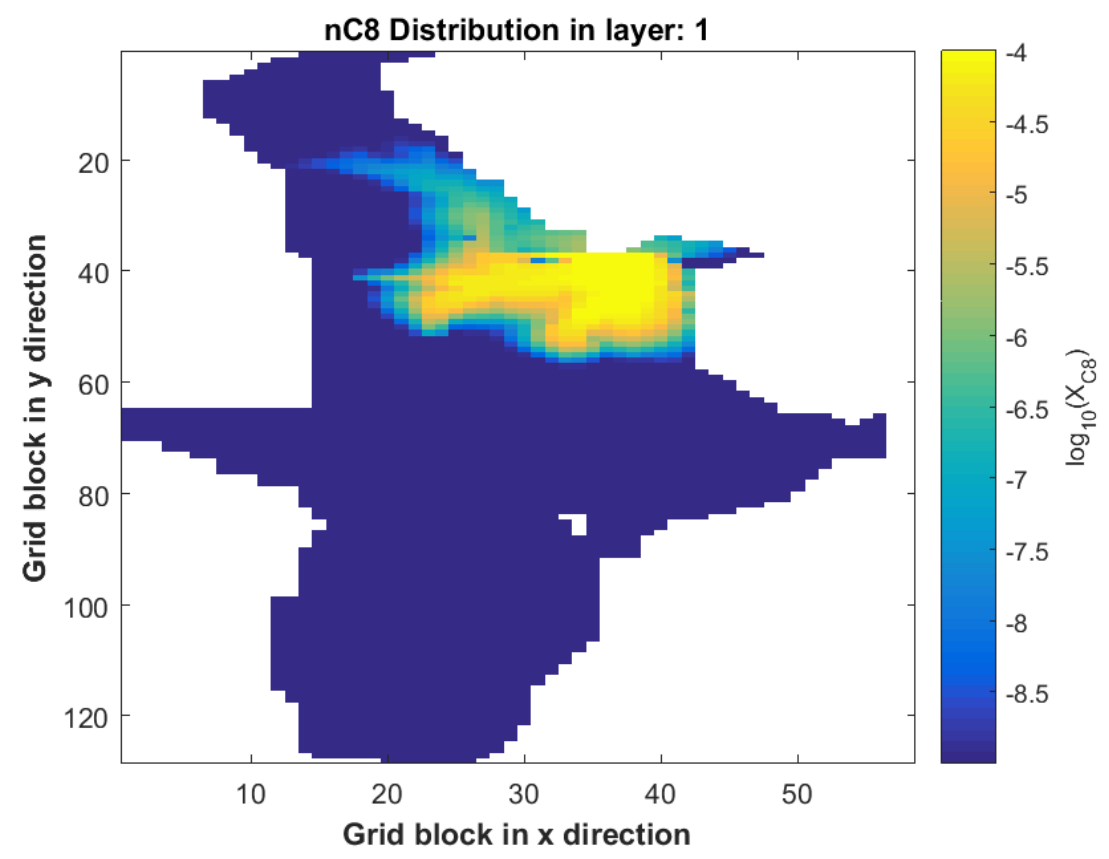

Figure 7.7: Contaminant Distribution After 5000 Days (single source)

Contaminant concentration as function of distance from the source is depicted in Fig. 7.8 , for 1000,3000 , and 5000 days. Clearly, the contaminant concentration decreases as distance from the source increases, as expected. 
Examples such as the previous two can also be used to predict the concentration of contaminant at any point within the model at any given time. This type of analysis could prove useful in evaluating different contamination scenarios by varying the location and concentration of contaminant introduced into the reservoir. In addition, the AD-GPRS/GFLASH modeling framework makes it possible to introduce contaminant levels greater than the corresponding solubility limits of those contaminant in water, which in turn could result in the formation of a second fluid phase. In addition, the migration of multiple fluid phases throughout the reservoir is easily modeled in the ADGPRS/GFLASH framework by including a model of the relative permeability as function of saturation. Figure 7.9 shows the saturation of the octane-rich phase in the two-phase example described previously. The octane concentration introduced into the source block is greater than the solubility of octane in water and a second liquid phase forms and propagates through the reservoir model. 


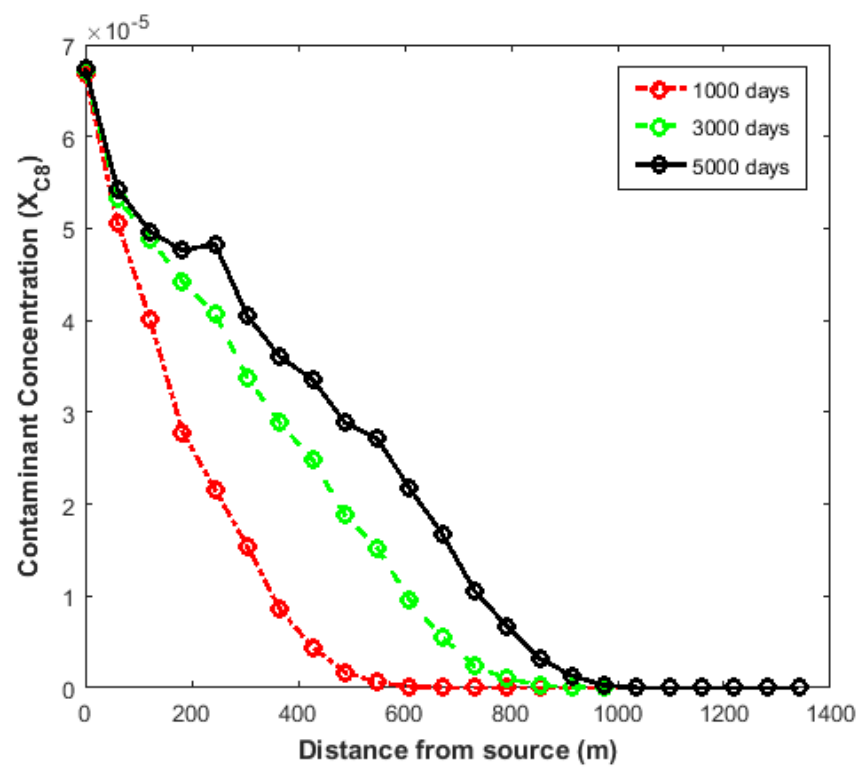

Figure 7.8: Contaminant Concentration as a Function of Distance from Source

These last examples clearly illustrate the capability of AD-GPRS/GFLASH to model fluid mixtures in the aquifer with variable density, the formation of a second liquid phase, and multi-phase flow through porous media. These features are useful for the development of a model for investigating the migration of contaminant 'spills', which have entered the model area in some or all of the of the inflow locations. 


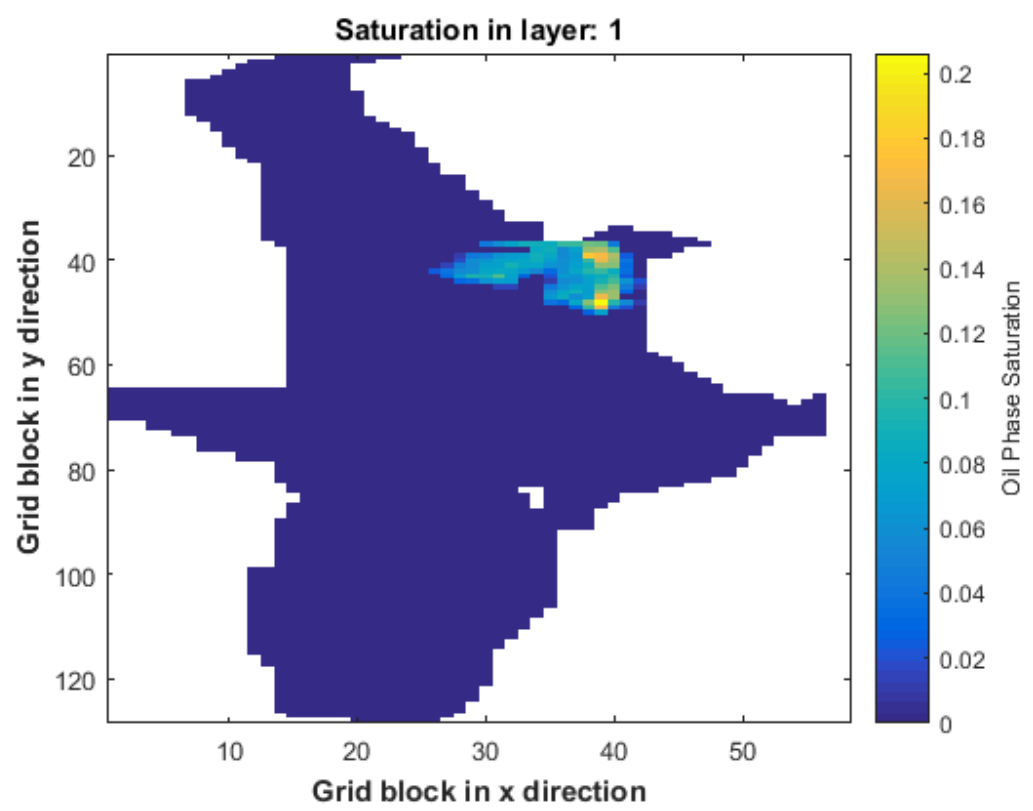

Figure 7.9: n-Octane Phase Saturation after 5000 Days

\subsection{Conclusion}

The numerical reservoir simulator AD-GPRS was used to investigate (1) the response of a real groundwater model system to 5 days of continuous pumping at various pumping rates, and (2) the migration of a contaminant. The examples studied in this work highlight the applicability of the AD-GPRS/GFLASH reservoir modeling and simulation framework to groundwater flow systems. Fully compositional treatment of the reservoir fluids allows mixtures to be easily incorporated into the model and many methods for the evaluation of fluid properties are available in AD-GPRS/GFLASH. In this work, for example, an equation of state model was used for determining the variation of density with pressure. An example in which the contaminant concentration introduced into the source is greater than the solubility of the contaminant in the water phase was presented to illustrate the capability of modeling multi-phase flow in groundwater applications. 
Currently, the boundary conditions that are required to model constant inflow rates over an area of the model such as non-point sources due to rainfall or runoff and the presence of ponds and streams within the model are not explicitly implemented in AD-GPRS. However, these features could easily be added. Future work may include the implementation of boundary conditions and features into AD-GPRS that allow the study of groundwater/surface water interactions in groundwater systems.

\subsection{Acknowledgement}

The authors would like to express our gratitude to Professor Denis Voskov of TU Delft for his guidance and to Professor Hamdi Tchelepi and the SUPRI-B project at Stanford University for permission to use AD-GPRS for this study. We would also like to thank the NIWR of Rhode Island and USGS for providing financial support of this work. 


\section{References}

Elenius, M. T., Voskov, D. V., Tchelepi, H. A. (2015). Interactions between gravity currents and convective dissolution. Advances in Water Resources, 83, 77-88. http://doi.org/10.1016/j.advwatres.2015.05.006

Harbaugh, A. W. (2005). MODFLOW-2005, the US Geological Survey modular ground-water model: the ground-water flow process (pp. 6-A16). Reston, VA, USA: US Department of the Interior, US Geological Survey.

Iranshahr, A., Voskov, D. V., Tchelepi, H. A. (2013). Tie-simplex based compositional space parameterization: Continuity and generalization to multiphase systems. AIChE Journal, 59(5), 1684-1701.

Lucia, A. (2010). A multiscale Gibbs-Helmholtz constrained cubic equation of state. Journal of Thermodynamics, 2010, 1-10. http://doi.org/10.1155/2010/238365

Lucia, A., Bonk, B.M., Roy, A., Waterman, R.R. (2012) A multi-Scale framework for multi-phase equilibrium flash. Comput. Chem. Engng. 36, 79 (2012). doi: 10.1016/j.compchemeng.2011.07.011.

Lucia, A., Padmanabhan, L., Venkataraman, S. (2000). Multiphase equilibrium flash calculations. Computers \& Chemical Engineering, 24(12), 2557-2569.

Masterson, J. P., Granato, G. E. (2012). Numerical simulation of groundwater and surface-water interactions in the Big River Management area, Central Rhode Island Scientific Investigations Report 2012 - 5077. Scientific Investigations Report 20125077.

Peng, D. Y., Robinson, D. B. (1976). A new two-constant equation of state. Industrial \& Engineering Chemistry Fundamentals, 15(1), 59-64.

Soave, G. (1972). Equilibrium constants from a modified Redlich-Kwong equation of state. Chemical Engineering Science, 27(6), 1197-1203.

Voskov, D. V., Henley, H., Lucia, A. (2017). Fully compositional multi-scale reservoir simulation of various $\mathrm{CO} 2$ sequestration mechanisms. Computers \& Chemical Engineering, 96, 183-195. http://doi.org/10.1016/j.compchemeng.2016.09.021

Voskov, D. V., Tchelepi, H. A. (2012). Comparison of nonlinear formulations for twophase multi-component EoS based simulation. Journal of Petroleum Science and Engineering, 82, 101-111.

Voskov, D., Zaydullin, R., Lucia, A. (2016). Heavy oil recovery efficiency using SAGD, SAGD with propane co-injection and STRIP-SAGD. Computers \& Chemical Engineering, 88, 115-125. http://doi.org/10.1016/j.compchemeng.2016.02.010 
Zaydullin, R., Voskov, D. V., James, S. C., Henley, H., Lucia, A. (2014). Fully compositional and thermal reservoir simulation. Computers \& Chemical Engineering, 63, 51-65. http://doi.org/10.1016/j.compchemeng.2013.12.008

Zhou, Y., Tchelepi, H. A., Mallison, B. T. (2011, January). Automatic differentiation framework for compositional simulation on unstructured grids with multi-point discretization schemes. In SPE Reservoir Simulation Symposium. Society of Petroleum Engineers.

Zhou, Y., Voskov, D. (2012). Technical Description: AD-GPRS Stanford University 's Automatic Differentiation based General Purpose Research Simulator. 